Shifting to low-carbon transport in ASEAN:

Policy development in a rapidly motorising region 
Graduation committee:

\section{Chairman/Secretary}

Prof.dr.ir. A. Veldkamp University of Twente

\section{Supervisor(s)}

Prof. M.F.A.M. van Maarseveen University of Twente

\section{Co-supervisor(s)}

Dr. H.C. de Coninck

Radboud University

Dr. M.H.P. Zuidgeest

University of Cape Town

\section{Members}

Prof.dr. K. Pfeffer

Prof.dr. R.V. Sliuzas

University of Twente

University of Twente

Prof.dr. J.R.F. Regidor

University of the Philippines

Prof.dr. H. Geerlings

Erasmus Universiteit Rotterdam

ITC dissertation number 317

ITC, P.O. Box 217, 7500 AE Enschede, The Netherlands

ISBN 978-90-365-4518-1

DOI 10.3990/1.9789036545181

Cover designed by Job Duim

Photo credits: Friedel Sehlleier (cover) and Stefan Bakker

Printed by ITC Printing Department

Copyright (C) 2018 by Stefan Bakker

17 FACULTY OF GEO-INFORMATION SCIENCE AND EARTH OBSERVATION 


\title{
SHIFTING TO LOW-CARBON TRANSPORT IN ASEAN: POLICY DEVELOPMENT IN A RAPIDLY MOTORISING REGION
}

\author{
DISSERTATION
}

to obtain

the degree of doctor at the University of Twente, on the authority of the rector magnificus, prof.dr. T.T.M. Palstra,

on account of the decision of the graduation committee, to be publicly defended on 29 March 2018 at 14.45 hrs

by

Stefan Bakker

born on 4 February 1976

in Texel, The Netherlands 
This thesis has been approved by

Prof.dr.ir. M.F.AM. van Maarseveen, supervisor

Dr. H.C. de Coninck, co-supervisor

Dr. M.H.P. Zuidgeest, co-supervisor 
To my family 


\section{Table of Contents}

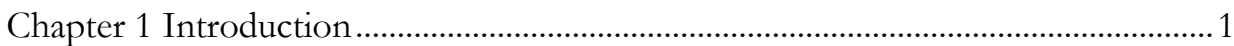

1.1 Trends in transport, climate change and sustainable development...........2

1.2 Geographical focus: Southeast Asia .............................................................. 4

1.3 Transport policy, sustainable development and climate change:

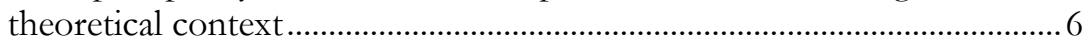

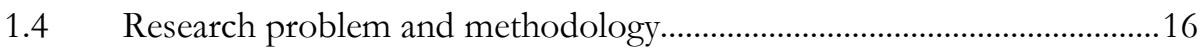

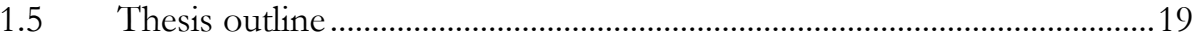

Chapter 2 Transport, development and climate change mitigation: towards an

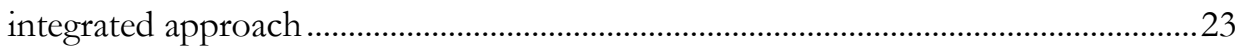

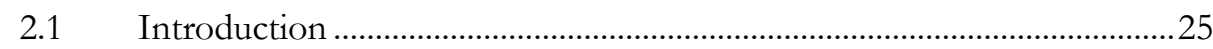

2.2 Policy Paradigms on Transport, Development and Climate.....................27

2.3 Visions on sustainable transport - guidance for policy?.............................32

2.4 Combining Avoid-Shift-Improve and the

climate-transport-development nexus......................................................... 38

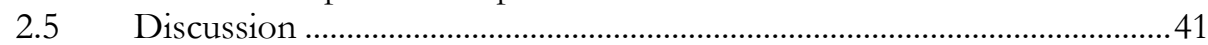

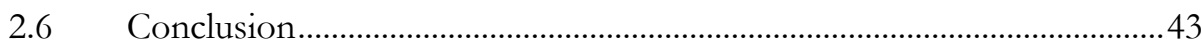

Chapter 3 Making climate instruments work for sustainable transport in

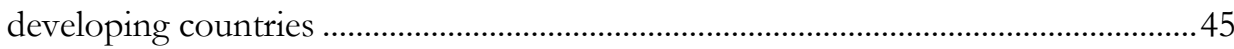

3.1 Transport and climate change ………………….......................................4

3.2 Transport under existing international climate mechanisms .....................49

3.3 Applicability of new mechanisms for transport .........................................56

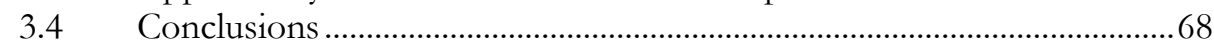

3.5 Addendum: The role of climate change policy for sustainable, low-carbon transport ..................................................................................69 69

Chapter 4 ASEAN cooperation on sustainable transport: progress and options ...77

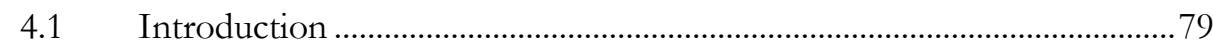

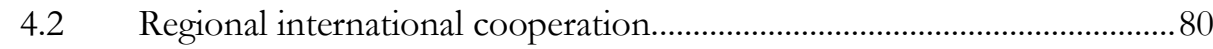

4.3 Regional governance and cooperation in ASEAN and EU ......................82

4.4 ASEAN policy framework for sustainable transport cooperation............85

4.5 ASEAN cooperation on sustainable transport: a review .............................87

4.6 Options for cooperation on sustainable transport.......................................91

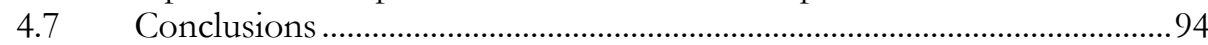

Chapter 5 Low-carbon transport policy in four ASEAN countries: developments

in Indonesia, the Philippines, Thailand and Vietnam .................................................97

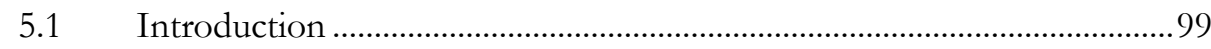

5.2 Theoretical Framework for Low-Carbon Transport Policy Analysis ...100

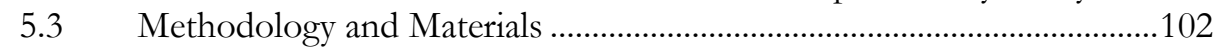

5.4 Results: Low-Carbon Transport Policy Components ..............................106

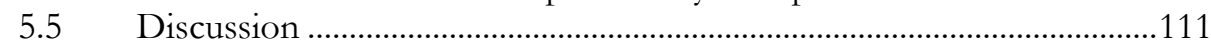

5.6 Conclusions …………………………………....................................113 
Chapter 6 Hot or not? The role of cycling in ASEAN megacities: case studies of

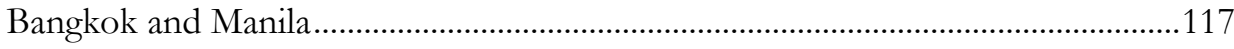

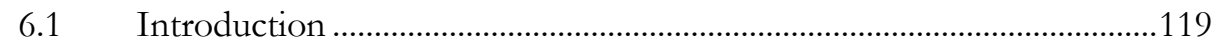

6.2 Framework and methodology ……………………………………….....120

6.3 Current situation in Bangkok and Metro Manila......................................128

6.4 Emerging picture: TIS analysis and discussion of cycling in

Bangkok and Metro Manila .......................................................................136

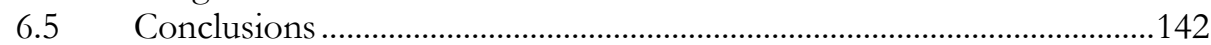

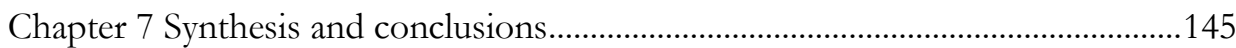

7.1 Main conclusions from Chapter 2-6........................................................146

7.2 Low-carbon transport policy: observations and options ...........................151

7.3 Multi-level governance in transport and climate policy .............................154

7.4 Conceptual framework: ASI + Access + Transitions + Lifestyles .......158

7.5 Contribution and link to theory …………………........................................ 163

7.6 Linking academics and practice.................................................................165

7.7 Research recommendations .....................................................................166

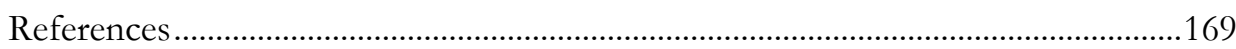

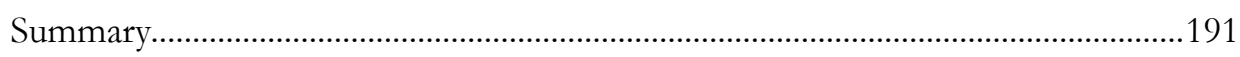

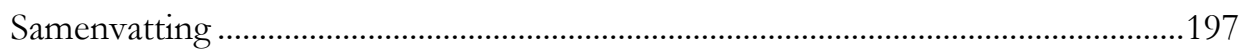

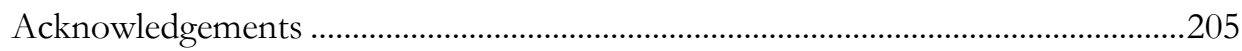

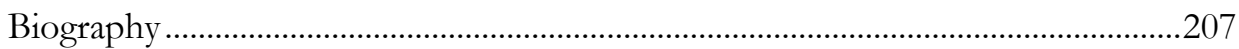

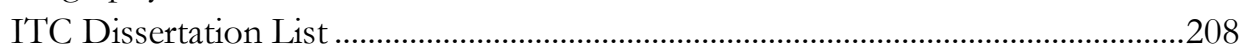


Chapter 1

Introduction

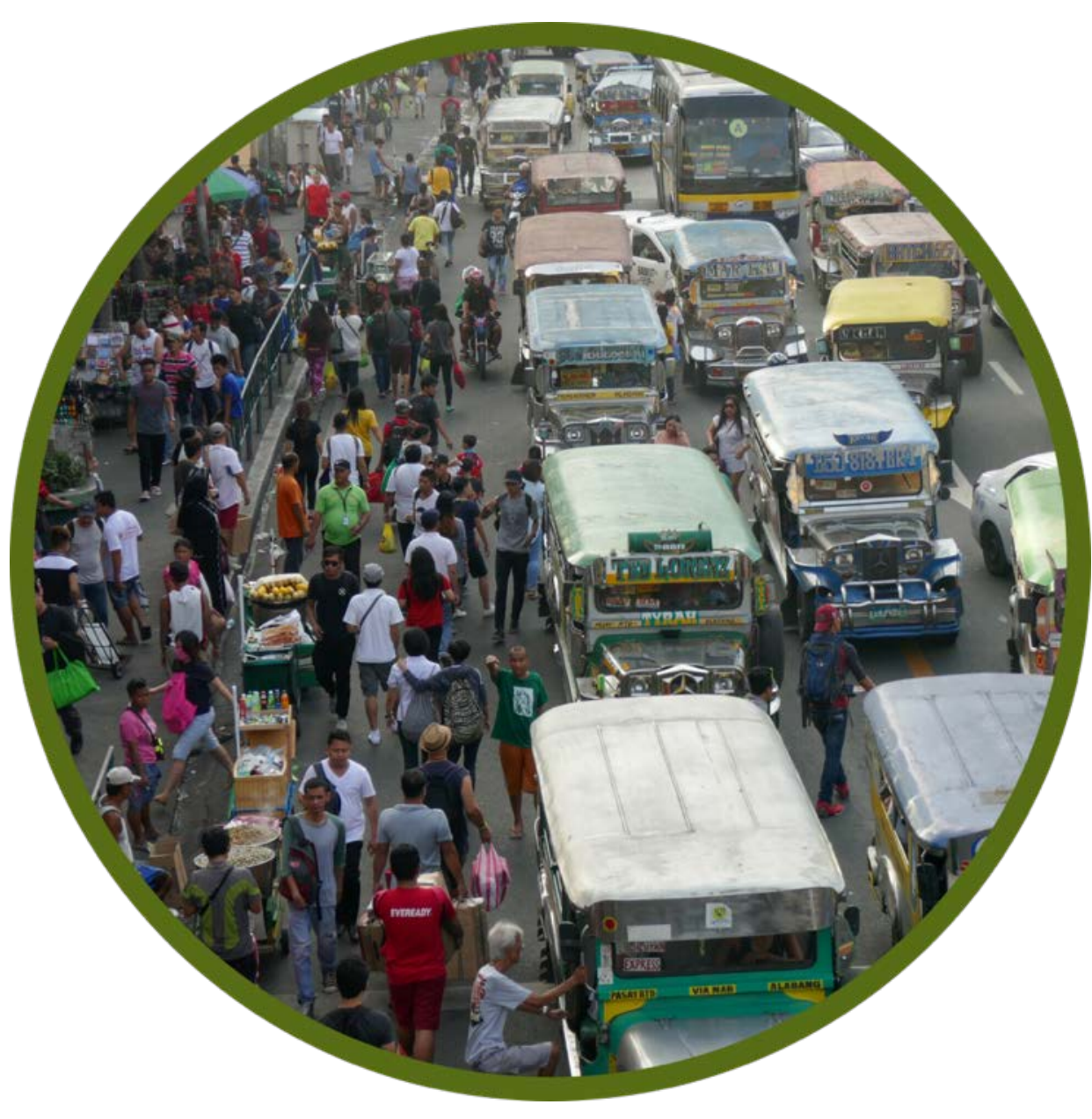




\subsection{Trends in transport, climate change and sustainable development}

Whereas mobility plays a key role in social and economic development by providing access to opportunities and enabling trade, the transport sector also has direct negative impacts. Fossil-fuelled vehicles are major emitters of air pollutants such as particulate matter, nitrogen oxides, sulphur oxides and volatile organic compounds, which affects human health, particularly in cities. Worldwide, 38,000 premature deaths are associated with $\mathrm{NO}_{\mathrm{x}}$ emissions exceeding the regulatory standards (Anenberg et al., 2017), whereas the economic cost of air pollution from road transport in OECD countries is estimated at close to USD 1 trillion per year, measured in terms of the value of lives lost and ill health (OECD, 2014 in OECD/ITF, 2017).

Of total oil consumption, transport uses 65\% (IEA, 2017) and with most countries being importer of oil, this causes a negative balance of payments and concerns of energy security (OECD/IEA, 2017a). Traffic crashes are one of the leading causes of deaths and injuries, with 1.25 million fatalities in 2013 (WHO, 2015). Traffic congestion, particularly in cities, causes substantial loss of productivity, estimated to be 2-5\% of GDP in Asian economies (ADB, 2017). Other impacts include noise (Korzhenevych et al., 2014; Sen et al., 2010), liveability in urban areas (Litman \& Burwell, 2006) and habitat fragmentation due to infrastructure (EEA, 2016). In addition, transport poverty and equity in mobility systems are considered, to achieve social goals such as access to mobility services for all members of society (e.g. Martens, 2017).

At the global level, the transport sector contributes to climate change, which is one of the defining challenges of our time. To 'prevent dangerous anthropogenic interference with the climate system' (UNFCCC, 1992: p. 3) and limit global temperature rise to well below 2 degrees - or even 1.5 degrees - above pre-industrial levels as agreed in the Paris Agreement (United Nations, 2015), deep cuts in greenhouse gas (GHG) emissions are required. It is estimated that in 2050, global GHG emissions need to be net zero to be compatible with a 1.5 degree emissions pathway (Rogelj et al., 2016). Given that current emissions are well above 2010 levels and have been stable from 2014 to 2016, with a 2\% rise expected for 2017 (Global Carbon Project, 2017), this poses a substantial need for change.

This challenge is particularly strong for the transport sector, which is a major emitter of GHG, with $23 \%$ of energy-related $\mathrm{CO}_{2}$ emissions, or $18 \%$ of all man-made $\mathrm{CO}_{2}$ emissions in 2015. More importantly, emissions in this sector have been rising 2.5\% annually from 2010 to 2015 (OECD/ITF, 2017), which is more than any other 
sector. There is a large regional spread in specific transport emissions with 2.8 tonnes of $\mathrm{CO}_{2}$ per capita per annum in the OECD versus 0.5 tonne in non-OECD countries (OECD/ITF, 2017). In a baseline scenario, global transport emissions are projected to rise from 4.6 billion tonnes (Gt) in 2010 to over 8 Gt in 2050 (Figueroa et al., 2013). The European Union aims to reduce emissions by at least $60 \%$ midcentury compared to 1990 levels (EC, 2016). This could be considered ambitious, given 2013 emissions were 21\% above the base year (EP, 2016), though since 2008 emissions are declining.

In summary, the current transport systems as well as the major trends are incompatible with sustainable development and long-term climate objectives. It should be noted that compared to climate change mitigation, local or national sustainable development are often more important transport policy drivers (Bache et al., 2014), or as a famous transport scholar, the late Lee Schipper, put it: "transport is very important for climate, but climate is not important for transport".

The drivers behind $\mathrm{CO}_{2}$ emissions ${ }^{1}$ from the transport sector can be broken down according to the activity-structure-intensity-fuel (ASIF) approach (Schipper et al., 1999). Transport activity, sometimes called transport demand, is typically expressed in passenger-kilometres and tonne-kilometres. It has been and still is growing in tandem with economic growth (OECD/ITF, 2017), although at different rates between countries. In general, demand is growing faster in the developing world due to more rapid economic growth and motorisation, whereas in developed countries growth is levelling off or stable in the last decade (EEA, 2016), with a decrease visible in some countries including Japan and France (OECD/ITF, 2017).

The modal structure with which the demand is met consists of road, rail, water and air for freight, while for passenger transport a large diversity of modes is distinguished, including car, taxi, motorcycle, tricycle, bus, train, metro, walking, bicycle, boat, airplane, and a variety of modified vehicles used in informal public transport. In developed countries, e.g. the EU, modal shares have been remarkably stable in the past decade (EEA, 2016). In developing regions, due to rapid motorisation, car travel is growing rapidly - both in absolute and relative terms -, often resulting in a decrease in public and non-motorised mode shares (Clean Air Asia, 2012). Private motorisation levels, especially car ownership, is however still substantially below values found in developed countries (OECD/ITF, 2017).

\footnotetext{
${ }^{1}$ For other environmental and social impacts from transport, demand and structure are also relevant drivers, however intensity and fuel only for energy security, air pollution and noise.
} 
The third factor in transport emissions is the energy intensity of each mode, expressed in Joules per vehicle-kilometre. For cars, the main energy consuming mode in passenger transport (OECD/ITF, 2017), this is improving in most countries, though at different speeds. For trucks, there has been little improvement in the past 20 years (Muncrief \& Sharpe, 2015).

Finally, the $\mathrm{CO}_{2}$ emissions per unit of energy (carbon intensity) has not changed to a large extent due to the dominance of oil, which covers over $90 \%$ of energy demand. However, biofuels, gaseous fuels and electricity are increasingly used in transport, which, depending on upstream emissions from their production, can decrease carbon intensity.

With developed countries' $\mathrm{CO}_{2}$ emissions at unsustainable levels and nearly all of the expected increase in emissions to come from developing countries, key questions include whether the emissions trend can be bent in the former (also known as 'decoupling'), what kind of transport system development path the latter will take, e.g. in terms of motorisation rate, modal structure and vehicle technology ${ }^{2}$, and what policy choices can be made to realise a sustainable transport future.

\subsection{Geographical focus: Southeast Asia}

One region where rapid motorisation is taking place is Southeast Asia. A significant part of this thesis focuses on transport and climate change policy in this region or parts of it, the choice of which was based on the following considerations. First, the ten member countries ${ }^{3}$ of the Association of the Southeast Asian Nations (ASEAN) are - collectively - significant in terms of e.g. economy ( $6^{\text {th }}$ in the world in 2015 (ASEAN, 2015)), economic growth (5.3\% per annum on average between 20072015), population (629 million in 2015), motorisation growth rate (see below) and GHG emissions from the transport sector: about 300 million tonnes of $\mathrm{CO}_{2}$-eq in 2010, and projected to triple by 2050 (ITPS \& Clean Air Asia, 2014).

Second, most ASEAN countries and cities have characteristics that set them apart from many other countries, particularly North-America and Europe. These include rapid motorisation $(8.1 \%$ growth in vehicle sales projected for 2017 (Nikkei Asian Review, 2017)), lower current urbanisation but rapid growth of megacities, higher urban density, importance of informal transport sector including paratransit, high modal share of motorcycles, inadequate and hierarchically unbalanced infrastructure,

\footnotetext{
${ }^{2}$ see for example two radically different futures for urban commutes in Delhi in 2050 in Bongardt et al. (2013)

${ }^{3}$ Brunei Darussalam, Cambodia, Indonesia, Lao PDR, Malaysia, Myanmar, the Philippines, Singapore, Thailand and Vietnam (see Figure 1.1)
} 
high but decreasing share of public transport (except Vietnam), lower government revenue and lack of private sector financing, and weak land-use control (Morichi \& Acharya, 2013).

Third, extant literature covers sustainable, low-carbon transport policy in Southeast Asia only to a limited extent. There is a growing body of research that analyse transport systems in ASEAN countries and cities, often quantitative, which is policy relevant. Examples include ex-ante evaluation of bus rapid transport systems or transport demand management in cities. Analysis of policy development, actual policy choices made and how these are influencing the transport systems is rarer (e.g. Barter, 1999; Khuat, 2006; Jittrapirom \& Jaensirisak, 2017).

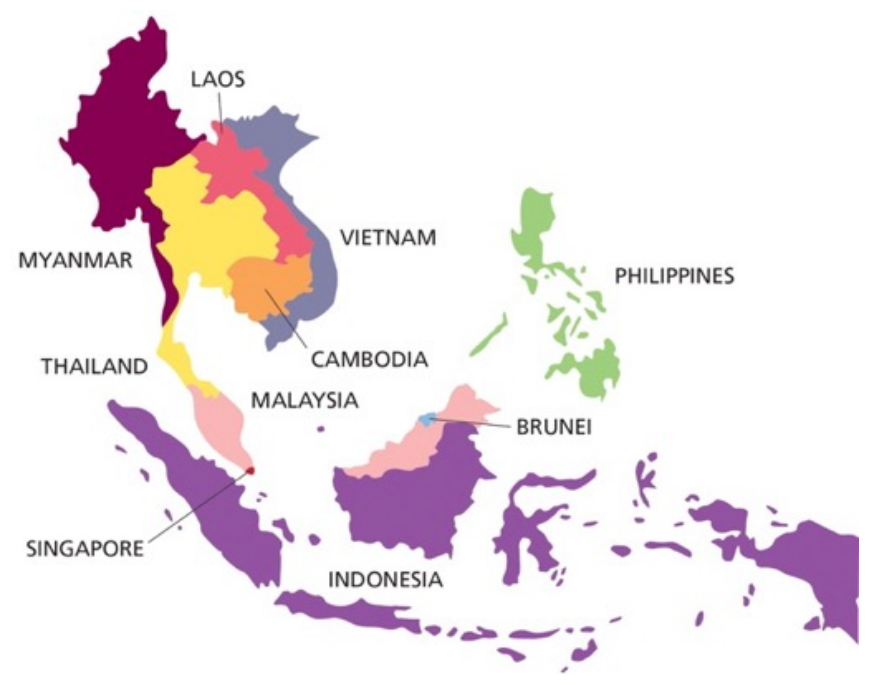

Figure 1.1. Map of the 10 ASEAN member countries (source: Pinterest)

Fourth, the region is on the one hand diverse with countries varying considerably in size, income, per capita emissions, urbanisation rates and political systems: for example very small (Brunei, 0.4 million) and large Indonesia (255 million) countries, per capita income ranging from US\$ 1,198 (Cambodia) to US \$ 52,744 (Singapore) in 2015-2016 (ASEAN, 2017), urbanisation rates between 21\% (Laos) to 100\% (Singapore) in 2015 (World Bank, 2016), and open democracies such as Indonesia and the Philippines, to socialist states (Vietnam, Laos), a one-party democracy (Cambodia) and a country under military rule (Thailand). Such differences are also apparent in the Worldwide Governance Indicators (World Bank, 2017), in which for five out of six indicators the countries cover nearly the entire scale, i.e. from less than 10 to over 90. For the three indicators Government Effectiveness, Regulatory Quality and Rule of Law, Singapore scores over 95, while Myanmar, Laos and Cambodia are roughly between 5 and 30. For Voice and Accountability, the 
Philippines and Indonesia gain the highest scores. On the other hand, several of them are in a relatively similar state of economic development (middle-income countries) and are facing similar challenges in balancing economic and social development and environmental issues. This could open up opportunities for crosscountry comparison and policy learning and transfer.

Finally, cooperation by the ten member countries in the framework of ASEAN as a regional intergovernmental body presents an opportunity to advance sustainable transport policy in an intergovernmental setting as well as research into the same. This could help filling gap in the existing literature, which has not covered intergovernmental cooperation in (sustainable) transport to a significant extent. ASEAN exists since 1967 (starting with five founding members) has achieved significant regional integration, as illustrated by the establishment of the ASEAN Economic Community in 2015. Transport cooperation has been pursued since the 1990s and environmental issues in transport have only recently been part of the agenda.

\subsection{Transport policy, sustainable development and climate change: theoretical context}

This section briefly introduces relevant concepts from policy studies and transport policy in connection to sustainable development.

\subsubsection{Policy studies}

"Public policy is, at its simplest, a choice made by government to undertake some course of action" (Howlett et al., 2009: p. 5). A more elaborate definition of public policy is "a set of interrelated decisions taken by a political actor or group of actors concerning the selection of goals and the means of achieving them within a specified situation where those decisions should, in principle, be within the power of those actors to achieve" (Jenkins, 1978: p.15). In policy studies, a distinction can be made between policy content (such as policy goals and means) and the making of policy as a process involving political actors.

Although this thesis mainly deals with policy content, we briefly touch upon the process as well. In analysis of policy processes, an often-used framework is the public policy cycle. This is based on Lasswell (1956) who was the first to break down the policy process in multiple stages. Since then, different versions of the policy cycle framework have been developed, however the differentiation between the five stages of agenda-setting, policy formulation, decision making, implementation, and evaluation has become relatively common (Howlett et al., 2009). Summarising some of the criticisms to this simple model it is noted that "real-world decision making 
usually does not follow such discrete stages" and the "stages are constantly meshed and entangled in an ongoing process" (Jann \& Wegrich, 2004).

The policy context consists of actors, institutions and ideas. In the realm of ideas, a distinction can be made between those in the background (policy paradigms and public sentiments) and the foreground (program ideas and symbolic frames) (Howlett et al., 2009). Relevant institutions and structures include those at the metalevel, such as democracy, capitalism, liberalism, socialism etc.; as well as in the realm of governance systems, such as unitary (strong centrally governed) or federal states. A multi-level governance framework (Hooghe \& Marks, 2003) can be relevant as well. In addition, regimes, which are 'sets of governing arrangements or networks of rules, norms, and procedures that regularise behaviour and control its effects', as well as international institutions, can affect public policy by promoting certain policy options and restraining others (Howlett et al., 2009). Relevant actors in various stages of the policy process include politicians and political parties, the public, bureaucracy, interest groups and civil society, think tanks and research organisations, mass media and experts and consultants (Howlett et al., 2009).

In connection to formulation of policy content, Hall (1993) decomposed policy into three distinct elements or variables: the overarching goals that guide policy in a particular field, the techniques or policy instruments used to attain those goals, and the precise settings of these instruments (see also Chapter 5). When looking at policy instruments, multiple typologies have been developed, most of which are variants of the NATO model (Hood, 1986), that distinguishes 1) nodality or information instruments, 2) authority-based or regulatory instruments, 3) treasure (economic) instruments, and 4) organisation instruments (e.g. public enterprises). In the domain of transport policy, direct investments in (road, rail) infrastructure can be distinguished as a category (e.g. Grazi \& van den Bergh, 2008), and in some cases land-use and transport 'planning' (Wittneben et al., 2009), although this could be considered part of regulatory instruments too.

Since World War II, policy studies has grown into a large domain of scientific research, however geographically it is dominated by the United States and Europe, with limited literature on Africa and Asia outside Japan (Sabatier, 2007).

\subsubsection{Sustainable development and transport policy and planning}

Ever since its conception in the Brundtland report, the term 'sustainable development' has been criticised for its lack of clarity and difficulty to operationalise into concrete policy goals (Litman \& Burwell, 2006). However, as an objective for the global community to develop in a fashion that 'meets the need of the present 
without compromising the ability of future generations to meet their needs' it is as relevant today as it was in 1987.

In analysing the transport sector's contribution to sustainable development, Figure 1.2 can be used (with this thesis focusing on the impacts, and the relationships with regulation) It shows that basic drivers such as economic growth, individual preferences, regulations etc. determine the demand for transport and the development of the transport system (infrastructure, vehicles, technology, regulations, market organisation, fuel prices).

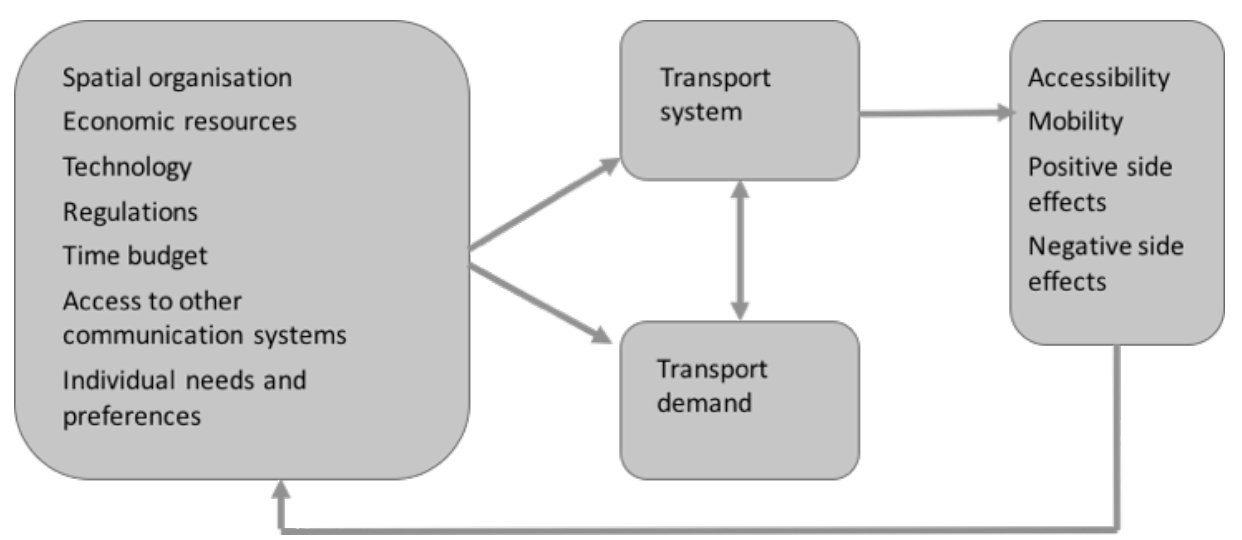

Figure 1.2 Transport system, drivers and impacts (Gudmundsson \& Höjer, 1996)

The demand and the system also respond to each other (Manheim, 1979), e.g. by increased road capacity as a response to (projected) demand growth and when infrastructure capacity is increased, demand for transport will also grow, e.g. as a result of increased speed ('induced demand'). Transport activity in the system will then result in direct benefits in terms of accessibility and mobility, and indirect negative (e.g. pressure on the environment) and potentially positive (e.g. status of owning a car) side effects (Gudmundsson \& Höjer, 1996). In addition, transport system characteristics strongly impact how cities and countries develop in the longer term, e.g. low fuel prices and focus on car infrastructure results in urban sprawl in American cities.

The key role transport plays in sustainable development has been widely acknowledged, for example by the fact that (sustainable) transport is relevant to seven of the 17 Sustainable Development Goals and essential in achieving eleven of the associated targets (United Nations, 2016) ${ }^{4}$. A sustainable transport scenario appears to be cheaper than business-as-usual when all costs and benefits are

\footnotetext{
${ }^{4}$ In addition to the SDGs transport is connected to unexpected aspects of life, for example the bicycle's role in promoting women's rights (Strange, 2002)
} 
considered (Lefevre et al., 2016), however this may not happen due to lock-in effects, vested interests and technological challenges. As noted in Section 1.1, currently the transport system is not compatible with sustainable development.

Approaches to transport planning have evolved from facilitating movement of private vehicles ('predict and provide', or demand-driven) to a more balanced set of interventions in which transport demand management (Buchanan, 1963) plays an important role. Such supply-driven approaches and paradigms have been developed using different terms, such as 'manage and predict' (Zuidgeest, 2005), 'the sustainable mobility paradigm' (Banister, 2008), 'accessibility' (OECD/ITF, 2017) and Avoid-Shift-Improve (Dalkmann \& Brannigan, 2007). The essence of these more holistic frameworks is that transport policy and planning need to reflect a wide range of goals including access, equity, environment, safety, liveability, energy security, rather than a narrow focus on vehicular movement.

For decarbonising the transport sector, changes in, on the one hand, the transport and land-use systems (i.e. the way mobility of people and goods is organised and used) and, on the other hand, vehicle and fuel technologies, are required (OECD/ITF, 2017; PPMC, 2017; Chapman, 2007). These are two rather distinct research and policy domains, often divided between different policy making bodies (e.g. Ministry of Transport on the one hand and Ministries of Energy, Environment, Industry on the other). Especially in transport policy, climate change mitigation is a relatively new (and minor) policy consideration, whereas in vehicles and fuels, climate change and air quality are key policy drivers. Prior to 2010, most low-carbon transport analyses focused on a 'technology-fix' only.

Progress on sustainable development and climate goals is mixed. For example, in the European Union, fatalities from road crashes and air pollution from the transport sector have declined significantly since 1990, energy consumption and $\mathrm{CO}_{2}$ emissions have been decreasing slowly in recent years (EEA, 2016). On other impacts such as congestion and noise, no data were found. In other world regions, particularly developing Asia, air pollution, $\mathrm{CO}_{2}$ emissions and congestion are increasing. At the local level, cities are taking initiatives to improve liveability and reduce the role of the car (Nieuwenhuijsen \& Khreis, 2016).

Air quality and to some degree road safety can be improved to a large extent by endof-pipe solutions and stringent laws and enforcement that do not necessarily require fundamental changes in the transport system. Reducing energy and $\mathrm{CO}_{2}$ emissions to climate-compatible levels and addressing congestion however, require more radical and systemic changes that affect a multitude of - sometimes powerful stakeholders in different, and often uncertain, ways. In this context, it can be noted 
that transport has an important contribution to the national economy. In the EU, for instance, the transport sector contributes about 5\% to employment and GDP (EU, no date).

Sustainable transport satisfies multiple criteria of 'wicked' policy problems (Ritter \& Webber, 1973; Baumann \& White, 2012), for example, transport and sustainability challenges can be perceived in different ways by different interest groups, the impact of solutions cannot be known immediately after implementation, many interventions and technologies result in unknown outcomes in the mobility system as well as other sectors, every decision will require follow-up decisions and there is no clear-cut 'end' to transport problems. Table 1.1 summarises key barriers to sustainable transport policy and planning and implementation, and possible responses.

Table 1.1. Barriers to sustainable transport planning and policy and their implementation (IEA/OECD, 2009; May et al., 2009; Givoni, 2014; Figueroa et al., 2013; Gössling et al. 2017; GIZ, 2017), and possible responses (source: author)

\begin{tabular}{|c|c|c|}
\hline Barriers & $\begin{array}{l}\text { Examples of possible } \\
\text { responses }\end{array}$ & $\begin{array}{l}\text { Role for research / } \\
\text { topics }\end{array}$ \\
\hline $\begin{array}{l}\text { Finance: government } \\
\text { budget allocation, priority } \\
\text { given to facilitating private } \\
\text { motorised mobility }\end{array}$ & $\begin{array}{l}\text { Lobbying by stakeholders; } \\
\text { information about benefits and } \\
\text { costs; public awareness; } \\
\text { adopting sustainable transport } \\
\text { policy paradigm }\end{array}$ & $\begin{array}{l}\text { Show how and why } \\
\text { government spending } \\
\text { has changed based on } \\
\text { which priorities; impact } \\
\text { of policy paradigms }\end{array}$ \\
\hline $\begin{array}{l}\text { Finance: access to capital } \\
\text { for infrastructure and } \\
\text { energy-efficient vehicle } \\
\text { investments }\end{array}$ & $\begin{array}{l}\text { Development of financing } \\
\text { models and policy options }\end{array}$ & $\begin{array}{l}\text { Innovative, feasible } \\
\text { financing models, } \\
\text { highlight good practices }\end{array}$ \\
\hline $\begin{array}{l}\text { High costs of (some) } \\
\text { cleaner technologies and } \\
\text { rail infrastructure }\end{array}$ & $\begin{array}{l}\text { Appropriate incentives and } \\
\text { financing models; cost } \\
\text { reduction projections }\end{array}$ & $\begin{array}{l}\text { Cost projections; } \\
\text { innovation research to } \\
\text { lower costs; financial } \\
\text { incentives, other policy } \\
\text { options }\end{array}$ \\
\hline $\begin{array}{l}\text { Vested interests, lobbying } \\
\text { by powerful stakeholders } \\
\text { for status quo }\end{array}$ & $\begin{array}{l}\text { Appropriate and inclusive } \\
\text { stakeholder processes; show } \\
\text { social costs and benefits }\end{array}$ & $\begin{array}{l}\text { Research into state-of- } \\
\text { the-art technologies and } \\
\text { existing market data } \\
\text { (e.g. ICCT Dieselgate } \\
\text { studies); analysis into } \\
\text { policy processes }\end{array}$ \\
\hline $\begin{array}{l}\text { Public acceptance of } \\
\text { sustainable transport } \\
\text { policies and planning }\end{array}$ & $\begin{array}{l}\text { Information/communication } \\
\text { instruments highlighting costs } \\
\text { and benefits; stakeholder } \\
\text { processes }\end{array}$ & $\begin{array}{l}\text { Ex-post analysis and } \\
\text { design of policy } \\
\text { instruments and } \\
\text { stakeholder processes; } \\
\text { policy transfer }\end{array}$ \\
\hline $\begin{array}{l}\text { Cultural and behavioural } \\
\text { barriers (e.g. car as status }\end{array}$ & Campaigns, rewards, incentives & $\begin{array}{l}\text { Behavioural research } \\
\text { into barriers and } \\
\text { (changing) values }\end{array}$ \\
\hline
\end{tabular}




\begin{tabular}{|c|c|c|}
\hline \multicolumn{3}{|l|}{$\begin{array}{l}\text { symbol inhibits } \\
\text { sustainable modes) }\end{array}$} \\
\hline $\begin{array}{l}\text { Lack of data (and } \\
\text { management), incomplete } \\
\text { policy appraisal, lack of } \\
\text { capacity, lack of } \\
\text { knowledge about solutions }\end{array}$ & $\begin{array}{l}\text { Capacity building, improved } \\
\text { modelling, better data, } \\
\text { exchange of best } \\
\text { practices/transfer }\end{array}$ & $\begin{array}{l}\text { Ex-ante evaluation of } \\
\text { policies; investigate } \\
\text { land-use - transport } \\
\text { linkages }\end{array}$ \\
\hline $\begin{array}{l}\text { Organisational, including } \\
\text { diversity in stakeholders } \\
\text { and lack of coordination } \\
\text { between relevant } \\
\text { government bodies, } \\
\text { institutional changes }\end{array}$ & $\begin{array}{l}\text { Intra-governmental } \\
\text { coordination and collaboration; } \\
\text { capacity building, training }\end{array}$ & $\begin{array}{l}\text { Analyse stakeholder } \\
\text { decision-making } \\
\text { processes }\end{array}$ \\
\hline $\begin{array}{l}\text { Technological barriers of } \\
\text { clean technologies }\end{array}$ & $\begin{array}{l}\text { R\&D in new vehicle } \\
\text { technologies, smart } \\
\text { technologies; development of } \\
\text { standards }\end{array}$ & $\begin{array}{l}\mathrm{R} \& \mathrm{D} \text {, technological } \\
\text { analysis; behaviour } \\
\text { research }\end{array}$ \\
\hline $\begin{array}{l}\text { Decision-making, e.g. } \\
\text { conflicting policy } \\
\text { objectives, disagreement } \\
\text { and uncertainty over best } \\
\text { solutions, corruption }\end{array}$ & $\begin{array}{l}\text { Decision-making processes, } \\
\text { KPIs covering sustainable } \\
\text { transport, change in broader } \\
\text { policy appraisal frameworks } \\
\text { (beyond GDP), common } \\
\text { strategy }\end{array}$ & $\begin{array}{l}\text { Analysis of decision- } \\
\text { making processes; } \\
\text { discourse analysis; } \\
\text { suitable indicators }\end{array}$ \\
\hline $\begin{array}{l}\text { Implementation } \\
\text { challenges, e.g. legislative, } \\
\text { jurisdictional barriers; } \\
\text { negative side effects from } \\
\text { single measures }\end{array}$ & $\begin{array}{l}\text { Policy packaging, political } \\
\text { leadership, enhanced } \\
\text { monitoring and evaluation } \\
\text { framework }\end{array}$ & $\begin{array}{l}\text { Highlight key success } \\
\text { factors, based on ex- } \\
\text { post evaluation }\end{array}$ \\
\hline $\begin{array}{l}\text { New models for services } \\
\text { and data gathering (e.g. } \\
\text { using apps) are required }\end{array}$ & $\begin{array}{l}\text { Targeted programmes (public } \\
\text { and/or privately financed) to } \\
\text { stimulate innovation }\end{array}$ & $\begin{array}{l}\text { Analyse possible } \\
\text { options }\end{array}$ \\
\hline $\begin{array}{l}\text { External, e.g. relatively } \\
\text { low oil prices }\end{array}$ & Fuel taxes & $\begin{array}{l}\text { Design of feasible } \\
\text { policy options to } \\
\text { 'compensate' low oil } \\
\text { price }\end{array}$ \\
\hline
\end{tabular}

KPI: key performance indicators; R\&D: research and development

Many of the suggested research topics on transport policy in relation to sustainable development are not yet covered by existing literature, i.e. much work remains to be done on how to address the listed barriers. In addition, most existing research focuses on developed countries, with limited coverage of ASEAN in particular.

\subsubsection{Climate change mitigation policy and transport}

As Stead (2016) notes, developments in governance of sustainable development result in an 'increasing influence of external bodies on government', including international agencies. This section focuses on the international climate regime and 
its relation to low-carbon transport policies and actions at the national, and to some extent local, level.

The international climate regime aims to promote global cooperation to prevent dangerous climate change, which - as noted in Section 1.1 - is only possible if substantial decarbonisation of the transport sector is realised. In the UNFCCC (1992), a distinction is made between developed and developing countries, with Parties to the Convention having 'common but differentiated responsibilities' (p. 3) but developed countries should take the lead in mitigation and assist developing countries in reducing GHG emissions and adapting to the impacts of climate change.

Applying this principle to the transport sector, the PPMC (2017) envisages decarbonisation of the sector by 2060 for developed and 2080 for less developed countries. OECD/ITF (2015) assumes in their 2 degree scenario modelling a narrowing of the difference in per capita transport sector emissions by 2050 compared to 2015 levels, resulting in an average decrease from 3 to $1.8 \mathrm{tCO}_{2} /$ capita for OECD countries and an increase from 0.5 to $0.9 \mathrm{tCO}_{2} /$ capita for non-OECD countries. IEA/OECD (2017) differentiates by assuming OECD countries would have to reduce transport GHG emissions by $2.1 \%$ annually between 2015 and 2025 whereas globally a stabilisation would be compatible with a 2 degree scenario. The fact that emissions grew by $2.5 \%$ annually from 2010 to 2015 clearly shows the challenge, in developed as well as developing countries.

All Parties to the Paris Agreement contribute to mitigating climate change by Nationally Determined Contributions (NDCs). These are national plans outlining climate change actions to be taken up to 2030, with 'nationally determined' recognising that each country has unique circumstances and challenges that affect emission reduction strategies, including socio-economic development patterns and financing options and requirements. Progress on climate change actions is reported in Biennial Reports and Biennial Update Reports for developed and developing countries respectively, with the latter having less stringent reporting requirements and review process. NDCs should be updated with more ambitious mitigation efforts over time.

In $75 \%$ of the submitted plans, which at the time represented 187 countries, transport was explicitly named as a sector with mitigation potential and in $18 \%$ implicit as part of the energy sector; 101 NDCs propose specific mitigation measures in the transport sector, predominantly in passenger transport (Gota et al., 2016). Few countries however, include a specific quantified emission reduction target for the sector. 
Various UNFCCC mechanisms exist for developing countries to receive assistance in designing and implementing mitigation measures: carbon trading (e.g. the Clean Development Mechanism), nationally appropriate mitigation actions, the Global Environmental Facility, the Green Climate Fund, and technology assistance and capacity building programmes. In addition, development banks and other development agencies prioritise climate change in their programmes and projects. Eight multilateral development banks are reporting their climate finance spending in their joint progress reports on sustainable transport, which have been published annually since 2014 (AfDB et al., 2017). Further, bilateral relations between countries, both South-South and North-South, contribute to assistance through international development projects financed by Official Development Assistance (ODA).

As opposed to the international organisations, for regional, national and local policymakers in developing countries, climate change mitigation is not a primary driver, whereas other sustainable development objectives are. Climate change mitigation or low-carbon transport can therefore be seen as a co-benefit of sustainable transport policy.

Besides official international organisations, various international development and research organisations work on the intersection between transport and the international agendas of climate change and sustainable development. The Partnership for Sustainable, Low-carbon Transport, the Deutsche Gesellschaft für Internationale Zusammenarbeit, Institute for Transport Development Policy and the World Resources Institute have been publishing reports on a regular basis since 2009. Key topics include costs and potentials of mitigation options, development of mitigation actions, the role of climate instruments and climate finance, data requirements and methodologies to estimate emission reductions from transport measures, suitable SDG indicators for transport, and low-carbon policy design. Yet in academic literature this field of inquiry remains relatively unexplored.

\subsubsection{Transitions in mobility}

The need for a transition in the transport sector in the light of climate change as well as sustainable development has been acknowledged by many, in different wordings, e.g. 'transformative change' 5 , 'disruptive solutions', 'transitions towards a more

${ }^{5}$ ICLEI, http://talkofthecities.iclei.org/transformative-change-in-transport-systems/

${ }^{6}$ Presentation on transport in the 2 degree scenario by Jose Viegas, former ITF president, May 2017 
sustainability system ${ }^{77}$ and Mobility Transition ${ }^{8}$. Fulton et al. (2017) argue that 'three revolutions in urban transport', i.e. electrification, automation and ride sharing, can achieve an $80 \%$ cut in city mobility emissions. Taking a broader sustainable mobility perspective, Banister (2008) concludes four transition lines are essential to sustainable mobility: travel mode choice, urban and regional planning, technology, and travel substitution. Common in these transition lines is the need for systemic change from current practices and technologies in the transport system towards utilisation of new technologies in vehicles and organisation of transport services, transport and land-use planning, and behaviour change. Incremental changes only may not lead us to a truly sustainable mobility system.

Put succinctly, transitions are "a set of processes that lead to a fundamental shift in socio-technical systems" (Markard et al., 2012: p. 956). They typically take place across long periods of time, e.g. 50 years or more, and are relatively rare (Kemp et al., 2012). They do not only change structure of existing systems, but also affect societal domains, such as living, housing and working, production and trade, and planning and policymaking (Kemp et al., 2012).

In the governance of transitions towards sustainability, four theories are distinguished (Markard et al., 2012). Transition management (e.g. Voss et al., 2009; Geerlings et al., 2012) is a governance approach to influence a transition process, through a combination of a long-term vision and a short-term process of learning and experimentation through interventions. A related process approach is strategic niche management (Kemp et al., 1998), which is about shaping interactions between key actors and developing networks and institutional connections. Key components include the 'creation, development and controlled phase-out of protected spaces' for promising technologies, successive experiments, and articulation (design, policy, meaning, market, production network, etc). The third theory ${ }^{9}$, of an explanatory or descriptive nature rather than management, is the Multi-Level Perspective (Geels, 2002), in which three levels of development interact with each other: “i) technological niches, where variation is generated, ii) sociotechnical regimes, which represent a 'deep structure' and account for stability, iii) a sociotechnical landscape, representing the wider context". When successful niches are destabilising the regime,

7 Title of the 2016 edition of the annual Transport and Environment Reporting Mechanism by the European Environment Agency

8 Used by 'Agora Verkehrswende', which is a "a protected space for constructive and well informed debate, helping to identify convergences on the transition process to a sustainable transport system", mainly focusing on electric vehicles. https://europeanclimate.org/wpcontent/uploads/2016/06/project_description_ENGLISH.pdf

9 or a "heuristic' for thinking through socio-technical transitions rather than a full-blown theory" (Tyfield, 2014: p. 586) 
assisted by landscape developments (e.g. momentum for sustainable development), innovative technologies or practices can become mainstream. The sociotechnical landscape is often seen as longer term and relatively stable trends in countries, e.g. the political context. Some authors (e.g. Tyfield, 2014) comment that in many developing countries the socio-technical landscape is less stable than in developed countries, thereby potentially opening up quick windows for change in the dominant regimes. Finally, Technological Innovation Systems (e.g. Bergek et al., 2008) is more policy-oriented approach. It is based on actor interactions and set of functions that an innovation system needs to fulfil in order to be successful for a specific technology.

Transition studies has become a research school of some relevance, and for the transport sector a sizeable body of literature has been published. Books and articles mainly deal with analysis and policy approaches related to the current 'car-based' system or 'automobility' as the dominant system of contemporary mobility ${ }^{10}$ (Urry, 2004). This regime is characterised by stability and lock-in, and a key question is whether we will "see a greening of cars, maintaining the car-based mobility system or is something more radical possible, combining modes and car less dominant" (Kemp et al., 2012). Cleaner vehicles help address air quality and climate change, not sustainable mobility as defined by Banister (2008), therefore 'the way in which sustainable mobility is defined and translated into policy is an interesting transition issue'. Sustainability experiments (Sengers, 2016) and policy experimentations (Stead, 2016) are considered important ways to promote sustainable transport.

Most of the transition literature focuses on Western Europe, however a few studies on transitions on sustainable transport in Asia have been published. Sengers (2016) concludes that sustainability experiments on urban mobility in Thailand do not (yet) challenge the dominant regime based on private motorised mobility. Raven et al. (2017) discuss urban mobility experiments in India. Tyfield (2014) analyses emobility in China based on the multi-level perspective, adding dimensions of 'power'. In reflecting on transition developments in Asia in general, Berkhout et al. (2009) note that "this sequence of transformations may be occurring earlier and more contemporaneously". The importance of 'leapfrogging' for transport technologies and practice in developing countries has been acknowledged as well, and these countries should "learn from developed countries' planning mistakes" (Bruun \& Givoni, 2015: p. 30).

${ }^{10}$ Implicitly this refers to the Western world and not necessarily to developing countries, where currently other modes are often dominant. 


\subsection{Research problem and methodology}

\subsubsection{Research problem and questions}

Sustainable, low-carbon transport policies in line with global objectives are far from a current reality in both developed and developing countries, including ASEAN, due to a range of barriers in the realms of economy, policy development, institutions, analysis techniques and society. Based on sections 1.2 and 1.3 , we see the following gaps in research and policy that are required to be filled to deal with this issue. First, as climate change mitigation is an international policy objective and (sustainable) development are priorities for transport policymakers, there is a conceptual challenge on how to reconcile these. There is a missing link between international and 'lower' governance levels which corresponds to a missing link between lowcarbon and sustainable transport, and a theoretical basis on how to address this gap is missing. Second, a research gap is the lack of knowledge on the current status and the applicability of concepts of policy analysis and transition thinking to sustainable transport policy in ASEAN countries at various jurisdictional levels. The third gap is of a more practical nature: the lack of knowledge on how low-carbon transport policy can be developed further, given the various challenges and barriers policymakers are facing. Finally, a knowledge gap exists on how various jurisdictional levels can contribute to each other's goals in transport and climate change policy.

This thesis aims to contribute to filling these four gaps, with the following central research question:

What are current policy responses to sustainability challenges in the transport sector and how can these be strengthened, particularly for climate change mitigation in rapidly motorising ASEAN countries?

More specifically, this thesis deals with the following sub-questions:

- How can the nexus between development, transport and climate change mitigation be characterised, and what would a framework that emphasises these aspects, look like for the transport sector?

- Which international climate change policy instrument currently in place and being proposed are most effective in promoting sustainable, low-carbon transport policy in developing countries?

- How does regional (international) cooperation address sustainable transport, and how can such cooperation be strengthened? 
- How can the current national policy framework for low-carbon transport in ASEAN countries be characterised?

- What is the current status and outlook for cycling as a mobility option in ASEAN cities?

This thesis aims to contribute to research and policy practice in multiple ways. Knowledge development on existing policies and gaps in the ASEAN region will help future policy development and can be used by policymakers and practitioners for policy learning. It also develops a new low-carbon transport policy concept based on sustainable transport thinking. In addition, this thesis brings some elements of the dynamic policy activity and knowledge development on the interplay of international climate change policy and transport policy in developing countries into the academic literature. Finally, it applies theoretical concepts from policy studies, governance and transitions to transport policy in emerging economies, thereby 'testing' these with the aim to contribute to theoretical development and potential avenues of further research.

\subsubsection{Conceptual framework and methodology}

Building on the concepts elaborated in Section 1.3, this thesis looks at how the transport sector responds to sustainable development challenges, and climate change mitigation in particular. As mentioned before, sustainable development objectives are primary drivers for transport policy, and climate change is driven by international policy. However, addressing national and local sustainable development often results in greenhouse gas emission reductions; thereby contributing to low-carbon transport as well.

In addition to developing a framework for transport, development and climate change mitigation, this thesis looks at the intersection of transport policy and climate change or sustainable development at four governance levels: global, regional, national and local (urban), with the last three focusing on Southeast Asia (see Figure 1.3). 


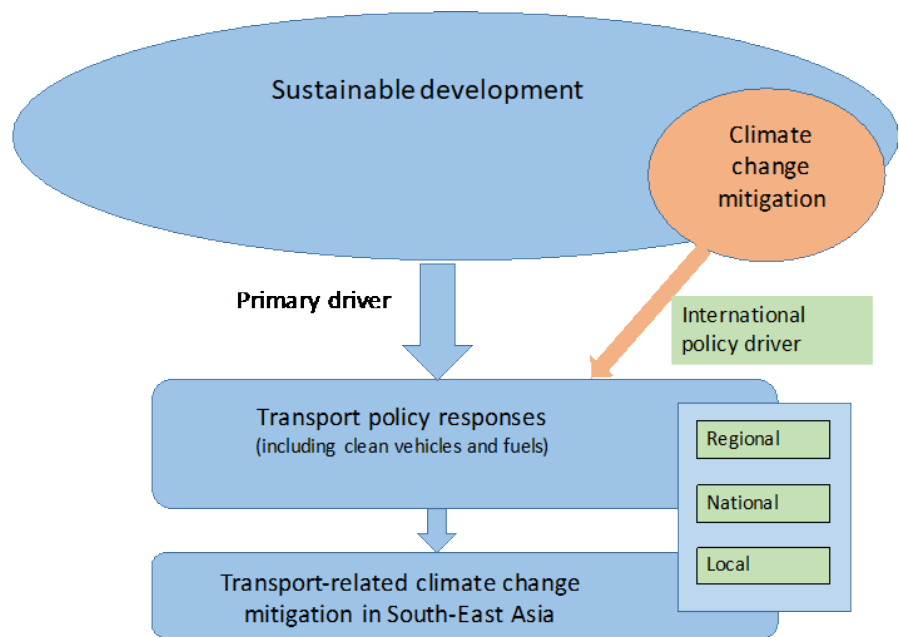

Figure 1.3. Thesis' conceptual framework. This thesis focuses on how low-carbon transport policy at various of governance is developed as a response to global challenges of sustainable development and climate change.

This thesis builds on and uses concepts from sustainable development, policy studies (Hall, 1993; Howlett \& Cashore, 2009), transition studies, particularly Technological Innovation Systems (Bergek et al., 2008), and international cooperation and governance (Abbot \& Snidal, 2000). The research methodologies are based on these concepts, in particular TIS analysis and policy component analysis, as well as conceptual thinking, project data analysis, ex-ante and ex-post policy analysis (see also Table 1.2). The methodologies are explained further in the respective chapters.

Rather than positivist policy analysis, i.e. based on quantitative data, modelling and welfare economics, this thesis mainly uses post-positivist approaches, in which 'values', 'framing', stakeholders (decision-makers), and qualitative data play a larger role (Hajer \& Wagenaar, 2003). This is an additional contribution to transport and climate change academic literature, of which the 'vast majority' is based on positivist epistemological principles (Schwanen et al., 2011; p. 995).

Data sources include:

- First, policy documents such as transport strategies, specific policies and supporting studies. Most of these are available publicly, yet a number were obtained in hardcopy from policymakers. In some cases, they were available only in languages other than English, and translation was done by a native speaker known to the author.

- Second, we use secondary data from literature, both peer-reviewed as well as 'grey' literature, and in some cases (online) media. 
- Third, we have conducted semi-structured interviews with policymakers and experts in ASEAN countries.

- Fourth, we use databases such as international climate change support projects on transport by international organisations.

- Finally, observations from regional and national workshops and meetings with policymakers on transport and climate change in ASEAN were used to support the analysis. These were taking place in the context of the ASEAN-German Technical Cooperation project on Transport and Climate Change in ASEAN ${ }^{11}$, of which I have been team leader and adviser.

The scope of this thesis is as follows. The main focus is on analysis of policy content, whereas some chapters include elements of policy processes such as governance, institutional development, and stakeholder involvement. It focuses on transport in developing countries, and in particular Southeast Asia. Within the transport sector, the scope is limited to surface transport, i.e. international maritime and aviation are excluded. Freight transport is not excluded, however its role in this thesis is more limited as compared to passenger transport, due to the lack of literature and policy attention for the former. As mentioned before, 'low-carbon transport policy' can be any government-led action that results in lower greenhouse gas emissions compared to business-as-usual.

\subsection{Thesis outline}

The core of this thesis are the five chapters - all published in peer-reviewed journals by December 2017 - that cover one research question each (see Section 1.4.1). The research in Chapter 2 will result in a conceptual policy framework used in the subsequent chapters. Chapters 3 to 6 cover different jurisdictional 'levels' of policy: global/international, regional, national and local. These policy spheres cannot be seen in isolation: they interact with one another in multiple ways, e.g. the global climate change agenda influence transport policy at the regional, national and local level. This multi-level interaction is discussed Section 7.3, and partially in the respective chapters. Chapter 7 also summarises and synthesises the findings, reflects on transport and climate change policy, and suggests future research. This is shown in Figure 1.4, while Table 1.2 shows a more detailed overview of Chapter 2 to 6 and their linkages.

11 www.transportandclimatechange.org 


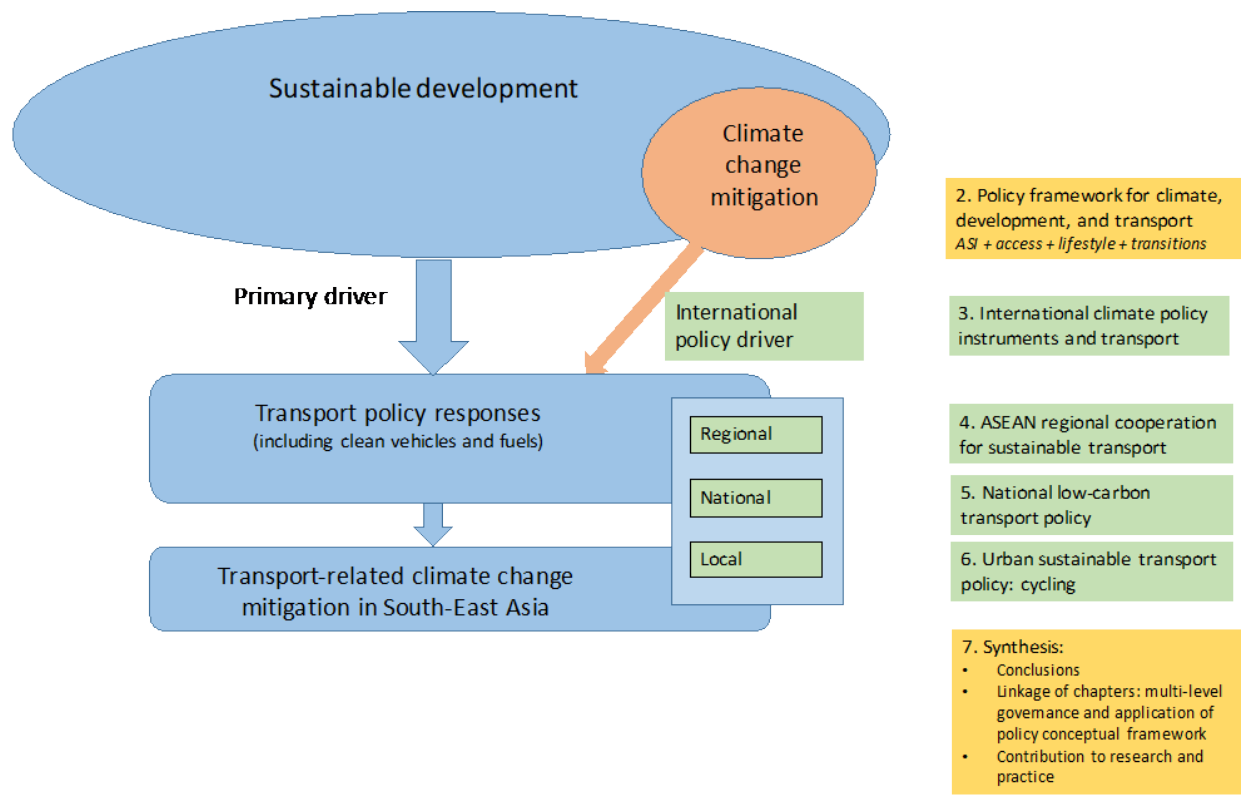

Figure 1.4. Thesis structure with chapter numbers (further detail added to Figure 1.3). 
Table 1.2 Overview of Chapters 2 to 6 and their links

\begin{tabular}{|c|c|c|c|c|c|c|}
\hline $\begin{array}{l}\text { Research question in } \\
\text { chapter\# }\end{array}$ & Theory & $\begin{array}{l}\text { Type of } \\
\text { analysis }\end{array}$ & Data & Results & Audience & $\begin{array}{l}\text { Links to other } \\
\text { chapters }\end{array}$ \\
\hline $\begin{array}{l}\text { 2. How can the } \\
\text { nexus between } \\
\text { development, } \\
\text { transport and climate } \\
\text { change mitigation be } \\
\text { characterised, and } \\
\text { what would a } \\
\text { framework that } \\
\text { emphasises these } \\
\text { aspects, look like for } \\
\text { the transport sector? }\end{array}$ & $\begin{array}{l}\text { Sustainable } \\
\text { development } \\
\text { (transitions) } \\
\text { (low-carbon } \\
\text { development) }\end{array}$ & $\begin{array}{l}\text { Literature } \\
\text { review, } \\
\text { conceptual } \\
\text { thinking }\end{array}$ & Literature & $\begin{array}{l}\text { Lack of } \\
\text { comprehensive } \\
\text { policy frameworks; } \\
\text { ASI needs access, } \\
\text { lifestyle and } \\
\text { transitions to be } \\
\text { framework for } \\
\text { sustainable, low- } \\
\text { carbon transport } \\
\text { policy }\end{array}$ & $\begin{array}{l}\text { Policymakers, } \\
\text { practitioners, } \\
\text { academics }\end{array}$ & $\begin{array}{l}\text { Used and } \\
\text { referred to in all } \\
\text { subsequent } \\
\text { papers }\end{array}$ \\
\hline $\begin{array}{l}\text { 3. Which } \\
\text { international climate } \\
\text { change policy } \\
\text { instrument currently } \\
\text { in place and being } \\
\text { promote are most } \\
\text { effective in } \\
\text { promoting } \\
\text { sustainable, low- } \\
\text { carbon transport } \\
\text { policy in developing } \\
\text { countries? }\end{array}$ & & $\begin{array}{l}\text { Ex-post, ex- } \\
\text { ante; Impact } \\
\text { of CC policy } \\
\text { on transport }\end{array}$ & $\begin{array}{l}\text { Project } \\
\text { documentation, } \\
\text { literature }\end{array}$ & $\begin{array}{l}\text { Limited impact of } \\
\text { international CC } \\
\text { policy mechanisms } \\
\text { on transport } \\
\text { projects; Policy } \\
\text { options }\end{array}$ & $\begin{array}{l}\text { International } \\
\text { CC } \\
\text { policymakers, } \\
\text { researchers }\end{array}$ & $\begin{array}{l}\text { Link to Chapter } \\
4 \text { and } 5 \text {; link to } \\
\text { Section } 7.3\end{array}$ \\
\hline $\begin{array}{l}\text { 4. How has regional } \\
\text { (international) } \\
\text { cooperation been } \\
\text { taking up sustainable } \\
\text { transport and how } \\
\text { can it be enhanced? }\end{array}$ & $\begin{array}{l}\text { International } \\
\text { cooperation } \\
\text { and } \\
\text { governance }\end{array}$ & $\begin{array}{l}\text { Ex-post and } \\
\text { Ex-ante; } \\
\text { Transport } \\
\text { policy } \\
\text { response to } \\
\text { SD }\end{array}$ & $\begin{array}{l}\text { Literature, } \\
\text { observations in } \\
\text { regional } \\
\text { meetings, } \\
\text { project } \\
\text { experience }\end{array}$ & $\begin{array}{l}\text { Increasing } \\
\text { attention for } \\
\text { environment and } \\
\text { SD in ASEAN } \\
\text { transport } \\
\text { cooperation, in } \\
\text { 'soft law'; policy } \\
\text { options }\end{array}$ & $\begin{array}{l}\text { Researchers on } \\
\text { governance; } \\
\text { ASEAN } \\
\text { regional } \\
\text { policymakers/ } \\
\text { practitioners }\end{array}$ & \\
\hline $\begin{array}{l}\text { 5. How can the } \\
\text { current national } \\
\text { policy framework for } \\
\text { low-carbon transport } \\
\text { in ASEAN countries } \\
\text { be characterised? }\end{array}$ & $\begin{array}{l}\text { Policy } \\
\text { component } \\
\text { analysis }\end{array}$ & $\begin{array}{l}\text { Ex-post } \\
\text { (current } \\
\text { status); } \\
\text { Transport } \\
\text { policy } \\
\text { response to } \\
\text { CC and SD }\end{array}$ & $\begin{array}{l}\text { Interviews, } \\
\text { policy } \\
\text { documents, } \\
\text { literature }\end{array}$ & $\begin{array}{l}\text { Sustainable } \\
\text { development and } \\
\text { climate change are } \\
\text { (mildly) reflected in } \\
\text { policy components; } \\
\text { Some differences } \\
\text { between countries } \\
\text { in policy content }\end{array}$ & $\begin{array}{l}\text { Transport and } \\
\text { CC policy } \\
\text { researchers, } \\
\text { practitioners } \\
\text { and } \\
\text { policymakers }\end{array}$ & $\begin{array}{l}\text { Referred to in } \\
\text { Chapter } 4\end{array}$ \\
\hline $\begin{array}{l}\text { 6. What is the } \\
\text { current status and } \\
\text { outlook for cycling } \\
\text { as a mobility option } \\
\text { in ASEAN cities? }\end{array}$ & $\begin{array}{l}\text { Technological } \\
\text { Innovation } \\
\text { Systems }\end{array}$ & $\begin{array}{l}\text { Ex-post, ex- } \\
\text { ante; transport } \\
\text { policy } \\
\text { response to } \\
\text { SD }\end{array}$ & $\begin{array}{l}\text { Local and } \\
\text { national policy } \\
\text { documents, } \\
\text { media, } \\
\text { interviews }\end{array}$ & $\begin{array}{l}\text { Momentum and } \\
\text { potential for } \\
\text { cycling but still } \\
\text { niche; framed in } \\
\text { health, 'fun', and } \\
\text { environment } \\
\text { context; Gaps in } \\
\text { policy, knowledge; } \\
\text { policy options }\end{array}$ & $\begin{array}{l}\text { Policymakers, } \\
\text { practitioners in } \\
\text { ASEAN; } \\
\text { transition } \\
\text { researchers }\end{array}$ & $\begin{array}{l}\text { Referred to in } \\
\text { Chapter } 5\end{array}$ \\
\hline
\end{tabular}

CC: climate change; SD: sustainable development; ASI: avoid-shift-improve 


\section{Chapter 2}

\section{Transport, development and climate change mitigation: towards an integrated approach*}

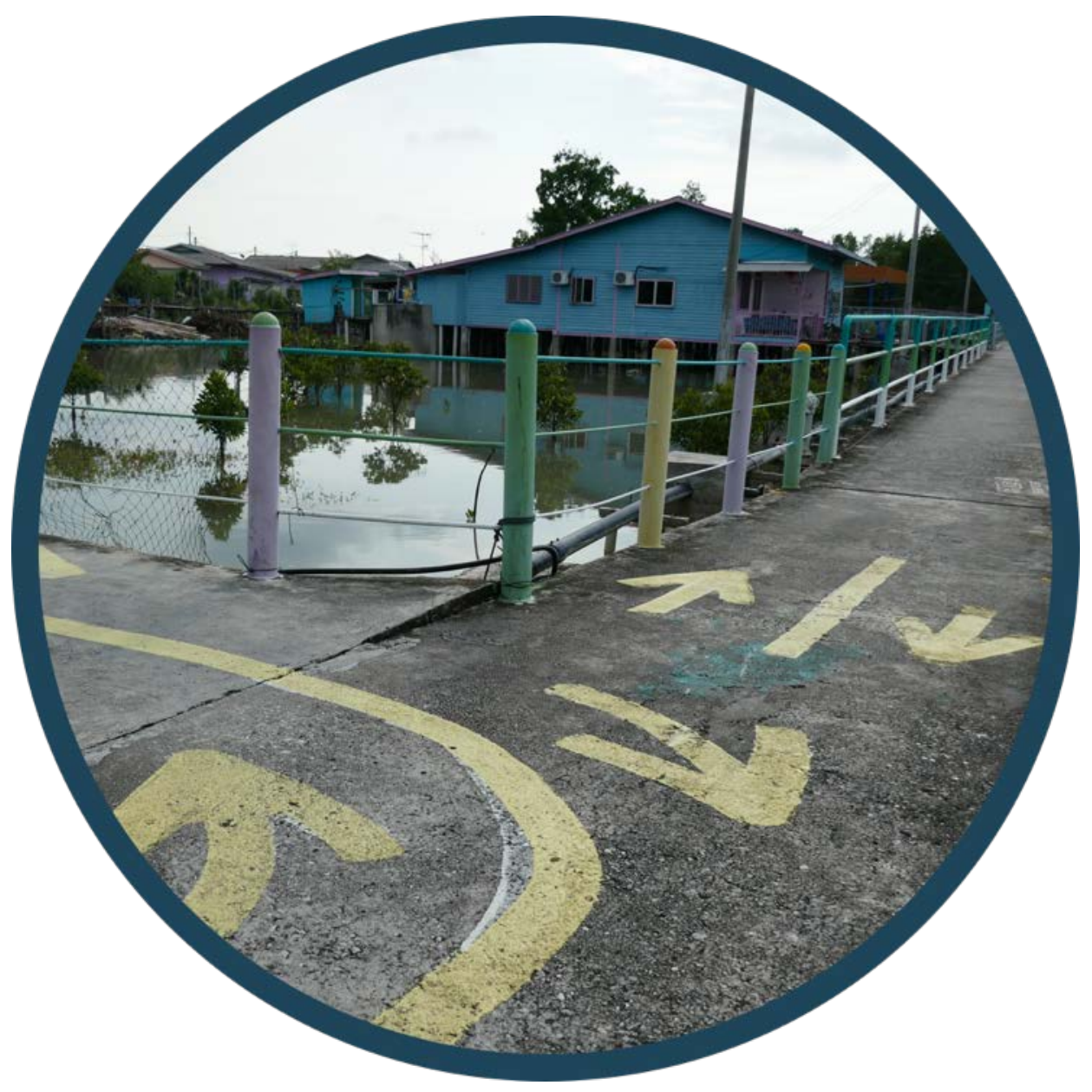

* Published as Bakker, S., Zuidgeest, M.H.P., de Coninck, H. and Huizenga, C. (2014) Transport, development and climate change mitigation: towards an integrated approach. Transport reviews, 34 (3) pp. 335-355. 


\begin{abstract}
Transport and infrastructure development enables economic and social development, but is often detrimental to sustainable development due to congestion, accidents, air pollution, as well as greenhouse gas emissions. Various policy frameworks have been created to connect transport with development, development with climate change and climate change mitigation with the trans- port sector. However, so far no consistent framework exists that addresses these three areas in an integrated manner. This article demonstrates that sustainable development of the transport sector is not viable on the longer term in the absence of such a three-way framework. First, current perspectives and practices on transport and (sustainable) development are reviewed, demonstrating that outcomes and policies are not consistently positive on all three dimensions. The article then re-evaluates the Avoid-Shift-Improve (ASI) approach, initially developed to address climate change mitigation and other environmental issues in the transport sector, adding two perspectives on sustainable development that are not generally taken into account when discussing ASI: transition theory and sustainable lifestyles. Together with attention to the development function of transport by incorporating Access into ASI, this could enable a more long-term sustainability-oriented view on transport, development and climate mitigation.
\end{abstract}




\subsection{Introduction}

Addressing climate change while advancing global well-being is regarded as one of the key challenges of the twenty-first century. Transport is responsible for $22 \%$ of global energy-related carbon dioxide $\left(\mathrm{CO}_{2}\right)$ emissions (IEA, 2012a), which are projected to increase by 35\% until 2035 under a New Policies Scenario (IEA, 2012a). At the same time the transport sector is playing an important role in economic and social development (UNESCAP, 2011), as it provides accessibility to services and facilities that society considers vital. However, conventional transport pathways and policies also contribute to local, national, regional and global problems, such as air pollution, climate-related impacts on transport infrastructure and services, transportrelated social exclusion, road safety and congestion. Consequently, dealing with environmental, development and transport issues simultaneously is a requirement for an overall sustainable development in the context of transport (Zusman et al., 2012). This article takes a step forward towards addressing the triple challenge of transport, development and climate change mitigation.

To promote the overall sustainable development of transport systems, including the reduction of greenhouse gas (GHG) emissions from the transport sector, different types of policy instruments have been developed, tested and implemented. These range from land use, transport and infrastructure planning instruments to economic, regulatory and behavioural instruments focussing on fuel pricing, driving behaviour and vehicle technology (Banister, 2008; Grazi \& Van den Bergh, 2008). Although the benefits of such actions are widely recognised (IEA, 2012a), to date the policies have had only limited success ${ }^{12}$. This is testified by fast-rising GHG emission trends in virtually all countries and worsening congestion and air quality in most cities, but especially in the developing world (IPCC, 2007; Zusman et al., 2012).

End-of-pipe policies have been implemented successfully, but their impacts are more than compensated by the fast urbanisation and increases in motorisation in many cities and countries; the root causes of the aforementioned transport-related problems. Therefore, while end-of-pipe solutions are an integral part of strategies to mitigate negative impacts of transport, they may need to be combined with policies that reduce the number of person-kilometres and tonne-kilometres by private and commercial road-based vehicles (Johansson, 2009).

12 In the fields of air quality and road safety, there have been successes in many countries and cities, e.g. due to end-of-pipe solutions, phase-out of leaded fuel, strict speed limits and safety regulations. Individual cities, e.g. Singapore and Shanghai, have demonstrated that it is possible to drastically slow down the rate of motorisation through a quota system, which reduces the number of new cars added to the fleet. 
Most policies implemented hitherto can be characterised as incremental policies and measures rather than transitional ones (Leather \& CAI-Asia Team, 2009; Litman, 2003). Radical systemic changes, needed to transform transport systems and their impact on people, cities and the environment, are rare as they are very complex and generally raise considerable resistance (Marsden et al., 2012), have longer pay-back times and fewer tangible direct economic benefits. If investments in large-scale, systemic and public transport systems are successful, their effects are frequently overwhelmed by even faster development in the traditional, individual car-based transport systems in the same geographical area (examples being Beijing (Zhao et al., 2010) and Mexico ${ }^{13}$ (Hidalgo \& Huizenga, 2013)). In summary, explanations for the lack of success of existing policy instruments are ample and include fast urbanisation and motorisation, inaccessibility of finance; costs of alternative fuels; technological challenges; technological lock-in; sunk costs and inertia of transport systems; vested interests; low-price elasticity of mobility; diversity of stakeholders and behavioural barriers (ECMT, 2007; IEA/OECD, 2009).

Several approaches or frameworks have been suggested to advance sustainable transport policy from the more traditional, incremental and mobility-centred approach to a transitional and accessibility-centred approach (Akinyemi \& Zuidgeest, 2000, 2002). This is in line with Massen et al. (1992), who suggest an equity and sustainable development-oriented approach in transport instead of a mobility or growth-based approach. Banister (2008), Huizenga and Leather (2012), and Litman (2003) argue that a shift towards sustainable mobility or sustainable transport is needed to balance the physical dimensions of conventional planning (i.e. urban form, infrastructure and traffic) with social dimensions (i.e. people and proximity to opportunities). In addition, authors such as Sheller and Urry (2006), Larsen, Urry, and Axhausen (2012) and others have emphasised that developments in information and communication technology (ICT) and social net- working are greatly impacting the need and extent of travel. Actions are required to reduce the need for travel (less physical trips), to encourage modal shift to cleaner modes, to reduce trip lengths and to encourage greater (fuel) efficiency in the transport system. This is well captured by the Avoid-Shift-Improve (ASI) concept, as proposed by Dalkmann and Brannigan (2007). Advancing sustainable transport this way deals with aspects of accessibility, i.e. reducing car dependency and the use through planning and (new) mobility, i.e. the promotion of clean, efficient and integrated forms of transport and communications.

${ }^{13}$ Mexico, for example, put in place three BRT corridors and extension of subway but at the same time each year 500000 cars were added as well. 
Current sustainable transport policy has failed to address this combined climate change mitigation, development and transport challenge. To arrive at a policy framework that does, this article first explores the current policy paradigms along the three axes of the transport-climate-development triangle. It discusses the transport-climate change mitigation link, the climate change mitigation-development link and the development-transport nexus in Section 2.2. In Section 2.3, existing frameworks for addressing transport and sustainable development are reviewed and discussed from a transformational and an integration perspective. Section 2.4 discusses additions to the ASI approach, taking into account accessibility challenges, thinking on transitions and social and lifestyle aspects of sustainable development. Section 2.5 concludes with a way forward.

\subsection{Policy Paradigms on Transport, Development and Climate}

This section discusses relevant existing and emerging concepts and policy frameworks related to the nexus transport, development and climate change mitigation ${ }^{14}$. As there is no paradigm for concrete guidance to policymakers covering all three elements simultaneously, we first discuss each part of the nexus as shown in Figure 2.1 in isolation.

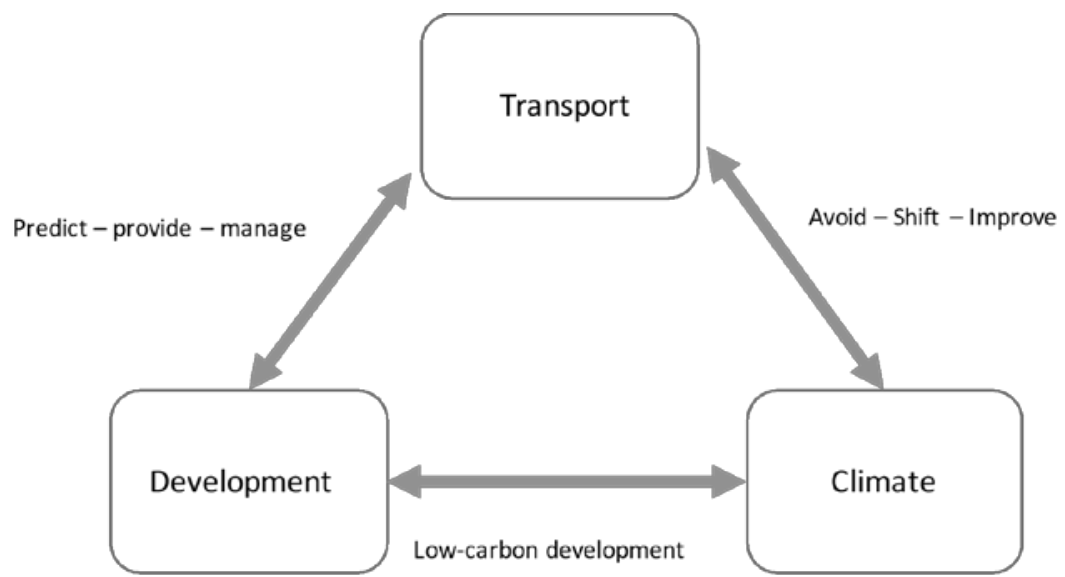

Figure 2.1. Schematic representation of the current situation featuring the three dominant policy paradigms: (1) Predict-provide-manage on the transport-development axis that aims for accessibility and equity, contributing to economic and social development; (2) avoid-shift-improve on the climate-transport axis, aiming to reduce GHG emissions (and other environmental impacts) from transport compared to some baseline; and (3) Low-carbon development on the climate-development axis, reducing GHG emissions of economic development patterns compared to some baseline.

${ }^{14}$ Referred to as 'climate' in this article. Climate change adaptation is not dealt with, as this is considered to be part of the 'development' aspect of transport policy. 


\subsubsection{Transport - development}

Transport is an important component of any economy, as it impacts development and the welfare of populations (Rodriguez, 2013) by providing people and companies access to spatially and temporally dispersed resources (Straatemeier, 2008). In the EU its direct contribution to GDP and employment are 7\% and 5\% respectively (Site \& Salucci, 2010). In most countries there is a strong correlation between economic growth and freight and passenger transport volume (Schroten et al., 2012; Ecola \& Wachs, 2012), even though this relation differs strongly between world regions and countries. Empirical evidence is, however, limited and controversial (Litman, 2010). Ecola \& Wachs (2012) for example state that "research on the relationship between vehicle-kilometre travelled and economic growth has not yet reached a definitive conclusion about causality". Decoupling of person and tonne-kilometres from GDP growth is a policy goal (CST, 2005), and evidence that freight transport demand (McKinnon, 2007) and passenger transport demand (Millard-Ball \& Schipper, 2011) are growing slower than GDP is emerging in some countries. In particular, the daily distance travelled by car is stabilising or decreasing in several developed countries, a trend which - even though not fully understood is also called 'peak car' (Kuhnimhof et al. 2013).

Transport Demand Management (TDM) measures that target avoiding of nonessential travel, thus allowing for economic activity to sustain, are however seen as viable decoupling measures. In this regard, Litman (2010) lists freight transport management, trip reduction and congestion management strategies. In addition, Schroten et al. (2012) identify drivers for decoupling for both the freight and passenger transport and show there is a large potential for decoupling through demand management policies, at least theoretically. This is well illustrated by two Chinese cities: vehicle ownership and use in Shanghai is much smaller than in Beijing because of 15 years of suppressing the rate of motorisation through a quota on new vehicles, yet GDP per capita in Shanghai remains higher than in Beijing (Yan \& Crookes, 2009).

Apart from its linkage with economic activity, transport is also closely linked to human well-being (Delbosc, 2012; Spinney et al., 2009), quality of life (de Groot \& Steg, 2006; Carse, 2011), social equity (Boschmann \& Kwan, 2008) and social inclusion (Grengs, 2001) through the provision of basic transport options and services to access social and economic opportunities. Recognising that transport is (mainly) a means to an end, the focus of contemporary transport research is gradually shifting away from the old mobility paradigm where travel demand was typically catered for by infrastructure expansion (so-called predict-provide-manage approach) to one focusing on accessibility (Akinyemi \& Zuidgeest, 2002; Huizenga \& Leather, 
2012) and where New Mobility options and their impacts are explored (Sheller \& Urry, 2006; Schwanen et al., 2006; Roy et al., 2012). Accessibility looks at people and their proximity to opportunities rather than vehicular travel per se. Linking land uses and multi-modal transport into one metric, accessibility looks at both the effectiveness of the transport system in terms of the ability to reach destinations as well as to the availability of facilities and services in terms of the geographical match between origins and destinations (Rodriguez, 2013). In this way an urban poor dweller living in a far-away slum area, which is connected well by road, but poorly by affordable public transport, is facing transport-related social exclusion (Zuidgeest et al., 2013). This problem is not exclusive to developing countries as for example in Australia and Canada accessibility and transport related social exclusion are issues as well for many lower income dwellers (Delbosc \& Currie, 2011; Foth et al., 2013). As such, there are important equity and distributional effects that accessibility can deal with (Wee \& Geurs, 2011).

The nexus transport - development can thus be addressed by adopting an accessibility and equity-based transport planning approach (Litman, 2013) as various land development and transport factors can affect accessibility and equity, including mobility, the quality of transport options, transport network connectivity, geographic proximity and urban form. In line with ASI (see Section 2.2.2) such an accessibility approach can help to reduce total vehicle- $\mathrm{km}$ travelled by implementing other ways (or 'new mobility' options) of 'reaching' activity locations, including ecommunication, modal shift, transport demand management etc. When combined with more comprehensive economic evaluation methods for guidance of planning (Litman, 2013), an accessibility-based planning approach can serve both social and economic development.

\subsubsection{Transport - climate change mitigation: Avoid, Shift, Improve}

The ASI approach was initially developed in the early 1990s in Germany as a way to structure policy measures to reduce the environmental impact of transport (Bundestag, 1994; Kagermeier, 1998). Dalkmann \& Brannigan (2007) described it as a useful approach to reduce environmental impacts associated with rapid motorisation in developing countries. In their view policies to limit GHG emissions in the transport sector need to consist of measures aimed at: (a) Avoiding the need to travel, e.g. by improved urban planning, transport demand management or road pricing, and e-communication options (mobile phone use, teleworking), (b) Shifting ${ }^{15}$ travel to the most efficient or clean mode, e.g. non-motorised or public

${ }^{15}$ Or maintaining the relatively sustainable modal split in favour of public transport in many developing countries. 
transport or, for freight, rail or water-borne transport; and (c) Improving the environmental performance of transport through technological improvements to make vehicles more energy efficient and fuels less carbon intensive. Kagermeier (1998) and GIZ (2011) have argued that there is a hierarchy in ASI: the 'Avoid' strategy should be implemented first, followed by the 'Shift' strategy, and finally an 'Improve' strategy.

The ASI approach is essentially an organising framework, which can fit a large range of diverse policies, regulatory instruments and best practices. The ASI approach is agnostic in terms of the scale or rate of change. Incremental change through a gradual tightening of fuel economy standards fits well within the Improve component, but so does a leapfrogging Shift towards high-speed rail to replace air travel.

In the development community, the ASI approach was first embraced by international NGOs, as well as multilateral and bilateral development organisations working on transport (ADB, 2010; GEF-STAP, 2010; Leather and CAI-Asia Team, 2009). They felt that ASI provided a worthwhile alternative to the predict - provide - manage approach, which had guided assistance to the transport sector especially through multilateral development banks. More recently, through the Bangkok 2020 Declaration (EST, 2010) and the Bogota Declaration on Sustainable Transport (Hidalgo \& Huizenga, 2013), countries in Asia and Latin America have started to endorse ASI as an organizing framework for transport policies in their countries. In Europe, attention for ASI has also picked up in recent years (EEA, 2012).

Most of the elements of ASI have actually been implemented at scale in both the developed and developing world (Huizenga and Leather, 2012), but not as part of an explicit ASI labelled transport policy. The institutional responsibility for the diverse nature of potential policies and measures under the ASI approach typically involves a wide range of stakeholders, both at national and local levels. This combined with the fact that transport policy is driven by a multitude of objectives, of which climate change is only one, helps to explain why as of 2014 no developed ${ }^{16}$ or developing ${ }^{17}$ country has formally adopted ASI as its policy framework for transport.

${ }^{16}$ Germany uses the concept in some recent policy documents (Lambrecht et al., 2009) but not in key transport strategies.

${ }^{17}$ Though Vietnam is an example of a country using ASI to organise transport policies (Tran, 2013) 


\subsubsection{Low-carbon development ${ }^{18}$}

In recent years, inspired by discussions in the context of the United Nations Framework Convention on Climate Change (UNFCCC) negotiations, a new concept emerged: low-carbon development (LCD). LCD refers to the complementarity between development and mitigation strategies (Mitchell \& Maxwell, 2010), or, 'use less carbon for growth' (Mulugetta \& Urban, 2010). Some scholars consider development in LCD to be synonymous or close to economic growth (e.g. Funder et al., 2009). But there are also other views on the relation between LCD and growth. UNEP (2011), for example, does not mention growth in its definition of Green Economy, but rather the promotion of human well-being and social equity. Ockwell et al. (2009), as an example, consider local innovative capabilities as a key condition for low-carbon development.

The starting point is development from a national or local perspective. Where this can be realised in a way that does not emit greenhouse gases or that reduces emissions below business as usual, it can be called low-carbon development (Tilburg et al., 2011). At the global policy perspective mitigation is viewed as a co-benefit of the national or local objective of a certain development path ${ }^{19}$. International policy mechanisms can provide support for national policies and measures, as long as these provide global benefits. An example is the Nationally Appropriate Mitigation Actions (NAMAs), which is a mechanism under the UNFCCC to support developing countries' low carbon policies and measures.

Mulugetta \& Urban (2010) differentiate interpretations of development in LCD based on two dimensions. Firstly the role of economic growth, with a distinction between narrow focus on economic growth and more emphasis on poverty reduction, social development, equilibrium ${ }^{20}$ economy and happiness, which resembles the discussion on accessibility and equity in the transport-development paradigm. Secondly a distinction is made whether LCD focuses on production sectors or on the consumption side, such as low-carbon lifestyles. They also note that LCD should be rooted in sustainable development, which is not necessarily the case with low-carbon growth. Ho et al. (2013), in defining the concept of the lowcarbon city, refer to 'patterns of consumption and behaviour that are consistent with

18 There are several related concepts in peer-reviewed literature, such low-carbon society, low-carbon economy, and green growth or low-carbon growth.

19 The name of the Partnership on Sustainable, Low-Carbon Transport (SLoCaT) also reflects this distinction of objectives.

20 This appears to be in line with sustainable economics, which maintains a distinction between growth (increased quantity) and development (increased quality) (Daly, 1996). 
low levels of greenhouse gas emissions in urban areas', including a 'high level of energy efficiency using low-carbon energy sources and production technologies'.

In developing countries perhaps more than elsewhere, GHG emission reductions are often seen as a secondary policy goal compared to improving accessibility and reducing negative externalities (Zusman et al., 2012; Bakker \& Huizenga, 2010). Under such conditions, LCD could be a useful concept as it attempts to serve both development and mitigation aims. Also, the approach taken in low-carbon development strategies, in which integrated development pathways include packages of policies (Tilburg et al., 2011), may provide opportunities for the transport sector.

\subsection{Visions on sustainable transport - guidance for policy?}

The terms sustainable development and sustainable transport are fundamental to the discussion on transport, development and climate. How do academics, policy makers and practitioners take sustainable development into account in their transport policy considerations?

Sustainable development reflects the understanding that ' 1 ) there is a limit to the scale of the economy, set by the need to sustain the carrying capacity of the ecosystems and resources of the globe; 2) a fair distribution of resources and output from the economy with and among generations of humans should be considered, and 3) with the restrictions of 1) and 2), analysis should be concerned with a socially efficient allocation of resources, maximising net benefits as is the case in traditional welfare economics' (Daly, 1991 in Gudmundsson \& Höjer, 1996). A similar approach where economic development is limited by social and environmental constraints is found in Journard \& Nicolas (2010), showing the continued relevance of this notion. Others have used the so-called triple bottom line, popularly known as "people, planet, profit" (Brown et al., 2006). In order to operationalise sustainable development, 'sustainability' (long-term stability of the social, economic and ecological system) and 'development' (improvement of human quality of life) can be seen as two linked, but different dimensions in the assessment of sustainable development (Gudmundsson \& Höjer, 1996).

Ever since its introduction several scholars and policy makers have applied the sustainable development concept to the transport sector. A seminal 1996 conference resulted in nine Sustainable Transport Principles on Access, Equity, Individual and Community Responsibility, Health and Safety, Education and Public Participation, Integrated Planning, Land and Resource Use, Pollution Prevention, and Economic well-being (OECD, 1997). Akinyemi \& Zuidgeest (2002) defined 'a sustainable transport system' as 'one that meets the people's transport related needs in terms of 
mobility, accessibility and safety, within limits of available or affordable environmental, financial and social resources capacities.' A more economic view is 'providing transportation services as long as those using the system pay the full social costs of their access, without leaving unpaid costs for others (including future generations) to bear' (Schipper et al., 1994). Jonsson (2008) considers a sustainable urban transport and land-use system one that 'provides access to goods and services in an efficient way for all inhabitants of the urban area; protects the environment, cultural heritage and ecosystems for the present generation; and does not endanger the opportunities of future generations to reach at least the same welfare level as those living now, including the welfare they derive from their natural environment and cultural heritage.'

\subsubsection{Sustainable transport views and definitions}

Table 2.1 lists a number of visions and definitions of sustainable transport that jointly form a representative set of those used by policymakers, both at national and international level.

Table 2.1. Sustainable transport definitions and views by policymakers and financiers

\begin{tabular}{ll}
\hline & Source \\
\hline 1 & Moving On Sustainable \\
& Transportation (1999)
\end{tabular}

2 Transport Association of Canada (1999)

http://www.tc.gc.ca/eng/ menu.htm

\section{Definition / vision}

The goal of sustainable transportation is to ensure that environment, social and economic considerations are factored into decisions affecting transportation activity. In the natural environment: limit emissions and waste (that pollute air, soil and water) within the urban area' ability to absorb/recycle/cleanse; provide power to vehicles from renewable or inexhaustible energy sources (such as solar power in the long run); and recycle natural resources used in vehicles and infrastructure (such as steel, plastic, etc.). (2) In society: provide equity of access for people and their goods, in this generation and in all future generations; enhance human health; help support the highest quality of life compatible with available wealth; facilitate urban development at the human scale; limit noise intrusion below levels accepted by communities; and be safe for people and their property. (3) In the economy: be financially affordable in each generation; be designed and operated to maximize economic efficiency and minimize economic costs; and help support a strong, vibrant, and diverse economy.

3 European Conference of Sustainable transport i) Allows the basic access and Ministers of Transport (2004), based on the 1997 definition of the Centre for Sustainable Transportation; development needs of individuals, companies and society to be met safely and in a manner consistent with human and ecosystem health, and promotes equity within and between successive generations, ii) Is affordable, operates fairly and efficiently, offers a choice of transport mode and 
adopted by several others including CST (2005) www.internationaltransport forum.org (since 2007)

4 Council of the European Union (2006) www.consilium.europa.eu

5 American Association of State Highway and Transportation Officials (2007) www.transportation.org

6 World Bank (2008) www.worldbank.org

7 New Zealand Ministry of Transport (2008) www.transport.govt.nz/

8 Metrolinx (2008) Formerly: Greater Toronto Transport Authority, www.metrolinx.com

9 Asian Development Bank (2010) www.adb.org supports a competitive economy, as well as balanced regional development, iii) Limits emissions and waste within the planet's ability to absorb them, uses renewable resources at or below their rates of generation, and uses non-renewable resources at or below the rates of development of renewable substitutes, while minimizing the impact on the use of land and the generation of noise. The overall objective of sustainable transport is "to ensure that our transport systems meet society's economic, social and environmental needs whilst minimising their undesirable impacts on the economy, society and the environment".

The transportation decision-makers of the future should adopt the triple bottom line as a yardstick to evaluate the sustainability of surface transportation system policies and performance in order to ensure that transportation strategies and investments will result in robust economic growth, better-than-before health of the environment, and improved quality of life for all citizens.

The goal of the (World) Bank strategy is safe, clean, and affordable transport that contributes to economic development.

Sustainable transport is about finding ways to move people, goods and information in ways that reduce its impact on the environment, the economy, and society. A transportation system that supports: A high quality of life. Our cities, owns, suburbs and rural areas will be more liveable, with more options for getting around the whole region conveniently, comfortably and safely; A thriving, healthy and protected environment. We will plan, establish and maintain a transportation system that conserves resources and leaves a legacy of a healthy and clean environment for our children and grandchildren; A strong, prosperous and competitive economy. At the heart of Canada's economy, our region will be competitive with the strongest regions in the world, based on an efficient and convenient transportation system. It will help attract and retain the best and the brightest, and make the shipping of goods and delivery of services efficient.

A sustainable transport system as one that is accessible, safe, environment-friendly, and affordable. It may generally be considered to be one that allows the basic access and development needs of individuals, companies, and society to be met safely and in a manner consistent with human health. Sustainable transport supports a competitive economy and balanced regional development, and promotes equity, including gender equity, within and between successive generations. Environmentally, a sustainable transport system minimizes the use of land and 
10 Global Environment Facility, GEF-STAP (2010) http://www.stapgef.org/

11 Environmentally Sustainable Transport Forum (2011) www.uncrd.or.jp/env/est emissions, waste, and noise. It uses renewable resources at or below their rates of generation, uses non-renewable resources at or below the rates of development of renewable substitutes, and limits emissions and waste within the planet's ability to absorb them. In terms of cost, a sustainable transport system is one that is affordable and operates efficiently, taking into account requirements for investment in capacity and the need for maintenance.

Sustainable low-carbon transport provides economically viable infrastructure and operation that offers safe and secure access for both persons and goods whilst reducing short and long term negative impacts on the local and global environments.

Sustainable transport: the provision of services and infrastructure for the mobility of people and goods needed for economic and social development and improved quality of life and competitiveness. These services and transport infrastructure provide secure, reliable, economical, efficient, equitable and affordable access to all, while mitigating the negative impacts on health and the environment locally and globally, in the short, medium and long term without compromising the development of future generations

12 Partnership for Sustainable, Sustainable transport enables access to goods and services low-carbon Transport (SLoCaT, 2012) that support equitable development while limiting short and long term adverse consequences for environmental, social and economic services and systems. www.slocat.net

Confirming Perschon (2012) and earlier also Jeon \& Amedzuki (2005), who carried out an extensive review of definitions and mission statements adopted in developed countries, Table 2.1 demonstrates there is no standard definition of sustainable transport, even though most definitions cover the three sustainable development pillars. Overall the definitions acknowledge the objectives of maximising the positive contributions of transport to society, while minimising the negative impacts. Differences occur in seven areas ${ }^{21}$ :

1. Stringency of the environmental (physical) sustainability including the use of renewable and non-renewable sources. This difference in stringency is likely to result in some organisations emphasising the need for transformative measures in the transport sector, while others could settle for incremental changes.

2. Intergenerational equity is explicitly addressed in some definitions, while in others it is absent. Including intergenerational equity sends a stronger signal that the needs of future generations are to be considered in current decisions.

${ }^{21}$ Some of these points were also discussed in OECD (1997) 
3. Several definitions include a specific target for sustainability. This means that sustainability is not achieved unless this goal is attained, while others focus on a process towards sustainability (e.g. 'limiting adverse consequences' or 'reduce impact').

4. There are differences in wording, notably the mentioning of 'accessibility' vs. 'mobility', with the former being broader focussing on the opportunity to fulfil a task or desire (e.g. working), and the latter the opportunity to transport people or goods (i.e. going to work)

5. Some include specific objectives including safety, comfort, affordable transport, the need for choices in mobility, and the contribution to development and economic growth, while others are more general (and, in these cases, shorter).

6. Three definitions explicitly include 'quality of life', which is in line with the broadest interpretation of development (Gudmundsson and Höjer, 1996), while others to not explicitly address this, thereby focussing on economic and/or social aspects of quality of life.

7. Some of the definitions explicitly acknowledge governance as a key element. This raises the question whether means - such as policy processes or stakeholder involvement - are required in definitions or visions, which are mainly about goals.

\subsubsection{Differentiating views and definitions}

Overall, the definitions of sustainable transport take into account the need for integrating transport, development and climate mitigation and/or environment, while the three policy concepts reviewed in the previous section necessarily act on one of the three combinations. However, the practical translation of the triple aim of sustainable development by the organisations in Table 2.1 differs greatly. We discuss this by differentiating the definitions along the two axes of development and low-carbon in Figure 2.1.

For development, we distinguish between an exclusive focus on economic growth and a broader sustainable development perspective, as expressed by the economic, social and environmental pillars and intergenerational equity. This follows the distinction made by Mulugetta \& Urban (2010) in the discussion on low-carbon development (section 2.2.3) and the discussion on economic development versus inclusion of other elements such as social equity, well-being and access (section 2.2.1). See also Schroten et al. (2012), who compare the implications for transport policy of Gross Domestic Product with alternative welfare approaches.

For the low-carbon axis, a difference is made between incremental changes, i.e. where any change in the right direction is considered in line with the vision (this 
appears to be in line with most definitions of low-carbon development, see section 2.2.3, but could perhaps better be called 'lower-carbon') and visions that (implicitly) acknowledge the need for long-term deep reductions of greenhouse gases, which requires a systemic transformation or transition of the transport system compared to today's practice (see also section 2.4.2).

In visions on sustainable transport, climate change mitigation is generally not explicitly mentioned, but included as part of the environmental considerations. A distinction can be made between visions that include a certain end-state (e.g. 'limits emissions and waste within the planet's ability to absorb them') and those that see sustainability as a process ('limiting', 'reducing') without specifying a desired endstate. The former can be considered in line with a transformational view, while the latter type of visions imply that any incremental change towards lower-carbon transport is part of sustainability in transport.

Figure 2.2 shows the results of the authors' assessment on the low-carbon and development axes. The authors independently reviewed the visions of sustainable transport and placed them along the two axes using a five-point scale (far left/down, left/down, middle, right/top, far right/top). When no agreement between the authors could be reached, the average of the values was taken. No distinction was made between longer and shorter definitions.

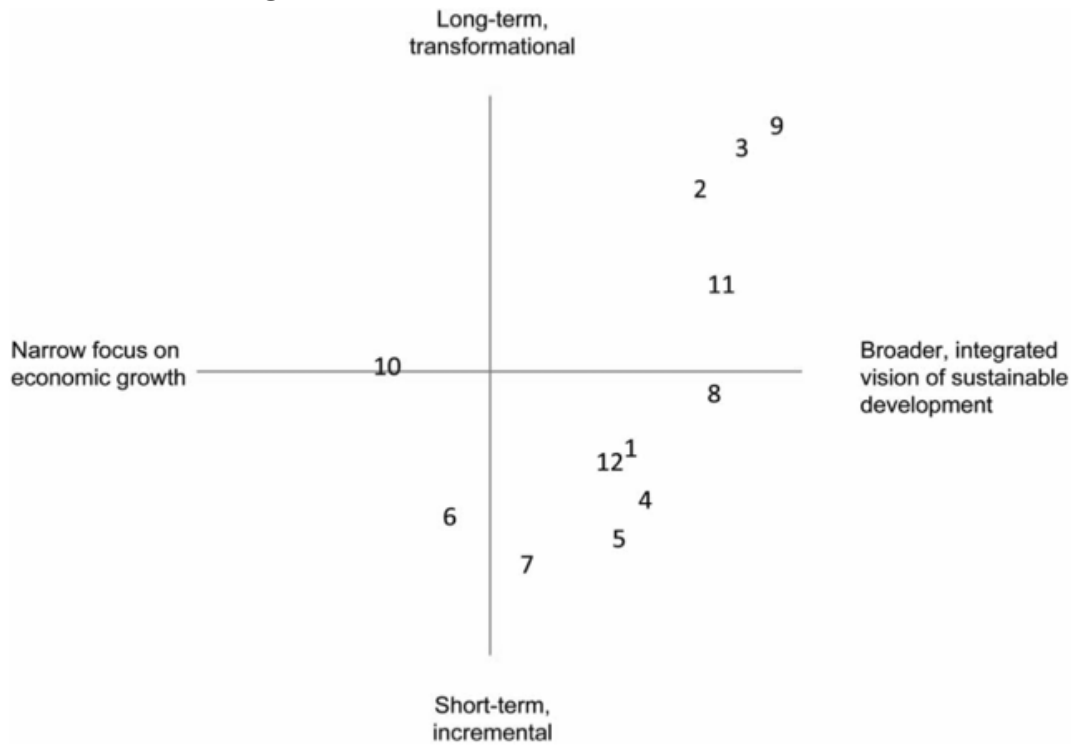

Figure 2.2. Distribution of views on sustainable transport by different organisations along two axes: 1) whether solely economic growth or broader sustainability objectives are taken on board (borizontal-axis), and 2) whether only incremental, lower-carbon options are considered or whether the change has to be transformational, taking into account deeper emission reductions in the more distant future. The numbers correspond to the numbers in Table 2.1. 
Most definitions fit in the right-hand half of the diagram, suggesting that these take into account the three dimensions of sustainability. Some of them however do not explicitly consider inter-generational equity, and are therefore placed left of those that do. The distinction between the incremental and transformational aspects appears to be more pronounced, with the bulk of the definitions in the lower part of the figure. The spread of the data points in the figure shows that the two axes are relevant in the discourse on transport and sustainable development, and are worthy of further exploration.

\subsection{Combining Avoid-Shift-Improve and the climate-transport- development nexus}

It appears that neither the policy frameworks for transport, development and climate mitigation introduced in section 2 nor the organisational visions on sustainable transport discussed in section 3 capture all potentially relevant aspects of sustainable development and transport. This section discusses the contours of an improved policy framework; in particular building on the potential for ASI to become the policy paradigm that can guide the sustainable development of transport, as well as methods, concepts and approaches for this.

\subsubsection{Adding access}

Our analysis starts from our observation that there is no coherent policy paradigm regarding the nexus of transport, development and climate change mitigation. Sustainable transport is an important enabler for growth and therefore development, but at the same time it is necessary to reduce negative externalities of transport, in particular climate change, in order to remain compatible with sustainable development. We then concluded in section 2.2.1 that the accessibility framework provides an important new approach to transport policy making. Although ASI can serve as a basis, in order to serve sustainable and economic development purposes, ASI would need to be expanded with accessibility. To realise its full potential as a policy paradigm ASI also needs to highlight positive contributions to economic and social development. Doing this by bringing access and ASI together serves the Rio +20 process and the discussion on transport in the post-2015 Sustainable Development Agenda (Huizenga, 2013).

If Access ${ }^{22}$ would be added as a fourth component, ASI could be restated as A-ASI to signify that improvement in access is the developmental objective that is prioritised, and that Avoid, Shift, Improve are important strategies to ensure that

${ }^{22}$ We use 'access', in short of accessibility or access to opportunities. 
Access will contribute to sustainable development. Sustainable access in this context will be access that is provided in a manner, which improves environmental, social and economic circumstances. This use of A-ASI is quite closely in line with the various definitions of sustainable transport as reflected in Section 2.3, in which the importance of maximising the positive impacts of transport by means of providing access, while reducing the negative externalities, is highlighted.

\subsubsection{Expanding ASI through transition theory}

Although expanding ASI with access helps including development, it is not enough from a sustainable development point of view. In order to arrive at deep emission reductions, systemic changes need to be made as indicated in Section 2.1. A-ASI does not necessarily address the challenge of implementing many measures and technologies simultaneously and in harmony. Focussing on policy and measures only (like A-ASI would do) could lead to political and social resistance, lock-in and neglect of important considerations around the incumbent system. This could (and arguably already has) lead to considerable implementation problems. Addressing climate, transport and development simultaneously requires more of a systemic approach.

Such a systemic approach has been described by transition theory (see Section 1.3.4). Transition theory describes major shifts in the socio-technical systems that are called transitions (Berkhout et al., 2011). The "socio-technical system" comprises a robust set of practices and linkages between elements that fulfil societal functions (such as transport) (Geels, 2004). It includes elements such as markets, vested interests, consumer practices, infrastructure, cultural meaning and scientific knowledge. The lock-in of both technology supply and user practice can make socio-technical systems difficult to change. The transport system can be considered a socio-technical regime; it is not only difficult to change, but even in areas with an emerging transport system (such as in fast-growing cities), the default choice replicates what is done in other parts of the world.

Changes in the socio-technical system, or transitions, may occur if landscape developments create space for niche innovations to challenge the dominant practices in the regime (Berkhout et al., 2011; Geels, 2012). It is also possible to set the sociotechnical regime up for a transition by preparing new technologies in niches, a practice called "strategic niche management" (Kemp et al., 1998), which can be compared to specific technology push policies in the economic literature.

For the transport sector it appears that niche innovations such as multi-modal integration, ICT, behaviour-oriented demand management, battery electric vehicles and socio-spatial innovations such as complete streets are generally not (yet) strong 
enough to challenge the internal combustion-based motorisation paradigm and its socio-technical system, which is stable with only a few cracks due to developments such as awareness on climate change, rising oil prices, the rise of the 'information society' (Geels, 2012), health and congestion concerns, which can be considered landscape developments. In some urban environments in the developed world, car ownership especially among younger people is dropping as public transport, walking and cycling become feasible alternatives (Kuhnimhof et al., 2013).

Views differ on what changes in the transport sector are required to achieve sustainable development, including long-term climate targets. Some scholars and influential organisations have predominantly focused on changes in vehicle efficiency, engine technology and alternative fuels in their emission scenarios, a vision sometimes referred to as the 'technology-fix' (e.g., IEA, 2012b). In the A-ASI approach, this would correspond with an implicit focus on "improve". Focussing on "improve" is attractive as the changes to the socio-technical regime are less disruptive and can materialise more easily. Others argue that new mobility concepts, demand management and behavioural change are required for sustainable development including sharp GHG reduction in the transport sector (e.g. Sheller \& Urry, 2006; Perschon, 2012; Banister et al., 2011; McCollum \& Yang, 2009; Anable et al., 2012). This would however imply that multiple elements of the socio-technical regime need to change simultaneously.

The transition literature could add to the ASI approach a more long-term and political, actor-based dimension benefitting policy frameworks and the longer-term orientation of the sustainable transport definitions of policy makers.

\subsubsection{The role of lifestyles}

The choice for ASI as a basis for a comprehensive transport policy paradigm is motivated by the support it has gained, in a relatively short time, by a wide range of organisations to guide and structure support to environmentally-friendly transport activities. The addition of a transition approach and accessibility framework are necessary conditions for systemic embedding and development, respectively. A transition-oriented A-ASI framework gives more scope for integrating climate change mitigation, transport aims and development. However, it is still not fully in line with a broader definition of sustainable development, which, according to Gudynas' (2011) conceptions of "the good life" must include a vision of what lifestyle people developing adopt. Moreover, lifestyles are a highly important determinant of carbon emission profiles. 
Sustainable lifestyles can be seen as a distinct policy aim, merging multiple objectives around health, environment and social cohesion in a single strategy (SPREAD, 2012). This can be contrasted against the current practice - also in ASI - of aiming policies on environmental indicators, such as $\mathrm{CO}_{2}$ emissions. In the emerging literature, lifestyle and behavioural change are mainly seen as shifting from car travel to more sustainable forms of transport, including ICT (Schwanen et al., 2011) which can be seen as part of an ASI framework. Anable et al. (2012), however, explore the impact of scenarios of changed preferences of individuals and society on passenger and freight transport trends, collectively called lifestyles, and observe that these may result in lower carbon emissions through significant changes to travel demand, choices for modes, vehicles and fuels. They note that policy agenda for lifestyle changes - as opposed to a policy agenda for measures or technologies - is underdeveloped.

The relation between transport and sustainable lifestyles is obvious, but complex. The contribution to or impact of mobility and the transport system on quality of life and well-being of individuals and societal groups is an under-researched topic. As Marsden et al. (2009) noted, 'there is a corresponding lack of definition what social progress might mean for transport'. Most studies on sustainable lifestyles focus on consumption goods (see e.g. Jackson, 2008). As discussed in Section 2.1, the emerging literature on well-being, social inclusion and equity shows a lack of consensus on what is a desirable level of mobility to support a high quality of life.

By placing sustainable lifestyles in the transport-climate-development nexus it could be part of the answer to the question what can be done to satisfy all three goals, in particular the integration of low-carbon development and transport. Promoting sustainable lifestyles could be a way to bring Avoid and Shift more clearly and attractively in the conversation about A-ASI.

\subsection{Discussion}

The ASI approach is predominantly a way to systematically categorise environmentally sustainable transport measures into three different strategies: avoidance of travel, shift to sustainable modes and improving technology. This arguably means a hierarchy of measures. From a strict climate point of view, it could be sufficient to implement only Improve strategies, as (near) zero-carbon technologies exist and are market-ready, although not always cost-effective. Most of the Improve measures will also eliminate air pollutant emissions. However, an approach that incorporates Avoid and Shift measures can be justified by an analysis of the additional climate benefits, because of avoided travel by private cars as well 
as multiple developmental benefits of avoid- and shift-based policy options over Improve options (IEA, 2012b).

Although ASI was initially developed to address environmental sustainability concerns, it is not necessarily inconsistent with all three pillars of sustainable development. The road safety community has argued that especially Avoid and Shift measures aimed at reducing negative environmental impacts of transport generally will also improve road safety. Improvements in vehicle technology or traffic management systems are also an integrated element of recommendations on road safety (Embarq \& SLoCaT, 2013). Integrated land-use planning, public transport and better facilities for walking and cycling generally will provide socially disadvantaged groups including handicapped, the elderly and children with better access to goods and services. Application of ASI strategies will also reduce land take, noise and use of resources.

However, ASI is not necessarily consistent with development goals as well as the systemic aspects of deep emission reductions including sustainable lifestyles. If strictly implemented, it may ignore the broader systemic dynamics and societal preferences based on multiple objectives that are needed for efficient implementation of the measures it propagates and, eventually, deep emission reductions.

It may be argued that climate change mitigation is a co-benefit of ASI-oriented sustainable transport strategies, rather than a primary driver. Like low-carbon development thinking, this is consistent with a transport policymakers view. The circumstance that ASI as a policy paradigm can be used to address a wide range of negative externalities from transport increases the developmental relevance of ASI, however still does not fully address the need for transport to act as an enabler of economic and social development.

As argued in section 2.4.1, ASI could be restated as A-ASI, to signify that improvement in access is the developmental objective that is prioritised, and that Avoid (including Transport Demand Management and New Mobility), Shift and Improve are important strategies to ensure that Access will contribute to sustainable development. Thereby A-ASI brings the paradigm in line with the various definitions of sustainable transport as discussed in section 2.3.

Despite the potential of the accessibility framework to include climate considerations, there are no indications as yet that this is being considered. The lowcarbon development concept, while making headway in development planning, in transport at this stage is mostly an abstract concept instead of concrete policy guidance. A-ASI therefore may have an advantage over these two concepts. Its 
applicability is shown in the context of the draft 'Results Framework for a Sustainable Development Goal for Sustainable Transport', in which two targets for access, one for road safety, one for air pollution and human health and one for greenhouse gas emissions are proposed as a new generation of development goals following on the Millennium Development Goals (MDGs). These can be achieved by following an A-ASI strategy (Sayeg et al., 2014).

Once a framework of Avoid, Shift and Improve measures in combination with accessibility considerations is adopted, the question arises how they are implemented. Progress towards sustainable transport is not a matter of a single measure or technology, and classical economic instruments that put a price incentive on a single option are only part of the solution. The distinction made by Geels (2012) into niches, patchworks of regimes and landscape enables a more systematic assessment of how far ASI related strategies have been institutionalised in a comprehensive manner. This in turn will allow for a more context-specific analysis of the different types of barriers, which may prevent A-ASI from being realised.

In addition, the sustainable lifestyle-aimed policies could play a role in changing landscape developments in transition frameworks, and exposing co-benefits of climate-related measures in the field of health, congestion, road safety and wellbeing; co-benefits that could become drivers on their own that open up possibilities for regime change (Anable et al., 2012). Therefore, a balanced application of the AASI approach in combination with transition theory and sustainable lifestyles could assist policymakers to make better decisions.

\subsection{Conclusion}

Addressing climate change mitigation, transport and development simultaneously is badly needed, in particular in developing countries, but lacks a policy framework to do so. We argue that using ASI as a basis, expanding it with access as a developmentoriented parameter, and involving transition approaches and sustainable lifestyles, could lead to a comprehensive framework that could bring a solution closer.

A-ASI as a policy paradigm goes beyond describing an organising framework for transport policies and instruments; by including access it sets out a direction for change. By combining and integrating different Avoid, Shift and Improve related strategies in a mutually reinforcing, access-oriented change strategy, the nature of AASI as a transformational approach to change rather than an incremental approach is emphasised. Existing reviews of ASI have mostly described its implementation in a qualitative manner focusing on describing how individual elements are implemented either in one city or country or across a range of countries. Facanha et 
al. (2012) however have used an avoid-shift-improve-transform approach, with the latter focusing (only) on zero-emission vehicle fleets and fuels, to achieve the required deep emission reductions.

Although we feel that A-ASI holds much promise, we see uncertainties as well. The same, especially institutional, constraints that have held back a comprehensive and integrated implementation of the ASI approach are likely to be relevant as well for A-ASI. The inclusion of lifestyle changes and transition theory, although conceptually sound and logical, also further complicates the institutional framework. In terms of next steps, many questions on what A-ASI would look like in practice remain to be answered. It can be argued, however, that the inclusion of access and lifestyles might motivate national and local decision makers to more fully embrace A-ASI as it has a stronger focus on development of transport infrastructure and services and on social aspects. This would be especially the case in places where there is still a rapid growth in transport. Applying the A-ASI framework in combination with transitions and lifestyles could form the basis for a truly sustainable and equitable transport systems in many places, could lead to more robust policy measures and more synergistic and integrated policies. 


\section{Chapter 3}

\section{Making climate instruments work for sustainable transport in developing countries*}

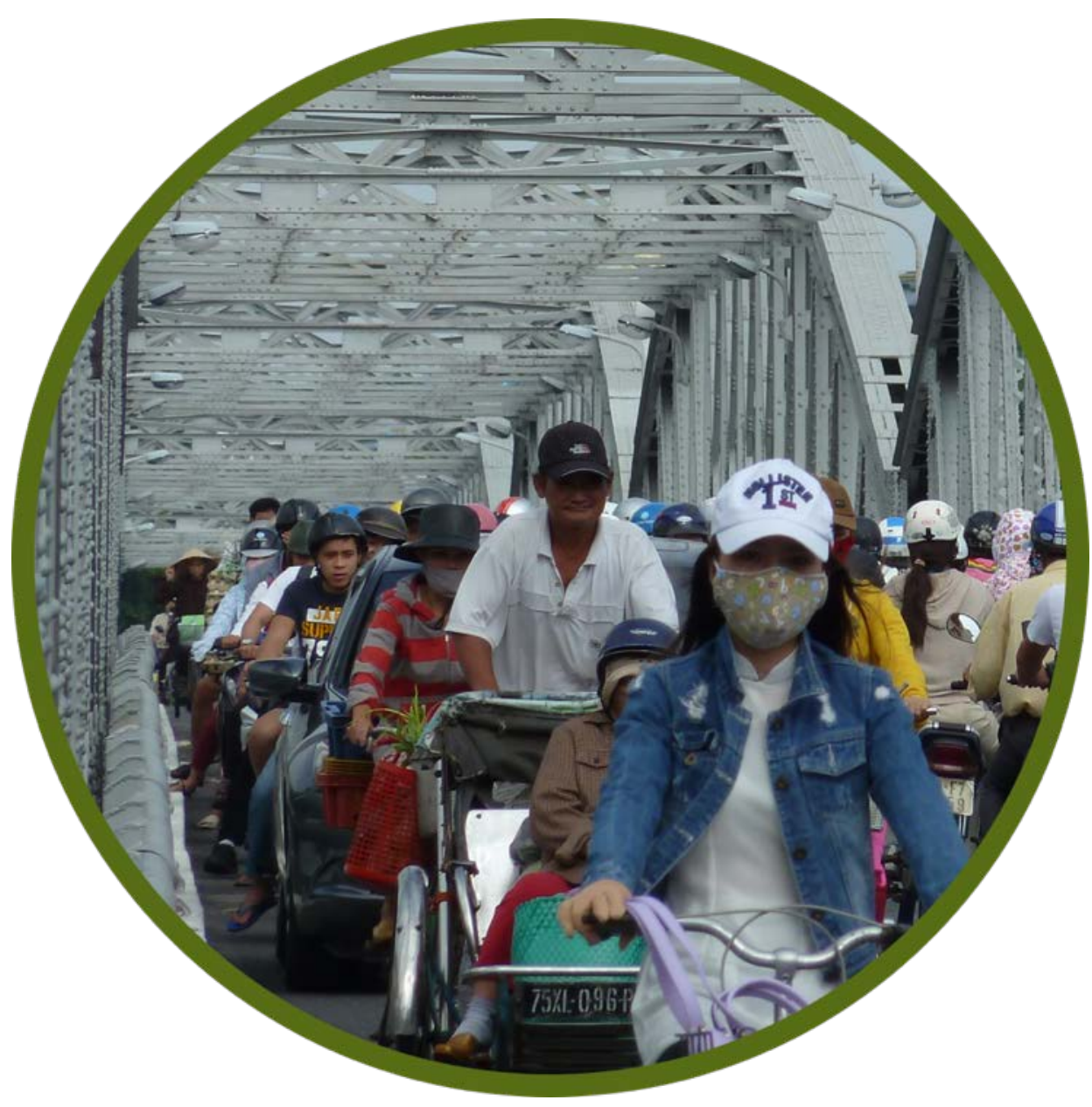

* Section 3.1 - 3.4 are published as: Bakker, S., C. Huizenga (2010) Making climate instruments work for sustainable transport in developing countries. Natural Resources Forum 34 (3), 314 - 326, Section 3.5 is an addendum to the article. 


\section{Abstract}

To meet long-term climate change mitigation objectives, emissions cuts are required in all regions across the globe and in all sectors, including transport. In financing this effort, the Clean Development Mechanism (CDM) and the Global Environmental Facility (GEF) are until now the only international climate policy instruments under the United Nations Framework Convention on Climate Change that provide incentives for emissions reductions in developing countries. More recently, the Clean Technology Fund (CTF) was established. In this paper, we show that the impact of these financing instruments on transport has been limited, due to methodological difficulties, a data-intensive monitoring process and the limited funding available. We argue that the transport sector is not likely to play a significant role in the continuation of a carbon credit offsetting scheme, unless these methodological requirements are simplified and significantly more funding is available.

In the post-2012 climate regime, there may be substantial international funding available in addition to existing credit schemes and international funds, which could be channelled through nationally appropriate mitigation actions (NAMAs). This can provide new and better opportunities for sustainable transport in developing countries. We propose a framework for NAMAs, including types of policies and measures, measurement, reporting and verification of the actions, and an institutional and financial structure. We conclude that climate funding needs to be aligned closely with domestic and multilateral development finance flows in order to make a difference for sustainable transport. 


\subsection{Transport and climate change}

In 2004 , the transport sector accounted for $6 \mathrm{GtCO}_{2}$-eq or $13 \%$ of global greenhouse emissions (Metz et al., 2007). Taking into account the effect of ozone and aerosols, the transport sector is estimated to have contributed $9 \%$ to the increase in global mean temperature up to the year 2000 since pre-industrial times, with $\mathrm{CO}_{2}$ and ozone being the most significant warming emissions, partly offset by cooling aerosols from shipping (Skeie et al., 2009). Unger et al. (2010) also attribute the largest radiative forcing contribution up to 2020 to road transportation, with an important part of that caused by black carbon. IEA/OECD (2009) projects transport emissions to rise by over $80 \%$ by 2050 in a business-as-usual scenario.

Although current per capita transport emissions in developing countries are relatively low compared to OECD countries, close to $90 \%$ of the increase is expected to take place in developing countries, mostly from private vehicles and freight (IEA/OECD, 2009). In order to meet the greenhouse gas (GHG) stabilisation target of $450 \mathrm{ppmv}$, global GHG emissions need to be reduced by more than 50\% compared to current levels, by 2050 (Metz et al., 2007). To achieve this, mitigation efforts in all sectors, including transport, are required in both developed and developing countries (IEA/OECD, 2009). It is now understood that in the case of a $450 \mathrm{ppmv}$ scenario, developing countries as a group would have to accomplish a reduction of 15-30\% below business-as-usual by 2020 (den Elzen \& Höhne, 2008; Karousakis, 2008).

In the ASIF framework (Schipper et al., 2000), often used in transport system modelling, emissions are a product of Activity (A), or the demand in person or tonne-kilometres; Modal shares (S); Energy intensity (I) of each mode; and the Carbon content of the fuel (F) used in each mode.

Substantially changing the rising emissions trend will require the adoption of a range of available and new technologies as well as a change in travel patterns (IEA/ OECD, 2009; Metz et al., 2007; Wright \& Fulton, 2005). The "Avoid-ShiftImprove" approach (ADB \& CAI-Asia, 2010) builds on ASIF and implies that policies to limit GHG emissions in the transport sector will have to consist of a combination of measures aimed at: (a) avoiding the need to travel, e.g. by the integration of land use and transport policies; (b) shifting travel to the most efficient mode, which in most cases will be either non-motorised or public transport for passenger transport and to rail or water transport for freight; and (c) improving existing forms of transport through technological improvements to make engines and fuels less carbon intensive. 
Transport policy instruments can try to influence each of these components by, for example, reducing the demand with improved spatial planning, shifting to public transport, improving engine technology and using electric vehicles. Tto achieve the large emissions reduction potential in both passenger and freight transport, strong policy packages are required that cover both the technological and behavioural aspects (e.g. Johansson, 2009; IEA/OECD, 2009; Chapman, 2007). Policy instruments can be differentiated into planning, economic, regulatory and "soft" (such as include institutional strengthening, capacity-building or awareness-raising and training) (Wittneben et al., 2009). Table 3.1 gives examples of how these instruments can be related to the Avoid-Shift-Improve strategies.

Table 3.1. ASI framework and examples of policy instruments

\begin{tabular}{|c|c|c|c|c|}
\hline & $\begin{array}{l}\text { Planning } \\
\text { infrastructure }\end{array}$ & Economic & Regulatory & Soft \\
\hline A & $\begin{array}{l}\text { Mixed-high } \\
\text { density planning }\end{array}$ & $\begin{array}{l}\text { Road pricing / } \\
\text { congestion charge }\end{array}$ & $\begin{array}{l}\text { Vehicle access } \\
\text { restrictions }\end{array}$ & $\begin{array}{l}\text { Campaigning for } \\
\text { locally produced } \\
\text { goods }\end{array}$ \\
\hline S & $\begin{array}{l}\text { Mass transit / } \\
\text { NMT } \\
\text { infrastructure }\end{array}$ & $\begin{array}{l}\text { Incentives for } \\
\text { mass transit / } \\
\text { NMT }\end{array}$ & & $\begin{array}{l}\text { Awareness raising for } \\
\text { mass transit / NMT / } \\
\text { car-pooling }\end{array}$ \\
\hline $\mathrm{I}$ & $\begin{array}{l}\text { Charging } \\
\text { infrastructure }\end{array}$ & $\begin{array}{l}\text { Incentives for } \\
\text { efficient / low- } \\
\text { carbon vehicles } \\
\text { and fuels }\end{array}$ & $\begin{array}{l}\text { Fuel economy } \\
\text { standard } \\
\text { target for low- } \\
\text { carbon fuels } \\
\text { and vehicles }\end{array}$ & $\begin{array}{l}\text { Eco-driving } \\
\text { campaigns }\end{array}$ \\
\hline ASI & $\begin{array}{l}\text { Integrated } \\
\text { transport } \\
\text { planning }\end{array}$ & Fuel/carbon tax & $\begin{array}{l}\text { Sectoral } \\
\text { emissions } \\
\text { target }\end{array}$ & $\begin{array}{l}\text { Institutional } \\
\text { restructuring in } \\
\text { support of integrated } \\
\text { planning }\end{array}$ \\
\hline
\end{tabular}

NMT: non-motorised transport. Source: Authors' elaboration.

Such policies may have strong national or local co-benefits in terms of air quality, energy supply security, reduced congestion, liveable cities, local employment and improved health (Nemet et al., 2010; Huizenga et al., 2008; IEA/OECD, 2009). In fact, many of the transport policies and interventions are being pursued with the primary goal being those benefits, and in those cases, the GHG reduction can also be seen as a co-benefit. The challenge, therefore, is to promote transport policies that foster national sustainable development and global benefits with respect to GHG emissions reduction.

This is particularly relevant to developing countries, which do not face a binding emissions target under the Kyoto Protocol. Considering the state of affairs in the international climate negotiations, it is unlikely that they will adopt such targets in the period up to 2020 (UNFCCC, 2009b; 2010a), although some countries have taken on national targets on a voluntary basis, such as Costa Rica, Indonesia, 
Singapore and South Korea (UNFCCC, 2010b). Developing countries are, however, in the future supposed to undertake nationally appropriate mitigation actions (NAMAs) in order to contribute to global mitigation of GHGs (UNFCCC, 2007; 2009b).

In this article, we assume that reducing GHG emissions from transport is a voluntary action for developing countries, which, based on the global benefit, is in principle eligible to receive support from developed countries. While the detailed nature of emissions reduction activities will vary between countries reflecting their unique characteristics, the supporting mechanisms under the United Nations Framework Convention on Climate Change (UNFCCC) are expected to be the same for all developing countries. Therefore, in this paper we treat them as one group, in line with their treatment under the UNFCCC. When more is known about the mechanisms, more attention to their implementation in different contexts, for example least developed countries, could be necessary.

This article aims to provide recommendations on how international support, in particular for supported NAMAs, can spur low carbon sustainable transport in developing countries. We analyse how the existing climate instruments are working for the transport sector (Section 3.2). Section 3.3 provides a preliminary analysis, partly based on four case studies ${ }^{23}$ of options for transport policies and measures under emerging or future instruments, focusing on NAMAs. In the final section, we provide conclusions and recommendations.

\subsection{Transport under existing international climate mechanisms}

In this section, we provide an overview of the extent to which the main existing international climate instruments have addressed the transport sector in developing countries: the Clean Development Mechanism, the Global Environmental Facility and the Clean Technology Fund. There are other international climate funding mechanisms that can support climate protection activities for the transport sector, for example the German Climate Initiative. Their scale is more limited than GEF, CDM and CTF, which is why they are not included in the analysis in this paper.

\footnotetext{
${ }^{23}$ The four case studies include: (a) Optimisation of conventional bus system in Mexico, by Ecofys; (b) Comprehensive mobility strategy, Belo Horizonte, Brazil by EMBARQ, WRI Institute for sustainable transport; (c) Travel demand management in Jakarta, Indonesia by the Transport Research Laboratory; (d) The use of standardised base lines for transport, Hefei, China by the Wuppertal Institute.
} 


\subsubsection{Clean Development Mechanism}

The Clean Development Mechanism (CDM) is an arrangement under the Kyoto Protocol allowing developed countries with a greenhouse gas reduction commitment to invest in project activities that reduce emissions in developing countries as an alternative to emissions reductions in their own countries. In addition to this, the $\mathrm{CDM}$ aims to contribute to sustainable development in developing countries (UNFCCC, 2005). Proposed projects have to use a baseline and monitoring methodology, reviewed by a Methodology Panel and approved by the CDM Executive Board to show how the certified emissions reductions (CERs) are derived. Once registered with the CDM Executive Board, a project can generate CERs on an annual basis for a maximum of 21 years, resulting in annual re- venues based on the prevailing CER price at the time a contract is drawn up. Another crucial feature of an approved CDM project is that it has demonstrated that the planned reductions would not occur without the additional incentive provided by emissions reductions credits, a concept known as "additionality" (UNFCCC, 2005). Since 2005, larger numbers of similar small-scale activities can be developed under one umbrella as a CDM Programmes of Activities (PoA).

To date, the transport sector has played a very limited role in the CDM. As of July 2010,30 out of 5,312 projects in the pipeline are related to transport (including biofuels) (UNEP/Risø, 2010). Out of these 30 projects only 2 are registered. The pipeline includes all projects and PoAs that are under validation by an operational entity, have been validated, are registered by the CDM Executive Board, or are requesting registration. Together, the current 30 transport projects are expected to reduce $3.2 \mathrm{MtCO}_{2}$-eq/yr up to 2012 , or $0.4 \%$ of the total reductions of the current pipeline. Table 3.2 shows the transport projects broken down by approved methodology.

Compared to its share in global emissions, the transport sector is highly underrepresented. A first explanation lies in the fact that across the globe, transport sector emissions are found difficult to abate, and most countries first look at "lowhanging fruit" in other sectors in order to meet climate objectives (Barías et al., 2005). The low share of transport projects in CDM can also be explained by the following barriers (adapted from ADB and CAI-Asia 2010; Millard-Ball \& Ortolano, 2010): difficulty in determining additionality, e.g. due to the small share of CER revenues in the total project $\operatorname{cost}^{24}$ and the fact that mitigation actions in the

${ }^{24}$ CERs will often only cover a few per cent of the investment costs of infrastructure projects such as BRTs. Therefore, in general, it can be said for transport projects that climate mitigation is only one of the considerations and often of lesser importance than congestion reduction or air quality improvement. 
transport sector can be implemented for a multitude of reasons; difficulty in establishing the baseline scenario, due to the fact that a multitude of scenarios can be made plausible; complexity in designing methodologies and modelling tools appropriate for the CDM, including, for example, rebound effects; lack of data required to apply the methodologies; emissions from individual sources are relatively small and dispersed, making monitoring difficult and costly; lack of uniformity in Methodology Panel recommendations; and, specifically for biofuels: difficulty in determining life cycle emissions.

\section{Table 3.2. Transport projects in the CDM pipeline, July 2010}

\begin{tabular}{|c|c|c|c|c|}
\hline Transport sub-type & $\begin{array}{l}\text { Additional } \\
\text { info }\end{array}$ & Methodology & $\begin{array}{l}\text { No. of } \\
\text { projects / } \\
\text { PoAs }\end{array}$ & $\begin{array}{l}\text { Emissions } \\
\text { reduction } \\
\left(\mathrm{ktCO}_{2} / \mathrm{yr}\right)\end{array}$ \\
\hline $\begin{array}{l}\text { Biodiesel from waste } \\
\text { oil }\end{array}$ & & AM47 / ACM17 & 1 & 226 \\
\hline Biodiesel for transport & & $\begin{array}{l}\text { AMS-III.T/ ACM } \\
17\end{array}$ & 5 & 495 \\
\hline $\begin{array}{l}\text { Bus Rapid Transit } \\
\text { (BRT) }\end{array}$ & & AM31 / ACM16 & 11 & 1467 \\
\hline Cable cars & & AMS-III.U & 1 & 17 \\
\hline $\begin{array}{ll}\text { Metro: } & \text { efficient } \\
\text { operation } & \end{array}$ & & AMS-III.C & 1 & 16 \\
\hline Mode shift: road to rail & $\begin{array}{l}\text { Freight and } \\
\text { passenger }\end{array}$ & $\begin{array}{l}\text { AMS-III.C/ } \\
16\end{array}$ & 3 & 688 \\
\hline $\begin{array}{ll}\text { Rail: } & \text { regenerative } \\
\text { braking } & \end{array}$ & & AMS-III.C & 3 & 112 \\
\hline Motorbikes & $\begin{array}{l}\text { Electric } \\
\text { bikes }\end{array}$ & AMS-III.C & 4 & 130 \\
\hline Scrapping old vehicles & PoA & AMS-III.C & 1 & 3 \\
\hline Total & & & 30 & 3153 \\
\hline
\end{tabular}

These barriers help explain the fact that few methodologies have been approved in the transport sector since 2005 when the first CDM methodology was approved, although a larger number have been proposed in recent years (Millard-Ball \& Ortolano, 2010). In addition, experience has shown that applying approved methodologies has been difficult, e.g. for BRT projects using AM31, which was approved in 2006, and biodiesel from waste fats using AM47 (approved in 2007). In late 2009, these methodologies have been consolidated in ACM16 and ACM17, which are used by three and four projects, respectively, as of July 2010.

The recent recommendations on priorisation for transport CDM projects by the CDM Executive Board (UNFCCC, 2009d) and the increase in approved methodologies can be seen as a sign that there is scope for more transport projects in the CDM. However, the CDM, in general, is now being criticised for including 
projects that would have happened anyhow (i.e., non-additional projects, Bakker et al., 2010a), and transport projects are among those having problems demonstrating additionality (Millard-Ball \& Ortolano, 2010).

\subsubsection{Global Environment Facility (GEF)}

The GEF provides grants to developing countries to address global environmental issues, including climate change, on the basis of the agreed full incremental cost (Article 4.3, UNFCCC (Bongardt et al. (2009)) and is used by the UNFCCC as its financial mechanism. In 2000, the GEF Council approved Operational Program \#11 (OP 11 - "Promoting Environmentally Sustainable Transport"), a programme aimed at enhancing efforts in the transport sector. As of April 2009, the GEF had funded 37 transportation projects in more than 73 cities. Initially, GEF support to the transport sector focused on technological solutions. However, GEF-4 (2006-10) emphasises "non- technology" options, such as planning, modal shift to low-GHGintensive transport modes and the promotion of better managed public transit systems. The strategic programme on "sustainable innovative systems for urban transport" prioritises countries with rapidly growing cities, which includes urban planning, public transport investments (particularly bus rapid transit (BRT)), transport demand management (TDM) and national policy development (GEF, 2009a).

During this period, out of a total replenishment of US\$ 3.1 billion, the GEF has allocated approximately US $\$ 201$ million to sustainable urban transport projects, with an average of US\$ 5.4 million per project. This funding has leveraged more than US $\$ 2.47$ billion in co-financing. This co-financing ratio of 1 to 12.3 is the highest in all GEF programmes as it often requires large-scale investments to develop infrastructures. The portfolio is quite diverse, with substantial investments in BRT (32\%), vehicles (25\%) and non-motorised transport (19\%), as well as capacity-building, planning, awareness-raising and policymaking (22\%) (Replogle \& Hook, 2010).

Estimating these projects' impact on $\mathrm{CO}_{2}$ emissions is difficult (GEF, 2009a). Project documents indicate an expected direct reduction of $31.5 \mathrm{MtCO}_{2}$ over the lifetime of the projects, and an expected indirect reduction of $34.5 \mathrm{MtCO}_{2}$. The methodologies for calculating these emissions reductions used by the different projects are diverse and not strictly comparable.

The GEF-5 programme (2011-15) will aim to further increase the focus on integrated transport planning, and will place more emphasis on local environmental and social benefits (GEF, 2009b). In particular, it will provide support for the 
development of sustainable transport and urban policy and regulatory frameworks. Also, greater attention will be given to measuring and quantifying global environmental benefits; outcome indicators will include the number of cities adopting sustainable transport and urban policies and regulations, the volume of investment mobilised, and tonnes of $\mathrm{CO}_{2}$ equivalent avoided.

A methodology specifically for estimation of the impact on GHG emissions of GEF transport interventions is being developed. This methodology will complement the methodology for energy efficiency and renewable energy projects (GEF, 2008). ${ }^{25}$ Particular to the GEF GHG assessment methodology is the distinction between: (a) direct emissions reductions; (b) post-project direct emissions reductions; and (c) replication and indirect emissions reductions.

\subsubsection{Clean Technology Fund 26}

In July 2008, the Climate Investment Fund was established by the World Bank in cooperation with other multilateral development banks (MDBs). Two strategic funds were set up under the CIF: the Clean Technology Fund (CTF) and the Strategic Climate Fund. The CTF is designed to fill an immediate financing gap before further details of the future climate regime are worked out and aims to provide scaled-up financing for "transformational actions" that contribute to the demonstration, deployment and transfer of low-carbon technologies with a significant potential for long-term greenhouse gas (GHG) emissions savings.

The CTF utilises a range of concessional financing instruments, such as grants and concessional loans, and risk mitigation instruments, such as guarantees and equity. For the transport sector, measures which the CTF support may include: modal shift to low carbon public transportation in major metropolitan areas, with a substantial change in the number of passenger trips by public transport; modal shift to lowcarbon freight transport, with a substantial change in tonnage of freight moved by road transport to rail; improvement of fuel economy standards and fuel switching; and deployment of electric and hybrid (including plug-in) vehicles.

As of March 2010, twelve country investment plans have been approved by the CTF: Egypt, Morocco, Mexico, Thailand, Philippines, South Africa, Turkey, Colombia

\footnotetext{
25 An expert meeting was held 17-19 February 2010, organised by the Scientific and Technical Advisory Panel of GEF and the Asian Development Bank. See Replogle \& Hook (2010) for an overview of the suggested contours of the GEF Transport methodology. An important recommendation of the expert meeting was to consider the use of default factors to predict the emissions reduction effects of certain transport interventions. The transport methodology is expected to be available by the end of 2010 and will include use of default factors as recommended by the expert meeting (Personal communication with Lev Neretin, GEF-STAP).

${ }^{26}$ This section is based on World Bank (2008) unless otherwise mentioned.
} 
Indonesia, Kazakhstan, Ukraine and Vietnam, and one regional investment plan for the North African region. Transport is included in seven plans, all in the realm of public transport, particularly BRT, see Table 3.3. The total required investment for these measures was estimated to be US\$ 9.3 billion. The CTF funding for the transport measures adds up to US $\$ 600$ million and the estimated annual emissions reduction to about $10 \mathrm{MtCO}_{2}$ per annum (CTF, 2010).

The CTF investment plans are approved by the Trustfund Committee without having been submitted to an external expert panel for the validation of the emissions reductions. In its assessment, the Trustfund Committee takes into account the potential transformational impacts of the proposed actions and considers criteria such as GHG reduction potential, demonstration and upscaling potential, development impact, and additionality of CTF funding (CTF, 2009a). Of specific importance is the potential contribution of the project to the transformation of the sector and the related demonstration and upscaling potential. The specific methodological guidelines on how to calculate the GHG reduction potential are outlined in CTF (2009b). An important difference with the GEF is that this methodology is not applied at the time of the initial approval of the investment programme but only at the time of detailed project design. ${ }^{27}$ Project developers are free to decide what specific methodology they use to assess the GHG emissions avoided by the project at the time of the initial approval of the country investment programme.

${ }^{27}$ Since none of the transport components has reached the phase of review of detailed design by the trust fund committee, no experience exists with the application of the CTF GHG assessment methodology. 
Table 3.3 Transport components under the Clean Technology Fund, March 2010.

\begin{tabular}{|c|c|c|c|c|c|}
\hline Country & $\begin{array}{l}\text { Total } \\
\text { investment } \\
\text { costs transport } \\
\text { component } \\
\text { (million \$) }\end{array}$ & $\begin{array}{l}\text { Total size } \\
\text { CTF } \\
\text { allocation } \\
\text { (million \$) }\end{array}$ & $\begin{array}{l}\text { Transport } \\
\text { CTF } \\
\text { allocation } \\
\text { (million \$) }\end{array}$ & Transport components & $\begin{array}{l}\text { Emission } \\
\text { reductions from } \\
\text { transport } \\
\text { component } \\
\left(\mathrm{MtCO}_{2} \text {-eq/yr) }\right.\end{array}$ \\
\hline Egypt & 865 & 300 & 100 & $\begin{array}{l}\text { BRT; light rail transit } \\
\text { and rail links; clean } \\
\text { technology buses }\end{array}$ & 1.5 \\
\hline Morocco & 800 & 150 & 30 & BRT; tramway; light rail & 0.54 \\
\hline Mexico & 2,400 & 150 & 30 & $\begin{array}{l}\text { Modal shift (BRT); } \\
\text { promotion of low- } \\
\text { carbon bus technology; } \\
\text { capacity building }\end{array}$ & 2.0 \\
\hline Thailand & 1,267 & 300 & 70 & BRT corridors & 1.16 \\
\hline Philippines & 350 & 250 & 50 & $\begin{array}{l}\text { BRT Manila, Cebu; } \\
\text { institutional } \\
\text { development }\end{array}$ & $0.6-0.8$ \\
\hline Viet Nam & 1,150 & 250 & 50 & $\begin{array}{l}\text { Enhancement of urban } \\
\text { rail }\end{array}$ & 1.3 \\
\hline Colombia & 2,425 & 150 & 100 & $\begin{array}{l}\text { Integrated public transit } \\
\text { systems; scrapping old } \\
\text { buses; introduction of } \\
\text { low-carbon buses }\end{array}$ & 2.8 \\
\hline Total & 9,257 & 1,900 & 600 & & $9.9-10.1$ \\
\hline
\end{tabular}

Source: http://www.climateinvestmentfunds.org

For the future, CTF aims to use guidelines, partly transport-specific, for assessing the results of its investments and tracking the fulfilment of its objectives (CTF, 2009b). A three-tiered approach is being recommended by the CTF for monitoring. One tier to be monitored is the transformational impacts of the CTF. This tier consists of indicators that demonstrate the extent to which CTF co-financing catalyses lasting changes in the structure or function of sub-sectors, sectors or markets. The second tier is the country outcomes indicators, which measure aggregate country outcomes and global trends relevant to the CTF's objectives. The third tier is monitoring the CTF's contributions to country outcomes. This tier consists of indicators covering the CTF's contributions to country outcome indicators at three different levels: 1) country: the preparation of country CTF Investment Plans will be monitored to measure progress in providing support for climate actions in country-led development processes; 2)portfolio performance: these consist of indicators to measure the MDBs' portfolio quality and organisational efficiency; and 3) project outputs, which measure the CTF's effectiveness in achieving its objective of scaling up low carbon technologies.

Table 3.4 provides an overview of the impact of investments from climate mechanisms on the transport sector. It appears the CTF, in its short history, has made a bigger impact in developing projects to reduce transport emissions than has 
the CDM and the GEF, which have been operational for a longer period of time. The overview also shows that the impact of climate instruments is currently rather limited, i.e. approximately $16 \mathrm{MtCO}_{2}-\mathrm{eq} / \mathrm{yr}$, as compared to the transport emissions in developing countries of approximately 3,100 $\mathrm{MtCO}_{2}$-eq/yr in 2005 (IEA/OECD, 2009). Therefore, current climate mechanisms can only be expected to play a limited role in achieving a 15-30\% reduction deviation from the baseline for all GHG emissions by 2020 . The overall funding made available of US\$ 1.4 billion is limited as well considering the size of the transport sector.

Table 3.4. Overview of transport projects in existing climate instruments

\begin{tabular}{lllll}
\hline & $\begin{array}{l}\text { Year of } 1^{\text {st }} \\
\text { project }\end{array}$ & No. of projects & $\begin{array}{l}\text { Funding }(\$ \\
\text { million) }\end{array}$ & $\begin{array}{l}\text { Reported/expected } \\
\text { emission reductions } \\
\left(\mathrm{MtCO}_{2} \text {-eq/yr) }\right.\end{array}$ \\
\hline CDM & 2006 & $30^{\mathrm{a}}$ & 672 (CERs) & 3.2 \\
GEF-4 & 2006 & 37 & 201 (grants) & $3.2^{\mathrm{c}}$ \\
CTF & 2009 & 7 & 600 (loans) & $10^{\mathrm{d}}$ \\
\hline
\end{tabular}

a in pipeline (registered, requesting registration and at validation);

$\mathrm{b}$ expected total undiscounted revenues at $10 \$ / \mathrm{CER}, 3 \times 7$ years crediting, excluding transaction cost;

c direct impact, assuming 10 years lifetime;

$\mathrm{d}$ assuming a life time of 10-20 years depending on type of investment

Source: Authors' elaboration.

\subsection{Applicability of new mechanisms for transport}

This chapter gives an overview of the potential of emerging climate instruments for fostering a significant shift towards low-carbon transport in developing countries. This analysis is preliminary, considering the yet unknown existence of these mechanisms in the future or their detailed features. We review CDM, sectoral crediting and NAMAs.

\subsubsection{Future of the CDM}

The first commitment period of the Kyoto Protocol runs until 2012. Although, as of March 2010, no formal agreement was reached on a new commitment period after 2012, there is widespread consensus in the UNFCCC that there will be a role for the CDM post-2012. The discussions on what this role should be and possible changes to the design of the CDM post-2012 are taking place mainly in the Ad Hoc Working Group on Further Commitments under the Kyoto Protocol (AWG-KP) (UNFCCC, 2009c). At COP15 in Copenhagen, some decisions to amend the CDM were adopted, most notably ones to prioritise baseline methodologies for underrepresented sectors. Also, a request to the Subsidiary Body for Scientific and 
Technological Advice was made to recommend modalities and procedures for the development of standardised baselines (UNFCCC, 2009c).

In the following section, we discuss how emerging developments such as Programmes of Activities, a standardised baseline and possible future changes, as discussed in the AWG-KP, may affect the prospects for the transport sector compared to the current situation. For a more elaborate description of these changes, see Bakker et al. (2010a), on which the assessment below is partly based.

\section{Further strengthening Programmes of Activities}

Currently similar project activities using one baseline and monitoring methodology can be developed under a PoA. This may improve conditions for transport to some extent, e.g. if $10 \mathrm{BRTs}$ in a country are combined this could reduce the uncertainty and transaction cost related to additionality demonstration and application of the baseline methodology. If different types of activities would be eligible under a PoA as well, this would further enhance opportunities, particularly for "mixed strategies" in which different kinds of activities of an integrated sustainable transport strategy relating to, for example, fuels, vehicle technologies, public and non-motorised transport, are combined. Data availability and quality will be a constraining factor, however, in the case of a PoA approach.

\section{Standardised baselines}

Baselines can be pre-determined based on a benchmark for a particular type of activity for a particular geographical area. Standardised baselines are often mentioned in the context of the industry or power sector, in which an emissions benchmark can be expressed per unit of product. Performance benchmarks and emissions intensity values are already used within the CDM, e.g. in the power sector. For the transport sector, standardised baselines may also be applicable, however, there are no concrete proposals as of yet. Possible examples mentioned include modal splits, occupancy rates and emissions per unit of travel (Bongardt et al., 2009; TRL, 2010), particularly for specific vehicle fleets such as taxis, buses or rail systems. If standardised baselines could be developed and applied successfully, this would significantly reduce the methodological and possibly the data-related problems that transport-CDM projects currently face. However, developing broadly applicable baselines is likely to be a challenge due to the considerably different circumstances under which taxis or buses operate in different cities. ${ }^{28}$ The increased upfront burden of necessary data collection costs to construct performance standards or

\footnotetext{
28 One possibility could be to define a limited number of representative operating conditions for which standardised baselines can be formulated.
} 
define adequate default values for standardised baselines is not to be underestimated either, even if transaction costs at the project level would be reduced in the long run.

\section{CER discounting}

Discounting is the application of a reduction factor to the emissions reductions achieved in a project: 1 tonne of $\mathrm{CO}_{2}$-eq reduced results in less than 1 CER. CER discounting is sometimes mentioned in the context of $\mathrm{N}_{2} \mathrm{O}$ and HFC-23 destruction projects, which are cheap and easy to implement actions, yielding a large amount of CERs. Other arguments mentioned in support of CER discounting are to create a mechanism with overall net atmospheric benefits rather than pure offsetting or the possibility to differentiate according to the contribution to sustainable development. If the CERs from transport projects were to be discounted less (or not at all) compared to other project types, the transport sector would improve its comparative position. However, the main difficulty with transport projects, i.e. methodological complexity, will not be addressed by this option. The key difficulty for CER discounting is the political feasibility of establishing the discount factors.

\section{Allocated demand}

Credit buyers can be required to procure a certain portion of their demand for CERs to certain sectors. If this can be done for the transport sector it will greatly improve its opportunities. It will stimulate development of transport-CDM projects, but achieving the required supply of successful projects may still be a challenge. In addition, this is a politically difficult differentiation option.

\section{Co-benefits}

The contribution of the CDM to sustainable development in the host countries has been limited (Olsen \& Fenhann, 2008). Under the current rules, only the host country may assess the sustainable development contribution, with no role for the validator or the CDM Executive Board. In order to improve the sustainability profile of the CDM, explicitly recognising sustainable development benefits by setting a threshold has been suggested and adding a required evaluation by the validator and/or the Executive Board. As many transport projects have very strong cobenefits, e.g. for air quality, reduced congestion, energy security and social equality (e.g. Leather \& CAI-Asia, 2010; CCAP, 2010; Nemet et al., 2010), the transport sector is likely to benefit from such an approach. However, this undermines the prerogative of developing countries to assess projects against their own sustainable development criteria and is something that may not be politically feasible. Another possibility would be to apply CER discounting to projects with no or few demonstrated co-benefits. 


\section{Positive list}

Project types on a positive list are deemed automatically additional and thus exempted from additionality testing. Since demonstrating additionality is often very difficult for transport sector projects, this could improve their prospects. However, the reason for this difficulty is that there are many objectives other than climate mitigation involved in the undertaking of an activity and the CER contribution to overall profitability is relatively low. It is hard to imagine that many transport sector project types will be included in a positive list (Bongardt et al., 2009).

\section{Sectoral CDM}

Taking the CDM from the level of a project-based instrument to the level of programmes (as is done in PoAs) or sector policies could enhance the opportunities for transport, particularly by the possibility to scale up efforts that are now taken on a case-by-case basis. Examples of eligible activities would be land-use planning, voluntary agreements for energy efficiency, a congestion charge, or eco-driving training. However, the methodological complexities and uncertainties are not likely to be reduced (Wittneben et al., 2009).

\section{Summary}

This section has shown that several possible changes to the CDM may improve conditions for the transport sector by simplifying methodologies, demonstration of additionality, and reducing the data needs. In addition, a broader application of the existing approved methodologies may also have a beneficial impact for the transport sector. At the end of the day, much depends on the total demand for CERs post2012. Many developed countries see a limited role for the CDM, focusing mostly on the least developed countries, with other instruments (see below) and domestic actions becoming more important for the more advanced developing countries (e.g. CEC, 2009). If the CDM market is indeed limited in size, it is not likely that it can play a significant role for the transport sector.

\subsubsection{Sectoral crediting approaches}

Discussions on a possible sectoral crediting mechanism (UNFCCC, 2008) ${ }^{29}$ suggest that it will be possible to credit emissions reductions from a covered sector against a threshold below the business-as-usual scenario. Thresholds represent country performance and can be expressed in absolute terms (e.g. GHG emissions in sector $\mathrm{x}$ ) as well as intensity terms (e.g. GHG emissions/ton of cement). Sectoral crediting

${ }^{29}$ Besides sectoral crediting, sectoral targets are also discussed in the negotiations. The difference between crediting and targets is that the latter lead to the issuance of allowances ex ante and imply compliance, while the former within a sectoral crediting mechanism are issued ex post. 
is different from CDM, as credits would be issued to the respective developing country Government, who would have to provide the incentives for emissions reductions to take place. Sectoral crediting based on no-lose targets, i.e. no penalty applies if the threshold is not met, aims to encourage emissions reductions (orchestrated by the host country) in key emitting sectors in developing countries.

A technical merit of sectoral crediting is its circumvention of the additionally test on a project basis and reduction of the methodological requirements for assessments for baselines and leakage. Sectoral crediting assesses the performance of a whole sector instead of individual activities, although monitoring will still need to be performed at an installation level for aggregation into a sector level. If this approach can be developed, it has great potential for the transport sector, but establishing full sectoral emissions inventories or sectoral benchmarks is likely to be a challenge (Bongardt et al., 2009).

The suitability of a sectoral approach for the transport sector was reviewed by Bodansky (2007), Meckling and Chung (2009), Schmidt et al. (2008), and Wittneben et al. (2009). Most of them focus on the sector-wide measures related to fuel economy, ignoring possible demand reduction-oriented mitigation strategies (Huizenga et al., 2010). There is limited discussion on how measures aimed at reducing the need for travel or modal shift can be incorporated into a sectoral approach. There is also little discussion on transport sub-sectoral approaches, such as freight, where some of the methodological concerns on baseline and project boundaries could be more easily overcome because of the more homogenous character of this sub-sector and better data collection practices.

Sectoral crediting has the potential to greatly increase the supply of credits. This may result in a downward pressure on credit prices if the supply is not matched by demand from increased mitigation targets of developed countries. Together with the methodological complexities, the political feasibility of sectoral approaches are the main obstacles, as developing countries may perceive this approach as an indirect way of imposing some sort of emissions commitments.

\subsubsection{Nationally appropriate mitigation actions (NAMAs)}

Paragraph 1(b)(ii) of the Bali Action Plan (UNFCCC, 2007) calls for: "Nationally appropriate mitigation actions by developing country Parties in the context of sustainable development, supported and enabled by technology, financing and capacity building, in a measurable, reportable and verifiable manner." The Copenhagen Accord (UNFCCC, 2009b) includes similar language. While for mitigation the main current role of developing countries in the Kyoto Protocol is as 
host countries in the CDM, the adoption of the NAMA concept would introduce a new form of developing countries' participation in global climate governance. Mitigation by developing countries is a key topic of the UNFCCC post-2012 climate regime discussions and, to a large extent, focuses on NAMAs, which indicates the significance of the concept. The discussions within the UNFCCC on NAMAs take place mostly in the Ad-hoc Working Group on Long-term Cooperative Action (AWG-LCA).

There is still a significant lack of clarity on the manner in which NAMAs will be designed, reviewed, implemented and monitored. Some of the key features of the NAMA concept are briefly discussed below, mainly based on the UNFCCC (2009a; 2010a). First, the Bali Action Plan is explicit that NAMAs will be implemented in the context of sustainable development. Yet, little discussion has been conducted on how this can be best accomplished. NAMAs are intended to be country driven and appropriate for the specific national context of the country where they are situated, and may be connected to Low Emission Development Plans (CEC, 2009).

Second, it is accepted so far that a NAMA can be a policy, a programme or a project. Most of the NAMA proposals submitted to the UNFCCC after COP15 are described at the sectoral level, mostly without any specification on whether the NAMA will be implemented at the national or the local or city level (UNFCCC, 2010b). The general understanding so far is that NAMAs are not restricted to investment activities which directly reduce GHG emissions but that they can also include actions that will facilitate or enable the reduction of GHG emissions, such as capacity-building or training.

Third, three types of NAMAs are generally distinguished: (a) unilateral NAMAs, which are implemented on a voluntary basis and which developing countries are expected to implement without external support; (b) supported NAMAs, which are to be supported and enabled by technology, financing and capacity-building in a measurable, reportable and verifiable manner; and (c) credited NAMAs, in the case of these NAMAs, emissions reductions can become part of a market mechanism like the CDM (UNFCCC, 2009b; 2010a). The international discussion has so far focused mostly on supported NAMAs.

Fourth, it is intended that NAMAs would be registered in a NAMA registry. The registration process would include the amount of emissions reductions estimated to be accomplished through the NAMA. The NAMA registry would also record the external support provided for the implementation of the NAMA. The Copenhagen Accord includes an Annex in which developing countries can inscribe their 
proposed NAMAs. As of September 2010, 42 countries have done so (UNFCCC, 2010b).

Fifth, NAMAs may be supported and enabled by technology, financing and capacitybuilding, in a measurable, reportable and verifiable manner. Few details are available on the manner in which the NAMAs will be financially structured. Is there a linkage between the financial payment and the amount of GHG emissions reduced under NAMAs? Will payments related to NAMA support be made up front, expost or on an annual basis? Apart from a reference in the AWG-LCA draft text to the principle of "full incremental costs" as the basis for NAMA support (UNFCCC, 2010a) little is known.

Finally, NAMAs and support need to be measurable, reportable and verifiable (MRV) in order to create transparency and trust between developed and developing countries, to ensure that the support is delivered and used for the purpose it was intended for, and to monitor the progress towards the ultimate objective of the UNFCCC, i.e. reducing GHG emissions so that dangerous human interference with the climate is prevented. In addition, MRV can be important for sharing experiences about best practices and creating incentives for action (Bakker et al., 2010b). A proper system of MRV is therefore of high importance. However, the bar for supported and unilateral NAMAs might be placed lower than in the case of CDM because under supported NAMAs there would be no emissions reductions generated to be counted as offsets for developed country emissions. MRV can focus on different aspects of mitigation actions (based on Neuhoff et al., 2009; Jung et al., 2010), including: input, e.g. the financial resources used to implement a policy; the process of developing a policy, e.g. development of a Low Carbon Growth Plan; outputs, which are a direct result of a policy, e.g. increased consumption of renewable energy; outcome, which relates to policy objectives, e.g. GHG emissions reductions.

Heavy emphasis has been placed, especially by the developing countries, on the need for NAMA-related funding to be predictable, measurable, reportable and verifiable. Also, mitigation funding should be clearly separated from - and additional to development assistance. In the Copenhagen Accord, US\$ 30 billion of additional financing has been promised by developed countries for adaptation and mitigation in developing countries for the period 2010-12, and US\$ 100 billion per year in 2020 (UNFCCC, 2009b). It is not clear from what sources this funding will come or how the funding could be delivered, though a Copenhagen Green Climate Fund (see Section 3.5.4) is mentioned. Considering the emerging consensus on the definition of NAMAs that appears to indicate that funding would be available, under supported 
NAMAs, for both emissions reduction and enabling activities, a different disbursement mechanism will have to be found than the one used for CDM.

\subsubsection{NAMAs in the transport sector: Proposed framework}

Even though the specifics of NAMAs are not yet known, they have been mentioned as having significant potential for reducing transport emissions in developing countries (CCAP, 2010; Dalkmann \& Binsted, 2010). In their NAMA proposals for the Copenhagen Accord Annex II, many developing countries have included the transport sector. As of February 2010, 16 out of 25 submissions explicitly included the transport sector. A range of actions is proposed, including infrastructure development, energy efficiency, biofuels, electric vehicles, fiscal incentives and regulatory measures (Dalkmann \& Binsted, 2010). The submissions do not provide details on how these actions are going to be implemented.

Policy-based, supported NAMAs would have many similarities with programmatic approaches applied in development assistance by Multilateral Development Banks. International decisions on structuring NAMAs could therefore evaluate such already existing experiences in support of the detailed modalities and procedures for NAMAs.

\section{Framework for supported NAMAs in the transport sector}

Drawing on experiences with existing instruments (CDM, GEF and CTF) and recent literature, in the following section we discuss a possible way forward for supported NAMAs in order to be successful in catalysing a shift towards low-carbon sustainable transport. We focus on supported NAMAs. Credited NAMAs may not have great potential, as these are likely to face similar problems as transport projects under the CDM. Unilateral NAMAs fall outside the scope of the paper, which focuses on a review of external climate financing instruments because, by definition, unilateral NAMAs will not be entitled to external support. This does not mean that the potential impact of unilateral NAMAs will be smaller than that of supported NAMAs. Huizenga et al. (2010) observe that the impact of currently unreported domestic actions will remain the most important in terms of GHG reductions, notwithstanding increased involvement of other instruments.

Scope

IEA/OECD (2009) conclude that all types of mitigation activities in the transport sector grouped in Section 3.1 under Avoid-Shift-Improve may be required to achieve low-carbon transport and therefore a framework for transport NAMAs needs to enable the full range of possible interventions. CCAP (2010) distinguishes three broad categories of potentially eligible supported NAMAs: (1) planning and research 
activities that support mitigation actions, such as national or subnational low-carbon transportation plans, public outreach, development of models, travel surveys or economic studies; (2) regulation and policy development, such as fuel standards, parking policies, congestion pricing and removal of subsidies; and (3) physical and technical infrastructure, such as bus rapid transit systems, bicycle lanes, biodiesel refineries or the transfer of intellectual property rights.

Jung et al. (2010) suggest single NAMAs need to be embedded in a sectoral strategy, which sets an overall course of action, in order to make sure different measures are compatible and enhance each other. This follows the approach of the CTF, which also attaches a high priority to a sector wide approach. This is an attractive argument for the transport sector, where a range of different measures are necessary in order to achieve the objectives (e.g. parking policies need NMT and public transport incentives as well as awareness-raising to be effective). It may depend on the local context whether it is required to have a sectoral strategy at the national level in order to have an effective transport NAMA or whether an integrated strategy at the city level could also establish such policy coherence and support. Alternatively, sectoral NAMAs can also cover the transport sector (or a sub-sector) of a country, region or city, in which a bottom-up analysis is undertaken to develop a GHG emissions (intensity) baseline and financing is allocated relative to achieving reductions below the baseline, irrespective of the policies implemented to achieve the reductions.

NAMAs by definition will have to be appropriate to the national context, yet many transport NAMAs aimed at improving transport systems are most likely to be local ${ }^{30}$ level NAMAs while transport NAMAs aimed at influencing standards and technology dissemination will more likely be at the national level.

\section{Criteria for assessment of supported NAMAs}

How can a limited amount of finance, technology and capacity-building be allocated to potentially competing proposals from developing countries? All three types of support are likely to be important for NAMAs in the transport sector, and the type and extent of support can be included in the submission of a NAMAs proposal.

Cost-effectiveness, as calculated by dividing the full incremental cost of an action by the total GHG reduction over the lifetime of the action, is a logical criterion from the point of view of getting the largest amount of atmospheric benefits against lowest cost. However, for the transport sector, the simple concept of cost effectiveness has limited value due to a number of factors (CCAP, 2010). Cost-

\footnotetext{
${ }^{30}$ Local level NAMAs are also "nationally appropriate", and may not be fundamentally different from actions at the sectoral level, apart from having a smaller scale.
} 
effectiveness cannot be quantified with a high degree of certainty. Some actions produce only indirect benefits, such as enabling activities, even though these are necessary for other measures to take effect. Co-benefits for e.g. local air quality or reduced congestion are not taken into account, giving a skewed picture of costs and benefits. Many measures can be considered no-regret options, particularly when cobenefits for air quality are taken into account (Johnson et al., 2009) but do not get implemented due to other barriers. In many cases, up-front costs for investments in infrastructure are high and the (monetary) benefits will only be reaped in the longer term. To achieve deep cuts in emissions, transformational measures (e.g. infrastructure for electric vehicles or a change in spatial planning) are required. Climate finance is only a small part of the total investment in the transport sector. In order to make a difference, it needs to catalyse a redirection of business-as-usual investment towards low-carbon transport.

The attractiveness of a (sub)-national transport NAMA would increase if it were to have provisions promoting the replication or scaling up of the NAMA that would in turn trigger further emissions reductions. This would be equivalent to the indirect emissions of GEF projects and the transformational impacts of CTF Projects.

\section{Acknowledgement of co-benefits}

Important policy goals associated with transport projects, apart from GHG reductions, are: congestion reduction, road safety and air quality. Co-benefits often play a decisive role in determining whether a measure with a certain GHG emissions reduction potential will be implemented or not. In addition, the co-benefits to be realised can influence the scale of a programme. It is increasingly acknowledged that it is important to recognise the co-benefits associated with projects, either qualitative or in quantitative terms.

A full acknowledgement of co-benefits needs to go beyond mere recognition and should include a certain reward for realising co-benefits. This can be achieved by making the amount of financial support contingent on the degree to which cobenefits are realised. This additional support can be justified based on the likely indirect GHG impact the action would have due to its replication potential. It would not affect the environmental integrity of the NAMA, as the amount of GHG emissions reduced and reported for inclusion in the NAMA registry maintained by UNFCCC would remain the same. This could help ensure that the transport sector participates fully in NAMAs. If co-benefits are to be recognised and rewarded in transport NAMAs they need to be part of the MRV of the NAMA, which means that they need to be part of the ex-ante, the intermediary and the ex post MRV framework (see below). 


\section{MRV}

Assessment of GHG emissions under the MRV for transport NAMAs could consist of a combination of bottom-up modelling, based on the ASIF concept (see Section 3.1), and top down approaches, e.g. fuel sales. A particular problem for transport NAMAs, especially for bottom-up modelling, is the requirement for data. In many cases, such data will not all be available at the start of a project and many assumptions will need to be made. To address the data problem, consideration could be given to the use of default values to describe the impacts of certain interventions. Lessons can be learned from the GEF GHG manual for transport which, as stated, will most likely include default values. This leaves a serious question as to whether a methodological approach with so many uncertainties can be used for arriving at a reliable estimate of emissions reductions if these are expected to be less than $10 \%$ below the business-as-usual scenario. ${ }^{31}$

MRV of sector-NAMAs based on proposed sectoral emissions baselines circumvents some of these methodological problems, as the baseline could be compared directly to a single output parameter of GHG emissions, derived from e.g. fuel sales. The difficulties are, to some degree, shifted to the setting of an acceptable reference baseline in the prior proposal stage of the NAMA (Jung et al., 2010).

Given the complexity of GHG MRV, other options for indicators or metrics could be considered. This could also help to address the time lags that occur in several cases before measures are effective in reducing emissions (e.g. Jung et al., 2010). These alternative metrics would include output indicators - such as number of vehicles, share of biofuel in the mix, modal split, quantity of infrastructure built or process indicators - such as existence of transportation planning. For each type of action, suitable indicators could be developed that would together define the impact of the transport-NAMAs. This approach would require an internationally established consensus on the existence of causal linkages between specific indicators and possibly also on the expected quantified GHG emissions reductions in specific operational conditions. In this regard, the experiences from the CDM can be taken into account and the application of the GHG methodologies developed by the GEF and the CTF, which are simpler to use and include default emissions factors. An important step towards further operationalising the application of different indicator types would be to set up an international database of transport projects and their estimated GHG impacts.

31 The US Department of Transport (2010) estimates that many of the possible mitigation strategies in the transport sector will, in the short to medium term, have emissions reductions of less than $10 \%$. 
Such an approach would most likely make it easier to integrate the MRV for capacitybuilding support and technology transfer, in an overall MRV framework, for transport NAMAs. Further, the building of a data-gathering capacity could be considered for inclusion in a NAMA.

\section{Institutions}

The institutional structure for NAMAs is still evolving, both at the national and the international level. From the perspective of the transport sector, it is important that future NAMA design adequately acknowledges and addresses the multi-sectoral character of the transport sector that will require well-defined institutional coordination mechanisms. Local governments in most developing countries are responsible for the development and management of the transport sector. The future institutional structure for NAMAs will need to reflect these institutional mandates and support actions at both national and local level.

The final design of the MRV framework for transport NAMAs will have its implications for the international institutional framework. Apart from the regular review function of NAMA proposals, there is expected to be a need for a panel of experts who would regularly review default values, if an MRV framework composed of bottom-up modelling based methodologies is adopted. If an MRV framework is chosen that makes use of output or process indicators, an expert panel will be needed in this case as well to determine acceptable indicator categories and to determine their relative weight.

\section{Financing}

Similar to the "allocated demand" principle described above for CDM, the international climate community could consider allocating a specific portion of future NAMA funding to the transport sector. The Bellagio Declaration on Transportation and Climate Change and CCAP (2010) propose a specific window within the funds for transport, in order to ensure that the sector does not get crowded out due to competition with other sectors. GEF is already making use of sectoral allocations under its different Strategic Programs.

NAMA financing will only cover a small part of the cost of individual programmes or projects to which transport NAMAs will contribute. Based on an assessment of current financing structures for transport in developing countries, Huizenga (2010) concludes that the contribution of climate finance to the development of sustainable, low carbon transport in developing countries is likely to be modest compared to other financing sources. The largest source of funding will be domestic financing from the public and private sector in developing countries. The second largest 
source of funding will be the Multilateral Development Banks, several of which will increase their funding for transport significantly in the coming years.

The impact of providing, in overall terms, limited climate finance through NAMAs will not substantially alter the trajectory of GHG emissions in the transport sector. This means that the overall impact that NAMA funding could have in the transport sector depends on how much it can leverage other financial flows, particularly domestic financing. NAMAs will therefore have to ensure that activities supported in the transport sector address barriers which might prevent the replication and scaling up of the activities supported through it. Equally important is to come to an agreement on how the objectives of climate instruments can complement objectives for other funding streams in the transport sector and how impact assessment methodologies can be harmonised.

\subsection{Conclusions}

Existing international instruments supporting GHG emissions reductions in the transport sector in developing countries include the Clean Development Mechanism, Global Environment Facility and the Clean Technology Fund. Emissions reductions resulting from these mechanisms have been very modest, compared to the sectoral share in emissions and considering the need to achieve significant reductions below business-as-usual levels by 2020 and beyond. We conclude that the CDM is not likely to play a large future role, although there may be scope for a bigger share of transport projects than is currently the case. The CTF aims to be a temporary financing instrument compatible with the UNFCCC objective, until a new financing mechanism is operational. This is a key issue in the light of the funding promised by developing countries for mitigation and adaptation in developing countries.

Our second conclusion is that nationally appropriate mitigation actions supported by finance, technology and capacity-building have the potential to generate greater emissions reductions than the existing instruments. In order to achieve this, a special "transport window" in the support for NAMAs would be beneficial, to alleviate the danger that the sector gets crowded out due to competition with other sectors. Second, the scope, design and procedures for transport NAMAs need to: (a) include finance, capacity-building and technology transfer support to enable mitigation activities which help to avoid future transport emissions; (b) shift transport activities to the most efficient mode, and improve the vehicle technology and fuel quality; (c) support national, sub-national and sectoral level actions; (d) provide for MRV arrangements which enable the transport sector to have unfettered access to NAMA funding. This can mean that MRV frameworks focus less on quantified emissions 
reductions, calculated through modelling, and that MRV frameworks consisting of indicators focusing on the assessment of implementation and progress of the action are considered. In all cases it is important that MRV frameworks allow for relatively large uncertainty in measuring of GHG impacts; (e) recognise and reward cobenefits with the aim of increasing replication and scaling-up of NAMAs. This could be part of a general strategy to reward NAMAs with a high scaling up potential or replication capacity.

The third conclusion is that, in light of the relatively limited contribution of climate financing to the overall financing of transport programmes and projects, it is important to ensure that the objectives of different climate finance instruments are mutually supportive and that they complement the objectives of other non-climate funding sources. If the specific MRV frameworks for climate finance instruments are compatible with the overall planning and monitoring approach for transport programmes and projects, it will increase the opportunities for the effective deployment of climate finance instruments in the transport sector.

Our final message is: keep it simple.

\subsection{Addendum: The role of climate change policy for sustainable, low-carbon transport}

Since the publication of Bakker \& Huizenga (2010) (Sections 3.1 to 3.4) in November 2010, the climate change policy framework has evolved. The Paris Agreement, agreed in 2015 and entered into force in 2016, has changed the international climate policy landscape and has introduced a number of new instruments and approaches. This section provides an update of international climate mitigation instruments relevant to low-carbon transport in developing countries. It does so by first discussing the Paris Agreement and the relevance of its specific provisions to low-carbon transport, and subsequently reflecting on the experiences with climate instruments discussed above for various Paris Agreement instruments. We focus on (non-market) nationally appropriate mitigation actions (NAMAs) ${ }^{32}$, the new cooperation instruments under Article 6 of the Paris Agreement and the Green Climate Fund. It then discusses how the broader global agenda is influencing policy development in sustainable transport, confirming that international organisations and regimes influence national policy development (Howlett et al., 2009; Wijaya, 2017).

32 Based on higher data availability compared to other instruments, and my involvement in the development of three NAMAs in ASEAN countries. Non-market NAMA implies there is no generation of carbon credits that are used to offset emissions. 


\subsubsection{The Paris Agreement and low-carbon transport in developing countries}

Some of the key elements of the Paris Agreement (United Nations, 2015) are the following:

- A long-term goal to limit global temperature rise to not more than 2 degrees Celsius above pre-industrial levels and to pursue efforts to keep temperature rise to 1.5 degrees

- A recognition that this goal requires peaking of global emission as soon as possible, and net-zero emission in the second half of the $21^{\text {st }}$ century

- A bottom-up approach to mitigation, with all Parties required to prepare national action plans, the nationally determined contributions (NDCs), which should be updated every 5 years and lead towards increased ambition. Developed countries should take the lead in mitigation of emissions, and have more stringent requirements

- New voluntary mechanisms that aim to enhance international cooperation to mitigation (see Section 3.5.3)

- Provision of finance, technology and capacity building support by developed countries to developing countries, for both adaptation and mitigation. It highlights the role of the Green Climate Fund and a new framework for technology transfer

- A reporting mechanism to enhance transparency, implementation and compliance

- A global stocktake in 2030, and every 5 years thereafter, to assess progress

- A recognition that non-Party stakeholders, such as cities, sub-national government, civil society and the private sector, are key in addressing climate change

In the literature, some progress has been made in assessing the implications of the PA for low-carbon transport. New assessments on what the transport sector needs to do contribute to meeting the temperature goals are carried out in mitigation modelling studies and bottom-up analysis (see e.g. Gota et al., forthcoming). Progress is made in analysing how transport has been included in NDCs in developing countries and how the NDCs can be strengthened (Gota et al., 2016; Löhr et al., 2017), how mitigation actions can be monitored (Eichhorst et al., 2017) and development of NAMAs (see Section 3.5.2). Peet et al. (2017) discuss how transport is reflected in the global climate change negotiation, and how this can be improved. However, there appears to be limited analysis how some of the elements of the PA are related to the transport sector, such as the new voluntary mechanisms 
and the GCF. Table 3.5 present a brief overview of PA elements that are relevant to low-carbon transport.

In this Addendum, we look at lessons learnt from Sections 3.1-3.4 and analyse options for improved instrumentation for low-carbon transport through the PA, and whether and how the PA has influenced national policy-making on low-carbon transport in ASEAN countries.

Table. 3.5 Paris Agreement articles and their relevance to low-carbon transport

\begin{tabular}{|c|c|c|}
\hline Article & Topic & Questions/relevance for transport \\
\hline 4 & $\begin{array}{l}\text { Mitigation, including global goal, } \\
\text { NDCs, differentiated responsibilities of } \\
\text { developed and developing countries }\end{array}$ & $\begin{array}{l}\text { As a key GHG emitting sector, } \\
\text { transport needs to decarbonise } \\
\text { globally, and be reflected appropriately } \\
\text { in NDCs }\end{array}$ \\
\hline 6 & $\begin{array}{l}\text { New voluntary cooperation } \\
\text { mechanisms (Article 6.2, } 6.4 \text { and 6.8- } \\
6.9 \text { ) }\end{array}$ & $\begin{array}{l}\text { How can these mechanisms be } \\
\text { designed in order to promote low- } \\
\text { carbon transport? }\end{array}$ \\
\hline 9 & $\begin{array}{l}\text { Financial support to developing } \\
\text { countries }\end{array}$ & $\begin{array}{l}\text { Low-carbon transport requires large- } \\
\text { scale funding and appropriate } \\
\text { financing instruments }\end{array}$ \\
\hline 10 & $\begin{array}{l}\text { Technology development and transfer, } \\
\text { establishment of Technology } \\
\text { Mechanism }\end{array}$ & $\begin{array}{l}\text { How can the TM be used to promote } \\
\text { key transport technologies? }\end{array}$ \\
\hline 11 & $\begin{array}{l}\text { Capacity building to assist developing } \\
\text { countries implementing mitigation and } \\
\text { adaptation actions }\end{array}$ & $\begin{array}{l}\text { How can capacity building support be } \\
\text { organised, and programmes be } \\
\text { designed, for the transport sector? }\end{array}$ \\
\hline 13 & $\begin{array}{l}\text { Transparency framework, including } \\
\text { GHG inventory reports, monitoring of } \\
\text { progress of NDC implementation, and } \\
\text { reporting of international support }\end{array}$ & $\begin{array}{l}\text { Methodologies and reporting } \\
\text { processes appropriate for monitoring } \\
\text { emissions and reductions from action } \\
\text { in the transport sector are required }\end{array}$ \\
\hline
\end{tabular}

\subsubsection{Experiences with NAMAs}

When we consider current (2017) experience with NAMAs and look back at the proposed framework for NAMAs in Section 3.3.4, it can be observed that 1) noncredited, internationally supported NAMA have gained the most traction; 2) the scope of transport-NAMAs in the current pipeline is broad and covers a range of actions and instruments, however there are none that cover the entire sector; 3 ) costeffectiveness still plays a large role e.g. in the NAMA Facility; 4) contribution to sustainable development is acknowledged but no key criterion; 5) MRV approaches are flexible, with (unofficial) guidance developed; 6) expert groups and knowledge development on MRV and NAMAs in the transport sector has grown through programmes by international organisations, rather than top-down; and 7) the suggested 'Transport Window' under climate funds has not emerged, yet the NAMA Facility has aimed to achieve a sectoral balance in the funded NAMAs. 
A NAMA aims at catalysing transformational change and has a flexible set up: it can support projects, programmes, policies and more broad strategies. In other words, it can help development and implementation of any type of policy instruments: regulatory, economic, information and public investments (see Chapter 5). For example, an urban transport programme with multiple components including investments, organisational changes, urban planning and new policies can be designed as a NAMA, if it reduces greenhouse gas emissions, the latter being a key objective of environmental policymakers. Thereby, it could be said, a transportNAMA connects transport and climate policy.

NAMA can address barriers to sustainable transport by means of 1) increasing the financial resources available to implement actions, 2) capacity building and institutional support, 3) enhancing the knowledge base and necessary transport data and monitoring systems, and 4) facilitating policy discussions and, through the NAMA being internationally recognised, increasing political momentum for policy actions (Eckermann et al., 2015). Challenges for transport-NAMAs include the limited total funding available, difficulty in designing 'bankable' proposals (partially because many interventions require relatively large investments), and often smaller emission reduction potentials compared to proposals in other sectors.

With six of the ten countries developing and implementing transport-NAMAs, ASEAN is a relatively active region (Bakker, forthcoming). The four abovementioned elements are visible to a certain degree. Indonesia has been successful in attracting finance from the NAMA Facility, and the link to international climate policy was a key driver in developing and submitting the NAMA. In Thailand, NAMA development led to discussions between ministries of transport and environment, and the requirements for MRV was one of the drivers to start working on a national transport-MRV system (Kijmanawat et al., 2016). Capacity building for transport policymakers is common element in most transport-NAMAs. Beyond the ASEAN region, the development TRANSPerú NAMA provided a consistent framework for discussions on urban transport measures that were discussed before but only through the NAMA agreement on measures was reached ${ }^{33}$. A general point of concern with policymakers and NAMA developers of transport-NAMAs is the uncertainty whether funding will be available. Stakeholders may have expectations that cannot be met in case a proposal is not successful in attracting funding. Another issue is the technical complexity of developing successful proposals, which in current practice means that only specialised consultants are able to do. Frequently, those are recruited internationally and don't educate local consultants.

${ }^{33}$ Peruvian Ministry of Transport official, personal communication, May 2015 


\subsubsection{Lessons for Paris Agreement Article 6 on voluntary cooperation}

In Article 6.8 and 6.9, 'non-market approaches' (NMAs), which should contribute to NDC implementation and sustainable development, are introduced. Development of a work programme on a framework to operationalise NMAs is going on as of December 2017. Some suggestions what NMAs potentially could look like have been made in the literature. NMAs can be NAMAs without carbon trading, while a range of policy instruments such as taxes/incentives, regulations (e.g. vehicle standards), voluntary agreements, sectoral framework targets (e.g. renewables share), information/education programmes, and research and development (UNFCCC, 2014), but also other issues such as 'urban planning' (Bhandary, 2017) are considered suitable as part of an NMA. Experience with NAMAs in the transport sector could be helpful in development of the NMA framework ${ }^{34}$, including e.g. identifying actions and instruments, MRV, the role of technology transfer and capacity building, and blending of climate and development finance. This is important so as to ensure NMAs will be appropriate for the transport sector.

A new market mechanism is established under Article 6.4, which is being referred to as the Sustainable Mitigation Mechanism (Olsen et al., 2018) or the Article 6 Mechanism (Bhandary, 2017). Compared to the CDM, it has a stronger mandate in terms of contribution to sustainable development, therefore a key question is related to how to operationalise the sustainable development benefits, including e.g. a link to the SDGs (Olsen et al., 2018). The development of the mechanism could build on the CDM, and with a mandate for strong international oversight, could extend the CDM to cover policy instruments and sectors (Michaelowa \& Hoch, 2017). Earlier in Chapter 3, we concluded that crediting mechanisms will likely be challenging for transport based on CDM experience, particularly in a project approach. However, with sectoral crediting and policy-based approaches there may be opportunities, which are not yet explored in the literature, yet raise additionality concerns.

Article 6.2 introduces internationally transferred mitigation outcomes (ITMOs) as an instrument to directly trade emission units between countries. Given limited international oversight and a diversity in approaches to establish baselines of the NDCs (Michaelowa \& Hoch, 2017), there is a risk of a perverse incentive to inflate baselines. This is relevant for the transport sector, where uncertainties are particularly high; for example, various baseline emissions in the transport sector

${ }^{34}$ List of issues in the NMA framework as of May 2017:

http://unfccc.int/files/meetings/bonn_may_2017/in-

session/application/pdf/sbsta_10c_informal_note_final.pdf 
analyses for the Philippines in 2030 differ by more than a factor of 2.5 (Mejia et al., 2017). To reduce the uncertainty, more analysis, identification of key uncertainties and exchange on countries' practice is needed.

\subsubsection{Lessons for Paris Agreement Article 9 and the Green Climate Fund}

Article 9 of the PA established that developed countries shall, and other Parties are encouraged to, provide financial resources to assist developing countries in implementing the agreement. The Green Climate Fund (GCF), in addition to GEF (see Section 3.2), is a key operating entity of the Paris Agreement financial mechanism.

Within the (GCF, low-emission transport is one of the four impact areas related to mitigation. The GCF approved its first projects in November 2015, and as of January 2018, it has allocated USD 2.6 billion in grants and loans to 53 approved projects. There are no approved transport projects yet, however there are two transport projects in the pipeline (in the review process). Out of in total eight result areas, transport thereby has a share of 3\% of the requested funding (GCF, 2017). The fund also has a Project Preparation Facility, in which 3 out of 29 project requests are in the transport sector.

The GCF investment framework (GCF, 2014) includes 6 criteria: 1) impact potential, 2) paradigm shift potential, 3) needs of the beneficiary country / alternative funding sources, 4) country ownership and institutional capacity, 5) economic efficiency, and 6) financial viability (for revenue generating activities). The performance measurement framework includes multiple transport-specific result indicators in the realm of 'shift' and 'improve', for example passenger $\mathrm{km}$ travelled via low-carbon transport, proportion of freight tons made by low-carbon transport, energy required per passenger $\mathrm{km}$ and per vehicle $\mathrm{km}(\mathrm{MJ} / \mathrm{km})$, emissions rates per $\mathrm{km}$ travelled $\left(\mathrm{tCO}_{2} \mathrm{eq} / \mathrm{km}\right)$, as well as strengthened institutional and regulatory systems for low-emission planning and development, which could be part of 'avoid' strategies (GCF, 2016). In the relation to the framework developed in Chapter 2, we could add that 'access' and 'transitions' are emphasised in criteria such as needs of beneficiary country and paradigm shift potential.

In summary, the GCF could be suitable to promote low-carbon transport at a significant scale. There clearly is specific acknowledgement of the sector through the impact area of low-emission transport, and the indicators in the performance framework, although care should be taken that monitoring and reporting of such indicators does not pose barriers as experienced in the CDM. On the other hand, the GCF emphasises cost-effectiveness and has no specific indicators for sustainable 
development co-benefits (similar to the NAMA Facility), implying a potential disadvantage of the transport sector compared to other sectors.

\subsubsection{The global climate change agenda and transport}

Beyond the international climate instruments supporting developing countries, the Paris Agreement and its implementation mechanisms appear to have an impact on transport policy. First, it contributes to policy agenda setting. The PA is a highprofile international agreement that puts climate change in the minds of citizens and policymakers, including in connection to transport. It has reached almost universal ratification in a record time, it includes long-term goals, and it is not considered a temporary architecture.

The PA has contributed to climate change becoming a more important policy driver, and may create 'policy windows' for transport policymakers and policy entrepreneurs. Due to development of the Nationally Determined Contributions (NDCs), which are to be updated periodically, countries are challenged to put in writing their contribution to GHG reduction. This process includes the transport sector in all ten ASEAN countries. In addition, an increase in policy discussions on climate change included transport mitigation options through workshops, ex-ante policy analysis and scenario modelling can be observed in ASEAN countries ${ }^{35}$. It should be noted in that in some countries, climate strategies were developed earlier than 2015, with e.g. the sectoral climate change action plan (RAN-GRK) process in Indonesia spurring mitigation action development in transport at both the national and local level since 2010. This process provided transport policymakers with additional arguments when developing policy proposals, and the NDCs may lend robustness to implementation of existing strategies.

Third, the climate agenda has improved institutional development and cooperation between agencies. Through NDC process in particular, the Ministries of Transport have cooperated more with ministries or environment and energy than before, as indicated by multiple ASEAN countries in regional workshops (Imboden, 2017). In addition, Ministries of Transport have been institutionalising climate change and sustainable transport through dedicated units or departments as well as working groups (see Section 5.5).

Finally, there is more interest in transport and climate change data and indicators and development of measurement, reporting and verification (MRV) systems. The NDC process, the Biennial Update Reports, and, in some cases (e.g. Thailand),

$35 \mathrm{http}$ / / transportandclimatechange.org/news-events/aseans-transport-sector-contributions-tocombating-climate-change-indc-analysis/ 
NAMAs, have improved MRV systems, including transport data gathering, methodologies for emission reduction estimation, scenario development, transport and energy/emission models and, to a lesser extent, sustainable transport indicators. There are still limited domestic resources and staff capacity available for MRV systems. Therefore, the increased attention for MRV is potentially partially facilitated by the available resources from international organisations, by means of NAMA development and implementation, and international cooperation projects on climate change in transport.

It can therefore be concluded that climate change, and the Paris Agreement in particular, appears to be taken seriously by transport policymakers, and helps sustainable transport policy, institutional development and monitoring systems. 


\section{Chapter 4}

\section{ASEAN cooperation on sustainable transport: progress and options*}

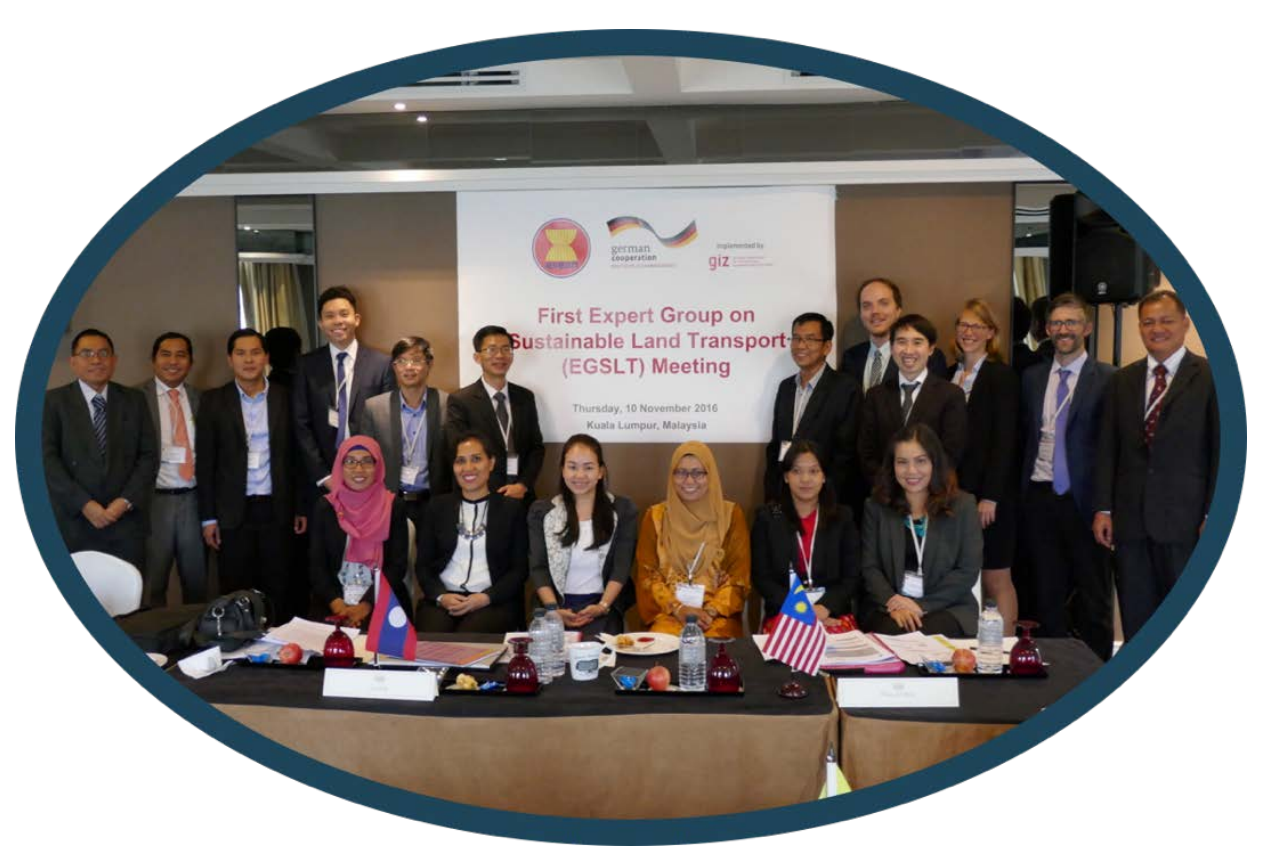

* This is an adapted version (changes mainly in Section 4.3) of the article: S. Bakker, M. Major, A. Mejia, R. Banomyong (2017). ASEAN Cooperation on Sustainable Transport: progress and options. Transport and Communications Bulletin for Asia and the Pacific, No 87, 1-15 


\begin{abstract}
The member states of the Association of Southeast Asian Nations (ASEAN) have been cooperating in the area of transport and connectivity since the early 1990s, contributing to economic and social goals in the context of ASEAN integration. However, in the area of transport and environment, actions included in the various strategies and action plans have been rather limited. Given rapid motorisation and the accompanying increase in congestion, fuel consumption and associated $\mathrm{CO}_{2}$ emissions and air pollution, the need for changing transport on to a more sustainable pathway is imminent. The ASEAN Transport Strategic Plan 2016-2025 (KLTSP) places more emphasis on sustainable transport than its predecessor, including a dedicated chapter with goals and actions. This paper reviews the KLTSP in the light of sustainable transport, in particular SDG 7 (energy efficiency), 11 (urbanisation), and 13 (climate change), and suggests options for regional international cooperation that have the potential to create significant impact on energy use and emissions of $\mathrm{CO}_{2}$ and air pollution, and sustainable development in general. It draws on regional environmental governance theory and practice in ASEAN, options for international cooperation in transport from literature and the experience in the EU and the existing ASEAN policy framework for sustainable development, e.g. the ASEAN Charter.
\end{abstract}




\subsection{Introduction}

Sustainable development is a key objective of the Association of Southeast Asian Nations (ASEAN), emphasised in e.g. the ASEAN Charter (ASEAN, 2007) and the ASEAN Community Vision 2025 (ASEAN, 2015a). Transport of people and goods is a key enabler of social and economic development, however the sector needs to become more sustainable to address a range of negative environmental, economic and social impacts. Indeed, it has been accepted that sustainable transport is a prerequisite for the achievement of the eight of 17 Sustainable Development Goals (United Nations, 2016) and climate change objectives. In the context of economic cooperation in ASEAN, improving connectivity by better transport infrastructure has been a key area of focus since the 1980s (ERIA, 2010).

The transport sector in ASEAN consumes approximately one-quarter of final energy consumption and related $\mathrm{CO}_{2}$ emissions, and is over $90 \%$ dependent on oil (IEA/ERIA, 2015). Without action, emissions may almost triple to 870 million tonnes in 2050 (ITPS \& Clean Air Asia, 2014), while air quality, energy security, city liveability, social equity, traffic safety and economic competitiveness may worsen as well. ASEAN's main role is to address issues at the regional level, such as facilitating trade and establishing a single market, yet it also has a mandate to promote coordination national policies of its Member States through regional cooperation or 'soft law' (Elliott, 2012).

For the transport sector, this coordination is recognised in regional transport plans and by the ASEAN Transport Ministers. It is acknowledged that climate change and sustainable transport are important, and that regional and national actions need to be taken (e.g. ASEAN, 2016a). At the national level, ASEAN countries are developing a range of transport plans in which local and national sustainable development concerns play a role (Bakker et al., 2017a). In the climate change action plans (Nationally Determined Contributions in response to the 2015 Paris Agreement), transport is a key sector as well, with ASEAN countries proposing a wide range of measures that save emissions, including on public transport, nonmotorised transport, transport demand management, fuel economy, electric and hybrid vehicles, vehicle maintenance, green freight, and biofuels (GIZ, 2016).

This paper aims to address the following research questions: 1) How did (sustainable) transport cooperation in ASEAN look in the past decades? 2) how can effective regional cooperation in the transport sector to promote sustainable development be designed? 
Sustainable transport should contribute to environmental, social and economic objectives. This paper focuses mainly on the environmental aspects, and is thereby related to SDG 7 on energy, SDG 11 on cities and SDG 13 on climate action. It is indirectly connected to SDG 17 on partnerships and considers social (SDG 3 on health) and economic aspects (SDG 9 on industry and infrastructure).

In the literature there is limited coverage of transport cooperation in ASEAN (e.g. Tongzon, 2016; Preece, 2016), and none focusing on sustainable transport has been found. In regional environmental governance, the literature on ASEAN mainly focuses on regional air pollution (haze) (Aggarwal \& Chow, 2009; Heilmann, 2015), climate change (Koh \& Bhullar, 2011), and biodiversity, forests and protection of flora and fauna (Elliott, 2012; Kheng-Lian et al., 2016). Kheng-Lian et al. (2016) also provide a review of and further options for collaboration in the areas of wildlife crimes, the ASEAN transnational water action plan and environmentally sustainable cities. In other areas, such as trade, energy and food security, more analysis is available.

This paper uses the following methodology and data sources. Literature on regional cooperation and governance literature, particularly on environmental issues, will provide the starting point. Then we look at the governance system and practice in ASEAN, in both economic and environmental sectors, as well as the broader policy drivers for sustainable transport in the region. As for cooperation in the transport sector, we draw on existing literature on policy options as well as experience in the European Union. Section 5 will provide a review of cooperation on sustainable transport since the 1990s, based on publicly available literature and documentation of ASEAN transport working group meetings. Section 4.6 will use the results and insights from the previous sections to consider which options for cooperation in the future may be worthwhile and feasible. Section 4.7 briefly concludes the paper.

\subsection{Regional international cooperation}

International cooperation between states at the regional level may take different forms. A basic distinction, although not a purely binary one, is that between hard and soft law, with the former defined as "legally binding obligations that are precise (or can be made precise through adjudication or the issuance of detailed regulations) and that delegate authority for interpreting and implementing the law" (Abbott \& Snidal, 2000: p. 421). Transaction costs, related implementation, enforcement, risk of free-riding or opportunistic behaviour, can be lower compared to other forms of legalisation, however, contracting cost of hard law (information collection, drafting, negotiation, ratification) can be significant. It is used particularly by states when "forming 'clubs' of sincerely committed states, like the European Union and 
NATO" (p. 429), and "when the benefits of cooperation are great but the potential for opportunism and its costs are high" (p. 429). In soft law, legal arrangements are weakened along the dimensions of obligation, precision and delegation, which reduces 'sovereignty cost' compared to hard law. It also reduces contracting costs, provides more opportunities to come to an agreement and enables parties to learn about the consequences of the agreement (Abbot \& Snidal, 2000). In this paper, we consider soft law as a broad range of regional cooperation arrangements that are different from hard law, and distinguish the following types of cooperation (see Table 4.1).

Technology cooperation: governments pool resources for research and development of cleaner technologies and/or agree to accelerate policies to deploy these. De Coninck (2007) considers several types of international technology-oriented agreements: knowledge sharing and coordination of research activities; research, development and deployment, e.g. in the form of cooperation programmes and based on joint funding; technology transfer, particularly benefiting developing countries; and internationally agreed technology mandates, performance standards or incentives.

Policy cooperation: Stead (2016) looks at new, 'soft', modes of governance concerned with intergovernmental coordination and 'networked arrangements and multi-level approach' for sustainable urban transport. He lists five key instruments: policy indicators and targets to measure progress, benchmarking against current or aspirational peers, policy transfer and best practices, policy experimentation, and the use of visioning exercises. In addition, policy cooperation may include discussion fora or expert groups that develop ideas and standards and guidelines, as well as certification schemes or promotion of low-carbon finance; in addition high-level political dialogues that help developing a common vision and building mutual trust can support all above-listed categories of cooperation (Stavins et al., 2014).

Cross-border infrastructure: infrastructure development is another area of cooperation between states in proximity, in sectors such as energy (connection of grids), communications, and transport (pipelines, roads, railways and waterways). This also includes software like common standards to use roads, rail, power. Such cooperation can reduce transaction costs significantly (Kuroda et al., 2007). 
Table 4.1 Typology of international cooperation (Source: authors)

\begin{tabular}{|c|c|c|c|}
\hline \multicolumn{2}{|c|}{ Types of cooperation } & Description & Examples \\
\hline $\begin{array}{l}\text { Hard law } \\
\text { agreements }\end{array}$ & binding & $\begin{array}{l}\text { International agreement on } \\
\text { mandatory policies that } \\
\text { countries will implement }\end{array}$ & $\begin{array}{l}\mathrm{EU} \mathrm{CO}_{2} \text { standards for } \\
\text { passenger vehicles and } \\
\text { vans }\end{array}$ \\
\hline \multirow{3}{*}{$\begin{array}{l}\text { Soft law / } \\
\text { regional } \\
\text { cooperation }\end{array}$} & $\begin{array}{l}\text { Technology } \\
\text { cooperation }\end{array}$ & $\begin{array}{l}\text { Governments pool resources } \\
\text { for R\&D, agree on } \\
\text { performance standards or } \\
\text { incentives; technology transfer }\end{array}$ & $\begin{array}{l}\text { European Organization } \\
\text { for Nuclear Research; } \\
\text { UNECE working group } \\
\text { on Harmonisation of } \\
\text { Vehicle Regulations }\end{array}$ \\
\hline & $\begin{array}{l}\text { Policy } \\
\text { cooperation }\end{array}$ & $\begin{array}{l}\text { Cooperation on policy } \\
\text { development involving little } \\
\text { sovereignty cost }\end{array}$ & $\begin{array}{lr}\text { Green Freight } & \text { Asia } \\
\text { labelling scheme } & \text { for } \\
\text { freight forwarders; EU } \\
\text { guidelines } & \text { for } \\
\text { Sustainable } & \text { Urban } \\
\text { Mobility Plans } & \end{array}$ \\
\hline & $\begin{array}{l}\text { Cross-border } \\
\text { infrastructure } \\
\text { and regional } \\
\text { connectivity }\end{array}$ & $\begin{array}{l}\text { Governments of nations in } \\
\text { proximity cooperate on hard } \\
\text { and soft infrastructure to } \\
\text { enable cross-border movement } \\
\text { of people and goods }\end{array}$ & $\begin{array}{l}\text { ASEAN connectivity } \\
\text { master plan (physical } \\
\text { connectivity): linkage of } \\
\text { road, rail, waterways } \\
\text { and pipelines }\end{array}$ \\
\hline
\end{tabular}

\subsection{Regional governance and cooperation in ASEAN and the EU}

The Association of Southeast Asian Nations was formed in 1967, and currently includes ten member states: Brunei, Cambodia, Indonesia, Laos, Malaysia, Myanmar, the Philippines, Thailand, Singapore and Vietnam. The total population is 629 million and GDP US\$2,432 billion. Differences among ASEAN member states (AMS) are considerable, with very small (Brunei, 0.4 million) and large Indonesia (255 million) populations, per capita income ranging from US $\$ 1,198$ (Cambodia) to US\$ 52,744 (Singapore) in 2015-2016 (ASEAN, 2017), and urbanisation rates between 21\% (Laos) to 100\% (Singapore) in 2015 (World Bank, 2017a). Many have undergone a process of decolonisation and political instability. Differences in political systems are still apparent, from open democracies such as Indonesia and the Philippines, to (post-)socialist states (Vietnam, Laos), a one-party democracy (Cambodia) and a country under military rule (Thailand). Such differences are also apparent in the Worldwide Governance Indicators (World Bank, 2017b), in which for five out of six indicators the countries cover nearly the entire scale, i.e. from less than 10 to over 90. For the three indicators Government Effectiveness, Regulatory Quality and Rule of Law, Singapore scores over 95, while Myanmar, Laos and Cambodia are roughly between 5 and 30. For Voice and Accountability, the Philippines and Indonesia gain the highest scores. 
ASEAN initially was formed, by its five founding member states, to promote peace and stability and the threat of communism, and to promote economic development (Severino, 2007; Nesadurai, 2008). ASEAN norms and practice of decision-making can be characterised by the so-called 'ASEAN Way'36, which emphasises principles of cooperation, consultation, non-interference in internal matters, informality, nonconfrontational and 'soft' diplomacy, pragmatism, flexibility, network structures and a preference for weak institutions (Elliot, 2012; Severino, 2007; Nesadurai, 2008; Jetschke \& Ruland, 2009). "The procedural norms include a preference for informal elite-based diplomacy, decision-making by mutual consultation and consensus, and a preference for incrementalism. Undergirding these norms is a basic belief that regional cooperation will provide AMS with enhanced political and economic benefits, both in the region and in the region's dealings in the broader international system. Together, these norms and beliefs constitute the ASEAN meta-regime." (Aggarwal \& Chow, 2010: p. 6). The ASEAN-minus-x formula (ASEAN, 2007) enables initiatives among a subset of member states and allows staged participation (Jones, 2015). Jayasuriya (2009: p. 337) notes that ASEAN works with "forms of regional regulation [that] rely more on the active participation of national agencies in the practices of regulation than on formal international treaties". According to Elliot (2012), non-hierarchical forms of multi-level governance complement intergovernmental relations, partially because states have limited capability of dealing with environmental challenges. Networks also provide 'fluidity to the policy-making process', supporting consultation, learning and exchange among senior officials, experts and stakeholders (p. 49-50). There is also a certain level of technical and financial dependency on national and international organisations.

In addition, political economy is important, e.g. for economic integration, the development of which is constrained by linkage of business and domestic political interests and relations that often favour protectionism. The "weak institutionalisation of ASEAN economic cooperation (...) persists because it is functional for powerful interests" (Jones, 2015). Through the ASEAN Free Trade Agreement, substantial deregulation has taken place and "average import tariffs fell from 12.3 per cent in 1993 to 1.5 per cent by 2006" (Hill \& Menon 2010, quoted in Jones, 2015). However, on non-tariff barriers and mutual recognition agreements for the free movement of skilled labour, progress has been limited. Ewing-Choi \& Hsien-Li (2013) argue that becoming an integrated production network is the main driver of ASEAN integration, of which the automotive industry is put forward as an example.

${ }^{36}$ Enshrined in the ASEAN Charter (2008) 
Since the late 1980s, environmental issues have become more important in the agenda of ASEAN cooperation, as a response to major international (UN) conferences and growing conscience with donor agencies (Elliott, 2012). The "regionalization of environmental governance proceeded from declarations and principles with minimal standards, to functional approaches and project-based cooperation, through to efforts to establish and implement regional policy initiatives through increasingly complex regulatory structures", including development of minimum regional standards for air and water quality (Elliott, 2012: p. 56). In the forestry domain, AMS have instituted a formal peer-consultation process to review the forestry policies and practices of individual countries, with such processes aiming to be non-adversarial and based on mutual trust.

Especially since the adoption of the ASEAN Charter in 2007, "numerous new treaties and protocols often with detailed obligations and dispute settlement procedures" were adopted, predominantly pertaining to economic cooperation (Ewing-Chow \& Hsien-Li, 2013: p.1). Other examples of binding agreements within ASEAN are the ASEAN Petroleum Security Agreement (Nicolas, 2009) and the transboundary air pollution ("haze") agreement. The latter is arguably the most important environmental cooperation instrument to-date. Heilmann (2015) argues "the agreement refers to these norms as binding (the parties "shall"), but the provisions are written in a way that gives discretion to the member states concerning their actions and the types of activities that they carry out to mitigate haze pollution", and no coercive steps can be taken, so it is "ultimately a soft law instrument" (p. 105) or a framework for cooperation. Key instruments in the agreement are a coordinating centre and a fund (USD 240,000 in 2014).

ASEAN strategies make use of various cooperation instruments related to policy and technology (see Table 4.1), which we briefly illustrate here. The Peatland Management Strategy (ASEAN, 2014) includes, inter alia, the following actions: Harmonise definitions and classification of peatlands; Status updates in national inventories; Develop a methodology and prepare guideline for monitoring of peatland areas; Undertake research on appropriate techniques and practices; Strengthen regional sharing of experience and networking through use of mechanisms such as the ASEAN Haze Action Online and the SEAPeat Network; Designate specific institutions responsible for peatland management and establish National Peatland Working Groups; Formulate or update national policies and strategies based on the thrust and objectives of the regional strategy; Establish pilot project(s) in each country to test new sustainable management. Other examples, such as on ASEAN Energy Market Integration and a Regional Policy Roadmap for Harmonization of Energy Performance Standards for Air Conditioners, show how 
roadmaps aim at regional harmonisation or at a least closer alignment of national approaches in terms of technical matters including definitions, standards and monitoring.

To provide further illustration of how international cooperation could work, we briefly review the governance system of the European Union (EU). We do not intend to carry out a comparative analysis, nor are we implying ASEAN wants to or should follow a similar path, a topic of considerable debate (Jetschke \& Ruland, 2009).

After two devastating World Wars, both of which originated in Europe, the six founding Member States (MS) sought to prevent conflicts by placing strategic resources in the hands of a "High Authority". This lead to the creation of the European Coal and Steel Community (Treaty of Paris, 1951), the first "supranational" international organisation. In 2017 the EU has 28 Member States, and implements policy in a wide range of policy areas on behalf of its MS, when it can be demonstrated that problems can be best solved at the "Union level". There is a single market, free movement of people good and capital, customs union, common competition policy and a single currency, the Euro, shared by 19 MS. The 28 countries are economically, geographically, culturally, climatically and linguistically diverse - but they share commitments to fundamental principles such as the rule of law, democracy and market based economies. In areas of EU "exclusive competence" such as trade policy the EU acts exclusively on behalf of all the MS. So, for example individual Member States are not allowed to conduct trade negotiations. Many policy areas are "shared competence" where the EU and MS share powers. EU policies are implemented through EU wide laws and funding programs; the EU budget is approximately $1 \%$ of GDP ${ }^{37}$. The EU is governed and administered by a number of institutions and agencies including a European Parliament and Council of Ministers (who together agreeing laws and policy), the European Commission (proposing and implementing laws and programs) as well as a European court and auditor. MS that do not meet their legal obligations can be taken before the European Court of Justice and ultimately face heavy fines - which are paid into the EU budget.

\subsection{ASEAN policy framework for sustainable transport cooperation}

In this section we look at how sustainable transport fits in the policy context of ASEAN, i.e. wider than the transport sector. This is relevant as sustainable transport cooperation is not merely about the transport sector per se, but rather involves area

${ }^{37}$ http://eur-lex.europa.eu/legal-content/EN/TXT/PDF/?uri=OJ:L:2016:048:FULL\&from=EN 
such as environment and climate change, energy, economy and research and innovation. Here we look at the frameworks for these issues as well as sustainable development, the ASEAN Economic Community and the ASEAN Socio-Cultural Community.

As stated in the ASEAN Charter, one of ASEAN's purposes is to 'promote sustainable development', which includes protection of the region's environment and ensuring 'high quality of life' (ASEAN, 2007: p.4). The ASEAN Vision 2025 highlights the 'complementarity' of the UN Agenda on sustainable development (ASEAN 2015a: p. 13). The importance of sustainable development, and the sustainable development goals have been reiterated since in various declarations. For example, ASEAN encourages cooperation on financing and research on climatefriendly technologies and integration of "sustainable consumption and production (SCP) patterns into our national policies".

In the 2025 vision for the ASEAN Economic Community, the vision for transport cooperation (in the context of 'promoting connectivity') is "towards greater connectivity, efficiency, integration, safety and sustainability of ASEAN transport to strengthen ASEAN's competitiveness and foster regional inclusive growth and development". In transport cooperation, it aims "to embrace sustainable transport as a new key sectoral focus as it has a vital role to play in the sustainable development of the ASEAN region" (ASEAN, 2015b: p.21). Biofuels are considered in connection to sustainable economic development, and can be promoted by free trade and investment in research and development for third-generation biofuels. The blueprint for the ASEAN Socio-Cultural Community (ASEAN, 2016b) refers to 'green lifestyle' and 'people-oriented', and, in the context of Environmentally Sustainable Cities, includes a measure "to enhance participatory and integrated approaches in urban planning and management for sustainable urbanisation towards a clean and green ASEAN" (p. 12).

ASEAN's commitment to the climate change agenda and the UNFCCC is stated in multiple declarations. The ASEAN Action Plan on Joint Responses to Climate Change (2012) includes actions related to GHG mitigation such as sharing best practices on energy production and use and policy towards low carbon development and green economy, establishing alliances to promote technology transfer, promoting common understanding on climate instruments and monitoring (MRV), promoting common understanding on access to climate finance and facilitating capacity building.

The Regional Action Plan on Healthy ASEAN Lifestyles (2012) includes in its programme work on road safety and physical activity: "to incorporate healthy 
lifestyle issues into public planning systems, especially with regard to transport and land use, safe transportation, provision for pedestrian and non-motorised traffic, considerations about noise, green space for physical activity".

In the context of energy, ASEAN has adopted an aspirational goal of reducing energy intensity by $20 \%$ by 2020 as a medium-term target and $30 \%$ by 2025 as a long-term target based on the 2005 levels. The transport sector has not played a significant role to date in energy cooperation. The ASEAN Plan of Action for Energy Cooperation (APAEC) 2016-2025 only includes 'The conduct of a feasibility study on [energy efficiency] in the Transport Sector would be considered during this period' (2016-2020). Energy security is considered a key issue in ASEAN, and the basis for cooperation is laid down in the (binding) ASEAN Petroleum Security Agreement, and refers to energy efficiency and conservation, fuel switching and energy diversification as medium and long-term strategies, without referring to the transport sector explicitly. Tongsopit (2016) shows that energy security in the ASEAN region has declined in 2010 compared to 2005.

No explicit references to the Sustainable Development Goals, the Paris Agreement on Climate Change and the New Urban Agenda have been found. This may be due the fact that these were adopted relatively shortly before many ASEAN plans were finalised. However, no references to the global agendas in general were found as well.

It should also be noted that in contrast to the adopted declarations and cooperation goals, ratification and implementation of agreements often falls behind (Jetschke, 2009; Olsen et al., 2015).

\subsection{ASEAN cooperation on sustainable transport: a review}

Since the 1980s, the transport sector has been an important area of cooperation in ASEAN. The main aims were to create an efficient and integrated transport system that supports the ASEAN Free Trade Area, an integrated production area and to narrow the development gap between the member states (ERIA, 2010). To date, transport cooperation has been a key part of ASEAN efforts to promote connectivity (ASEAN, 2016c) and essential in realising the ASEAN Economic Community (ASEAN, 2015b). Most of the efforts are related to cross-border infrastructure and measures to facilitate trade, such as reducing non-tariff barriers.

\section{Institutional structure and governance framework}

The biannual ASEAN Senior Transport Officials Meetings (STOM), with participation by all AMS usually at the level of permanent secretary, have the 
responsibility to supervise, coordinate and implement the transport action plans and strategies. It is supported by four working groups (land transport, aviation, maritime, and transport facilitation) and one Special Working Group on the Singapore Kunming Rail Link. These working groups, facilitated by the ASEAN Secretariat, meet once or twice annually and are represented by mid to high-level staff from the ministries of transport of the 10 AMS. The STOM reports to the ASEAN Transport Ministers meeting, which has taken place annually since 1996. Transport cooperation is part of the economic pillar of ASEAN, and progress is reported through the AEC scorecard and indicators in the Master Plan on ASEAN Connectivity (MPAC). There are no institutionalised cooperation or coordination efforts with other sectoral economic bodies such as energy, automotive industry, trade, research/technology, or with the socio-cultural pillar of which environmental working groups are part. However, in some cases, representatives from other working groups are invited to transport working group meetings (ERIA, 2010). Dialogue Partners, mainly development organisations, may be invited to participate in (parts of) the STOM and working group meetings. Some Dialogue Partners, such as Japan, China and Korea, convene dedicated meetings with STOM and ASEAN Transport Ministers. Other actors, such as civil society and business associations, may play an indirect or informal role, but are not known to participate in official transport meetings.

\section{Sustainable transport in ASEAN policies and action plans}

Environmental considerations first appeared in 1996, and the plan (ASEAN, 1997) noted cooperation on transport can focus on "where externalities such as safety and pollution as well as competition have acquired regional dimension to warrant cooperative action." As early as 1998, specific measures were also included in action plans, e.g. to "adopt harmonised standards and regulations with regard to vehicle specifications (e.g. width, length, height and weight), axle load limits, maximum weights and pollution or emission standards" 38 . In transport cooperation plans until 2010, promoting environmentally sustainable transport was emphasised, however as ERIA (2010) notes "limited efforts were made in selected [AMS]" and sharing of experiences and capacity building appeared to be limited to exchange in working group meetings and some workshops. The ASEAN Strategic Transport Plan 20112015 included more actions related to energy efficiency, (GHG) emissions, and "environmental-friendly transport system, vehicles and fuels" and "green public transport system" in the capital cities.

\footnotetext{
${ }^{38} \mathrm{Ha}$ Noi Plan of Action, which supports the ASEAN 2020 vision. There is no evidence however, that action has been taken on pollution or emission standards between 1998 and 2015.
} 
With the Kuala Lumpur Transport Strategic Plan (ASEAN, 2016a), sustainable transport was covered in a dedicated chapter for the first time. The chapter includes ten actions and 31 milestones (see Appendix I), and widens the scope of topics compared to earlier plans, by including non-motorised transport, fuel economy, green freight and logistics, economic instruments, development of a monitoring framework and integration with land-use planning. In addition, other chapters of the plan cover rail infrastructure, inland and maritime transport, intelligent transport systems and road safety. However, the plan does not refer to global agendas on sustainable development, climate change or urbanisation, which all AMS have agreed to.

In energy cooperation plans, transport has played a limited role to date, with e.g. consideration of a study on energy efficiency the transport sector in the ASEAN Plan of Action on Energy Cooperation 2016-2025. Cooperation on science and technology included an action on fuel cell research and biofuel life-cycle methodology harmonisation.

\section{Instruments and implementation}

The instruments used in actions and milestones on sustainable transport in the KLTSP are mainly exchange of experience and knowledge, capacity building, workshops and carrying out studies (see Appendix I). ASEAN plans also 'encourage' member states to adopt and implement suggestions and results from studies. A few notable examples of milestones are i) to "develop 'Avoid', 'Shift' and 'Improve' (ASI) strategies at the regional and Member States level", ii) development of databases on sustainable transport and green freight, iii) convening of expert groups, iv) formulation of a regional fuel economy roadmap, v) creation of a 'checklist guide' on green logistics, vi) development of a monitoring framework and harmonised approach for indicators, vii) compilation of data, viii) development of guidelines (on green logistics and transport - land-use integration), ix) creation of a platform for information exchange, and $\mathrm{x}$ ) carrying out trainings. The road safety strategy (ASEAN, 2016d) includes, inter alia, 'harmonisation of standards, road rules and legislation' and 'monitoring and reporting progress'. Implementation of the actions and milestones mainly depends on projects and funding from Dialogue Partners such as Japan, Germany and the Asian Development Bank. As the KLTSP (adopted November 2015) is in its early stage of implementation at the time of writing (July 2017), it is not possible to evaluate the implementation of the plan. 


\section{Drivers, agenda setting}

The overall vision for post-2015 transport cooperation, adopted by the transport ministers, includes a reference to 'sustainability': “Towards greater connectivity, efficiency, integration, safety and sustainability of ASEAN transport to strengthen ASEAN's competitiveness and foster regional inclusive growth and development" (ASEAN, 2016a; p. 4). The Strategic Goal for Sustainable Transport, is to "Formulate a regional policy framework to support sustainable transport which includes low carbon modes of transport, energy efficiency and user-friendly transport initiatives, integration of transport and land use planning (p. 17). Further explicit references to air quality, the UNFCCC agreements and sustainable development have not been found in official ASEAN transport strategies. Earlier, ERIA (2010), the study used as a basis for the 2011-2015, does refer to the millennium development goals, including environment and climate change. In addition, we note that the AEC Blueprint (ASEAN, 2015a), which includes a chapter on transport and connectivity, does not refer to the ASEAN socio-cultural blueprint, its environmental goals and scorecard. In short, environment may not be a strong driver for transport cooperation hitherto.

The MPAC (ASEAN, 2016c) indirectly supports sustainable transport, particularly modal shift strategies, through development of multi-modal transport including rail and maritime / in-land transport. Energy cooperation seems to focus on electricity production. Energy-efficiency in consumption sectors such as buildings are of lower priority and appear more driven by international organisations. In petroleum security, energy efficiency is mentioned but the key actions in the agreement are related to securing supply in emergency situations. In general, ASEAN regional cooperation is driven by its member states, with a key role for the chair of the respective working groups, and a topic can be pursued if countries benefit from cooperation. Looking at the country perspective, there is limited evidence of drivers for regional cooperation or cases where one or multiple AMS are pushing an agenda (other than cross-border infrastructure or trade facilitation). Thailand has organised an ASEAN workshop to discuss car taxation based on $\mathrm{CO}_{2}{ }^{39}$. The Singapore Land Transport Academy regularly organised workshops and trainings on transport where ASEAN countries are invited to, including on urban transport. Malaysia was driving the green freight and logistics topic, together with Japan. In reviewing national transport strategies and plans, we found that for multiple AMS, ASEAN and its strategies are being referred to in the context of the AEC, connectivity and free trade - predominantly in sections on improving infrastructure -, and in some cases road

$39 \mathrm{http}: / /$ transportandclimatechange.org/news-events/towards-co2-based-vehicle-taxation-in-aseancountries/ 
safety. We did not find evidence of other sustainable transport aspects of ASEAN plans playing a role in national strategies yet.

\section{Summary}

This brief review shows ASEAN cooperation on sustainable transport is growing since the 1990s, both increasing in breadth and depth. Yet it can be said sustainable transport is still of lower importance compared to the connectivity agenda. In terms of activities, cooperation predominantly focuses on to carrying out studies, sharing experience and discussions in expert groups. Work on developing standards and tools for policies and transport indicators and monitoring has started or is being planned. Many of the activities are dependent on international organisations to be developed and funded. Cooperation with other relevant ASEAN bodies such as energy, environment and industry is rather limited as well. In general, absence of a strong ASEAN mandate and few country-level drivers limit the current ambition. These aspects can be contrasted with the European Union, as illustrated in Box 4.1.

\section{Box 4.1 Transport policy in the European Union}

Transport has been a shared competence of the European co-operation since 1957, the aim has been to develop facilitate transport of passengers and freight between and across the EU Member States through a common transportpolicy. A vision and ten quantified goals for EU action on transport is set out in the European Commission's (2011) White Paper "Roadmap to a Single European Transport Area - Towards a competitive and resource efficient transport system", although since 2014 there has been an adjustment of policy priorities. Important drivers of action on the environmental impacts of transport have been EU environment and single market policy - not transport policy. For example, EU laws on climate and air quality drive action on urban transport, aviation, and $\mathrm{CO}_{2}$ emissions from new vehicles.

\subsection{Options for cooperation on sustainable transport}

Based on the preceding evaluation, the cooperation typology and instruments (Section 4.2) and the discussion on regional governance in ASEAN in Section 4.3, we explore options (instruments) for strengthening ASEAN sustainable transport cooperation, some of which may be relevant to other sectors as well.

Common vision and strategy: a vision on sustainable transport in ASEAN endorsed and adopted by all ten member states can provide point of reference for regional and national policymaking. If politically feasible this vision could include quantitative, 
long-term targets for objectives such as energy, climate change mitigation and air pollution ${ }^{40}$. A strategy can elaborate necessary steps to realise the vision. The EU White Paper (EC, 2011) includes such a vision, targets and actions.

Knowledge sharing, policy transfer: the current actions promoting knowledge sharing and policy transfer can be strengthened and expanded to make them more effective. In addition to learning from countries and cities outside the region, there is a large and untapped potential to learn from intra-ASEAN experience, as AMS are developing and experimenting with new policies and programmes (Bakker, forthcoming). Involving the right government staff and, as staff turnover/change tends to be quick in the region, a sufficient number of mid- and high-level policymakers is critical in developing knowledge exchange programmes. In addition, development of knowledge platforms, such as a dedicated website where data and information on country policies is gathered and maintained, and dissemination are required.

Studies, knowledge development: carry out, publish and disseminate high-quality research into sustainable transport solutions that can be applied in the region, while considering the different national and local circumstances and transferability of policies.

Institutions: sustainable transport policy development is a multi-sectoral undertaking and currently the topic is missing a 'home'. The institutional setup can be improved by strengthening the transport working group meetings and the interaction with other relevant ASEAN bodies such as energy and environment. Regional expert groups on dedicated topics can improve the link between national and regional policies. In addition, data collection and knowledge development and management could be enhanced by a dedicated institution, e.g. following the example of the ASEAN Centre for Energy, and annual conferences. Setting up a facility to support public-private partnerships may provide assistance in developing viable projects.

Data, indicators, monitoring: a common and harmonised approach for monitoring sustainable transport indicators within ASEAN at the national level provides benefits for monitoring progress towards common goals related to transport and climate change, avoids duplicating research work for developing monitoring systems, enables benchmarking and cross-country learning as to effectiveness of policies, and can inform the public about emerging issues and trends. In addition, output and outcome indicators, linked to the SDGs, could be added to the AEC and ASCC Scorecards, which are the key monitoring tools at the regional level. In the

${ }^{40}$ There is a precedent for quantitative targets: ASEAN already has adopted a target to halve road crash fatalities by 2020 
EU, the publication of comparable data, indicators and monitoring has been a key "soft" mechanism to drive action and progress.

Awards: recognition of countries, cities or individuals that show remarkable achievements in the field of sustainable transport policy by awards or other means provides an additional incentive and is a means to highlight best practices. The current practice of the ASEAN Environmentally Sustainable Cities awards can be built upon.

Technical and performance standards, common definitions, guidelines, tools: examples could be a fuel economy standard or label ${ }^{41}$; guidelines for national policies (such as included in the ASEAN ITS Roadmap (ASEAN, 2015c)) and indicators/monitoring, and greenhouse gas impact assessment tool for policies or specific options such as alternative fuels.

Research and technology cooperation: to date, under the ASEAN Science and Technology Network, activities on related to the transport sector have been limited to biofuels and fuel cells (funded by the ASEAN Science Fund). The 2016-2025 ASEAN Plan of Action on Science, Technology and Innovation emphasises the role of green and low-carbon technology, 'transformation to low-carbon society', energy security and energy efficiency, however transport is not addressed explicitly. Development of partnerships between scientists, universities and other stakeholders, pooling of resources for research and development in key transport technologies, joint policy research on transport and land-use planning (e.g. in urban areas) are actions that may be considered.

To show how such instruments can be used to promote the different strategies in sustainable transport, Table 4.2 summarises these options based on the "Access + Avoid-Shift-Improve" approach (Bakker et al., 2014). This sustainable transport policy framework emphasises that in addition to improving access to opportunities, transport policy should aim to avoid the need to travel, e.g., by improved urban planning, travel demand management or road pricing, and e-communication options; shift transport to cleaner or more efficient modes, e.g., rail freight or public transport; and (c) improve the environmental performance of modes by making vehicles more energy efficient and fuels less carbon-intensive. In addition to policy instruments, there are cross-cutting and supporting actions. Possible drivers and rationales for developing such cooperation instruments are also highlighted (see Section 4.4), as well as possible key actors involved in implementation.

${ }^{41}$ This does not necessarily mean that all member states adopted the same standards at the same time; a convergence approach could be appropriate as well. 
Table 4.2 Cooperation options, policy drivers and key actors: illustrative examples differentiated by categories of measures

\begin{tabular}{|c|c|c|c|c|}
\hline & $\begin{array}{l}\text { Access / } \\
\text { connectivity }\end{array}$ & Avoid / shift & Improve & $\begin{array}{l}\text { Cross-cutting / } \\
\text { supportive } \\
\text { instruments }\end{array}$ \\
\hline $\begin{array}{l}\text { Typical } \\
\text { measures }\end{array}$ & $\begin{array}{l}\text { Infrastructure, } \\
\text { reduction of } \\
\text { trade barriers }\end{array}$ & $\begin{array}{l}\text { Rail, water } \\
\text { infrastructure } \\
\text { (inter-urban); } \\
\text { Public transport, } \\
\text { NMT, planning, } \\
\text { logistic centres }\end{array}$ & $\begin{array}{l}\text { Fuel efficiency, } \\
\text { alternative fuels, clean } \\
\text { fuels }\end{array}$ & $\begin{array}{l}\text { Monitoring system; } \\
\text { institutional } \\
\text { development; } \\
\text { knowledge } \\
\text { development }\end{array}$ \\
\hline $\begin{array}{l}\text { Regional } \\
\text { cooperation } \\
\text { instruments }\end{array}$ & $\begin{array}{l}\text { Joint action } \\
\text { plans for } \\
\text { infrastructure } \\
\text { development } \\
\text { and national } \\
\text { policy changes } \\
\text { (current } \\
\text { practice); }\end{array}$ & $\begin{array}{l}\text { Joint action plans } \\
\text { (current practice); } \\
\text { policy transfer; } \\
\text { networks, expert } \\
\text { groups; studies; } \\
\text { guidelines; awards; } \\
\text { benchmarking; PPP } \\
\text { facility }\end{array}$ & $\begin{array}{l}\text { Fuel economy and } \\
\text { technology roadmap; } \\
\text { standards; mutual } \\
\text { recognition schemes; } \\
\text { expert groups; } \\
\text { technology cooperation; } \\
\text { studies/ best practice; } \\
\text { green freight labelling } \\
\text { scheme; policy } \\
\text { dialogues; policy tools; } \\
\text { capacity building; } \\
\text { benchmarking }\end{array}$ & $\begin{array}{l}\text { Joint vision / } \\
\text { strategy; capacity } \\
\text { building; joint } \\
\text { indicator system; } \\
\text { knowledge sharing; } \\
\text { knowledge centre } \\
\text { and website; } \\
\text { curricula } \\
\text { development; } \\
\text { academic } \\
\text { cooperation; } \\
\text { conferences / } \\
\text { Mobility Week }\end{array}$ \\
\hline Drivers & $\begin{array}{l}\text { Economic / } \\
\text { social } \\
\text { development }\end{array}$ & $\begin{array}{l}\text { Accessibility, urban } \\
\text { liveability, } \\
\text { environment, } \\
\text { (sustainable } \\
\text { development) }\end{array}$ & $\begin{array}{l}\text { Environment, trade / } \\
\text { economic integration, } \\
\text { single market, energy } \\
\text { security, R\&D policy }\end{array}$ & $\begin{array}{l}\text { Supports various } \\
\text { goals stated in } \\
\text { ASEAN strategies }\end{array}$ \\
\hline Actors & $\begin{array}{l}\text { Ministries of } \\
\text { transport, } \\
\text { trade/industry; } \\
\text { MDBs }\end{array}$ & $\begin{array}{l}\text { Ministries of } \\
\text { transport, urban } \\
\text { development; local } \\
\text { governments; civil } \\
\text { society; MDBs, } \\
\text { technical } \\
\text { cooperation }\end{array}$ & $\begin{array}{l}\text { Ministries of transport, } \\
\text { energy, environment, } \\
\text { trade/industry; business } \\
\text { sector; research / } \\
\text { science community; civil } \\
\text { society; IOs }\end{array}$ & $\begin{array}{l}\text { Ministries of } \\
\text { transport; } \\
\text { academics; civil } \\
\text { society; IOs }\end{array}$ \\
\hline
\end{tabular}

\subsection{Conclusions}

Sustainable transport is a relatively new topic in ASEAN transport cooperation, which focuses mostly on facilitating trade and connectivity as part of the ASEAN Economic Community agenda. Sustainable transport covers social, economic and environmental dimensions, and is essential in achieving multiple SDGs, notably on poverty reduction, road safety, energy efficiency and climate change, while ASEAN transport cooperation itself could be seen as contributing to SDG 17 on partnerships.

With the adoption of the ASEAN Transport Strategic Plan 2016-2025, sustainable transport has gained importance due to a dedicated chapter on the topic, with actions 
mainly related to energy and environmental topics. However, transport development strategies in ASEAN are not strongly linked with global environmental and sustainability agendas nor to the ASEAN Socio-Cultural Community and its (environmental) goals.

The instruments used are predominantly focussing on policy cooperation, e.g. by best practice and knowledge sharing, capacity building, information platforms and development of a harmonised monitoring approach. This approach is common in ASEAN cooperation frameworks, with its strong preference for consultation and networking, dialogue, non-interference, soft diplomacy, and our findings are line with literature on networked regionalism. The private sector and civil society are involved to a limited extent, and implementation of actions partially depends on funding from international Dialogue Partners.

With climate change, air quality, energy security and liveability becoming more important as policy drivers, as well as the strong basis in various ASEAN declarations and strategies to advance sustainable transport, there may be potential to raise the ambition. This would require 1) increased awareness with policymakers of the importance of sustainable transport for economic development, 2) institutional development, in particular collaboration between transport and environment institutions at the regional and national level, 3) integration of sustainable transport indicators in the monitoring mechanisms of the AEC and ASCC, 4) more intensive cooperation to exchange best practices, enhance capacity and develop harmonised approaches in action areas such as fuel economy policies, green freight and urban transport, and 5) continued funding for implementation of action plans, by AMS, international organisations and the private sector. 
Appendix I. Instruments in the KLTSP Sustainable Transport Chapter

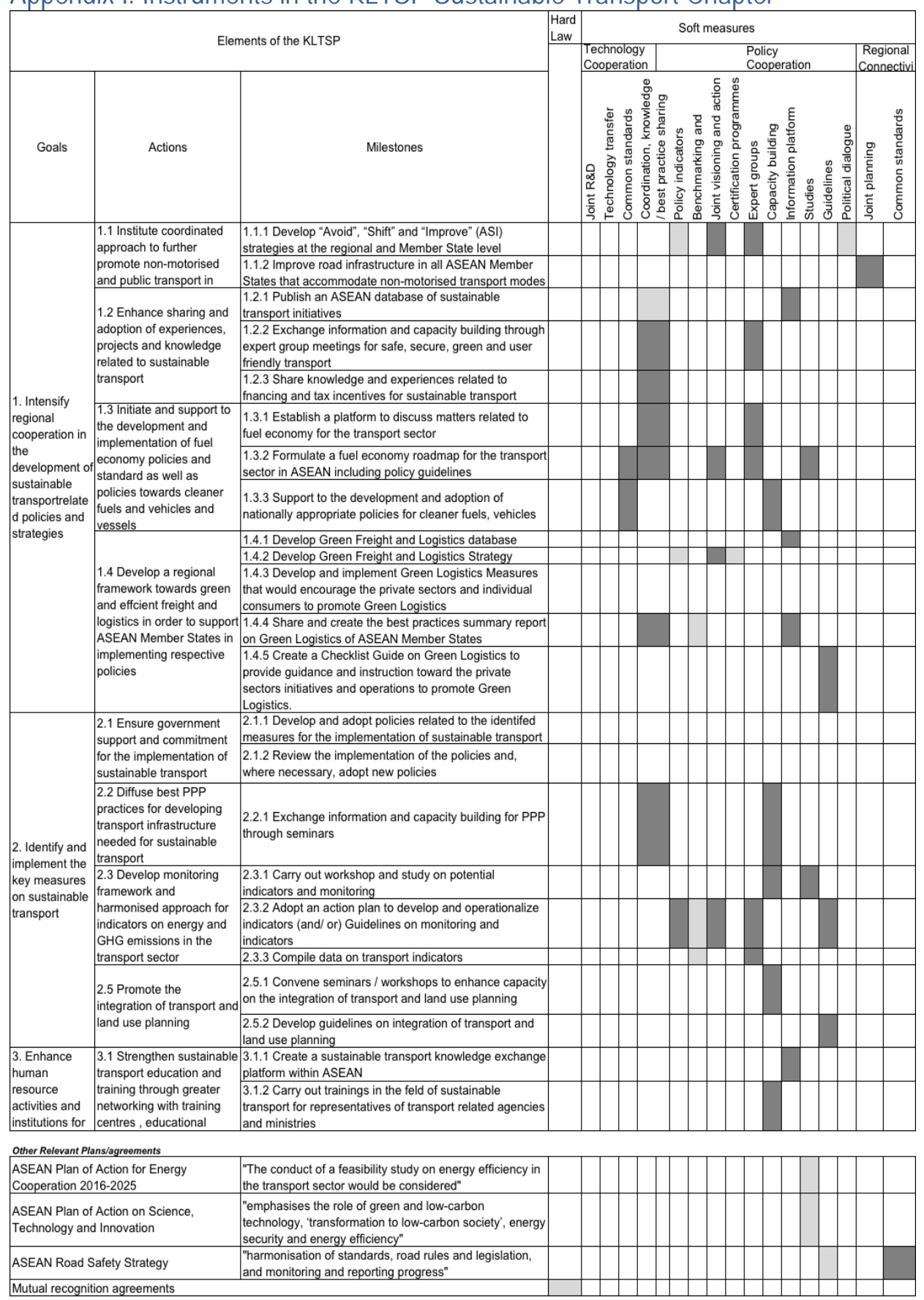

Notes: The typology of instruments is based on Table 4.1 and instruments commonly used in ASEAN cooperation. The table focuses on the KLTSP elements on land transportation. 


\section{Chapter 5}

\section{Low-carbon transport policy in four ASEAN countries: developments in Indonesia, the Philippines, Thailand and Vietnam*}

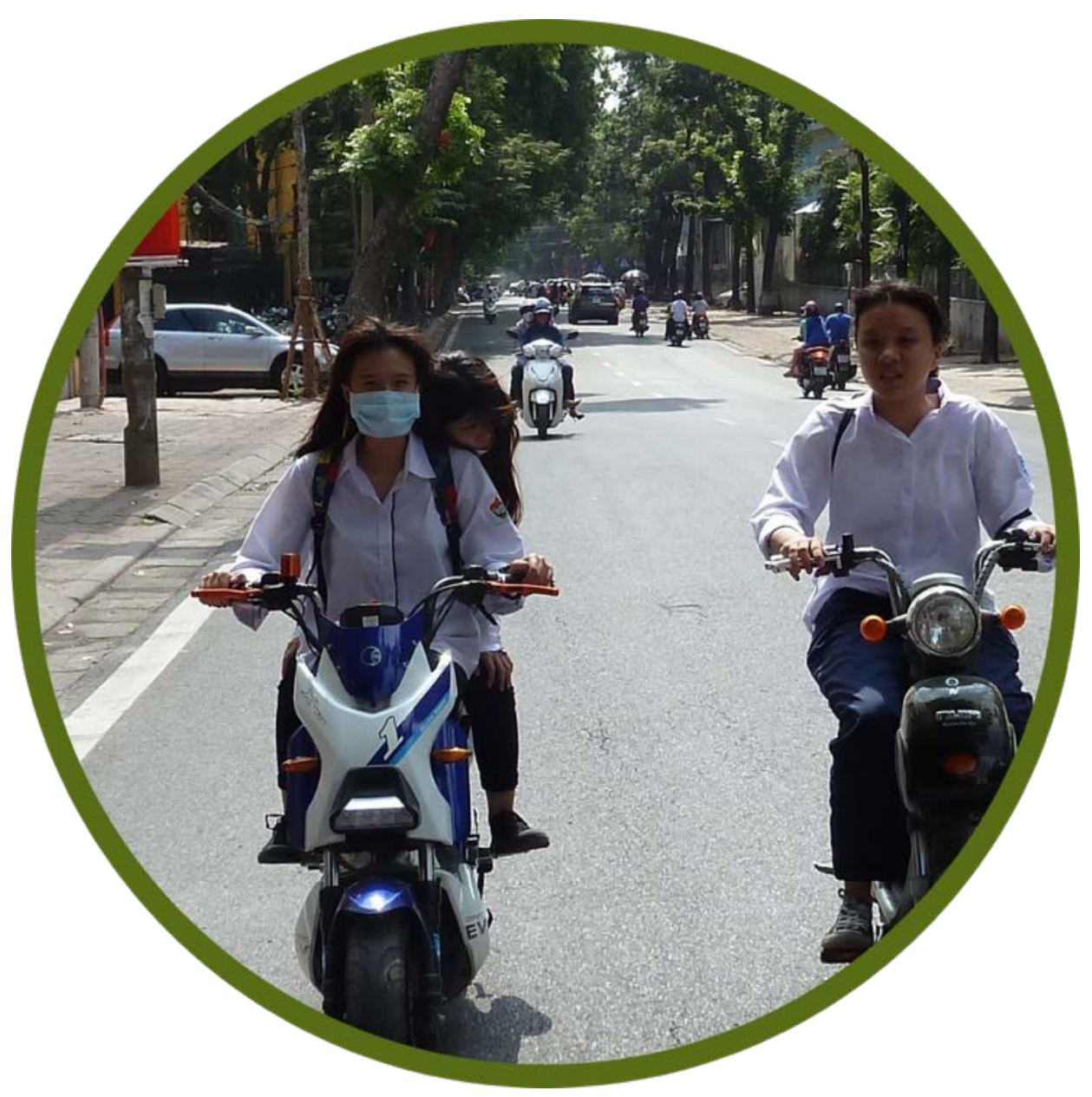

* Published as: Bakker, S., K. Dematera, M. Kappiantari, A. T. Nguyen, M. D. Guillen, G. Gunthawong, M. Zuidgeest, D. Liefferink, M. van Maarseveen (2017) Low-Carbon Transport Policy in Four ASEAN Countries: Developments in Indonesia, the Philippines, Thailand and Vietnam. Sustainability 9 (7), 1217 


\section{Abstract}

Emerging countries in Southeast Asia are facing considerable challenges in addressing rising motorisation and its negative impact on air quality, traffic, energy security, liveability, and greenhouse gas emissions. This paper presents a comparative analysis of the approach and status of sustainable, low-carbon transport policy in ASEAN countries and identifies differences and similarities. The methodology is based on a taxonomy of policy components as developed by Howlett and Cashore. The data come from comprehensive country studies for Indonesia, the Philippines, Thailand and Vietnam and interviews with policymakers. We find that each country has a specific set of goals, objectives and targets that support sustainable transport, and, directly or indirectly, climate change mitigation. In terms of specific mechanisms and calibrations, which we analyse based on the Avoid-Shift-Improve approach, there are notable differences between the countries, for example in terms of fuel economy policy. Even though an initial response to climate change mitigation challenges is visible in these countries' transport policies, much more effort is required to enable a transition to a transport system compatible with long-term climate change and sustainable development targets. 


\subsection{Introduction}

The member countries of the Association of Southeast Asian Nations (ASEAN) are experiencing robust economic growth in recent years. This growth has resulted in a rapid increase in the demand for motorised transportation. Southeast Asian countries already face serious problems including congestion, fossil fuel consumption, air pollution and road crashes, while significantly contributing to the ever-increasing global greenhouse gas (GHG) emissions, notably $\mathrm{CO}_{2}$ and black carbon, as transport accounts for approximately one-quarter of regional final energy consumption (OECD/IEA, 2015). This picture is likely to worsen with vehicle registrations increasing by over 10\% annually in many countries (Clean Air Asia, 2012) and demand for transport in ASEAN projected to increase by $60 \%$ from 2013 to 2040 in a business-as-usual scenario (OECD/IEA, 2015). Many of the ASEAN countries are facing challenges in providing timely sustainable transport solutions to keep up with the rapid increase in transport demand and motorisation rates. In the ASEAN Transport Strategic Plan 2016-2025 (ASEAN, 2016a), ASEAN member countries agreed to "actively pursue sustainable transport" and "develop 'Avoid', 'Shift' and 'Improve' strategies at the regional and Member States level”' (p. 32).

In the extant literature, analysis on how transport policy in ASEAN countries is responding to the challenge of climate change mitigation is limited. However, a growing body of research analyses transport systems in Southeast Asia and related policy options, while various researchers compare countries in the region on different aspects of transport. Akimura (2015) does so for cities while Nguyen et al. (2013) analyses motorcycle accessibility. Khuat (2006) characterises cities and countries according to their transport system development, particularly related to the extent to which these are "motorcycle dependent". Van et al. (2014), writing about citizen preferences and attitudes towards travel modes, show that in Indonesia, the Philippines, Thailand and Vietnam, the car scores higher on "affective" and "social orderliness" values as compared to China and Japan. Moreover, research is available on the characteristics and trends of urban transport systems in megacities (Morichi \& Acharya, 2013). In the policy field, Barter (2012) discusses parking management; Silitonga et al. (2012) discuss fuel economy policies for Singapore, Indonesia, Malaysia, Philippines, Thailand and Vietnam; and Mofijur et al. (2015) discuss biofuel policies in eight ASEAN countries. Furthermore, business-as-usual and low-carbon scenarios for the transport sector in ten ASEAN member countries by 2050 have been developed (ITPS \& Clean Air Asia, 2014). With respect to transport policy choices in Asia-Pacific countries, it is concluded that a crucial issue explaining differences in motorisation and success of public 
transport is the "decision of whether or not to restrain private vehicle ownership and use" (Barter, 1999: p. ii).

There is not much analysis of the approaches and content of policies related to sustainable, low-carbon transport (except for a few cases, e.g., Thailand (Uabharadorn, 2013)). In an analysis of peer-reviewed literature on transport policy, it is found that only $13 \%$ of papers consider specific aspects of the policy cycle, fewer than $10 \%$ of papers engage with debates about policy aims and that two-thirds of papers did not engage with real-world policies examples or policy makers and focussed on quantitative ex-ante analysis of potential policy options alone (Marsden \& Reardon, 2017)

This article aims to present a comparative analysis of the approach and status of sustainable, low-carbon transport policy in ASEAN countries and identifies differences and similarities. Such analysis aims to enable and contribute to the assessment of feasibility of low-carbon transport policies, help cross-country policy learning, and inform future studies on policy innovations.

The countries studied here are Indonesia, the Philippines, Thailand and Vietnam, the four most populous in the ASEAN region. They face similar challenges including rapid motorisation and declining public transport modal share, however are different in other aspects, such as economic development and cultural orientation. Lowcarbon transport policies are considered to be those that result in lower GHG emissions in the sector than would happen in absence of implementation of such policies. Passenger transport is the primary focus of this paper. As for freight and logistics, policies in this subsector are generally much less developed; thus, data on such policy development are limited.

Section 5.2 outlines the theoretical framework and Section 3 the methodology and an overview of key indicators for the transport system in the four countries. Section 5.4 shows the results: an overview of policy components based on the methodology developed in Sections 5.2 and 5.3. Section 5.5 discusses the methodology and results, after which conclusions are drawn in Section 5.6.

\subsection{Theoretical framework for low-carbon transport policy analysis}

In his seminal work on policy development as a process of social learning, Hall (1993) decomposed policy into three distinct elements or variables: the overarching goals that guide policy in a particular field, the techniques or policy instruments used to attain those goals, and the precise settings of these instruments (p. 278). These components can change at different speeds, with change in settings, instruments and goals referred to as first, second and third-order change respectively. Building on 
Hall's work, Howlett and Cashore (2009) developed a more elaborate taxonomy of policy components. At the level of ends and aims, they distinguish the goals, which are the ultimate ends and general ideas that policy development is trying to achieve; objectives, which operationalise the goals into formal policy aims; and settings, the more specific requirements specified in the policies or measures. At the level of policy means and tools, the components are divided into the instrument logic, referring to the general norms that guide the choice of the mechanisms or specific instruments, and the calibrations, or the specific ways the instruments are used.

In transport policy analysis, Howlett and Cashore's taxonomy has been used in various articles. In their analysis of transport policy change in the United Kingdom, Marsden et al. (2012) observe changes in calibrations and the types of instruments being deployed to respond to the need to address climate change, however paradigmatic change has not taken place. Bache et al. (2014) argue that climate change mitigation policy can be seen as a meta-policy in relation to transport policy. They found the impact of climate change objective on transport policy "symbolic" for the UK, in other words, having a minor impact on the ground. In addition, the aforementioned study (Marsden \& Reardon, 2017: p. 9) found that "the majority (60 papers) focused on the 'means or tools' components of policy: the instrument logics, mechanisms and calibrations, with only four of them focused on the 'ends or aims' of policy; the goals, objectives or settings".

Before we explain in Section 5.3 how Howlett and Cashore's taxonomy is applied in this study, we briefly discuss concepts of sustainable transport policy. Over the past decades, shifts in approaches and frameworks for transport policymaking have taken place in the context of sustainable development. Such changes include the shift away from "predict—provide—manage" to "provide—predict" (Zuidgeest, 2005), a renewed emphasis on transport indicators such as accessibility, quality of life, equity and justice (Martens, 2017) and interventions aimed at improving these, such as transport demand management (Buchanan, 1963; Banister, 2011) or people-focused policy development (Wright, 2001). There is an emerging consensus among scholars, international organisations and governments that in addition to the contribution transport makes towards economic and social development, its negative impacts on society need to be minimised to move towards sustainable transport (Bakker et al., 2014). The climate change policy agenda, in particular the notion that dangerous climate change cannot be avoided without deep GHG reductions in the transport sector, is one key driver for thinking on sustainable transport policy. It is also widely acknowledged that sustainable transport is essential in realising the Sustainable Development Goals (United Nations, 2016) and that reducing GHG emissions from transport yields important sustainable development benefits at the local and national 
level (Sims et al., 2014). These benefits, rather than climate change per se, are often stronger arguments for decision makers for sustainable transport policy, particularly in developing countries.

One policy approach to addressing GHG emissions and other environmental impacts of transport is captured in the so-called Avoid-Shift-Improve (ASI) framework (GIZ, 2012). In this framework, low-carbon transport policy needs to cover measures aimed at: (a) avoiding the need to travel, e.g., by improved urban planning, travel demand management or road pricing, and e-communication options (mobile phone use, teleworking); (b) shifting travel to the most efficient or clean mode, e.g., non-motorised or public transport; and (c) improving the environmental performance of transport through technological improvements to make vehicles more energy efficient and fuels less carbon-intensive (see also Appendix A). Bakker et al. (2014) argue that, to bring the ASI approach closer to a practical guide to sustainable transport policy, "access" needs to be added to cover the positive impacts of transport as well as elements of sustainable lifestyles and transition thinking, the latter based on, e.g., Geels (2012). An analysis of transport transitions and experimentation concludes that in Thailand, sustainable transport niches do not (yet) challenge the dominant regime of motorisation (Sengers, 2016).

\subsection{Methodology and materials}

In carrying out the comparative policy analysis, we apply concepts of low-carbon transport policy and policy components based on Howlett and Cashore's taxonomy. It is noted that our interpretation is close to that of Marsden et al. (2012), although there are differences in operationalisation for some components, particularly the instrument logic.

Table 5.1 explains how we operationalise their framework for low-carbon transport policy, which will be used in Section 5.4. Goals are related to overall development objectives as well as those for the transport sector and are derived from visions in development plans and sectoral transport strategic documents. Objectives are more specific aims of transport policy as stated in transport strategies and plans. In addition, we consider as objectives the Nationally Determined Contributions (NDCs) submitted to the United Nations Framework Convention on Climate Change (UNFCCC, no date) in 2015. These include country-wide emission reduction targets and thereby can be seen as "meta-policy" objectives (Bache et al., 2014) that are relevant to the transport sector. The settings are the quantified targets related to those objectives. While there is often a plethora of such targets, we selected those directly or indirectly related to climate change mitigation (if available): GHG 
emission reduction, public transport modal share, energy efficiency, renewable or alternative energy or energy diversification, and limitation of motorisation.

Table 5.1 A taxonomy of policy components, with examples for low-carbon transport (adapted from Howlett \& Cashore, 2009)

\begin{tabular}{|c|c|c|c|c|}
\hline & & \multicolumn{3}{|l|}{ Policy Content } \\
\hline & & High-Level Abstraction & $\begin{array}{l}\text { Programme Level } \\
\text { Operationalisation }\end{array}$ & $\begin{array}{l}\text { Specific on-the-Ground } \\
\text { Measures }\end{array}$ \\
\hline \multirow{13}{*}{$\begin{array}{l}\text { Policy } \\
\text { focus }\end{array}$} & \multirow{5}{*}{$\begin{array}{l}\text { Policy } \\
\text { ends } \\
\text { or } \\
\text { aims }\end{array}$} & Goals & Objectives & Settings \\
\hline & & $\begin{array}{l}\text { What general types of ideas } \\
\text { govern policy } \\
\text { development? }\end{array}$ & $\begin{array}{l}\text { What does policy } \\
\text { formally aim to address? }\end{array}$ & $\begin{array}{l}\text { What are the specific on- } \\
\text { the-ground requirements of } \\
\text { policy? }\end{array}$ \\
\hline & & $\begin{array}{l}\text { Protection of the } \\
\text { environment }\end{array}$ & $\begin{array}{l}\text { Increase public } \\
\text { transport ridership }\end{array}$ & $\begin{array}{l}\text { Per cent or quantity of } \\
\text { GHG reduced in the }\end{array}$ \\
\hline & & $\begin{array}{l}\text { People-oriented transport } \\
\text { system }\end{array}$ & $\begin{array}{l}\text { Increase energy- } \\
\text { efficiency }\end{array}$ & $\begin{array}{l}\text { transport sector by year } \mathrm{x} \\
\text { compared to baseline }\end{array}$ \\
\hline & & & Save GHG emissions & $\begin{array}{l}\text { Modal share target for } \\
\text { public transport }\end{array}$ \\
\hline & \multirow{8}{*}{$\begin{array}{l}\text { Policy } \\
\text { means } \\
\text { or } \\
\text { tools }\end{array}$} & Instrument logic & Mechanisms & Calibrations \\
\hline & & $\begin{array}{l}\text { What general norms guide } \\
\text { implementation } \\
\text { preferences? }\end{array}$ & $\begin{array}{l}\text { What specific types of } \\
\text { instruments are } \\
\text { utilised? }\end{array}$ & $\begin{array}{l}\text { What are the specific ways } \\
\text { in which the instrument is } \\
\text { used? }\end{array}$ \\
\hline & & $\begin{array}{l}\text { Behaviour change } \\
\text { Primacy of economic } \\
\text { growth }\end{array}$ & $\begin{array}{l}\text { Investing in public } \\
\text { transport infrastructure } \\
\text { Electronic road pricing }\end{array}$ & $\begin{array}{l}\text { Introduction of Euro } 6 \\
\text { emission standards for new } \\
\text { cars }\end{array}$ \\
\hline & & Limit motorisation & Vehicle fuel efficiency & Free public transport before \\
\hline & & Decentralisation & standard & $7.15 \mathrm{am}$ \\
\hline & & $\begin{array}{l}\text { Preference for cooperation } \\
\text { with private sector }\end{array}$ & & $\begin{array}{l}\text { Annual budgets for } \\
\text { transport infrastructure }\end{array}$ \\
\hline & & Use of & & \\
\hline & & Avoid-Shift-Improve & & \\
\hline
\end{tabular}

The instrument logic is based on two aspects. First, we look at specific features or aspects in strategic policy documents that could be indicative of the background of policy directions, such as those related to vehicle manufacturing industry development and mentioning of "lifestyle" issues. It is noted that there may be a subjective element here, and our data are not necessarily comprehensive. Second, we consider the use of ASI as a policy framework in strategic documents: it can be argued that its use — explicitly or implicitly in the instruments being deployed—may indicate an understanding with policymakers that a comprehensive approach to sustainable transport including changing behaviour is required. For mechanisms and specific instruments, we use a comprehensive inventory (explained below) of lowcarbon transport policies and measures in each country as organised in the ASI framework. We also examine if and how countries are making use of international climate change instruments for the transport sector, in particular nationally appropriate mitigation actions (NAMAs), the Clean Technology Fund of the World Bank and other multilateral development banks, and the carbon trading instrument 
Clean Development Mechanism (see Chapter 3). Finally, as we cannot cover calibrations for all low-carbon transport measures, we provide examples for three types of measures that are important for climate change mitigation, but that are differently used across the four countries: specific measures in transport demand management, promotion of cycling and fuel economy of new vehicles.

The choice of the four countries is based on three sets of considerations, starting from the observation that sustainable transport policy in Southeast Asia is an underresearched topic yet relevant e.g., based on the ASEAN Transport Strategic Plan (ASEAN, 2016a). First, the countries constitute four of the five largest transport sector GHG emitters of the region (Bakker, forthcoming). Second, they have characteristics that set them apart from many other countries-particularly North America and Europe-including rapid motorisation, lower current urbanisation but rapid growth of megacities, higher urban density, importance of informal transport sector including paratransit, high modal share of motorcycles, inadequate and hierarchically unbalanced infrastructure, high but decreasing share of public transport (except Vietnam), lower government revenue and lack of private sector financing, and weak land-use control (Morichi \& Acharya, 2013). Third, they have differences amongst them in other aspects including culture, economic development, economy structure, governance systems, geography and roles of actor groups. These could help in explaining differences that may be found (see also Section 5.5). In addition, a more practical consideration was that data on policy development in these countries were readily available to the author team.

Table 5.2 shows a set of indicators that help describe the context of transport and climate change policy in the four countries, using secondary data from a range of sources. Out of a larger set of possible indicators, we have limited ourselves to those that provide key information on the transport system, particularly related to climate change, and those that are arguably relevant in explaining differences between countries. 
Table 5.2 Selected country indicators

\begin{tabular}{|c|c|c|c|c|c|c|c|}
\hline & Unit & Source & Year & Indonesia & Philippines & Thailand & Vietnam \\
\hline Population & million & $\mathrm{a}$ & 2015 & 257.5 & 100.7 & 68.0 & 91.7 \\
\hline GDP growth & $\% / a$ & a & $\begin{array}{l}2012- \\
2015\end{array}$ & $5.4 \%$ & $6.4 \%$ & $3.4 \%$ & $5.8 \%$ \\
\hline GDP/capita & USD (PPP) & $\mathrm{a}$ & 2015 & 10,385 & 6926 & 15,345 & 5668 \\
\hline Urbanisation & $\%$ & a & 2015 & $51.4 \%$ & $44.4 \%$ & $50.4 \%$ & $33.6 \%$ \\
\hline $\begin{array}{l}\mathrm{CO}_{2} \text { emissions } \\
\text { from transport }\end{array}$ & $\mathrm{Mt}$ & $\mathrm{b}, \mathrm{c}$ & 2010 & $\begin{array}{l}121.4^{\mathrm{b}} \\
(2012)\end{array}$ & $23-36^{c}$ & $61.1^{b}$ & $28.0^{b}$ \\
\hline $\begin{array}{l}\mathrm{tCO}_{2} / \text { capita } \\
\text { (transport) }\end{array}$ & tonnes & & 2010 & $0.49(2012)$ & $0.25-0.4$ & 0.91 & 0.32 \\
\hline Motorisation index & $\begin{array}{l}\text { \#vehicles/ } \\
1000 \text { capita }\end{array}$ & d,e,f & 2010 & $344^{\mathrm{f}}$ & $75 \mathrm{e}$ & $310^{d}$ & $364 \mathrm{~d}$ \\
\hline $\begin{array}{l}\text { Annual passenger } \\
\text { vehicle fleet growth }\end{array}$ & $\%$ & $\mathrm{~d}, \mathrm{e}, \mathrm{f}$ & $\begin{array}{l}2000- \\
2010\end{array}$ & $10.4 \mathrm{f} \%$ & $6 \mathrm{e} \%$ & $8 \mathrm{e} \%$ & $16 \mathrm{~d} \%$ \\
\hline $\begin{array}{l}\text { Share two-wheelers } \\
\text { in passenger vehicle } \\
\text { fleet }\end{array}$ & & $\mathrm{d}, \mathrm{g}$ & 2012 & $87 \mathrm{~d} \%$ & $55 \mathrm{~g} \%$ & $61 \mathrm{~g} \%$ & $95 \mathrm{~d} \%$ \\
\hline $\begin{array}{l}\text { Domestic } \\
\text { car/motorcycle } \\
\text { production } \\
\end{array}$ & $\begin{array}{l}\text { Million } \\
\text { units/annum }\end{array}$ & $\mathrm{h}$ & 2015 & $1.1 / 5.7$ & $0.1 / 0.8$ & $1.9 / 1.8$ & $0.2 / 2.9$ \\
\hline $\begin{array}{l}\text { Fuel prices } \\
\text { (diesel/petrol) }\end{array}$ & USD/litre & i & 2014 & $0.80 / 0.93$ & $0.82 / 1.05$ & $0.90 / 1.29$ & $0.91 / 1.04$ \\
\hline
\end{tabular}

The lowest and highest per capita incomes differ by a factor of three, yet all countries are rapidly motorising - in line with global trends for vehicle ownership in low and middle-income countries (Dargay et al., 2014). The growth rate for cars is higher than for motorcycles, however the latter still dominate the vehicle fleets. It could be expected that the share of motorcycles will decrease over time as income levels grow (Nishitateno \& Burke, 2014). Thailand has the highest rate of passenger cars per 1000 inhabitants, of which a significant share are domestically manufactured pickups with relatively low fuel efficiency as compared to sedans (Kijmanawat et al., 2016), which explains the relatively high per capita transportation emissions. Biofuel blending targets are present in all countries for biodiesel and/or ethanol (Mofijur et al., 2015).

The data used in the analysis in Section 5.4 were collected through a literature survey and studying the contents and context of national and local policy documentsmany of which in the local language_-as well as through semi-structured interviews (Bryman, 2016) with key informants. Five interviews with policymakers from the four Ministries/Departments of Transport and two with transport researchers were held on the sidelines of various transport workshops and meetings. The interviews provided insights into the institutional structure, the development of policy 
documents, as well the role of different policy objectives, including climate change mitigation, in policy development. Feedback from policymakers and academics was gathered in workshops and in writing, and draft results were discussed in a workshop with representatives from all four countries. The results are included in four country studies, named Stocktaking Reports on Sustainable Transport and Climate Change for Indonesia (Purwanto et al., forthcoming), the Philippines (Mejia et al., 2016), Thailand (Narupiti et al., 2014) and Vietnam (Dematera et al., 2015). These studies review the existing sustainable transport policy framework and key policy documents and related sources that include strategies, policies or measures with a direct or indirect impact on energy use and $\mathrm{CO}_{2}$ emissions from transport, resulting in an inventory of policies and measures for each country, organised along the ASI approach (see Appendix A). For Thailand and Vietnam, additional literature and policies that were developed since publication of the Stocktaking Reports in 2014 and 2015 were reviewed for this article.

\subsection{Results: low-carbon transport policy components}

In Table 5.3, we provide an overview of policy components related to sustainable (passenger) transport and climate change mitigation for the four countries, following the methodology introduced in Section 5.3. When policy components are relatively similar for all four countries, we use merged cells. As noted in Section 5.2, sustainable transport is a wider concept than just low-carbon transport. However, most measures taken to promote sustainable transport will reduce greenhouse gas emissions. We assume (confirmed in multiple interviews) that most of the policy ends and tools are developed by policymakers for local and national sustainable development objectives such as congestion reduction, efficiency, comfort, safety, rather than climate change. Therefore, for the analysis this paper it is deemed useful to consider sustainable transport policy.

Looking at the level of policy goals, we observe that sustainable transport appears to support various high-level national development goals, such as inclusive growth, sufficiency economy, people-oriented development. Visions in transport strategies acknowledge the need to be environmentally-friendly, and in some cases explicitly mention climate change or energy issues. In general, improving connectivity and transport infrastructure is the key goal in transport strategies, with "accessibility" included in policy documents in Thailand (Jaensirisak et al., 2016) and Indonesia.

Each country has a set of objectives for the transport sector, which include climate change mitigation explicitly for two countries, however indirectly, through other objectives such as increasing public transport and energy efficiency, all countries address low-carbon transport. The same is true for the settings: all countries have 
quantified targets related to sustainable transport (e.g., public transport modal share, energy self-sufficiency, GHG emission reduction); however, these targets are different in nature and in the way these are formulated. When considering the NDCs, which for all countries include quantified GHG emission reduction targets for 2030 compared to business-as-usual, we observe that the transport sector is included, even though the level of ambition and detail differs from a minor mention as part of the energy sector (Indonesia) to concrete actions (Vietnam) (Bakker, forthcoming).

In support of the NDCs (also part of settings), the Biennial Update Reports and overall climate change policy, countries are carrying out initial mitigation potential analysis and developing climate mitigation scenarios (e.g., for 2020 or 2030). In connection to these and other policy processes, stakeholder dialogues around the required, desirable and feasible changes in the transport systems, are held. However, a comprehensive approach going beyond incremental improvements appears to be lacking, and the scenarios are mostly based on existing policies, leading to emission savings compared to a reference scenario, but not yet in a stabilisation or absolute reductions in emissions. Long-term (e.g., 2050), ambitious scenarios to achieve deeper carbon reduction in line with global climate change goals (ITPS \& Clean Air Asia, 2014), and visions on what low-carbon transport should be and which technologies and changes in the transport systems are required, are not yet developed by national governments. The need for a "transition" or transformational change, and changes in behaviour and lifestyle are discussed in a limited fashion (e.g., in Vietnam). 
Table 5.3 Components of low-carbon transport policy in four ASEAN countries (status: end 2016)

\begin{tabular}{|c|c|c|c|c|c|}
\hline $\begin{array}{l}\text { Policy } \\
\text { Component }\end{array}$ & Operationalisation & Indonesia & Philippines & Thailand & Vietnam \\
\hline \multirow[t]{2}{*}{ Goals } & $\begin{array}{l}\text { Vision/theme in } \\
\text { medium term } \\
\text { development plan }\end{array}$ & $\begin{array}{l}\text { Realisation of an } \\
\text { Indonesia that is } \\
\text { prosperous, } \\
\text { democratic and just }\end{array}$ & $\begin{array}{l}\text { Pursuit of } \\
\text { inclusive growth }\end{array}$ & $\begin{array}{l}\text { A happy society } \\
\text { with equity, } \\
\text { fairness and } \\
\text { resilience under the } \\
\text { philosophy of a } \\
\text { Sufficiency } \\
\text { Economy }\end{array}$ & $\begin{array}{l}\text { A modern, } \\
\text { industrialised } \\
\text { country by } 2020\end{array}$ \\
\hline & $\begin{array}{l}\text { Visions relevant to } \\
\text { sustainable } \\
\text { transport }\end{array}$ & $\begin{array}{l}\text { "to develop transport } \\
\text { infrastructures which is } \\
\text { environmental friendly } \\
\text { and takes into account } \\
\text { carrying capacity } \\
\text { through climate change } \\
\text { mitigation and } \\
\text { adaptation as well as } \\
\text { improving safety and } \\
\text { quality of } \\
\text { environment"b }\end{array}$ & $\begin{array}{l}\text { To achieve "a } \\
\text { safe, secure, } \\
\text { efficient, viable, } \\
\text { competitive, } \\
\text { dependable, } \\
\text { integrated, } \\
\text { environmentally } \\
\text { sustainable and } \\
\text { people-oriented } \\
\text { Philippine } \\
\text { transportation } \\
\text { system."d }\end{array}$ & $\begin{array}{l}\text { An efficient } \\
\text { transport system } \\
\text { that is } \\
\text { environment- } \\
\text { friendly and } \\
\text { appropriate for the } \\
\text { development of } \\
\text { sufficient and } \\
\text { sustainable socio- } \\
\text { economic } \\
\text { infrastructure for } \\
\text { Thailand } \\
\end{array}$ & $\begin{array}{l}\text { Transport } \\
\text { Development } \\
\text { Strategy refers to } \\
\text { "modern and high- } \\
\text { quality system with } \\
\text { reasonable cost, } \\
\text { safety, reducing } \\
\text { environmental } \\
\text { pollution and } \\
\text { energy saving by } \\
\text { application of } \\
\text { advanced transport } \\
\text { technology, } \\
\text { especially multi- } \\
\text { modal } \\
\text { transportation and } \\
\text { logistics." }\end{array}$ \\
\hline Objectives & $\begin{array}{l}\text { Selected objectives } \\
\text { in transport sector } \\
\text { documents }\end{array}$ & $\begin{array}{l}\text { Reduce GHG } \\
\text { emissions; Promote } \\
\text { public transport and } \\
\text { multimodal transport; } \\
\text { create jobs; Limit the } \\
\text { growth of the } \\
\text { ownership and use of }_{\text {private vehicles }^{\text {b }}}\end{array}$ & $\begin{array}{l}\text { Fuel } \\
\text { diversification, } \\
\text { energy self- } \\
\text { sufficiency; } \\
\text { Promote public } \\
\text { transport }\end{array}$ & $\begin{array}{l}\text { Reduce GHG } \\
\text { emissions; Promote } \\
\text { public transport; } \\
\text { Increase energy } \\
\text { efficiency; } \\
\text { Promote electric } \\
\text { cars }\end{array}$ & $\begin{array}{l}\text { Limit motorisation; } \\
\text { Promote public } \\
\text { transport; Promote } \\
\text { renewable and } \\
\text { clean energy and } \\
\text { energy efficient } \\
\text { vehicles }\end{array}$ \\
\hline \multirow[t]{2}{*}{ Settings } & $\begin{array}{l}\text { Selected specific } \\
\text { targets in transport } \\
\text { plans and strategies }\end{array}$ & $\begin{array}{l}-\mathrm{CO}_{2} \text { reduction up to } \\
4.109 \mathrm{MtCO}_{2} \mathrm{e} \text { by } 2020 \\
\text { for land transport } \\
\text { (including rail) } \\
\text {-Modal share for } \\
\text { public transport in } \\
\text { mega-cities increased } \\
\text { to at least } 32 \%(2019)^{\mathrm{b}}\end{array}$ & $\begin{array}{l}\text {-Energy self- } \\
\text { sufficiency from } \\
59.6 \text { to } 60.3 \%{ }^{c} \\
-10 \% \text { energy } \\
\text { savings and } \\
\text { target }(30 \%) \text { for } \\
\text { alternative fuels } \\
\text { in public utility } \\
\text { vehicles by } 2030 \\
\text { (energy plan) }\end{array}$ & $\begin{array}{l}\text {-Reduce } 15-16 \\
\mathrm{MtCO}_{2} \text { by } 2020 \\
\text { from transport } \mathrm{f} \\
\text {-Modal share } \\
\text { targets for freight } \\
\text { and passenger } \\
\text {-Energy savings } \\
\text { target in energy } \\
\text { efficiency plan } \\
-1.2 \text { million electric } \\
\text { vehicles sold in } \\
2036 \\
\end{array}$ & $\begin{array}{l}-25-30 \% \text { mode } \\
\text { share target for } \\
\text { public transport by } \\
2020^{\mathrm{h}} \text {; } \\
-10 \% \text { of fuel from } \\
\text { clean and } \\
\text { alternative sources } \mathrm{h} \\
\text {-Restraint of } \\
\text { growth of private } \\
\text { vehicles to } 4 \\
\text { million cars and } 40 \\
\text { million motorcycles } \\
\text { by } 2020 \mathrm{~g} \\
\end{array}$ \\
\hline & & $\begin{array}{l}\text { Short (2020) to mediun } \\
\text { NDCs and other strate } \\
\text { long-term low-carbon }\end{array}$ & $\begin{array}{l}\text { n (2030) term quan } \\
\text { egies, however no c } \\
\text { transport has been }\end{array}$ & $\begin{array}{l}\text { ntitative scenarios are } \\
\text { comprehensive gover } \\
\text { found. }\end{array}$ & $\begin{array}{l}\text { e developed in the } \\
\text { mment scenario on }\end{array}$ \\
\hline $\begin{array}{l}\text { Instrument } \\
\text { logic }\end{array}$ & $\begin{array}{l}\text { Salient features of } \\
\text { plans and strategies }\end{array}$ & $\begin{array}{l}\text { Involvement of private } \\
\text { sector participation } \\
\text { and restructuring in the } \\
\text { business sectors in } \\
\text { accordance with the } \\
\text { demands of the } \\
\text { domestic market and } \\
\text { the global market as } \\
\text { well as in the spirit of } \\
\text { free trade }\end{array}$ & $\begin{array}{l}\text { National Climate } \\
\text { Change } \\
\text { Framework } \\
\text { Strategy calls to } \\
\text { "formally adopt a } \\
\text { socially equitable } \\
\text { and integrated } \\
\text { land-use and } \\
\text { transport }\end{array}$ & $\begin{array}{l}\text { EV promotion plan } \\
2015-2036 \text { includes } \\
\text { research, } \\
\text { development, } \\
\text { production and } \\
\text { incentives for } \\
\text { vehicles and } \\
\text { charging } \\
\text { infrastructure }\end{array}$ & $\begin{array}{l}\text { "greening lifestyle" } \\
\text { and promotion of } \\
\text { "thrifty energy } \\
\text { consumption of } \\
\text { citizens' lifestyles" h }\end{array}$ \\
\hline
\end{tabular}




\begin{tabular}{|c|c|c|c|c|c|}
\hline & & & $\begin{array}{l}\text { planning } \\
\text { processes" }\end{array}$ & & \\
\hline & $\begin{array}{l}\text { Use of ASI in } \\
\text { transport plans and }\end{array}$ & $\begin{array}{l}\text { ASI used as organising } \\
\text { dprinciple in the } 2010\end{array}$ & $\begin{array}{l}\text { ASI implicit in } \\
\text { measures in }\left(^{(}\right)\end{array}$ & $\begin{array}{l}\text { ASI mentioned in } \\
\left({ }^{(f)} \text { but not explicitly i }\right.\end{array}$ & $\begin{array}{l}\text { ASI explicitly used } \\
\text { in Environmentally }\end{array}$ \\
\hline & strategies & Sectoral Climate & & used & Sustainable \\
\hline & & Change Roadmap & & & Transport Strategy \\
\hline \multirow[t]{8}{*}{$\overline{\text { Mechanisms }}$} & Avoid & $\begin{array}{l}\text { Number plate } \\
\text { restrictions; Electronic } \\
\text { road pricing in } \\
\text { discussion }\end{array}$ & $\begin{array}{l}\text { Number plate } \\
\text { restrictions }\end{array}$ & $\begin{array}{l}\text { Several measures } \\
\text { being studied }\end{array}$ & $\begin{array}{l}\text { Vehicle restriction } \\
\text { measures in } \\
\text { discussion }\end{array}$ \\
\hline & & \multicolumn{4}{|c|}{$\begin{array}{l}\text { Parking management and land-use-transport integration limited; fuel prices } \\
\text { relatively low }\end{array}$} \\
\hline & Shift & $\begin{array}{l}\text { Greater Jakarta inter- } \\
\text { provincial transport } \\
\text { agency established }\end{array}$ & $\begin{array}{l}\text { Public transport } \\
\text { reform planned; } \\
\text { integrated } \\
\text { ticketing }\end{array}$ & $\begin{array}{ll}\text { Integrated } & 1 \\
\text { ticketing; Initial } \\
\text { cycling policies }\end{array}$ & $\begin{array}{l}\text { Bus management } \\
\text { reform in Hanoi } \\
\text { and Ho Chi Minh } \\
\text { City (HCMC) } \\
\end{array}$ \\
\hline & & \multicolumn{4}{|c|}{$\begin{array}{l}\text { Rail (urban and inter-urban) and bus rapid transit being developed; non- } \\
\text { motorised transport (NMT) not prioritised }\end{array}$} \\
\hline & Improve & $\begin{array}{l}\text { Incentives for small } \\
\text { cars }\end{array}$ & $\begin{array}{l}\text { Electric jeepney } \\
\text { programme }\end{array}$ & $\begin{array}{ll}\text { Fuel economy } & \text { l } \\
\text { incentives; EV } & 1 \\
\text { production } & \\
\text { promotion } & \end{array}$ & $\begin{array}{l}\text { Fuel economy } \\
\text { policies }\end{array}$ \\
\hline & & \multicolumn{4}{|c|}{$\begin{array}{l}\text { Biofuel blending targets; alternative fuels for public and informal transport; Euro } \\
\text { standards for vehicles and fuels } \\
\text { Missing: promotion of electric two-wheelers, hybrid buses }\end{array}$} \\
\hline & $\begin{array}{l}\text { International } \\
\text { climate change } \\
\text { instruments }\end{array}$ & $\begin{array}{l}\text { NAMA: sustainable } \\
\text { urban transport } \\
\text { programme }\end{array}$ & $\begin{array}{l}\text { NAMA: } \\
\text { improvement of } \\
\text { public transport } \\
\text { system and } \\
\text { vehicles; CTF: } \\
\text { electric jeepneys }\end{array}$ & $\begin{array}{ll}\text { NAMA: urban } \\
\text { public and non- } \\
\text { motorised } \\
\text { transport }\end{array}$ & $\begin{array}{l}\text { NAMA: promotion } \\
\text { of low-carbon } \\
\text { buses and public } \\
\text { transport } \\
\text { improvement; CTF } \\
\text { co-finances metro } \\
\text { in Hanoi }\end{array}$ \\
\hline & & \multicolumn{4}{|c|}{ No Clean Development Mechanism projects in transport } \\
\hline \multirow[t]{3}{*}{$\begin{array}{l}\text { Calibrations } \\
\text { (examples) }\end{array}$} & $\begin{array}{l}\text { Transport Demand } \\
\text { Management }\end{array}$ & $\begin{array}{l}\text { dOdd-even number } \\
\text { plate scheme in Jakarta }\end{array}$ & $\begin{array}{l}\text { Prohibition of } \\
\text { vehicles based on } \\
\text { last digit of } \\
\text { number plate for } \\
\text { certain week-days } \\
\text { week in Manila }\end{array}$ & $\begin{array}{l}\text { Transit-oriented } \\
\text { development } \\
\text { piloted in Bangkok }\end{array}$ & $\begin{array}{l}\text { Congestion pricing } \\
\text { scheme in HCMC } \\
\text { under discussion }\end{array}$ \\
\hline & Cycling & $\begin{array}{l}\text { Weekly car-free day in } \\
\text { multiple cities; limited } \\
\text { infrastructure }\end{array}$ & $\begin{array}{l}\text { Weekly car-free } \\
\text { day in Pasig City } \\
\text { in Metro Manila; } \\
\text { limited bike lane } \\
\text { construction }\end{array}$ & $\begin{array}{l}\text { Budget (USD 50 } \\
\text { million) for bike } \\
\text { lanes in 2015; bike } \\
\text { sharing system; } \\
\text { road design } \\
\text { guidelines }\end{array}$ & $\begin{array}{l}\text { No policy } \\
\text { implemented yet }\end{array}$ \\
\hline & $\begin{array}{l}\text { Fuel economy of } \\
\text { new carsi }\end{array}$ & $\begin{array}{l}\text { Low Cost Green Car } \\
\text { Program: zero luxury } \\
\text { sales tax for }<1200 \mathrm{cc} \\
\text { vehicles with } 20 \\
\mathrm{~km} / \text { litre or } 128 \\
\mathrm{gCO}_{2} / \mathrm{km}\end{array}$ & $\begin{array}{l}\text { Labelling scheme } \\
\text { planned; fuel } \\
\text { efficiency } \\
\text { standards and } \\
\text { incentives } \\
\text { proposed }\end{array}$ & $\begin{array}{l}\text { Labelling; } \mathrm{CO}_{2^{-}} \\
\text {based excise tax } \\
\text { (pick-ups } \\
\text { excluded); } \\
\text { incentives for "eco- } 1 \\
\text { cars" ( }<23 \mathrm{~km} / \mathrm{L})\end{array}$ & $\begin{array}{l}\text { Labelling and } \\
\text { voluntary standards } \\
\text { based on vehicle } \\
\text { weight classes in } \\
\text { place, mandatory } \\
\text { standard planned }\end{array}$ \\
\hline
\end{tabular}

a OECD (2013); b Medium and long-term development plans of the Ministry of Transport Indonesia; ${ }^{\mathrm{c}}$ National action plan on GHG (RAN-GRK); d Philippine Development Plan; e National Implementation Plan for environmentally sustainable transport (DOTC, 2016); ${ }^{\mathrm{f}}$ Master Plan for Sustainable Transport and Climate Change (Thailand); g Transport Development Strategy (Vietnam); ${ }^{\text {h }}$ Green Growth Strategy (Vietnam); ${ }^{\text {T Transport-NAMA }}$ Database; i Hygge \& Mahalana (2016); other sources are the Stocktaking Reports for each country. ASI avoid-shift-improve; EV: electric vehicles; CTF: Clean Technology Fund. 
In terms of the instrument logic, it should first be noted that, to improve sustainability in the transport sector, a large set of policies and measures can be deployed (see Appendix A). Indeed, we find that the four countries are using or considering the majority of these options, which cover economic (including public investments), regulatory (including planning) and information instruments. In many cases, a combination of instruments is used to achieve a similar objective such as improving vehicle energy efficiency. Further research would be required to be able to draw conclusions on long-term preferences for types of instruments, if at all such statements are possible for the transport sector as a whole. That said, some initial observations may include that the government aims to play a role in behaviour change and limiting motorisation in Vietnam and Indonesia, and in the Philippines with the number coding scheme. The electric vehicle roadmap in Thailand, which focuses predominantly on the vehicle production side, could be indicative of the key role of economic development versus other policy drivers. We should note however that these are merely examples, and it cannot be concluded that in the other countries the situation is fundamentally different. In relation to this, the absence or relatively low level of fuel taxes for both petrol and diesel for all countries could be seen as a sign that limiting the use of private vehicles is considered difficult or not necessarily a shared objective among stakeholders. In the instrument logic component, we also look at the ASI approach, which is used explicitly in policy documents on environmentally sustainable transport or climate change in two countries, however it does not appear in the main transport development strategies. ASI therefore may not play a major role as a policy concept yet. As it has only become well-known in recent years (Bakker et al., 2014), it would be premature to draw conclusions from this observation. Nevertheless, all four countries are developing or implementing measures in each of the ASI categories.

When looking at the mechanisms, many of the Shift and Improve policies included in ITPS \& Clean Air Asia (2014) are being developed and implemented in the four countries, even if not yet sufficient in ambition. The Avoid policies such as transitoriented development, road pricing, parking and vehicle restrictive policies are essential in meeting long-term targets (ITPS \& Clean Air Asia, 2014), however are in an early stage of development or missing. In this context, Han (2010) also notes that "fast developing countries are at a crossroad in transport policy development", and current policies may not be sufficient to avoid a lock-in into high-carbon, unsustainable transport based on individual motorised transport.

There are also notable differences in calibrations, e.g., for fuel economy policies, with Vietnam (labelling and standards) and Thailand ( $\mathrm{CO}_{2}$-based vehicle excise tax) having more advanced policies than the other two countries. On the other hand, 
Philippines and Indonesia employ transport demand management such as number plate-based vehicle restrictive measures.

A final observation concerns institutional development in connection to transport and climate change. This is an aspect that may not fit in well with Howlett and Cashore's taxonomy that focuses on policy content, however could be indicative of the development of policy ideas (Howlett et al., 2009) and thereby relevant for lowcarbon transport policy. In response to climate change and other environmental issues, all four countries have set up specific institutions in their ministries of transport. These include climate change and sustainable transport committee (Thailand), a transport technical working group in the climate change council (the Philippines), a Department of Environment (Vietnam), a Center for Sustainable Transport Management (Indonesia) and an Environmentally Sustainable Transport Unit (the Philippines). Even though the number of full-time staff is currently limited (eleven in Vietnam for example, in the other countries fewer), emergence of these institutions shows the growing relevance of climate change in transport policy.

\subsection{Discussion}

In this section, we first reflect on the methodology and then consider explanatory factors related to the findings in the comparative analysis. Application of the policy component taxonomy of Howlett and Cashore to sustainable transport policy was possible after interpreting and operationalising it for our purpose, and yields insights into similarities and differences between ASEAN countries. Its benefit lies in the consideration of multiple components relevant for policy, which may not have become apparent without using it. For example, we could observe that the components of sustainable transport policy at the level of policy ends (goals, objectives, settings) are not consistently matched with the currently applied tools (instrument logic, mechanisms, calibrations) to achieve these.

We however note several methodological challenges as well. First, tackling climate change in the transport sector is a complex problem and requires simultaneous implementation of policies and measures in the realm of mobility (Avoid and Shift) on the one hand, and vehicles and fuels (Improve) on the other. All of these can be taken with a view to a wide range of different policy objectives (see Table 5.3), with climate change mitigation being only one of them. Assessing the current situation in a comprehensive manner, and assessing progress in the future, is therefore challenging. This is particularly the case when describing the mechanisms and the calibrations, for which we could only show three examples out of a much larger set of options, due to space limitations. Dupuis \& Biesbroek (2013) appear to suggest a similar approach-i.e., based on selected examples—for assessing policy change in 
climate change adaptation. Second, the presence of long-term quantitative scenarios for low-carbon transport was considered in connection to "settings", however this could also be seen as being part of "goals". Third, assessing the instrument logic poses methodological challenges and since our data are limited and we chose to report specific examples from each country, implying a level of subjectivity. Finally, we consider institutional development specifically for sustainable transport and climate change a relevant aspect of policy even if not a component of policy content per se.

The framework offered by Howlett and Cashore is useful for taking stock of sustainable transport policies in the four countries, however their categorisation does not explain the content and character of those policies nor differences between the countries. Although not a core aim of this article, we will now explore possible explanatory factors for the trends and differences found between the four countries. We will do so in an inductive way, i.e., starting from our research findings we will flag up possible explanatory factors and suggest links to the broader literature. It is duly noted this is rather challenging due to the complex array of factors influencing transport policy, the large number of possible options in the sector, as well as our data limitations. A more systematic explanatory analysis is beyond the scope of this paper.

When it comes to fuel economy policy instruments and calibrations (see Table 5.3), different approaches appear to exist in countries with (Thailand and Indonesia) and without (Vietnam and Philippines) a large domestic car manufacturing industry (see Table 5.2). Vietnam was the first country to implement labelling for all new passenger cars, while Thailand and Indonesia provide incentives for smaller cars and Thailand exempts larger pickups from the incentive scheme, which benefits domestic manufacturers. "Limiting motorisation" as a policy objective and/or implementation of vehicle restriction measures was found in three countries, although the relatively low fuel taxes (calibration), found in all four countries, may not support this objective. While no firm causal relationship can be established from our data, we could theorise that policy coherence (Bache et al., 2014; Kivimaa \& Virkamäki, 2014), i.e., the use of policy means and tools based on consideration of different and potentially conflicting (Purwanto et al., forthcoming) policy ends and aims (see Tables 5.1 and 5.3), may be a factor influencing transport policy instruments and calibrations. In other countries, "industry promotion" was also found (e.g., in Vietnam, based on interview) to be a policy objective. As Kivimaa \& Virkamäki (2014) note, "established regimes not only for transport but for energy and industry, i.e., multi-regime interaction" are relevant to low-carbon transitions, which require coherence in policies in different sectors. 
Local stakeholders are also relevant factors. For example, non-motorised transport policies such as those for cycling appear to be more developed in Thailand and the Philippines, in the development of which an advocacy role for civil society groups was observed (Bakker et al., 2017b), although in transport policy development in general non-governmental organisations are important in Indonesia as well (Purwanto et al., forthcoming). Aside from local stakeholders, international organisations and processes such as ASEAN meetings, UNFCCC conferences and the UNCRD Environmentally Sustainable Transport Forum are likewise relevant. Such meetings (according to three interviews with policymakers) appear to influence policymakers in transport agencies who develop strategies and action plans. Howlett et al. (2009) consider them policy entrepreneurs by their way of using policy windows to put issues on the policy agenda. Whether other factors, such as cultural values and orientations (Okma et al., 2010), political systems and decision-making processes (Howlett et al., 2009), income levels and professionalism of legislature (Berry \& Berry, 2007) are relevant in low-carbon transport policy development would require more analysis. In such research, the design should include a list of possible factors and clearly defined policy outcomes as the dependent variable.

In addition, we consider to what extent climate change objectives are relevant for transport policy. In all countries, we observe that the transport sector is included in climate change action plans as one of the key sectors that should contribute to the national mitigation objectives as included in the NDCs. As to the question whether climate change objectives have a real impact on transport policy development and implementation, i.e., whether it is symbolic (Dupuis \& Biesbroek, 2013), there is evidence from one country (Indonesia, based on interviews) that the climate change objectives and sectoral action plans provide additional arguments or drivers for national and local transport policies, i.e., it can create new windows for policy entrepreneurs to influence the transport policy agenda. For other countries, we could not find direct indications for such windows. In all four countries, mitigation actions (NAMAs) are developed in the transport sector, however none of these are implemented yet, hence no impact on transport policy can be observed yet. Therefore, although we consider it possible that climate change mitigation is more than a "symbolic" meta-policy, more research is required to test this hypothesis.

\subsection{Conclusions}

Countries in Southeast Asia are experiencing rapid growth in motorisation and associated negative impacts on congestion, air quality, road safety, energy security, urban liveability, and greenhouse gas emissions. To be compatible with sustainable development and climate change objectives, significant change is required. This 
article has shed light on the policy developments in four ASEAN countries in this context: Indonesia, the Philippines, Thailand and Vietnam. When looking at the current transport system, the countries are relatively comparable in some aspects such as the importance of motorcycles and vehicle fleet growth rates, while there are substantial differences in motorisation levels and per capita transport $\mathrm{CO}_{2}$ emissions. These can only partially be explained by the variation in income levels.

When looking at the current status of policies on sustainable transport and climate change, we found several common elements across the four countries. First, at the level of policy ends, each country has a set of goals, objectives and specific targets or settings in policy plans and strategies that support sustainable transport, and, directly or indirectly, climate change mitigation. Second, looking at the component of policy mechanisms, all four countries are active in development of nationally appropriate mitigation actions in the transport sector. In the realm of transport demand management and "Avoid" strategies, policies and measures are in an early stage of development or absent. Shift and Improve measures are generally more developed. Third, the policy ends are not always consistently matched with the policy tools.

There are notable differences as well: (i) a policy objective to limit motorisation was only found in two countries, while the others do not address this explicitly; (ii) as part of the instrument logic, the Avoid-Shift-Improve approach is used in transport policy documents in two countries, however as yet it does not appear to have major importance as a framework to structure and develop policies; and (iii) with regard to policies to improve vehicle fuel efficiency, the use of different policy mechanisms and their calibrations vary strongly from one country to the other.

Although climate change mitigation is generally of lower concern for transport policymakers compared to improving efficiency of the transport system and reducing local impacts, we found significant attention to the climate change agenda. First, climate change is addressed in key transport policy documents and is becoming relevant as a policy driver; and, vice versa, transport plays a role in climate change policies. Second, institutions are being set up to specifically deal with transport and climate change. Finally, our policy review also shows that a range of ASI policies are being discussed, developed or implemented, which could result in significant emission savings compared to business as usual. However, stabilisation or an absolute reduction in GHG emissions from transport is not likely in the near future, nor are long-term plans in place that enable a transition to climate-compatible transport development. 
With regard to policy research, we found that applying the taxonomy of policy components of Cashore and Howlett can readily be applied to structure the comparative policy on sustainable transport in ASEAN countries. The analysis results in relevant insights into similarities and differences in policy emphasis. Future research using this framework could be carried out to observe changes in low-carbon transport policy, both at the national and urban level. Other research topics include the role of institutional development and transport policymaking process. Finally, it would be relevant to know how climate change can be better reflected in and used as a driver for transport policy would be relevant in connection to the transformational change required in transport policy in order to meet long-term climate change objectives. 
Appendix A. Reference table for ASI policies and measures analysis, as used in Stocktaking Reports

\begin{tabular}{|c|c|c|c|c|c|}
\hline & $\begin{array}{l}\text { Policy Instrum } \\
\text { Type }\end{array}$ & tPolicy/Measure & Strategy & $\begin{array}{l}\text { Policy Instrumer } \\
\text { Type }\end{array}$ & tPolicy/Measure \\
\hline \multirow[t]{3}{*}{ Avoid } & Infrastructure & Telecommunications & Improve & Economic & $\begin{array}{ll}\mathrm{CO}_{2} \text { based vehicle } \\
\text { taxation }\end{array}$ \\
\hline & Information & Telecommuting & & Economic & $\begin{array}{l}\text { Tax rebates for efficient } \\
\text { vehicles }\end{array}$ \\
\hline & Regulatory & $\begin{array}{l}\text { Transport-land use } \\
\text { planning integration }\end{array}$ & & Regulatory & $\begin{array}{l}\text { Import restrictions for } \\
\text { inefficient vehicles }\end{array}$ \\
\hline \multirow[t]{9}{*}{ Avoid, shift } & Regulatory & $\begin{array}{l}\text { Transit-oriented } \\
\text { development }\end{array}$ & & Economic & Vehicle scrapping \\
\hline & Economic & Parking pricing & & Regulatory & $\begin{array}{l}\text { Fuel economy } / \mathrm{CO}_{2} \\
\text { emission standard }\end{array}$ \\
\hline & Regulatory & $\begin{array}{l}\text { Reduce available parking } \\
\text { space }\end{array}$ & & Regulatory & $\begin{array}{ll}\text { Inspection } & \text { and } \\
\text { maintenance } & \end{array}$ \\
\hline & Economic & $\begin{array}{l}\text { Road pricing, congestion } \\
\text { charging }\end{array}$ & & $\overline{\text { Regulatory }}$ & $\begin{array}{l}\text { Speed limits/speed } \\
\text { management }\end{array}$ \\
\hline & Regulatory & $\begin{array}{l}\text { Vehicle use restrictions } \\
\text { (e.g., number plate } \\
\text { schemes) }\end{array}$ & & Regulatory & Low-emission zones \\
\hline & Regulatory & Vehicle sales limits & & Information & Eco-driving \\
\hline & Regulatory & $\begin{array}{l}\text { Traffic calming, access } \\
\text { restrictions }\end{array}$ & & Information & Car labelling \\
\hline & Regulatory & $\begin{array}{l}\text { High-occupancy vehicle } \\
\text { lanes }\end{array}$ & & Regulatory & Traffic management \\
\hline & Regulatory & Street design standards & & Economic & $\mathrm{EV}$ tax incentives \\
\hline \multirow[t]{17}{*}{ Shift } & Infrastructure & Bike sharing & & Economic & Hybrid vehicle incentives \\
\hline & Regulatory & $\begin{array}{l}\text { NMT friendly building } \\
\text { regulations }\end{array}$ & & Economic & $\begin{array}{ll}\text { Electric } & \text { two-wheeler } \\
\text { incentives } & \\
\end{array}$ \\
\hline & Regulatory & $\begin{array}{l}\text { Design standards for } \\
\text { intermodal integration }\end{array}$ & & Economic & EV programmes \\
\hline & Information & $\begin{array}{l}\text { Real-time public } \\
\text { transport information }\end{array}$ & & Economic & Biofuel incentives \\
\hline & Information & $\begin{array}{l}\text { Campaigns promoting } \\
\text { public transport/NMT }\end{array}$ & & Economic & CNG/LPG incentives \\
\hline & Regulatory & $\begin{array}{l}\text { Master planning for } \\
\text { public transport/NMT }\end{array}$ & & Regulatory & Emission standards \\
\hline & Regulatory & Bus route optimisation & & Information & Clean vehicle campaigns \\
\hline & Regulatory & Bus management reform & & Infrastructure & Charging infrastructure \\
\hline & Infrastructure & $\begin{array}{ll}\text { Bus } & \text { prioritisation } \\
\text { measures } & \\
\end{array}$ & & Regulatory & $\begin{array}{ll}\text { Biofuel } & \text { blending } \\
\text { standards } & \\
\end{array}$ \\
\hline & Regulatory & Integrated ticketing & & Economic & $\begin{array}{ll}\text { Fleet } & \text { renovation } \\
\text { programme } & \\
\end{array}$ \\
\hline & Infrastructure & NMT infrastructure & & Economic & $\begin{array}{ll}\text { Clean bus fleet } \\
\text { programmes }\end{array}$ \\
\hline & Infrastructure & Park and ride & $\begin{array}{l}\text { Avoid, } \\
\text { improve }\end{array}$ & shift,Infrastructure & $\begin{array}{ll}\text { Intelligent } & \text { transport } \\
\text { systems } & \\
\end{array}$ \\
\hline & Infrastructure & Urban rail infrastructure & & Economic & $\begin{array}{l}\text { Fuel taxation/subsidy } \\
\text { reduction }\end{array}$ \\
\hline & Infrastructure & Bus rapid transit & & Economic & Vehicle taxation \\
\hline & Infrastructure & Inter-urban rail & & & \\
\hline & Infrastructure & High-speed rail & & & \\
\hline & Economic & $\begin{array}{lll}\begin{array}{l}\text { Public } \\
\text { policy }\end{array} & \text { transport fare } \\
\end{array}$ & & Source: Authors & \\
\hline
\end{tabular}




\section{Chapter 6}

\section{Hot or not? The role of cycling in ASEAN megacities: case studies of Bangkok and Manila*}

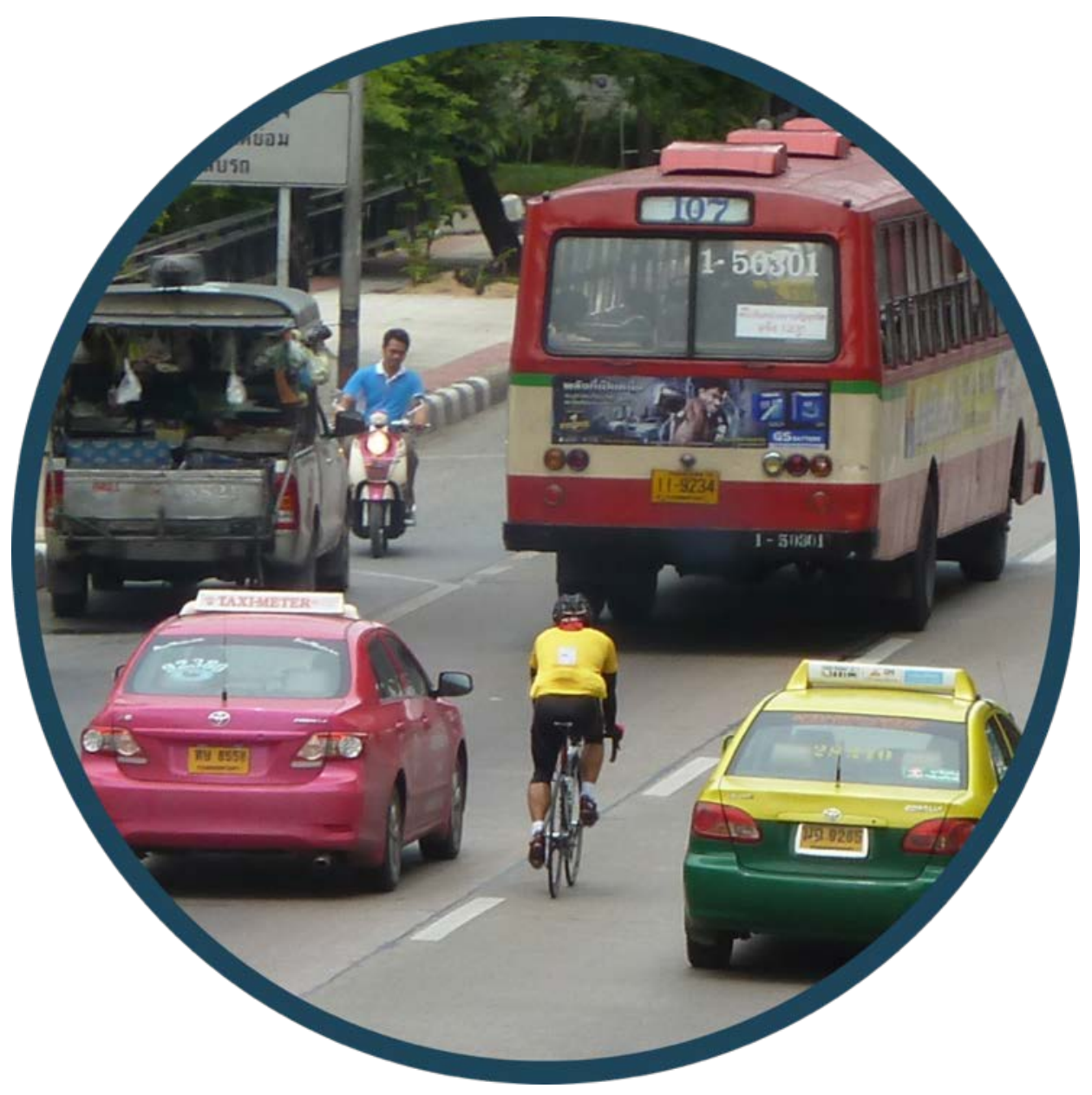

${ }^{*}$ Published as: Bakker, S., M.D. Guillen, P. Nanthachatchavankul, M. Zuidgeest, C. Pardo, M. van Maarseveen (2017) Hot or not? The role of cycling in ASEAN megacities: case studies of Bangkok and Manila. International Journal of Sustainable Transportation, online 4 October 2017 


\section{Abstract}

The Association of the Southeast Asian Nations (ASEAN) recognises the role of non-motorised transport for sustainable urban development in its policy framework. National and local policymakers in Thailand and The Philippines, two tropical countries without a tradition of urban cycling, are increasingly paying attention to cycling as well. This article aims to assess the current situation and progress in cycling, using Bangkok and Metropolitan Manila as case study cities, and to describe the necessary conditions for advancing the significance of cycling in tropical megacities. This is done by operationalising the so-called Technological Innovation Systems (TIS) framework, which has been used in transition studies since 2008, however never for cycling. As such this article also 'tests' this framework for its application in sustainable transportation. The two case studies are characterised with regards to the current role of cycling in the mobility system, its infrastructure, governance system and existing research on the potential and barriers. Although not a perfect fit, we find that TIS can be applied to our cases, with the analysis showing that elements such as knowledge development, actor networks, e-bike adoption, infrastructure, resource mobilisation and legitimation are not well developed; on the other hand, flat terrain, attention for cycling for health and environment, heavy congestion, expansion of public transport, growing bike industry, active university communities, and the emergence of advocacy coalitions, could open up opportunities for increasing its modal share. 


\subsection{Introduction}

Within the policy framework of the Association of South-East Asian Nations (ASEAN), non-motorised transport (NMT) such as walking and cycling is recognised as an important component in the context of sustainable urban mobility and health. In the road safety/physical activity programme of work, the Regional Action Plan on Healthy ASEAN Lifestyles (ASEAN, 2012) aims to 'incorporate healthy lifestyles issues into public planning systems, especially with regard to transport and land use, safe transportation, [and] provision for pedestrian and nonmotorized traffic'. The ASEAN Kuala Lumpur Transport Strategic Plan 2016-2025 includes NMT in the chapter on sustainable transport with action ST 1.1: 'Institute coordinated approach to further promote non-motorised and public transport in ASEAN cities' (ASEAN, 2016: 32).

At the national level, the importance of NMT is also appreciated. In their comprehensive modelling study on low-carbon transport in Thailand, Selvakkuram \& Limmeechokchai (2015) include modal shift from motorcycles to NMT as an important climate mitigation option. The national sustainable transport strategy of the Philippines (UP-NCTS, 2011) also sees a role for NMT. Similarly, for Metropolitan (Metro) Manila, NMT including cycling has been recognised as an element of sustainable transport solutions (Gozun \& Guillen, 2008) and a 1.42\% reduction in air pollutants from developing 'bikeways' was estimated (Vergel \& Tiglao, 2013). Harnessing such potentials in cities and regions may not be an easy task in general, given that traditionally the public and policymakers in South-East Asia associate cycling with poverty and the motorcycle seen as 'the modern substitution of the bicycle' (Khuat, 2006: p. 41). Although there are some studies for countries outside Southeast Asia (e.g. Rahul \& Verma, 2014; Nkurunziza et al., 2012), not much has been published about the requirements, or even the possibility, to have a substantial role for cycling in tropical megacities in this region. This is an important research gap given the potential contribution to sustainable urban transport, the current interest of policymakers and the significant effort required to establish cycling as a normal practice.

Though detailed data are not always available due to lack of adequate monitoring of cycling trips (Rios et al., 2015), it is evident that cities in developed countries have widely diverging shares of cycling, roughly between 0 and $60 \%$ of all daily trips. Vietnamese cities for example have significant, though decreasing, modal shares of cycling (in the order of 10-30\%, Dematera et al., 2015), as opposed to Singapore with around $1 \%$ cycling for work trips. Kumar et al. (2014) assume a potential of $10 \%$ for cycling in public transport access trips up to $3 \mathrm{~km}$ and for door-to-door 
trips up to $5 \mathrm{~km}$ in Singapore, which could be realised through adding infrastructure aimed at utility cycling to the currently available bike paths that are mainly targeting leisure cycling. Koh \& Wong (2012) find a lower catchment radius of $1.5 \mathrm{~km}$, and that about $30 \%$ of pedestrian and bus feeder commuters would 'very likely' or 'maybe' shift to cycling when there is better infrastructure. Most other ASEAN cities start from a lower base and do not have dedicated cycling infrastructure, however attention for transport and recreational cycling in politics, media and the public is picking up throughout the region, as discussed in this study. The drivers of this positive image of cycling appear to be diverse, from green image to health, and from sustainable transport to recreation and fun. Given the potential benefits of transport cycling (see Section 6.2.1) - as well as the challenges and uncertainties of increasing daily ridership and thereby reap these benefits - it is useful to put the current developments into a comprehensive picture of necessary and sufficient conditions, and draw lessons for the future.

This article aims to assess the current situation for urban cycling for transportation (also called 'utility cycling'), and the progress made therein in the ASEAN region using two megacities in The Philippines and Thailand as case studies, following the Technological Innovation Systems (TIS) framework. As TIS has not yet been applied to cycling this article also aims to investigate the suitability of the framework to a relatively mature practice such as cycling and thereby add to the literature on TIS analysis in the context of sustainable transport. In addition, it aims to highlight key enabling and blocking factors to future cycling policy development and implementation.

\subsection{Framework and methodology}

\subsubsection{Cycling in the context of sustainable transport and transitions}

It is widely recognised that cycling can play a key role in a sustainable transport system and therefore should be promoted by policymakers. In his 'green transport hierarchy' for multimodal transport planning that emphasises choice between modes, Litman (2008), concurring with Banister (2008), states walking and cycling are the first two modes to consider, followed by public transport, service and freight vehicles, taxis, multi-occupant vehicles and finally single-occupant vehicles. Wang (2011) shows that cycling in Chinese cities has a lower full cost per kilometre travelled compared to all other modes for short radial trips, only to be overtaken by bus systems for other types of trips. Meschik (2012) adds to this that every personkilometre cycled has external benefits for society versus significant cost for car travel. This is based on the notion that walking and cycling are 'active' transport modes that 
provide substantial health benefits to individuals and therefore reduce costs to society. CTC (2015) provides an extensive overview of studies related to costs and benefits of cycling and infrastructure investments for the economy and society. Cycling also provides a mode choice to those who choose to use, or cannot afford other modes, or are physically impaired. In countries with a high bicycle share by choice, the key reasons to choose cycling as a mode of transport relate to personal benefits, e.g. lower cost, time savings, higher reliability, greater comfort, better personal health) rather than environmental or societal benefits (e.g. City of Copenhagen, 2015). Personal benefits (utility gains) are therefore a strong predictor of first or continuing bicycle use (Pardo, 2013a).

In the context of climate change, cycling, being a zero-emission mode, can play a role too (Massink et al., 2011; Selvakkuram \& Limmeechokchai, 2015). However, it may not be easy and straightforward to assess the impacts of cycling on greenhouse gas emissions, especially in isolated contexts. Fishman et al. (2014) for example find that in two cities bike-sharing led to reduced vehicle-kilometres, while in one city these increased due to truck use for rebalancing the bicycles, thereby also increasing emissions. Probably in the short term impacts are rather limited, but it can play a more important role as part of system changes that help low-carbon transport, as shown in an example from The Netherlands (Brons et al., 2009) where the bicycle is the most popular access mode to train stations.

In order to give policymakers options to reduce greenhouse gas emissions from the transport sector, the 'avoid-shift-improve' approach to transport policy was developed (Dalkmann \& Branningan, 2007). In order to make this approach fully compatible with the wider notion of sustainable transport, Bakker et al. (2014) added components of 'access', lifestyle aspects and transition thinking to this approach. Cycling fits well in this framework: it provides accessibility to opportunities (Pettinga et al., 2009) and an alternative to other modes especially for trips up to 5-7 km, with larger distances in case of electric bikes. If a cyclist used another mode before, the policy or measure inducing the change is a 'shift' measure (Gilbert \& Dajani, 1974). In addition, if trip lengths can be reduced by means of 'avoid' measures, i.e. through spatial planning measures, and air pollution reduced through 'improve' measures, cycling becomes more attractive.

To further analyse how cycling can be looked at from a transitions perspective, we consider three broad frameworks. First, in the Multi-level Perspectives Framework for Socio-technical Transitions (Geels, 2012), large changes in a system may occur when pressures from the socio-political-economical 'landscape' result in opening of spaces in the 'regime' (e.g. car/motorcycle-dominated transport) so that niches (e.g. cycling) are able to increase their role and change the regime. In the traditional 
transport system, Geels (2012) sees 'cracks' in the current private car-dominated system, but also observes that major transitions may still fail, especially in terms of inducing a modal shift.

The second transitions approach is related to Practice Theory (e.g. Watson, 2012), which studies routinised types of behaviour in relation to social order and change. Large-scale cycling as a 'normal' mode of travel can be seen as a socio-technical transition from the current paradigm (see e.g. Gössling, 2013). Sengers (2016) notes that present day cycling in tropical megacities can be considered to be at risk, due to the very low modal shares, hence lack of critical mass, fast rise in incomes, hence private vehicle ownership and use, as well as the current regime of car-oriented planning. Shove (2012) discusses the re-emergence of cycling in the UK, currently a niche and predominantly associated with leisure. She argues that in theory, the stages of an innovation journey (from niche, through to alignment, diffusion and breakthrough) are the same whether the sociotechnical configuration in question is being introduced for the first time, or reintroduced at a later stage'. As cycling is not a new technology but rather an "old" technology that has been "reinvented", development of cycling could start not by 'niches of innovation but for pockets of persistence', i.e. the reactivation of past configurations, rather than it being a fully new regime. Similarly, in the context of 'stories of innovation', Oldenziel \& De la Bruheze (2012) note that 'the bicycle has gone through many incarnations, from serving as symbols of modern mobility and pride to the sure signs of poverty and nostalgia' (p. 22).

Elements of technological innovation can be found with the emergence of full electric or pedal-assisted bikes (pedelecs) and public bike sharing systems. As to the latter, third generation systems have fixed docking stations, tracking technology and dedicated smart cards, while fourth generation may feature dockless systems, electric bicycles, and better integration with public transport (Shaheen et al., 2010; Fishman, 2016). In Section 6.2.3 we further discuss this third transitions approach of Technological Innovation Systems.

To be successful in (re)capturing a significant modal share, cycling requires innovation in the technological system, economics (shops/manufacturing, repair workshops) (Gausemeier et al., 2015), the transport policy and planning framework (e.g. avoid-shift-improve; see also below), and social realm (a lifestyle where daily cycling is acceptable to most or all segments of society), apart from merely transport policy-related measures (i.e. transport demand management and NMT-related improvements on infrastructure, regulation, education). Currently in many countries and cities, for example in the UK, there are 'emerging' rather than 'established' cycling cultures (Aldred \& Jungnickel, 2014; p. 85), and cycling being related to 
subcultural choices (i.e. distinct identity from the broader culture). A recent surge in the "fashion" or "cycle-chic" connotation of this mode of transport is also observed (see Pardo, 2013a).

\subsubsection{Literature on development of cycling as a transport mode}

A growing body of literature deals with factors that attract individuals to or deter them from cycling; the so-called 'necessary conditions', or barriers that need to be taken away. However, these factors are not necessarily sufficient to make people cycle more (Gatersleben \& Appleton, 2007). The 'sufficient conditions', i.e. those that, when met, will effect a real change, will depend on each country's context. This section discusses conditions related to infrastructure, socio-economic factors, natural environment, and policy.

Separate cycling facilities, traffic calming measures, integration with public transport, and transport demand management are identified as important measures in Pucher \& Buehler (2008). Pettinga et al. (2009) define five criteria as necessary conditions for 'cycling-inclusive' transport planning: 1) coherence: most or all destinations can be reached by bicycle and there is integration with public transport, 2) directness: minimisation of detours and U-turns, 3) safety, e.g. through dedicated infrastructure and speed limits), 4) comfort: smooth road surface and protection from sun and rain, and 5) attractiveness, i.e. a pleasant environment. Rios et al. (2013) include these conditions into a broader framework that includes four necessary components of cycling policy. The first deals with the infrastructure and services, which are focused on the physical characteristics of the network and any other physical implementation (bicycle parking, on-the-road services, etc.). The second component focuses on regulations and institutions which relates to laws, decrees or general regulation of cycling and the institutions that are capable of managing cycling in a city. The third relates to citizen participation, which includes active participation (e.g. user groups, activists, citizen organisations), but also education and promotion activities of cycling. The fourth is monitoring and operation, which is focusing on the operation of systems (e.g. public bicycles, high-end parking systems) and monitoring of all data related to cycling and its effects.

Other important factors that are relevant when discussing cycling development are given in Gatersleben \& Appleton (2007), who discuss the process of intentional behaviour change for cycling to work trips, including stages of pre-contemplation, contemplation, preparedness for action, action, maintenance and potentially relapse. This was then used to study the need for different policy interventions for people in different stages of change for cycling in the tropical city of Dar-es-Salaam, Tanzania (Nkurunziza et al., 2012). Targeting specific user-groups has also been discussed in 
Park et al. (2011) who, interestingly, observe that in Singapore 57\% of commuter cyclists were leisure cyclists before, and suggest that 'young white-collar workers who live in high-rise apartments and enjoy intensive leisure-cycling in groups, are a good target' for cycling promotional campaigns. Aldred \& Jungnickel (2014) for the UK, as do Jones \& Novo de Azevedo (2013) for Brazil, discuss the cultural dimension and how the meanings of cycling, including its association with other social identities by groups in society are connected to the materials and competences seen as necessary for cycling. In a comprehensive review of studies, Heinen et al. (2010) conclude however that the relationship between socio-economic factors, such as age, gender, income, household structure, and cycling remains unclear, both in terms of direction and causality. Travel cost and safety are more important for cycling than for other modes.

Handy et al. (2014) discuss urban densities, infrastructure, distance, costs, socialdemographic factors, individual perceptions, bicycle availability (including ebikes/pedelecs), and bicycle access, similar to Brons et al. (2009) who look at the role of cycling in increasing the propensity of people travelling by train. Weather, and its perception, is also a key factor, even though most literature discusses weather in the context of Western countries and cold and moderate climates (Böcker et al., 2013), rather than tropical climates. Meng et al. (2016), being one of the exceptions to this, finds that rainfall is the most important weather factor for cyclists in Singapore, secondly humidity and thirdly temperature (with a preference for 29.5$\left.31.1^{\circ} \mathrm{C}\right)$.

Other literature discusses problems of (upfront monetary and non-monetary) investments in cycling infrastructure and the delay in realising the benefits through the so-called valley of death analogy (Gatersleben \& Appleton, 2007). Deffner et al. (2012) argue that investments into cycling infrastructure can be justified based on the argument that it gives choice to people to choose the transport mode they prefer, i.e. it facilitates a diversity of lifestyles and promotes equity and a multimodal transport system. The role of specific facilities, awareness (car-free days, bike fairs etc.), social media and different user-groups (particularly university students) as enablers is discussed in various articles (e.g. Rose \& Marfurt, 2007; Rimano et al., 2015; Gozun \& Guillen, 2008).

From this brief review it follows there is a lot of literature on factors influencing bicycle use and how to improve conditions for cycling (i.e. the 'necessary conditions'), however not on the actual impact of these conditions on real levels of bike use (i.e. the 'sufficient conditions'), particularly in developing and tropical countries. In Latin America, Rios et al. (2013) did an effort to systematise current 
status of cycling policies, but it is far from a thorough long-term review; in Africa, Pendakur (2005) did a review, but with only scarce information available. No expost assessments that cover bike transport development over several decades in tropical countries have been found. Experience of Western-European countries, and evaluation of new infrastructure development in US cities and Tokyo, cannot easily be transferred to other cultures, climates and urban contexts, which highlights a research gap, as confirmed by Handy et al. (2014).

\subsubsection{Analysis framework: Technological Innovation Systems}

In order to analyse the current situation and potential for a transition towards a more urban transport cycling in ASEAN megacities we adopt the Technological Innovation Systems (TIS) framework of Bergek et al. (2008), which is based on theoretical school of Innovation Systems (e.g. Lundvall, 1992). TIS is defined as "socio-technical systems that are focused on the development, diffusion and use of a particular technology (in terms of knowledge, product or both)" (Bergek et al. 2008: p. 408) and is used to characterise what key functions in an innovation system are fulfilled for specific technologies in a country or a region. Its advantage over analysis based on other, more conceptual analysis systems, such as the Multi-Level Perspective (Geels, 2002), is that it is intended to answer policymakers' questions on what interventions to make, which provides a good fit with our research objective.

TIS is usually applied to hardware technologies, such as energy efficient air conditions, biodigestion systems (Tigabu et al., 2015) and $\mathrm{CO}_{2}$ capture and storage in a country (Alphen et al., 2009). However, as a technology or a practice is always subject to some combination of knowledge, institutions, markets, actors, public and political factors and resources, a well-established practice such as cycling could also be examined in such a functional way (with electric bikes and bike sharing system as technologically innovative elements). To our knowledge, however, this has not been done earlier. Shove (2012) analysed cycling in the context of innovation journeys, which has a related yet different approach, as discussed above. Therefore, this paper is also a test for applying TIS to an established practice such as cycling.

The TIS framework (Bergek et al., 2008) follows a staged approach of analysis in six steps, (1) define the innovation system, (2) identify the components (actors, networks and institutions), (3) describe the seven functions of the system, (4) assess the functionality, (5) analyse blocking and inducement mechanisms based on the functional patterns, and (6) identify policy issues and recommendations.

The seven functions in step three are: (i) knowledge development \& diffusion, which looks at the breadth and depth of the knowledge base, its development over time, 
and how it is diffused, including scientific, technological, design and market knowledge; (ii) influence on the direction of search, looking at factors that support development and use of the technology, such as belief in its growth potential, incentives, regulatory pressure and support, and the articulation of interest by customers / users; (iii) entrepreneurial experimentation, i.e. the breadth and number of experiments, projects and (pilot) applications etc. taking place; (iv) market formation, including the progression of phases such as nursing, bridging and mature market and may include indicators such as the size of the market as well as types of users and the demand profile; (v) legitimation, dealing with the technology needs to be considered appropriate and desirable by relevant actors in order for resources being mobilised, demand formed and political momentum built up; (vi) resource mobilisation, which looks at human capacity in technical skills and financial resources, e.g. for infrastructure and products; and (vii) development of positive externalities for different actors in the TIS, e.g. through labour markets, emergence of specialised intermediate goods and service providers and information flows. Figure 6.1 schematically presents the six TIS steps and seven functions as applied in this paper.

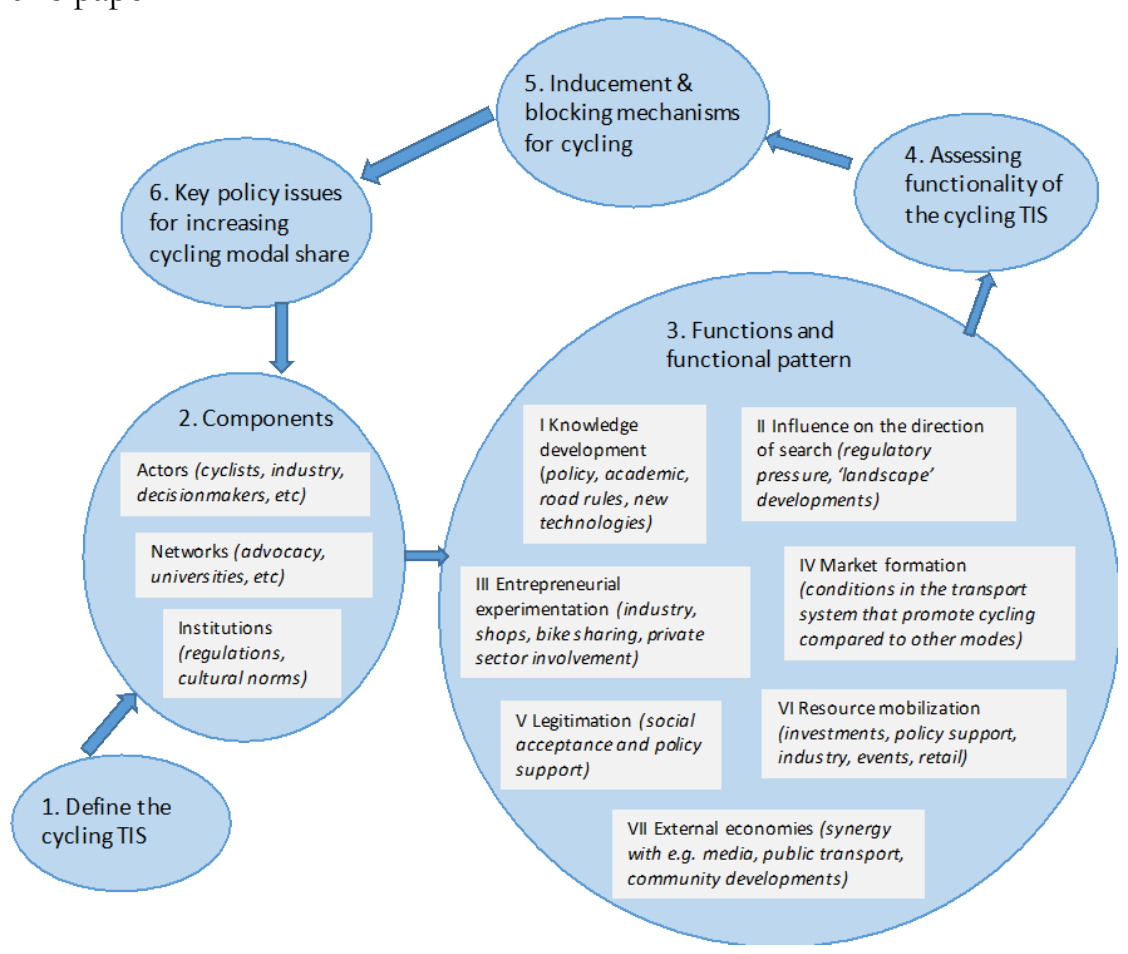

Figure 6.1 TIS steps, applied to cycling (adapted from Bergek et al., 2008) 


\subsubsection{Methodology}

The current situation of cycling, with a focus on Metro Manila and Bangkok, two megacities that are relatively comparable in several respects (see Table 6.1), will be assessed following the TIS steps and functions as introduced previously. The definition of the system of innovation, or the 'unit of analysis', is the use of bicycles, including e-bikes/pedelecs, bike sharing and pedicabs, as a means of transport in ASEAN megacities. The two cities can be considered representative for other megacities in the Southeast Asia region in terms of size and climate, are in middleincome countries, and are chosen based on their progress in cycling policy compared to other cities in the region; Singapore, which has progressed as well, will be discussed briefly too.

To identify the seven functions in step 3 of the TIS approach we first conduct a systematic review of international and local literature about Thailand and the Philippines to identify and characterise the key contextual factors for cycling as well as qualitative research including field visits in Bangkok and and Metro Manila. We use the five criteria for cycling-inclusive planning of Pettinga et al. (2009) to characterise the current situation. The public discourse is analysed using printed and social media published between 2013 and 2015 for Thailand (40 articles $\left.{ }^{42}\right)$ and the Philippines (20 articles $\left.{ }^{1}\right)$ respectively, following e.g. Gössling (2013), who carried out a similar content and discourse analysis for Copenhagen, and Rimano et al. (2015), who investigate the mass media image of bicycles by performing a cluster analysis on 'risk and danger', 'sustainable mobility', 'wellness and leisure' for Italy.

The governance structure and relevant policies are reviewed through policy documents in both countries, insights of members of the Firefly Brigade, which is one of the biggest associations of cyclists in the Philippines, the Inclusive Mobility Network and the University of the Philippines, as well as three key informant interviews in the context of urban transport policy from Thailand, including representatives of the Ministry of Transport and the Thailand Cycling Club. A rapid survey of advocacy groups involved in mainstreaming of cycling was also done through interviews and a review of their printed and online media.

We then compare the results of the two cities, and discuss these in the context of international experience from European Latin American cities as well as Singapore, from which possible futures for the role of cycling in tropical megacities in the ASEAN are derived.

42 Available upon request 


\subsection{Current situation in Bangkok and Metro Manila}

This section describes the status-quo of cycling in Bangkok and Metro Manila and the context within which this is happening. This information will subsequently be used in the TIS analysis in the next section. The data are summarised from Bakker et al. (2016), which includes all detailed documentation and references to the relevant media, policy documents and additional literature.

\subsubsection{General city statistics and information}

Table 6.1 gives general indicators with relevance to cycling (see Heinen et al., 2010) for Thailand and the Philippines and their respective capitals, including general information on the cities' economy, demographics, vehicle ownership and natural environment. For other indicators, e.g. trip patterns, we have not been able to find recent and reliable statistics.

Table 6.1 General indicators relevant to transport in Metro Manila and Bangkok

\begin{tabular}{lll}
\hline Aspect & Thailand / Bangkok & $\begin{array}{l}\text { Philippines / Metro } \\
\text { Manila }\end{array}$ \\
\hline GDP/ cap (\$, 2014) & & 2872 \\
GDP growth (av. 2010-2014) & 5977 & $5.9 \%$ \\
Urban population (million) & $3.2 \%$ & $12(24)^{45}$ \\
Urban density (cap/ $/ \mathrm{km}^{2}$ ) & $8(14)^{44}$ & 19,000 \\
$\mathrm{tCO}_{2} /$ cap (transport sector, national, & $0.88^{47}$ & $0.25^{48}$ \\
2010) & & $86 /$ up to $432^{50}$ \\
Motorisation (city proper) \# cars / \# & $198 / 303^{49}$ & $($ entire country) \\
motorcycles per 1000 cap & & Tropical, monsoon \\
Climate & Tropical, monsoon & Flat \\
Urban topography & Flat & \\
\hline
\end{tabular}

${ }^{43}$ World Bank Indicators, http://data.worldbank.org/indicator/NY.GDP.PCAP.CD

${ }^{44}$ Based on the 2010 census (http://popcensus.nso.go.th/upload/popcensus-08-08-55-E.pdf)

452010 Census of Population and Housing: National Capital Region. National Statistics Office of the Republic of the Philippines.

${ }^{46}$ Calculated from Sintusingha (2012): 6842 population, $1569 \mathrm{~km}^{2}$ in 2007

${ }^{47}$ Narupiti et al. (2014)

48 Mejia et al. (2017). It is noted that this is likely to be an underestimation

${ }^{49}$ Department of Land Transport (2015). http://apps.dlt.go.th/statistics_web/vehicle.html; includes pickups

50 total vehicle registration, 2013; Land Transportation Office Annual Reports, quoted in Mejia et al. (2017)

51 30-35 C mean high throughout the year; four months' monsoon, mostly short heavy showers late afternoon 


\subsubsection{Thailand: Bangkok Metropolitan Region}

Bangkok is the capital and economic powerhouse of Thailand, producing more than $50 \%$ of the countries' GDP. The city has been sprawling into many directions and has developed into a metropolitan area comprising Bangkok and five other provinces, together referred to as the Bangkok Metropolitan Region (BMR). As of March 2017, there are five urban rail lines in operation, with another seven being constructed or planned, and several suburban rail lines. Buses stop on the side of the road, implying conflict with other road users including cyclists. Motorcycle taxis, motorised three-wheelers (tuk-tuks), and songthaews (local paratransit) are a common sight across the city, providing a key public transport feeder service, as most destinations can only be accessed via long narrow side roads (sois), which emerged without any central planning' (Sengers \& Raven, 2014). Khuat (2006) developed a 'motorcycle-dependency' rating, in which Bangkok would be qualified as 'medium' motorcycle dependency. Non-motorised three-wheelers (samlors) have been banned in the city of Bangkok since 1964, however remain common in urban areas in the surrounding provinces i.e. the outskirt of the BMR. Other aspects of transport in Bangkok include prevalence of dead-ends, U-turns, long traffic signal cycle times and lack or low quality of zebra crossings and footpaths.

Bangkok's urban development from 1960 to the early 1990s was laissez-faire, and there was no official urban plan until 1992 (Sintusingha, 2010). Furthermore, urban transport policy and planning is characterised by car-oriented planning, responsibilities split across more than twenty agencies, political influence, and lack of standards and regulations. Charoentrakulpeeti et al. (2006) highlight the significance of the 'modern lifestyle and forms of consumption that logically bear heavily on the transport situation in Thailand', i.e. the 'middle-class propensity for peripheral and suburban type of single detached home ownership, private car ownership and associated car dependence for travel'. Ownership and use of private cars are seen as 'a necessity and desirable' including for enhancement of social status, safety and a reduction of one's exposure to pollution.

Although no cycling modal share data for the entire city or region of Bangkok appear to be available, several studies indicate bicycle ownership and use is significant, and in the order of $1 \%$ of the modal split of trips, (Raha \& Taweesin, 2013) including feeder trips to public transport (OTP, 2014). Many poor people are using bicycles, which are also called 'maid bikes'. In addition, the Pun Pun bike sharing system ( $3^{\text {rd }}$ generation like most contemporary systems) started in 2013, and as of 2016 consists of 50 stations and over 500 bikes, with expansion planned. A more or less increasing trend in 2013-2014 to 5-10 trips per day per station was observed. Most Pun Pun trips are between $0.5-2 \mathrm{~km}$, with approximately $10 \%$ over $2 \mathrm{~km}$ (Raha, 2015). 
Household bicycle ownership, in Thailand country-wide, is approximately $60 \%$ (Oke et al., 2015).

Since 2008, the Bangkok Metropolitan Administration (BMA) has been improving bike infrastructure with approximately $200 \mathrm{~km}$ of bike lanes as of 2016. However, these are often built primarily for sport and recreation purposes (e.g. the cycling track around the airport) and are sometimes disconnected from the main transport network; other stretches are on sidewalks and along main roads (see Figure 6.2). Many urban rail stations have small bicycle parking racks and at some stations these are being used by public transport users and street vendors. In terms of the five criteria for cycling-inclusive planning by Pettinga et al. (2009) (see Section 6.2.2) we can summarise the current situation as follows:

1. Low directness: cycling from origin to destination requires large detours rather than the shortest possible route, as bicycles must follow car infrastructure including U-turns and due to the many cul-de-sacs; in addition, there are long waiting times at traffic lights

2. No coherence: the few bike lanes are scattered, not connected, and of different typologies (see Figure 6.2), therefore only a small share of possible destinations can be reached;

3. Low safety due to many crossings and mixing with motorised traffic, unexpected situations, little priority to bicycles by other users, few protected bike lanes

4. Little comfort: no shading in existing infrastructure, exposure to hazards, noise and pollution

5. Attractiveness: good in quiet alleys, near local markets and in parks, however not attractive on bigger roads.
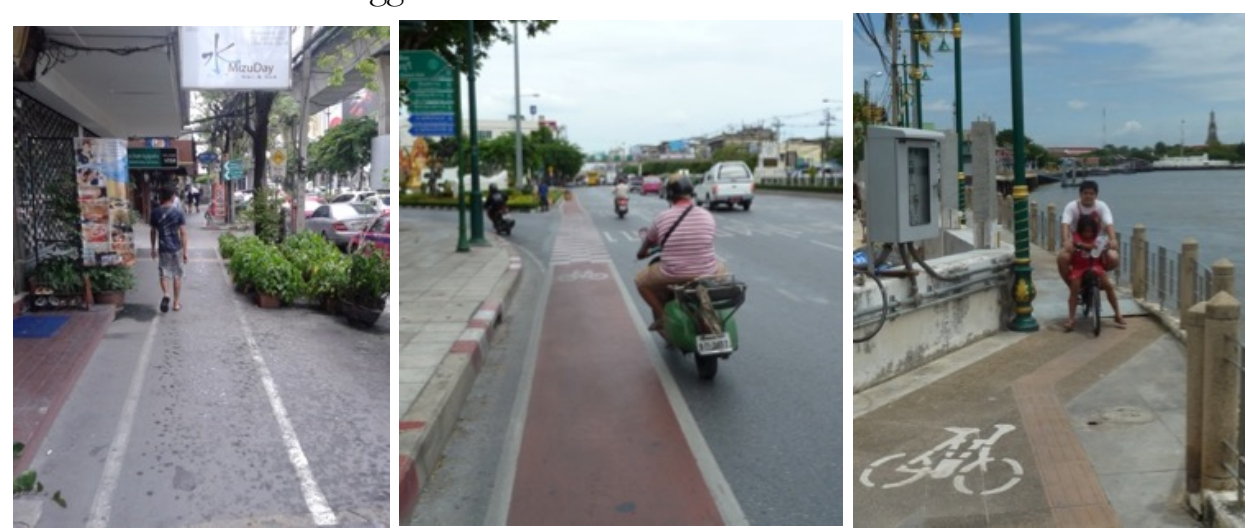

Figure 6.2 Examples of shared paths, bicycle lanes on the road and exclusive bike lanes (photos: Stefan Bakeker) 
These days, cycling is trendy, fashionable and increasingly popular among several user groups, especially the higher educated (across different age groups), but predominantly for leisure. The car-free day is held annually in Bangkok since 2005, with participation increasing every year, and large bike-related events, such as fairs, are held on a regular basis, with visitors in the thousands. Dozens of smaller or larger bicycle groups or clubs regularly organise group rides in inside or outside the city, mostly on weekends. At universities there is an active bicycle community as well, linking transport and environmental issues with trendiness. Meetings at cyclingthemed cafes are commonplace. In (social) media, cycling is a popular theme, both from a lifestyle as well as a policy perspective. We found over 100 Facebook pages ${ }^{52}$ directly or indirectly related to cycling in Bangkok, which together have approximately 1.2 million followers as of March 2016. These include communities and cycling groups (mostly for fun and recreation), NGOs or campaigns for cycling as transport mode, media (e.g. sports cycling) and initiatives from academic institutions, e.g. those that promote cycling on university campuses. The latter can be seen as protective spaces for innovation, where 'sustainability experiments' take place (Sengers, 2016).

The bicycle market, especially for high-end models, has been growing by $15-25 \%$ and exceeds USD 200 million, and the International Bangkok Bike Fair in September 2015 branded Thailand as the hub of ASEAN cycle business.

Also in newspapers and magazines the topic has gained attention in recent years. When looking at some of these articles analysed in Bakker et al. (2016) we can observe how cycling is framed. Prime Minister General Prayuth Chan-o-cha spoke about the 'government policy to promote the use of bicycles as means of exercise or daily commute vehicle', which 'helps to improve people's health and reduce air and noise pollution'. Another article reports that a new cycling route is part of the government's programme "Return Happiness to Thais", and aims to promote cycling as a way to maintain health and cultivate a love of exercise. Cycling also has been associated with the idea of 'liveable city' and 'low-carbon society' while contributing to GHG emission reduction, and cycling has a 'social value'. However, there are plenty of different views in society, e.g. 'cyclists don't belong on the road', and motorists 'who treat cyclists as a nuisance and bike lanes as an intrusion into their road space (...) and that roads are exclusively meant for motor vehicles, and not for bicycles' (Bakker et al., 2016).

Advocacy groups include e.g. Thailand Cycling Club (TCC), Thai Cycling for Health Association and the Bangkok Bicycle Campaign; their activities include campaigning,

${ }^{52}$ List available upon request from the first author. 
organising events, carrying out research and surveys, and initiating and influencing policy discussions. The Bike and Walk Forum, organised by several advocacy groups and government agencies, is held annually since 2013 and provides a platform for sharing research on NMT. A bicycle policy working group, convened by the BMA and joined by several groups and experts, discusses bicycle issues related to infrastructure, events, safety etc. The public can learn about the outcomes of these meetings e.g. through social media.

Significant policy activity related to cycling can be observed since a few years, although local politicians have paid some attention to it for over a decade. Through the National Health Commission Office of Thailand and initiated by TCC, the Cabinet has adopted a Resolution on 'Supportive Systems and Structures for Walking and Cycling in Daily Living' in which nine Ministries are assigned tasks and responsibilities to promote NMT (National Health Commission of Thailand, 2012). The NMT feasibility Study (OTP, 2014) provides a blueprint for 140 public transport stations in Bangkok that can be upgraded to facilitate interconnectivity and NMT accessibility. BMA's 'City of Happiness' policy includes various public transport and cycling measures such as 10,000 public bike sharing-bikes and speed limits on shared roads. The Environmentally Sustainable Transport Master Plan (OTP, 2012) proposes measures such as the development of networks and facilities for cycling, promotion of NMT and introduction of bike sharing. The Ministry of Transport adopted the Manual of Standards for Bikeway Design and construction, which is based on American standards and specifies which types of bike infrastructure (shared road, shared lane, bike lane, segregated track) is to be provided on road categories based on speed and volume of motorised vehicular traffic (Thailand Cycling Club, 2016). More guidelines for infrastructure and promotional activities are being developed by other agencies. In 2015, approximately USD 39 million was invested in cycling infrastructure throughout the country, mainly by the Ministry of Tourism and a smaller share by the Ministry of Transport.

The approach currently in Thailand may be characterised by fragmentation and focus on individual stretches of infrastructure, with little attention for data and monitoring, communication and education, electric bikes, or other necessary policies such as transport demand management, traffic calming, car taxation (Narupiti et al., 2014). To date, there appears to be limited involvement of international experts or sharing of best practices, though a nationally appropriate mitigation action is being proposed and developed that includes technical assistance for cycling as a public transport feeder mode.

There is limited literature on public acceptance of cycling in Thailand, although one article suggests it may be relatively low. Nongnuch (2015) carried out a 
representative survey among 15,700 respondents in 10 provinces across different regions in Thailand and found that the public image of cycling as a daily mode of travel is 'moderate', and, though there are strong positive associated images as well, negative images such as 'poor man bike', 'dirty biker', 'embarrassed to ride to work or school' and 'obsolete way' also scored high.

\subsubsection{The Philippines: Metro Manila}

In the Philippines, Metropolitan Manila, also known as the National Capital Region, is constituted into a special development and administrative regions subject to direct supervision of the President and composed of 17 cities. The Metro Manila Development Authority (MMDA) is the agency that performs planning, monitoring and coordinative functions, and exercises regulatory and supervisory authority over the delivery of metro-wide services. Most cities or Local Government Units in Metro Manila have their distinct traffic management offices or boards, operating under the Office of the Mayor or adjunct to the latter with their own personnel and budgets. The Department of Public Works and Highways is the agency involved in all infrastructure related to roads, the planning of which draws heavily from US references and standards (Regidor, 2015).

Culturally and traditionally, the bicycle has never been mainstreamed nor encouraged in the country's public transport system. Only in the late 1980s to early 1990s bicycles and pedicabs (non-motorised three-wheeler taxi) were seen, due to the oil price surge in that period. By the 1990s, they were banned on major roads due to safety and congestion issues. Approximately $23 \%$ of households own bicycles (Oke et al., 2015). Although it is estimated that up to $35 \%$ of destinations are within a $15-$ minute walk or bicycle trip, the majority of short trips are made by paratransit and cars (Leather et al., 2011). Only 2\% of all trips in Metro Manila are made by bicycles (Gozun \& Guillen, 2008). At least two universities have initiated bike sharing initiatives. There was also a small scale Asian Development Bank demonstration project in Pasig City. In the initial mapping activity of the Ateneo School of Government's Inclusive Mobility Project supported by the Rockefeller Foundation, in four cities in Metro Manila, there are over 60 bike shops estimated. Since 2008, there is also a bike courier service, Pedala Bike Messenger, with a pool of 150 bike messengers in 2013.

Designated bike lanes are being constructed and as of 2015 add up to approximately 70 km, including one World Bank project (MMDA, 2015; Romero et al., 2014). As can be seen in Figure 6.3, some of these are fully segregated, others painted on the side of the road, and some are on the sidewalks. Quality of the infrastructure varies, and conflict with pedestrians has also been reported. On all five criteria of cycling- 
inclusive planning currently Metro Manila would be doing poorly, though it can also be argued that given the stage of policy and planning it is too early to meaningfully apply these criteria.
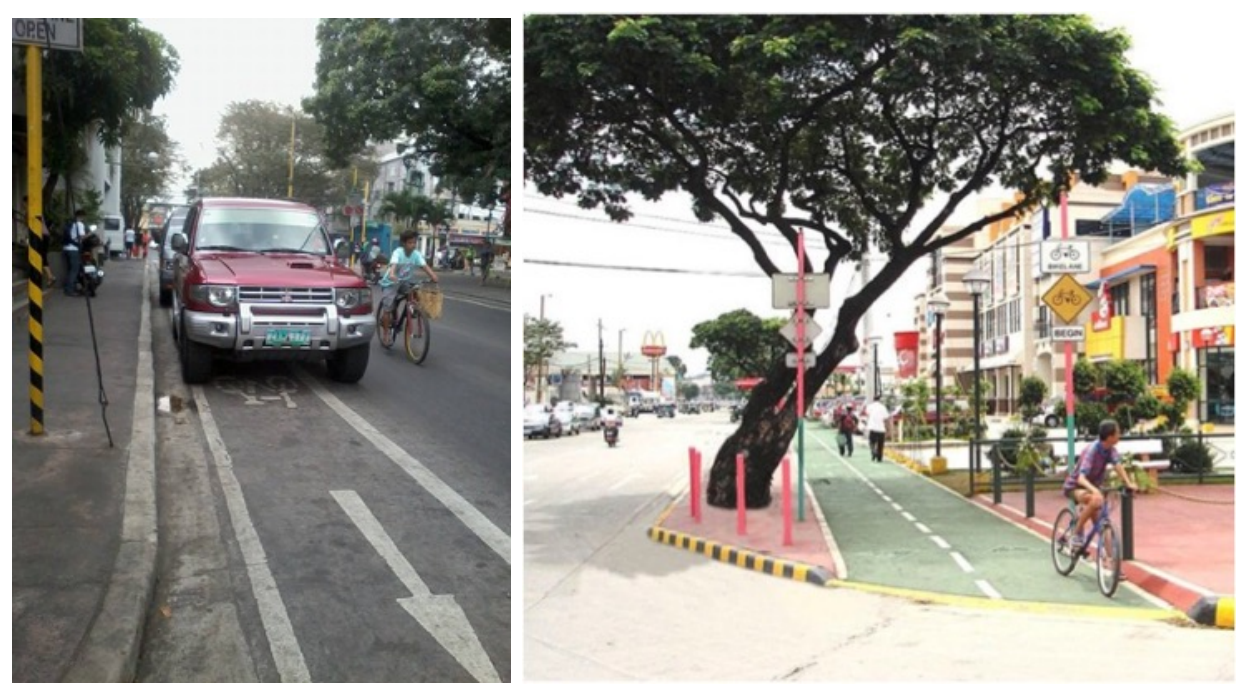

Figure 6.3. Existing bike infrastructure in Metro Manila (source: Danielle Guillen (left) and Regidor (2015) (right)

Since 2010, a range of policy documents including Administrative Orders and Senate and House Bills, have been proposed and some of these are adopted at the local level, even though there is no clear national policy yet. The key policy objectives and issues highlighted in these bills include global warming, fuel consumption, environmental protection, protecting bicycle-using labour force from injuries and death, health of the people, cheap alternative means of transport in the light of fluctuating fuel prices, advance the right of the people to a balanced and healthful ecology in accord with the rhythm and harmony of nature, air pollution, reduction of traffic congestion, exercise and relief of stress, cheaper transport, reduced road damage, and enhance well-being (Bakker et al., 2016). Administrative Order No. 254 calls for 'Reform the transport sector to reduce the consumption of fossil fuels. The new paradigm in the movement of men and things must follow a simple principle: "Those who have less in wheels must have more in road." For this purpose, the system shall favor non-motorized locomotion and collective transportation system (walking, bicycling, and the man-powered mini-train).' The Nationally Environmentally Sustainable Transport Strategy (NESTS) (UP-NCTS, 2011) includes strategies and indicators related to NMT. Designation of bike lanes is called for by several proposed bills, such as the Sustainable Transport Act of 2013, Bicycle Lane Act of 2014 and the Bicycle Lane Act of 2015. Other policies and measures 
such as parking, incentives for electric bikes, establishment of Local Bikeway Office and transport demand management (TDM) is included in other bills. However, it is important to note that while the Department of Transportation has the NESTS framework is in place, none of the bills in Congress or its counterpart in the Senate have passed. In the Philippines, for a national law to be enacted, it should both pass the majority of the Senate and Congress members. The pending bills reflect that for the majority of policy makers, such bills were not a priority at the time it was being deliberated.

In the Philippines, key bike advocacy organisations are active, including the Firefly Brigade, the Tiklop Society and the "Share the Road" movement. The pioneering Firefly Brigade is an NGO that promotes the use of the bicycle for clean air and sustainable communities. Activities include an annual awareness raising tour, monthly critical mass biking tour, installing provisions for bike parking, engaging with government agencies promoting the cycling agenda in urban design, conducting NMT forum and providing training. The National Bicycle Organization founded in 2014 is also active in organising bike rides, in smaller groups as well as large events such as National Bicycle Day held every year on November $4^{\text {th }}$, bicycle education, seminars, partnering with national and local government agencies, as well as related advocacy, e.g. by supporting the Share the Road movement. Their main task is to encourage local government units to develop NMT policy by providing templates for local government units to utilise in the crafting of their own respected NMT policy. The Tiklop Society of the Philippines seeks to promote the use of folding bikes as a means to better oneself and achieve cleaner air to breathe and more liveable cities. It promotes multi-modal transportation and has successfully lobbied for having folding bikes be allowed on the light rail system. The Share the Road Movement has been instrumental too in promoting car-free days and road-sharing exercises together with MMDA as well as in some local government units like Pasig City, Iloilo City among others. They also conduct the "Bayanihan sa Daan" Awards (Cooperative Heroism) together with the Office of the President on Environmental Protection on recognising pioneering local governments, individuals, civil society groups and organisations from across the country that are actively promoting walkable-bikable communities and road-sharing initiatives. There is also the Inclusive Mobility Network, a relatively new NGO and an offshoot of the Ateneo de Manila University School of Government Inclusive Mobility Project, the interviewee of which noting the need for political will to implement the plans being advocated. The Inclusive Mobility Network aims to provide a platform for all champions of related sustainable mobility initiatives including those working on walking, cycling and its integration with public transport system as first and last mile 
connectivity means. To date in the Philippines, in the absence of national policy on cycling, there are four cities (Marikina City, Pasig City, Iloilo City, Davao City) that initiated their own local policies on bicycles. Some cities and municipalities also have separated policy for three-wheelers or pedicabs for public transport use.

In a brief survey of social media pages, we found approximately 40 Facebook pages directly related to cycling, together having over 400,000 followers. Most pages are dedicated to recreational or sport cycling, however around 50,000 fans are for seven advocacy related pages. These organisations use these pages to report on their activities, highlight issues, recruit participants to events and spread ideas. There is regular media coverage of cycling related policies and events. A media content analysis of online media, mostly newspapers, shows cycling is framed as supporting green living and low-carbon society, and articles normally highlight the infrastructure and discipline problem on the streets. Examples of framing include Marikina being dubbed the "Healthy City" and cycling having "many physical and mental health benefits. It is also fun, cheap and good for the environment". Other articles related cycling to 'lifestyle' and a 'people-oriented method of transportation'. However, cyclists on the road can also be seen as a 'nuisance' (Bakker et al., 2016).

One of the earliest researches on the reason why bicycle is not a significant transportation/commute mode was done by Gozun (2001). It noted the role of personal attitudes and community values which affect the potential use of cycling in the non-cycling community of the University of the Philippines; even respondents who find cycling as a good recreational sport do not think of cycling as a viable transportation mode for commuting. Generally cycling may be identified with poorer sections of society, such as security guards, construction workers, pedicab drivers etc., however these days it is also being looked at as something good and perhaps 'cool', particularly when certain brands of bikes are used. Pedicabs in urban areas are usually for last mile connectivity and perceived to be the cheaper and safer mode while in the suburbs, they are usually found in less well-off gated communities as an alternative to tricycles as they are the noiseless modes for the public last mile connection of around $250 \mathrm{~m}$ to $2 \mathrm{~km}$ (Guillen, 2000).

\subsection{Emerging picture: TIS analysis and discussion of cycling in Bangkok and Manila}

Using the case study data as introduced in Section 6.3, we apply the TIS framework to cycling in Bangkok and Metro Manila. The results are included in Table 6.2 and should be read in conjunction with the city contexts described in Section 6.3. Where aspects are relatively similar for Bangkok and Metro Manila we use merged cells. 
Table 6.2. Overview of existing situation for cycling in Metro Manila and Bangkok using the TIS framework.

\begin{tabular}{|c|c|c|}
\hline TIS steps & Bangkok & Metro Manila \\
\hline \multicolumn{3}{|l|}{ Components (step 2) } \\
\hline -Actors & \multicolumn{2}{|c|}{$\begin{array}{l}\text { Cyclists, policy makers (local and national), advocacy groups, media, bicycle } \\
\text { shops, recreational cycling groups, private sector e.g. (e-)bike industry and } \\
\text { commercial developers, pedicab drivers, traffic police }\end{array}$} \\
\hline \multirow[t]{2}{*}{-Networks } & \multicolumn{2}{|c|}{$\begin{array}{l}\text { Groups on social media, university cycling organisations, international } \\
\text { networks of bicycle advocacy groups }\end{array}$} \\
\hline & Bicycle policy working group & \\
\hline -Institutions & \multicolumn{2}{|c|}{$\begin{array}{l}\text { Cultural norms, with the car seen as status symbol, giving a low status to the } \\
\text { bicycle; importance of 'comfort' compared to travel time; pro-car policies and } \\
\text { regulations, e.g. road guidelines, policies, including transport planning practices } \\
\text { and strategies; initial bike lane regulations are developed }\end{array}$} \\
\hline \multicolumn{3}{|c|}{ Functions (step 3 and 4) } \\
\hline \multirow[t]{2}{*}{$\begin{array}{l}\text { Knowledge } \\
\text { development } \quad \& \\
\text { diffusion }\end{array}$} & \multicolumn{2}{|c|}{$\begin{array}{l}\text { - Lack of data on trip patterns and current cycling levels/modal share, showing } \\
\text { low priority with planners } \\
\text { - Knowledge and capacity to develop and implement cycling-inclusive } \\
\text { transport plans are limited; no formal cycling education in schools or in } \\
\text { planning and engineering curricula in universities } \\
\text { - Limited exchange of global, regional and local knowledge } \\
\text { - User experience: everyone can cycle but no experience in navigating the } \\
\text { streets and route finding } \\
\text { - Motorised vehicle drivers do not know how to share the road safely with } \\
\text { cyclists } \\
\text { - E-bike knowledge limited }\end{array}$} \\
\hline & - Annual Bike and Walk Forum since 2013 & \\
\hline \multirow[t]{2}{*}{$\begin{array}{l}\text { Influence on the } \\
\text { direction of search } \\
\text { (high-level } \\
\text { developments, } \\
\text { 'landscape } \\
\text { pressures') }\end{array}$} & \multicolumn{2}{|c|}{$\begin{array}{l}\text { - Some first policy activity, though it is not possible to assess whether there is } \\
\text { a clear believe with governments that cycling can and will play a substantial } \\
\text { role in the future } \\
\text { - Drivers for cycling acknowledged by policymakers and communities include } \\
\text { congestion, air pollution, climate change and health } \\
\text { - Cycling caters to values such as collectivism and feeling of 'community' } \\
\text { - No important historical role of the bicycle (as compared to e.g. Vietnam) }\end{array}$} \\
\hline & $\begin{array}{l}\text { - High-level policy and statements supportive } \\
\text { towards cycling } \\
\text { - Motorcycle taxi considered convenient: } \\
\text { competes with cycling }\end{array}$ & $\begin{array}{l}\text { Bottom up policy initiatives } \\
\text { seeking regulations on } \\
\text { cycling-inclusive planning }\end{array}$ \\
\hline \multirow[t]{2}{*}{$\begin{array}{l}\text { Entrepreneurial } \\
\text { experimentation }\end{array}$} & \multicolumn{2}{|c|}{$\begin{array}{l}\text { - Bicycle manufacturing industry thriving } \\
\text { - Many bicycle shops; also cafes that act as meeting places for cyclists } \\
\text { - Private sector involvement in bike sharing and rental; however public } \\
\text { transport companies have not yet shown interest } \\
\text { - Various businesses including retail and restaurants want to associate } \\
\text { themselves with bikes as a fashion symbol }\end{array}$} \\
\hline & $\begin{array}{l}\text { - Tricycle can still be seen in suburban areas } \\
\text { - No e-bikes yet }\end{array}$ & $\begin{array}{l}\text { - Pedicabs (tricycles) re still } \\
\text { popular } \\
\text { - Few e-bikes on the road }\end{array}$ \\
\hline $\begin{array}{l}\text { Market formation } \\
\text { (i.e. conditions that } \\
\text { promote cycling }\end{array}$ & \multicolumn{2}{|c|}{$\begin{array}{l}\text { - In terms of modal share cycling is in the take-off phase or 'bridging market', } \\
\text { yet bicycle is a mature technology }\end{array}$} \\
\hline
\end{tabular}




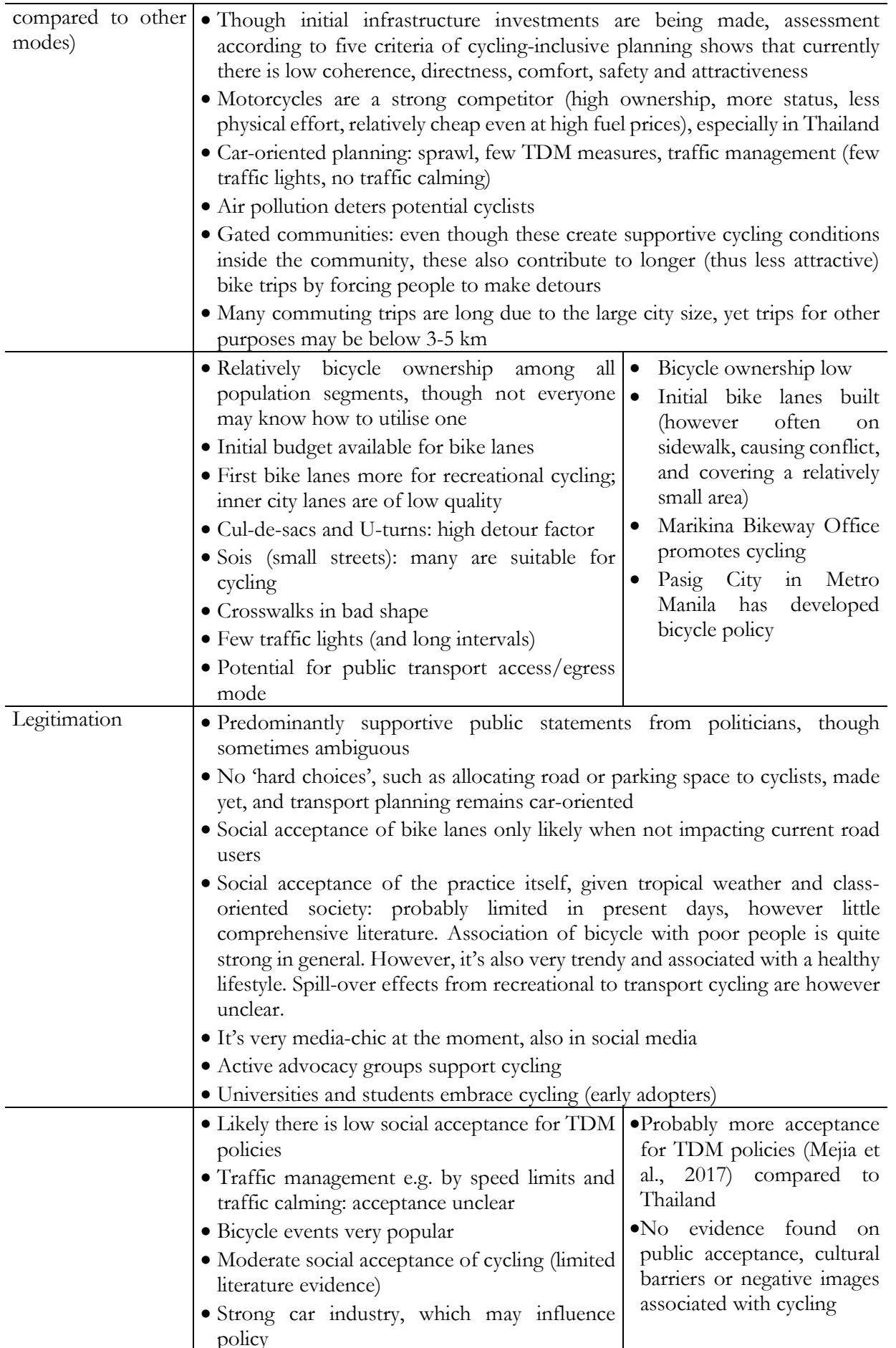




\begin{tabular}{|c|c|c|}
\hline \multirow[t]{2}{*}{$\begin{array}{l}\text { Resource } \\
\text { mobilisation }\end{array}$} & \multicolumn{2}{|c|}{$\begin{array}{l}\text { - Many people involved in various ways: groups, shops/cafes, universities } \\
\text { - Growing bicycle industry, both domestic and international brands } \\
\text { - Bicycle-related events are getting bigger } \\
\text { - Knowledge development takes place through conferences, networks }\end{array}$} \\
\hline & $\begin{array}{l}\text { - Initial budget allocation, up to } \$ 40 \text { million in } \\
\text { 2015, mainly from Ministry of Tourism } \\
\text { - High-level policy support } \\
\text { - Bike sharing system is small but being } \\
\text { expanded }\end{array}$ & $\begin{array}{l}- \text { Budget allocation very } \\
\text { limited up to now } \\
\bullet \text { Bottom-up policy initiatives } \\
\text { - Philippines is significant } \\
\text { bicycle exporter } \\
\text { - Bike sharing system very } \\
\text { limited and no clear plans } \\
\text { for large scale } \\
\text { implementation }\end{array}$ \\
\hline & \multicolumn{2}{|c|}{$\begin{array}{l}\text { - Synergy with public transport (first/last mile connectivity), particularly given } \\
\text { urban rail expansion } \\
\text { - Cycling clubs (for recreation) and events } \\
\text { - Media like cycling } \\
\text { - Bicycle industry is significant and growing: employment benefits } \\
\text { - Bicycle-themed cafes and shops } \\
\text { - Business benefits for local communities along cycling routes }\end{array}$} \\
\hline \multirow[t]{2}{*}{$\begin{array}{l}\text { Inducement } \\
\text { mechanisms (step 5). } \\
\text { Based on existing } \\
\text { information and } \\
\text { current trends }\end{array}$} & \multicolumn{2}{|c|}{$\begin{array}{l}\text { - Increasing congestion could build momentum for 'alternative' mode } \\
\text { - Investments in public transport } \\
\text { - Attention to health benefits, 'healthy city' } \\
\text { - Climate change: cycling fits into e.g. 'low-carbon society' } \\
\text { - Other policy objectives, such as well-being, equity, air quality, noise reduction } \\
\text { support cycling } \\
\text { - Flat terrain } \\
\text { - 'Incremental' infrastructure improvements }\end{array}$} \\
\hline & - Bangkok promoted as 'City of Happiness' & \\
\hline $\begin{array}{l}\text { Blocking mechanisms } \\
\text { (step 5). Based on } \\
\text { existing information } \\
\text { and current trends } \\
\text { as well as potential } \\
\text { future mechanisms }\end{array}$ & \multicolumn{2}{|c|}{$\begin{array}{l}\text { - Culture, potential unwillingness of population to cycle (though no conclusive } \\
\text { evidence exists) } \\
\text { - Climate: temperature, humidity, precipitation, exposure to sunlight are } \\
\text { considered barriers } \\
\text { - Personal benefits of cycling are not well communicated or emphasised } \\
\text { - Air pollution and general environmental condition of the cities are not } \\
\text { conducive } \\
\text { - Lack of coordinated and high-quality planning, lack of budget or policy low } \\
\text { priority } \\
\text { - Lack of willingness to take 'unpopular' measures (TDM, traffic management) } \\
\text { - Inadequate knowledge and lack of data on the relation between investments } \\
\text { and benefits (see also section 2.2); potentially low usage of bike lanes being } \\
\text { built, reducing political willingness for further policies } \\
\text { - Isolated measures, sometimes introduced for image reasons, rather than } \\
\text { comprehensive vision and planning } \\
\text { - Competition with motorcycles and relatively convenient paratransit (a } \\
\text { politically powerful interest group) } \\
\text { - Unclear whether the current advocacy coalitions have sufficient power to } \\
\text { make sure progressive policies will be developed and implemented }\end{array}$} \\
\hline
\end{tabular}




\begin{tabular}{|c|c|c|}
\hline & $\begin{array}{l}\text { clear whether majority of society considers } \\
\text { ling an appropriate means of transport } \\
\text { e-bike policies yet } \\
\text { eet vendors may oppose cycling on } \\
\text { ewalk }\end{array}$ & \\
\hline \multirow[t]{2}{*}{$\begin{array}{lr}\text { Policy issues: options for } \\
\text { immediate or future } \\
\text { consideration by } \\
\text { national and local } \\
\text { decision makers } & \text { (step } \\
\text { 6). Based on } \\
\text { preceding } & \text { TIS } \\
\text { steps, local and } \\
\text { international } \\
\text { literature and } \\
\text { summary from } \\
\text { Bakker et al. (2016) } \\
\end{array}$} & \multicolumn{2}{|c|}{$\begin{array}{l}\text { - Invest in quality infrastructure based on cycling-inclusive planning; } \\
\text { improvements can be incremental, but should be of high-quality in order to } \\
\text { show commitment and create 'status' for the cyclist and follow a plan } \\
\text { towards a comprehensive network } \\
\text { - Carry out comprehensive ex-ante evaluations including cost-benefit analysis } \\
\text { for infrastructure } \\
\text { - Analyse propensity to cycle of urban population, e.g. based on categories } \\
\text { from Dill and McNeill (2012) } \\
\text { - Develop supporting policies including national and urban cycling strategies, } \\
\text { cycling-friendly road and intersection design standards, incentives for electric } \\
\text { bikes, liability laws in favour of cyclists and education and communication } \\
\text { promoting cycling to the public as a 'normality' and convenient daily } \\
\text { transport mode (Nongnuch, 2015), e.g. through projects such as bike to } \\
\text { school } \\
\text { - Implement traffic management and TDM measures, potentially including } \\
\text { restrictions or disincentives for paratransit and motorcycles } \\
\text { - Engage private sector in e.g. bike sharing, rental and bicycle parking, as well } \\
\text { as bike industry } \\
\text { - Ensure sufficient staff in local governments dedicated to cycling and build } \\
\text { capacity for planning } \\
\text { - Work with and strengthen the advocacy coalition } \\
\text { - Support knowledge development by funding research programmes, } \\
\text { conferences, curricula } \\
\text { - Make use of national and international knowledge and best practices, though } \\
\text { avoid copying without consideration or employing only foreign consultants. } \\
\text { Ensure appropriateness in the local application } \\
\text { - Adopt targets related to increasing cycling modal share, gather data and } \\
\text { develop a monitoring system }\end{array}$} \\
\hline & & \\
\hline
\end{tabular}

Table 6.2 and Section 6.3 illustrate a significant theoretical potential to increase the cycling modal share in both ASEAN cities. However, to harness this potential, barriers need to be addressed. Key gaps in the current TIS include limited knowledge development (including data), actor networks, advocacy coalition, e-bike adoption, infrastructure, resource mobilisation and legitimation; the latter due to issues such as car-oriented planning, competition from motorcycles and paratransit, weak bikefriendly policies, and potentially limited public acceptance. These gaps, together with mechanism that (could) promote or block cycling development, lead to a set of policy recommendations as provided in Table 6.2. 
Given the preceding overview and analysis, what can be said about the future of cycling in tropical megacities in the ASEAN? Can it become a mainstream practice with modal shares in the range of $5-30 \%$ or will it remain a niche? Obviously, both are possible. Addressing (most of) the policy issues can be seen as necessary conditions to move beyond cycling as a niche; without implementing these policy recommendations with the required resources the modal share is unlikely to go up significantly ${ }^{53}$

Many cities across the globe aim to increase the role of cycling, spearheaded by Dutch and Danish cities where in excess of $30 \%$ of urban trips are by bike, followed e.g. by German cities where significant policy efforts also resulted in modal share growth of over 2\%-points between 2002 and 2008 in three cities (Lanzendorf \& Busch-Geertsema, 2014). In Bogotá, there has been a substantial increase from $0.58 \%$ in 1998 to $5 \%$ modal share a few years later, however then it stagnated due to lack of safety in crossings, reduced policy interest in cycling during eight years of poor mayoral mandates, lack of funding, and lack of institutional follow-up (Pardo, 2013b).

If we compare Bangkok and Metro Manila to these cities, it is clear they are in a relatively early stage - with lack of bicycle infrastructure resulting in low safety - and policy efforts will need to be sustained for years if not decades to see results. The same can be said for advocacy coalition, which are not yet well-developed in either city, as shown by the example of Santiago which had a civil society movement already since the late 1990s. The members were able to build up momentum and gain successes in the course of many years through collaborative planning processes (e.g. the Citizen-Government Roundtable for Cycle-Inclusion), and increase the modal share from 2\% in 2006 to 4\% in 2012 (Sagaris \& Ortuzar, 2015). We did not find examples of cities that invested heavily in infrastructure for more than ten years, and where no seeing a significant increase in cycling resulted, though it may well be that this will be found in the future, as many cities have been developing bike lanes since recent years.

Singapore may be able to provide interesting lessons in the future as well, as the city has started in 2013 expanding the bicycle network from the existing $200 \mathrm{~km}$ to 700 $\mathrm{km}$ by 2030. The existing segregated bike lanes are mainly part of the Park Connector Network. The planned network focuses on improving footpaths to accommodate cyclists together with pedestrians, as well as dedicated cycle tracks; on-road cycling lanes are not considered. Both intra-town cycling, especially integration with public

53 The example of Tokyo, with a 16.5\% modal share in 2008 (Pucher et al., 2012) despite absence of dedicated bike lanes, shows it is not impossible. 
transport, and cycling between towns, are promoted. The Singaporean town of Tampines was the first to develop a full network, which resulted in a significant increase in cycling levels on upgraded stretches, particularly near the metro station, even if starting from a low base of peak rates between 10 and 100 cyclists per hour (Nguyen et al., 2015). Compared to most ASEAN cities, it should be noted that Singapore currently has much higher quality footpaths and more space to expand. Although the approach could work elsewhere - provided it is implemented well - it is recommended to monitor the results and experiences with shared pedestriancycling lanes in Singapore, and evaluate carefully before implementing elsewhere.

However, even if policymakers, planners and other stakeholders follow international best practices, spend resources accordingly, and are able to make the necessary and often politically difficult choices, the future of cycling cannot be predicted: ultimately cycling as a daily practice is a human behaviour change issue. At this point in time it is not known, and arguably cannot be known fully, what the conditions are in these cities, or any city with a currently low modal share, that would result in mass cycling as seen in Vietnamese cities in the $20^{\text {th }}$ century; and whether such conditions are desirable and acceptable. Research and monitoring can only assist decision makers and reduce uncertainty, while time will tell the impact.

\subsection{Conclusions}

In recent years, cycling gained public interest in ASEAN at the regional, national and local level. This paper set out to analyse the current situation and future potential of cycling as a mode of transport in ASEAN's megacities using the Technological Innovation Systems (TIS) framework as a research method and applied to Bangkok and Metro Manila.

The two cities are relatively comparable in many aspects of cycling. Starting from a low base, both cities acknowledge cycling as a key option to achieve sustainable urban transport and public health objectives by policymakers and media. The bicycle is often used by both the poor for short trips as well as the more affluent for sports, recreation and fun activities. As a fashion symbol, group activities, social media and events, cycling or the bicycle is very popular. As a comfortable choice for transport purposes, cycling is still a niche and not (yet) an established culture. The TIS analysis shows that common elements not conducive to cycling include limited knowledge development, actor networks, advocacy coalition, e-bike adoption, infrastructure, resource mobilisation and legitimation; the latter due to issues such as car-oriented planning, competition from motorcycles and paratransit, few bike-friendly policies, and potentially limited public acceptance - with weather being one among several factors. On the other hand, flat terrain, attention for cycling for health and 
environment, heavy congestion, expansion of public transport, growing bike industry, active university communities, emergence of advocacy coalitions and a potential to fit with cultural values could open up opportunities.

Although initial investments in infrastructure dedicated to cycling are being made, these are fragmented. Integrated plans or visions are missing. Especially in Bangkok, cycling infrastructure appears being more for recreation and health rather than transport, and it is not clear at the moment to what extent policymakers believe cycling can play a significant role in urban transport, despite high-level supportive statements and development of policies. In Manila there is a strong bottom-up approach, both in civil society and policymakers, who are proposing regulations supporting cycling, but given the absence of a comprehensive national policy to mainstream cycling in the transport system, challenges remain.

To move cycling beyond a niche transport practice and achieve a transition to significant modal shares, incremental but consistent improvements in infrastructure focusing on a comprehensive network based on cycling-inclusive planning are required. This implies creating adequate conditions for safe cycling in as many roads as possible - which may or may not require segregation. Other policy issues include 1) improving regulations to protect cyclists, 2) education and communication strategies towards bicycle use and respect for cyclists, 3) progressive transport demand management policies, 4) ensuring sufficient dedicated staff in relevant government institutions, 5) promotion of e-bikes as a convenient option in a tropical climate and alternative for motorcycles, 6) data and monitoring, 6) working with the private sector and 8) enhance the advocacy coalition.

We found the TIS framework can readily be applied - although not a perfect fit even to a technology that has been around for more than a century but re-emerging and gaining popularity in recent days. It provides a practical approach to investigate missing elements or functions in the current system and identify policy issues. It provides a practical approach to investigate missing elements or functions in the current system and identify policy issues. TIS is useful as it analyses the entire 'technology system' comprehensively and specifically focuses on what policymakers can do to address blocking factors; it forces the researchers to think more broadly about issues which otherwise might have been missed, e.g. knowledge development, advocacy coalitions, industry development. As TIS is often applied to and oriented towards new and complex technologies developed by the private sector, applying the functions of knowledge development and entrepreneurial experimentation is perhaps less straightforward. However, overall TIS provided a helpful framework for our analysis and policy recommendations. 
Future research may look into more detailed data on cycling trips and their characteristics, a comprehensive study into the potential for cycling in tropical megacities and the conditions under which these potentials can be achieved, especially for ASEAN megacities where motorcycles are a dominant mode of travel, and the propensity of recreational cyclists to start cycling for daily mobility. 


\section{Chapter 7}

Synthesis and conclusions

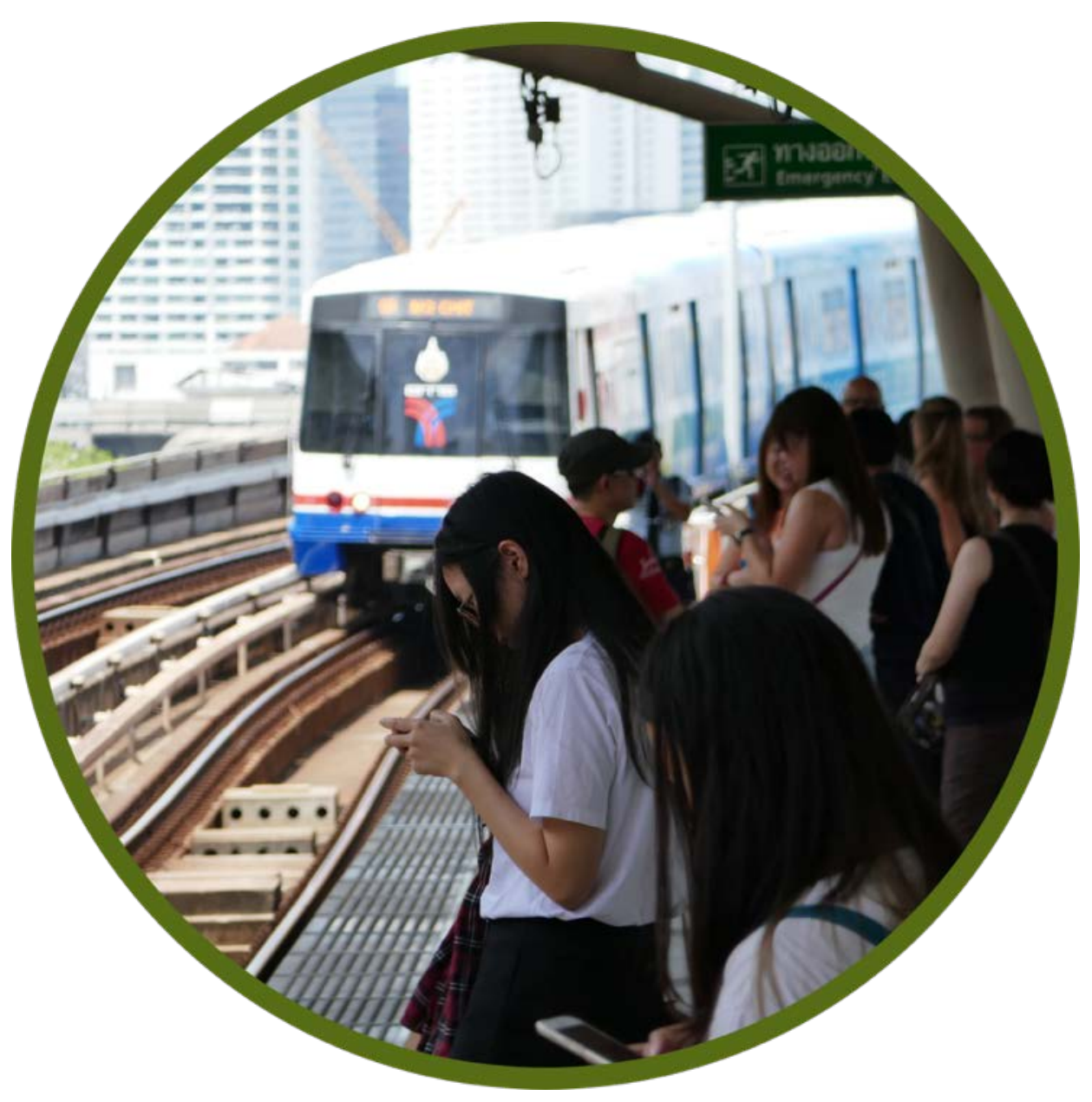


The main research question of this thesis was: What are current policy responses to sustainability challenges in the transport sector and how can these be strengthened, particularly for climate change mitigation in rapidly motorising ASEAN countries?

The five research sub-questions, covered in Chapters 2-6, are:

- How can the nexus between development, transport and climate change mitigation be characterised, and what would a framework that emphasises these aspects, look like for the transport sector?

- Which international climate change policy instruments currently in place and being proposed would be most effective in promoting sustainable, low-carbon transport policy in developing countries?

- How does regional (international) cooperation address sustainable transport, and how can such cooperation strengthened?

- How can the current national policy framework for low-carbon transport in ASEAN countries be characterised?

- What is the current status and outlook for cycling as a mobility option in ASEAN cities?

Section 7.1 syntheses and assesses the main conclusions based on these questions.

The following sections addresses overarching findings not included in the previous chapters. Section 7.2 and 7.3 look at broad trends and multi-level governance in lowcarbon transport, respectively (see fourth research gap identified in Section 1.4). Section 7.4 discusses how the policy framework developed in Chapter 2 is used in the subsequent chapters. Section 7.5 and 7.6 summarises this thesis' contribution to academics and practice, respectively, after which I will end with recommendations for future research.

\subsection{Main conclusions from Chapter 2 - 6}

Policy development in the transport sector in the ASEAN region is not yet in line with global climate change and sustainable development objectives, however policies undertaken in the context of sustainable development support low-carbon mobility.

An overall conclusion of this thesis is that initial low-carbon transport policies are being developed and implemented at different levels of jurisdiction in the rapidly motorising region of Southeast Asia, however these do not yet lead to the transition needed to meet the Paris Agreement objective of staying well below 2 degrees warming (see Section 7.2). 
The global climate change agenda is being reflected at the national level, but only to a limited extent at the ASEAN regional and local level, in policy and institutional development.

The Avoid - Shift - Improve approach needs to be expanded with Access, Lifestyles and Transition considerations in order to be an effective framework that does justice to the distributional, systemic and behavioural aspects of (low-carbon) transport policy.

Chapter 2 proposes a framework to integrate transport, development and climate change mitigation by combining lifestyles, access, transitions and ASI-approaches. Existing frameworks and approaches for transport policy and planning increasingly emphasise the need to move from a narrow focus on mobility and vehicular travel, to a broader view on accessibility. Accessibility in this context refers to the proximity of people to opportunities and the relative ease at which these can be reached. To optimise the contribution of transport to economic and social development, it is key to manage the demand for transport rather than building more infrastructure to meet an ever-increasing demand.

To address environmental challenges in the transport sector, the Avoid - Shift Improve (ASI) approach was proposed in 2007. ASI suggests that for low-carbon transport, policy and planning should look at 1) reducing the need to travel, 2) shifting to more environmentally-friendly transport modes, and 3) improving the carbon-efficiency of vehicles and fuels. This also implies that both technological and behavioural change is required to enable a long-term transition to low-carbon, sustainable transport.

Therefore, ASI should be combined with a development focus based on accessibility and thinking on sustainable lifestyles and transitions, thereby establishing a comprehensive policy framework for sustainable transport. This framework is applied in the regional, national and local level policy analysis of this thesis.

The newer international climate instruments, including those resulting from the Cancun Agreements (2010) (in particular NAMAs) and the Paris Agreement (NDCs, GCF), which are partly still under development, show more potential than the Kyoto Protocol instruments to promote sustainable and low-carbon transport, as they are better aligned to national circumstances and better suited to address the barriers that developing country policymakers face.

Chapter 3 concludes that in carbon trading instruments such as the Clean Development Mechanism, the transport sector does not play a significant role with approximately $1 \%$ of the projects and limited impact on the ground. This is due to 
stringent requirements for monitoring emission reductions, and the relatively small financial contribution from the credits as compared to total project investment. In the Clean Technology Fund and the Global Environment Facility, transport plays a larger role (SLoCaT, 2016) ${ }^{54}$, and the Green Climate Fund, which has been operational since 2015 , has the potential to play a role.

Nationally Appropriate Mitigation Actions are a better fit with the transport sector, than the CDM, as they tend to include technical as well as financial assistance, and programmes can be tailored to the needs of the countries. Thereby they support policy development at the national and local level. As NAMAs do not involve carbon trading, monitoring requirements are flexible and lack of data is less of a barrier. There is also a role for sustainable development co-benefits, and the potential for transformational change, when assessing NAMAs. In the newer Green Climate Fund, transport is one of the eight key result areas.

Since 2011, significant effort has been put in developing transport-NAMAs, and as of mid-2017, 11\% of the 229 existing NAMAs are in the transport sector, which is almost proportional to the sector's contribution to global greenhouse gas emissions $(14 \%)$. However, few NAMAs are in the implementation stage yet and securing funding is a challenge due to limited available funding compared the proposals developed. If climate finance can be used more effectively to leverage finance from development banks, domestic public and private sources, the impact of NAMAs could be larger.

ASEAN instruments around transport focus on policy cooperation and reflect "networked regionalism". Sustainable transport has played a relatively small role in ASEAN cooperation but this role is growing; a range of "soft" measures can be used to promote low-carbon transport.

As shown in Chapter 4, since the 1990s, transport cooperation in the ASEAN has focused on promoting connectivity by cross-border infrastructure and reducing regulatory barriers. Sustainable transport was included in the ASEAN Kuala Lumpur Transport Strategic Plan 2016-2025 (KLTSP) for the first time as a dedicated chapter.

Actions in this KLTSP chapter focus on topics such as fuel economy, green freight, non-motorised transport, data and indicators, capacity building, and strategy development based on the avoid-shift-improve approach. Instruments include knowledge sharing, information platforms, development of a regional strategy,

\footnotetext{
${ }^{54}$ Compared to the period up to the year 2010, when Chapter 3 was published, these funds have approved a relatively larger share of transport projects.
} 
roadmap and action plan, training, workshops, expert groups and development of guidelines. Such 'soft law' measures are common in ASEAN cooperation settings, with its preference for consultation and networking, dialogue, non-interference, and soft diplomacy.

Although sustainable transport supports a range of objectives in ASEAN strategies outside the transport sector, these are not acknowledged explicitly. There are no references to the global agendas on sustainable development and climate change in the KLTSP, and a mechanism to collaborate with other relevant sectors such as energy and environment, is not yet established. To strengthen policy and technology cooperation on sustainable transport, several instruments could be used. These include harmonisation of standards, coordination of research, infrastructure action plans, high-level policy dialogues and a joint vision, supported by development of a monitoring system and improved institutional structure.

Countries' policy objectives are in line with international SD and climate goals, but the instruments, mechanisms, calibration don't add up to the objectives. The focus is mostly on Shift and Improve, as public and political support for "Avoid" is limited. Climate change has, in a few cases, led to policy windows for modifying transport policy.

Chapter 5 analyses the current status of policies on sustainable transport and climate change in Indonesia, the Philippines, Thailand and Vietnam, using a taxonomy of Howlett and Cashore, who distinguish six policy components. We found several common elements across the four countries. First, at the level of policy ends, each country has a set of goals, objectives and specific targets or settings in policy plans and strategies that support sustainable transport, and, directly or indirectly, climate change mitigation. Second, looking at the component of policy mechanisms, all four countries are active in development of nationally appropriate mitigation actions in the transport sector. In the realm of transport demand management and "Avoid" strategies, policies and measures are in an early stage of development or absent. Shift and Improve measures are generally more developed. Third, the policy ends are not always consistently matched with the policy tools.

There are notable differences as well: (i) a policy objective to limit motorisation was only found in two countries, while the others do not address this explicitly; (ii) as part of the instrument logic, the Avoid - Shift - Improve approach is used in transport policy documents in two countries, however as yet it does not appear to have major importance as a framework to structure and develop policies; and (iii) with regard to policies to improve vehicle fuel efficiency, the use of different policy mechanisms and their calibrations varies strongly from one country to the other. 
Although climate change mitigation is generally of lower concern for transport policymakers compared to improving efficiency of the transport system and reducing local impacts, we found significant attention to the climate change agenda, pointing at an increasing role of climate change in national transportation policy. Climate change is addressed in key transport policy documents and is becoming relevant as a policy driver. Moreover, institutions are being set up to specifically deal with transport and climate change.

The policy review in Chapter 5 also shows that a range of ASI policies are being discussed, developed or implemented, which could result in significant emission savings compared to business as usual. However, stabilisation or an absolute reduction in GHG emissions from transport, which would be required to stay below the temperature limits in the Paris Agreement, is not likely in the near future, nor are long-term plans in place that enable a transition to climate-compatible transport development.

Cycling receives much media attention in ASEAN megacities and fits with societal trends on health and active living, yet for mobility purposes policy development is still in an early stage, and may lack 'legitimation' and market formation.

Chapter 6 concludes that policymakers and media in Bangkok and Manila acknowledge cycling as a key option to achieve sustainable, low-carbon urban transport and public health objectives. The bicycle is used by the poor for short trips, and by the more affluent for sports, recreation and fun activities. As a fashion symbol, group activities, social media and events, cycling or the bicycle is very popular among the more affluent. As a mobility option, cycling is still associated with poverty and therefore remains a niche and not (yet) an established culture.

Using a Technological Innovation Systems framework, we show that common elements not conducive to cycling include limited knowledge development, actor networks, advocacy coalition, e-bike adoption, infrastructure, resource mobilisation and legitimation; the latter due to issues such as car-oriented planning, competition from motorcycles and paratransit, and potentially limited public acceptance - with weather being one among several factors. Although initial investments in infrastructure dedicated to cycling are being made, particularly in Bangkok, these are fragmented and there are no integrated plans or visions. On the other hand, flat terrain, attention for cycling for health and environment, heavy congestion, expansion of public transport, growing bike industry, active university communities, emergence of advocacy coalitions and a potential to fit with cultural values, could open up opportunities. 
To move cycling beyond a niche transport practice and achieve a transition to significant modal shares, incremental but consistent improvements in infrastructure, focusing on a comprehensive network based on cycling-inclusive planning, are required. Other policy issues include 1) improving regulations to protect cyclists, 2) education towards bicycle use and respect of cyclists and communication, 3) progressive transport demand management policies, 4) ensuring sufficient dedicated staff in relevant government institutions, 5) promotion of e-bikes as a convenient option in a tropical climate and alternative for motorcycles, 6) data and monitoring, 7) working with the private sector and 8) enhancing the advocacy coalition.

These findings are specific to the case of cycling, however a similar approach can be used to identify policy challenges for other sustainable urban mobility options, such as electric vehicles (including two and three-wheelers), cars and buses, intelligent transport systems, water transport, mass rapid transit systems and green logistics systems.

\subsection{Low-carbon transport policy: observations and options}

Transport GHG emissions in emerging ASEAN economies are growing rapidly, driven by motorisation. A downward bend of this emissions trend cannot be observed yet. However, per capita emissions are still much lower (0.4-0.8 tonnes) compared to OECD country emissions. For example, the EU average is approximately 2 tonnes (EEA, 2016), but have stopped increasing. Saturation levels of car ownership and use may be lower in ASEAN compared to OECD due to lack of road space in ASEAN cities. For example, in Vietnam many car owners use a motorcycle for their daily commute for its convenience and flexibility. Yet, even if ASEAN per capita transport emissions may not reach current OECD levels, for long-term decarbonisation (e.g. to 0.33 t/cap, ITPS \& Clean Air Asia, 2014) transformational change is required and current policy effort remains insufficient.

In this context, it is hopeful that the Nationally Determined Contributions submitted by ASEAN countries include transport mitigation actions. These actions are mainly based on existing policies and strategies, as well as inputs from stakeholders. No assessment that could indicate whether or not the NDCs will result in a significant deviation from business-as-usual of transport emissions in 2030 has been done. Regardless of this emissions impact, however, Chapter 5 shows that climate change is increasingly being considered in policy development, can create policy windows, and helps framing of transport policy issues such as fuel efficiency and public transport. Policymakers realise the Paris Agreement and NDCs are here to stay. Therefore, the impact should be evaluated in broader terms than merely on which low-carbon transport measures are developed and implemented. As shown in 
Section 3.5 and 5.4, there are institutional changes, initiation of policy development processes, development of low-carbon scenarios, increased efforts for data gathering, and reporting efforts. All of these may have an 'enabling' impact on sustainable, low-carbon transport policy.

Chapter 1 argues that objectives other than climate change are stronger drivers for transport policy. Such objectives are captured by the Sustainable Development Goals (SDGs), agreed globally in September 2015. Chapter 4 (and literature such as United Nations, 2016) show sustainable transport contributes directly to SDGs related to health, energy, cities, sustainable consumption, climate change, economy, and industry and infrastructure. Chapter 6 suggests that promoting cycling as a mobility mode would support a range of policy objectives, including climate change mitigation, industry development, health and sustainable urban development. This is in line with ECF (2016), which highlights the contribution of cycling to the SDGs.

Some of the SDGs that are supported by sustainable transport correspond with transport policy objectives but others don't. In Chapter 5, for example, we find that the four ASEAN countries we examined have adopted a range of quantified targets that would support low-carbon and sustainable transport, including on public transport modal share, GHG emission reduction, energy savings, energy selfsufficiency, alternative energy and production of electric vehicles. In addition, economic drivers such as reducing congestion and promoting the vehicle industry appear to be relatively prominent. These may support low-carbon transport in the form of measures to promote public transport or production of fuel efficient cars, but another common policy response is to create more road space for private vehicles - further inducing travel demand - and less for other, more sustainable, modes.

Chapter 5 also suggests a gap between policy ends and policy means. A case in point is reducing congestion, which, as a policy goal, has helped putting 'limiting motorisation' on the agenda. Yet, development and implementation of instruments to realise this, such as high taxes, vehicle quota, low-emission zones and road pricing, are limited in most ASEAN countries. This gap suggests car-oriented policy and planning is still prevalent. The only examples of large high-density cities that have succeeded in adopting a more systemic approach to sustainable urban transport by limiting motorisation and having high-quality public transport - are arguably Singapore, Hong Kong and some Chinese cities. These have in common a strong government and tradition of urban planning, as well as financial resources.

What needs to be done to enhance sustainable, low-carbon transport policy development? Based on the preceding chapters, as well as further policy analysis in 
all ten ASEAN countries (Bakker, forthcoming) and discussions with policymakers, a number of suggestions can be made for low-carbon transport strategies and action plans. As shown schematically in Figure 7.1, the suggested elements are divided into overarching framework, policy domains, and crosscutting and supporting actions.

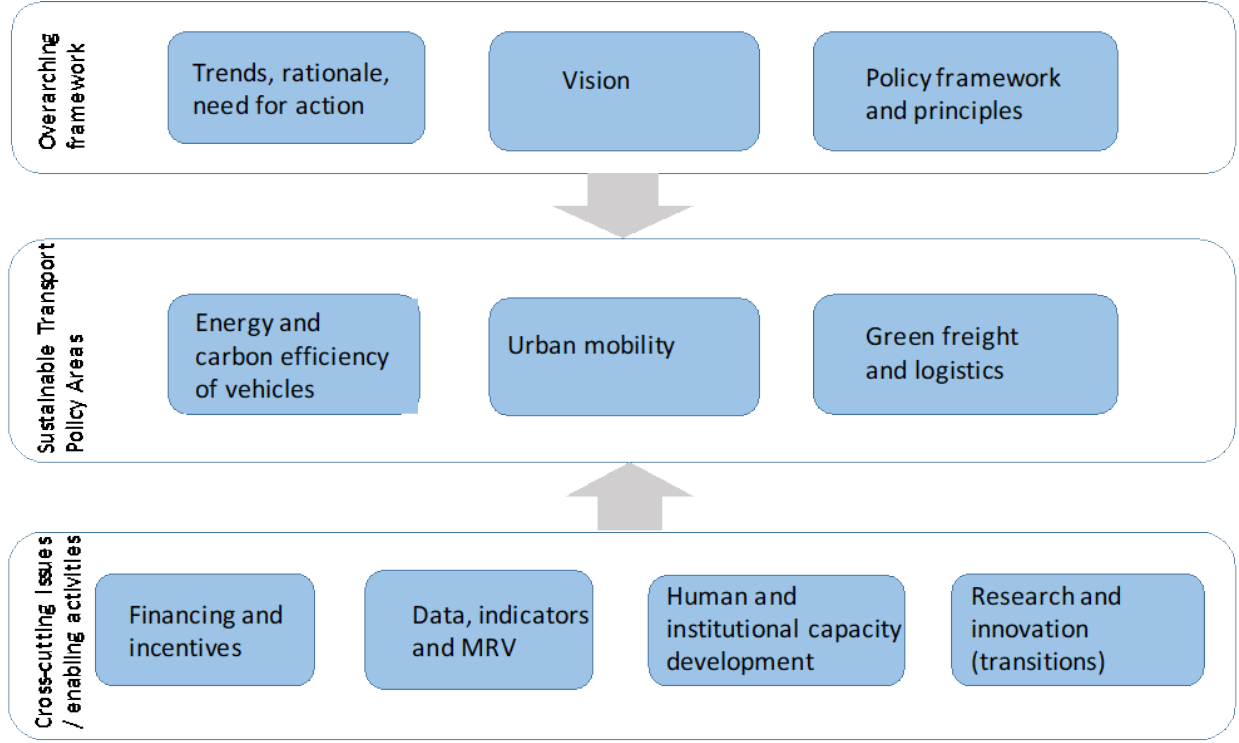

Figure 7.1 Suggested elements for national low-carbon transport strategies, organised by overarching, policy and enabling components

The overarching elements include a rationale for action, part of which is an analysis (quantitative if possible) of impacts of the current transport system on sustainable development aspects, e.g. through the SDG indicators. Second, as many actions have long lead and payback times, a long-term vision, e.g. for 2040 or 2050, on sustainable transport needs to be developed, which addresses the need for a transition or transformation to achieve the global goals on climate change and sustainable development. Building on this vision, a policy framework is needed that includes e.g. a focus on 'access', or 'moving people rather than vehicles' 55 , Avoid-Shift-Improve policies, consideration of sustainable lifestyles and transition management. In addition, setting quantitative targets and developing scenarios to realise the longterm visions and policy objectives for accessibility, energy efficiency, modal share, active transport, air pollution, low-carbon or zero-emission vehicles, etc., help to steer policy efforts, particularly if these are translated into key performance indicators in the responsible government agencies.

Addressing GHG emissions from (surface) transport calls for action in at least three policy domains (see middle pane in Figure 7.1). First, (mostly national) policies are

55 This implicitly acknowledges the need for integration of transport and land-use planning 
needed to reduce emissions per vehicle-kilometre ('improve' strategy), such as standards and incentives to promote fuel economy improvements and alternative drive trains for different types of vehicles as well as required infrastructure. Second, sustainable urban mobility policies (mostly 'avoid' and 'shift') require, inter alia, specific attention for non-motorised transport, (electric) two-wheelers ${ }^{56}$, transport demand management, intelligent transport systems, land-use integration, and national support programmes for urban mobility. Third, green freight and logistics programmes should target improving truck load factors, optimisation of logistics, modal shift from road to rail and water transport, and improving energy-efficiency of truck fleets ('avoid', 'shift' and 'improve' strategies).

Crosscutting actions (lower pane in Figure 7.1) that have an enabling role in developing and implementing such policies include the following. First, shifting investments from unsustainable towards sustainable, low-carbon transport options can be enabled by applying principles such as polluter-pays and an investment and project prioritisation framework based on sustainability criteria. Second, a more comprehensive system for transport and emissions data, indicators and monitoring supports the climate change reporting system, and, potentially, the transport policy development, decision, implementation and evaluation process. Third, human and institutional capacity building to improve skills with policymakers and enhance cooperation between agencies is required, e.g. through training, knowledge sharing events and setting up of working groups or new institutions. Finally, a research and innovation strategy, e.g. based on transition management approaches, helps to develop and adapt low-carbon transport technologies and policies through protected spaces and stakeholder platforms.

Most ASEAN countries already address many of these elements, yet there is significant scope for more comprehensive national strategies and strengthening existing policy efforts. Thereby, such strategies support the NDC and SDG processes, and help to slow down, and eventually reverse, the increasing trend in emissions.

\subsection{Multi-level governance in transport and climate policy}

Addressing climate change requires engagement of various levels and types of governance (Romero-Lankao et al., 2018). This thesis assesses policy at the global

\footnotetext{
${ }^{56}$ Motorcycles, despite their popularity with the public, are often seen as problem rather than a solution for efficient mobility by policymakers in Southeast Asia. Shifting to electric two-wheelers, as done on a large scale in China, would reduce local air pollution and life-cycle GHG emissions substantially (even in coal-based electricity grids (IEA, 2014)), however only in Malaysia and Singapore initial policy action promoting these was found.
} 
level (climate change and transport), regional (ASEAN transport cooperation), national, and local (cycling). How do these different levels of jurisdiction influence one another? We look predominantly at vertical policy integration, i.e. between different levels of governance (Stead, 2016; Elliot, 2012) in Type I institutions ${ }^{57}$ in multi-level governance (Hooghe \& Marks, 2003), i.e. within existing regional, national and local institutions. In general, it could be said that the different levels of government have different roles based on their mandates. The global climate instruments and ASEAN regional governance cannot develop mandatory legislation. However, these governance levels help putting climate change on the policy agenda, and promote international and regional cooperation through soft law and climate instruments. Thereby, global and regional governance supplement governance at the national and local level. The latter two have have a more extensive mandate to develop and implement laws and regulations across a wide range of policy issues, and need to balance a multitude of stakeholders and interests (Figure 7.2).

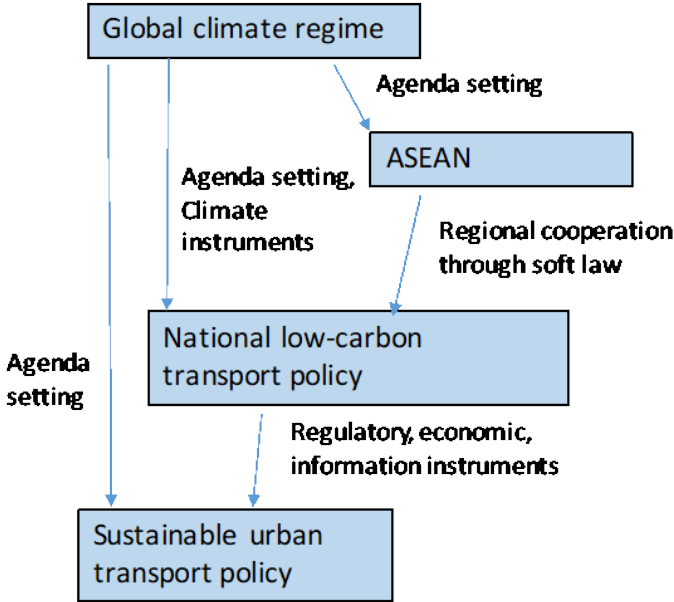

Figure 7.2 Examples of roles of levels of governance in low-carbon transport policy (which includes national energy and industry policies related to vehicles). Potential Impacts of 'lower' levels of governance to 'bigher' levels, e.g. by agenda setting from the urban to the national and ASE AN levels, are not shown for reasons of simplification

The global agenda of climate change, and, to some extent, sustainable development ${ }^{58}$, has had an impact on transport policy most clearly visible at the

${ }^{57}$ Type I institutions are those that have a range of policy responsibilities, are usually stable for several decades and often have a nested structure (e.g. international, national, meso, local); examples include national ministries of transport and local departments of transport. Type II institutions are more flexible governance arrangements which are often designed to address a particular policy issue or provide a specific service.

${ }^{58}$ Linkage between transport and sustainable development has been strong only since the adoption of the SDGs in 2015, therefore the impact of the SDG agenda may become more apparent in the future 
national level in ASEAN countries, as shown in Chapter 5. This suggests that climate change is a stronger policy driver at the national level than local or regional, potentially due to the fact that it is the national government that signs and ratifies the PA. Some countries (e.g. Thailand and Vietnam) have dedicated transport strategies in the context of climate change and/or sustainable development, and all countries include transport in their NDCs. In addition, inter-ministerial cooperation and coordination has grown because of the need to address GHG emissions, which could be seen as a facet of horizontal policy integration (Stead, 2016).

Due in part to different policy drivers, institutional responsibility for (sustainable) transport tends to be fragmented. At the national level, ministries of transport often focus on infrastructure, planning and regulations to facilitate mobility of vehicles and people. Traditionally, energy use and emissions of these vehicles are of lower concern (e.g. no key performance indicator on emissions), and are dealt with by ministries of energy and environment (and industry). In such an institutional setting, low-carbon transport - which requires addressing both the movement as well as energy use of vehicles - risks being a topic 'without a home'. However, the gap between ministries appears to be decreasing, through more regular interactions between policymakers of different sectors, e.g. in development of climate change strategies and scenarios in the transport sector.

In local level policy, framing of cycling as part of a 'low-carbon society' and the inclusion of cycling in the Thailand Mobility NAMA show the relevance of climate change policy for urban transport issues.

At the ASEAN regional level, climate change has been acknowledged in transport cooperation since 2011, however a stronger link with both the Paris Agreement and the SDGs will be made in an upcoming strategy on sustainable land transport. As noted in Section 4.5, the ASEAN Expert Group on Sustainable Land Transport was established in 2016 to address climate change and sustainable development in ASEAN transport strategies.

In ASEAN regional cooperation, predominantly 'soft' instruments (see Chapter 4) are used that can be seen in the light of "a shift in governance toward more networked arrangements and a more multi-actor, multi-level approach for governing" (Stead, 2016: p. 43). ASEAN does not have the mandate to develop mandatory legislation that its member states have to implement. However, regional networks of policymakers and experts focussing on a specific issue, e.g. fuel economy, could develop policies or standards that can become mandatory at the national (or regional) level in the future. It should be noted that due to the ASEAN Way, which emphasises cooperation and non-confrontational dialogues, 
benchmarking different countries on key indicators may not be considered an appropriate instrument. A more process-oriented approach, such as done in the biannual Forum of the ASEAN Fuel Economy Platform, which decision makers and experts exchange national policy experience and discuss regional approaches in regional workshops (see e.g. Imboden, 2017), would be more acceptable, and could also lead to regulatory changes at a later stage.

In addition, a key role of ASEAN is promoting and facilitating policy learning, by exchange of experiences between national and local policymakers. The potential benefits for policy development has been acknowledged, however to realise this in practice has proven difficult (Pojani \& Stead, 2015). This is due to differences in social and physical context, the need for political windows of opportunity to bring about change, and a complex institutional landscape of transport planners. In addition, technical capacity of government staff is often limited and there is a high turnover of staff, leading to loss of learning experiences. Finally, in ASEAN, exchange programmes are relatively limited in scope and number due to their reliance on international organisations and funding.

National transport strategies refer to ASEAN plans particular for regional infrastructure connectivity. Until today, however, they do not yet rely on ASEAN for sustainable or low-carbon transport. At the local level, no links to ASEAN have been found, however in the latest ASEAN transport plan, urban transport issues play a role in the sustainable transport chapter.

National level policies are of substantial relevance to local transport policy and planning, by means of infrastructure funding, regulations, incentives and information instruments. In the case of cycling (Chapter 6), examples include road design standards, planning laws, infrastructure budget allocation, broader policy framing and cultural norms, knowledge and actor networks, and information instruments such as campaigns.

These findings confirm conclusions by Romero-Lankao et al. (2018), who found that multi-level governance be effective in climate change policy by enhancing linkages between levels of government and between sectors. At the same time, the complexity of MLG in low-carbon transport policy should be acknowledged. For example, local governments in Indonesia have been struggling to translate national climate targets to local action in the transport sector (Jaeger et al., 2015). Wijaya (2017) shows that financial, socio-political and discursive tensions between international, national, provincial and local levels of governance caused difficulties in implementing BRT projects, leading to only partial implementation or even cancellation in Indonesian cities. 


\subsection{Conceptual framework: ASI + Access + Transitions + Lifestyles}

This section considers the elements of the conceptual framework discussed in Chapter 2: the role of the Avoid-Shift-Improve approach, 'access', 'transitions' and 'lifestyles' in transport policy, based on the findings in Chapter 3 to 6. Table 7.1 presents an overview of how these elements are reflected in the chapters.

Table 7.1 Application of conceptual framework in Chapter 3-6

\begin{tabular}{|c|c|c|c|c|}
\hline & $\begin{array}{l}\text { 3. Climate } \\
\text { instruments }\end{array}$ & $\begin{array}{l}\text { 4. ASEAN } \\
\text { Cooperation }\end{array}$ & $\begin{array}{l}\text { 5. National } \\
\text { policy }\end{array}$ & 6. Cycling \\
\hline Access & & $\begin{array}{l}\text { Regional } \\
\text { connectivity key } \\
\text { policy goal }\end{array}$ & $\begin{array}{l}\text { Transport } \\
\text { policy goal }\end{array}$ & $\begin{array}{l}\text { Cycling can } \\
\text { improve access } \\
\text { for all income } \\
\text { groups }\end{array}$ \\
\hline ASI & $\begin{array}{l}\text { Discussed as } \\
\text { categorisation of } \\
\text { transport } \\
\text { measures }\end{array}$ & $\begin{array}{l}\text { Acknowledged in } \\
\text { transport strategic } \\
\text { plan 2016-2025 }\end{array}$ & $\begin{array}{l}\text { Used in } \\
\text { some } \\
\text { country } \\
\text { strategies }\end{array}$ & Is 'shift' policy \\
\hline Transitions & $\begin{array}{l}\text { Some instruments } \\
\text { aim to catalyse } \\
\text { transformational } \\
\text { change, apply } \\
\text { elements of } \\
\text { transition } \\
\text { management }\end{array}$ & $\begin{array}{l}\text { Expert groups } \\
\text { and actor } \\
\text { networks are } \\
\text { developed at } \\
\text { regional level; } \\
\text { development of } \\
\text { standards }\end{array}$ & $\begin{array}{l}\text { No long- } \\
\text { term } \\
\text { strategies on } \\
\text { low-carbon } \\
\text { mobility } \\
\text { found }\end{array}$ & $\begin{array}{l}\text { None of the } \\
\text { cities discussed } \\
\text { apply } \\
\text { transition } \\
\text { management } \\
\text { to cycling }\end{array}$ \\
\hline Lifestyles & Not found & $\begin{array}{l}\text { Regional action } \\
\text { plan on healthy } \\
\text { lifestyles }\end{array}$ & $\begin{array}{l}\text { Touched } \\
\text { upon by } \\
\text { some } \\
\text { countries }\end{array}$ & $\begin{array}{l}\text { Is positioned } \\
\text { as part of a } \\
\text { healthy, active } \\
\text { lifestyle }\end{array}$ \\
\hline
\end{tabular}

\subsubsection{Avoid-Shift-Improve}

The Avoid-Shift-Improve (ASI) approach, originating in Germany in the early 1990s but revived internationally in 2007, has gained traction in ASEAN over the past decade. In Chapter 4 and 5 we find the ASI approach in multiple country strategies on transport and climate change, as well as in the ASEAN regional transport plan adopted in 2015. ASI may have been largely promoted by international organisations working in developing countries such as GIZ and SLoCaT. In Europe (EEA, 2016) and globally (OECD/ITF, 2017), ASI is also recognised as a necessary approach to addressing climate change in transport. Whether ASI also plays a role in developed countries' national strategies is not known.

Looking at each of the three strategies individually, particularly in the four ASEAN countries in chapter 5 , it can be seen that 'avoid' is relatively underdeveloped. In 
pricing of private transport, social and environmental costs are not fully incorporated, transport demand management policies, such as parking pricing, are often weak, and there is no evidence of use of ICT for teleworking.

When considering 'shift', it should be noted that it could be more appropriate to avoid a deterioration of the relatively high but decreasing public transport modal share in most countries (Vietnam being an exception). This is a priority especially in cities due to congestion, with considerable efforts going into mass rapid transit infrastructure such as metro and BRT, however progress on maintenance and upgrading of traditional bus systems (the backbone of urban mobility in most cities) is mixed.

In terms of 'improve', fuel efficiency of cars is slightly below world average in ASEAN, with improvement rates also below most other world regions due to relatively few policies in place. Electric vehicle policies are developed in some countries in which automotive manufacturing industry is present. As argued in Section 7.2, the role of electric two-wheelers for sustainable urban mobility is not well recognised.

One of the benefits of the ASI approach is to explicitly acknowledge the need to address both transport policy in terms of the transport system, as well as the environmental performance of the vehicles with which the transport demand is met. In addition to the institutional fragmentation in the national policy domain (energy/industry vs transport, see Section 7.3), the research and policy support community also has tended to either focus on transport or on energy/emissions. This has resulted in a focus on vehicle technologies in transport and climate change discourse and modelling ('technology fix') and underrepresentation of modal shift, transport demand management and logistics optimisation, let alone changes in economic and social systems that may lead to a lower need for mobility. However, such options have become increasingly acknowledged and included in scenario modelling, with the International Energy Agency for example noting on their transport webpage that "to meet the IEA 2 Degree Scenario targets requires implementing a broad set of policies, summed up as "Avoid, Shift, Improve"” 59 .

\subsubsection{Access}

Within ASEAN regional cooperation on transport, 'regional connectivity' is the predominant theme. Key strategies for improving connectivity are development of road, rail and port infrastructure and reduction of non-tariff barriers in the freight and logistics sector. ASEAN has a limited mandate when it comes to local and

${ }^{59}$ https://www.iea.org/topics/transport/ 
national level policy, where 'access' is more relevant. However, the issue of land-use and transport integration is included in the ASEAN Strategic Transport Plan 20162025 (KLTSP).

In our review of four ASEAN countries' policies in Chapter 5, accessibility as a concept played a limited role. We found that "in general, improving connectivity and transport infrastructure is the key goal in transport strategies, with 'accessibility' included in policy documents in Thailand (...) and Indonesia" (Section 5.4). Policy targets on average vehicle speeds and public transport mode share were found, yet these could be considered indirectly related to access at best. In a broader assessment for all ten ASEAN member countries, we found that Singapore has a target to have 8 in 10 households within a 10-minute walk from a rail station in 2030 (Bakker, forthcoming).

At the local level, reducing congestion is a key urban transport objective, but often looked at in terms of improving vehicle flow rather than moving people and convenient first and last mile access. There is less - yet increasing - attention for land-use policies such as transit-oriented development. Cycling is a good option to improve access, however Chapter 6 indicates that policies to promote cycling are mostly framed in a health, fun and environment context rather than as a serious mode of transport to improve accessibility on its own. As a first and last mile connectivity option together with public transport it is widely acknowledged, yet in policy and planning, let alone implementation, this is not yet reflected in ASEAN cities other than Singapore.

\subsubsection{Transitions}

As discussed in Section 1.3.4, addressing climate change and meeting sustainable development goals requires a transition to a sustainable transport system. Chapter 2 argues that transition studies can provide additional insights into possible long-term pathways to sustainable transport based on changes in the socio-technical regime. Here I explore briefly how developments in transport systems and policy in ASEAN and in climate instruments fit in the transition framework. It is loosely based on the elements of the transition management (TM) approach (Loorbach, 2007): problem structuring and organising multi-actor network; developing a joint vision and agenda; experiments; and evaluation, monitoring and learning.

The need for transformational change in the transport sector is widely acknowledged in international climate policy. Yet in national transport strategies and plans in ASEAN countries we have not been able find such references. This is in contrast to for example the European Commission, which published a Strategy for low- 
emission mobility in 2016, which refers to the 'transition to low-emission mobility' six times. In public discourses in Southeast Asia, sustainable development and climate change are emphasised to some extent, however the automobility is generally not directly framed as a huge problem other than for congestion and sometimes air pollution. The private car still enjoys a high status and is a good fit with cultural values. Building road infrastructure is the main transport strategy in most ASEAN countries, even if it is acknowledged demand management is required as well. In some countries, such as Thailand, coalitions have developed that aim to stimulate electric vehicle production and deployment through the Electric Vehicle Roadmap, which includes long-term targets.

As for policy experiments, in Manila and Bangkok investments in infrastructure and policy development for cycling for mobility have been made, however there have been no comprehensive pilots where cycling could develop in a 'protected space', with Singapore being the exception. There are some platforms for stakeholder discussion yet no joint visions and little data and monitoring. Learning is done to a certain degree in annual forums for experts and stakeholders.

According to Stead (2016), reallocating road space to more sustainable modes (such as bikes or buses) would be an example of 'more radical change' (as compared to incremental change). This has been carried out only to a limited extent in ASEAN cities, for example in the BRT network in Jakarta, and single BRT corridors in Bangkok and Hanoi.

Other transition experiments for sustainable transport include for example electric jeepneys in the Philippines, where the very popular but polluting and unsafe jeepney is framed as a problem now, and a coalition to produce and promote electric vehicles has formed. Policies to limit the growth of private vehicles are commonplace in Singapore and experimented with in other countries such as Vietnam.

At the ASEAN regional level, elements for transition pathways could include actor networks (e.g. the fuel economy expert group) and attempts at developing technical standards.

In climate instruments such as NAMAs ${ }^{60}$, some elements of transition management (TM) are considered and applied (Mersmann et al., 2014; see also Section 3.5). The focus is on scaling up of new but market-ready technologies that require limited financial assistance for implementation. They aim to bring about lasting regulatory changes that help the new technologies, which could be considered. Innovative and

${ }^{60}$ Within other climate instruments, such as the Green Climate Fund, there may be aspects of transition management as well (see Section 3.5.4), however experience is more limited. 
new technologies or practices ("niches" or pilots) may be favoured by e.g. the NAMA Facility fund in NAMA Support Projects, as long as the mitigation potential is significant, the potential for transformational change is clear (e.g. through replication) and the implementation risks are manageable. NAMAs can also support development of actor networks, and facilitation of vision development and reframing of policy problems and solutions, as well as policy development. The requirement and support for monitoring (MRV) in NAMAs may considered to reflect the fourth element of the TM approach. Examples for the transport sector include the transit-oriented development NAMA in Colombia (novel practice) and the sustainable urban transport NAMA in Indonesia which, inter alia, aims to enhance the national framework for urban transport projects and policy. It could be concluded that through climate instruments, TM approaches are introduced at the national and local level.

However, compared to the EU, where climate policy and actors at the supra-national level 'change the socio-cultural context and exert landscape pressure on the automobility regime' (Hoffmann et al., 2017; p. 404) and affect national and local transport policy, the multi-level governance system is less strong in ASEAN as of now.

\subsubsection{Lifestyles}

Lifestyles, including citizens' 'preferences' (World Bank Group, 2017), are a key determinant in the future of transport. Examples include level of vehicle ownership and use, shared mobility, adoption of electric vehicles, acceptance of public and nonmotorised transport and urban planning. In general, the choice for a particular regular transport mode that fits one's lifestyle could be considered being part of broader citizens' preferences. In Chapter 2 we suggest that sustainable lifestyles may need to be part of broadening the policy framework for sustainable transport, in particular in the context of behaviour change.

In Southeast Asia, there appears to be some attention for lifestyles in the policy realm. For example, the ASEAN Regional Action Plan for Healthy Lifestyles (2012) aims to "incorporate healthy lifestyle issues into public planning systems, especially with regard to transport and land use, safe transportation, [and] provision for pedestrian and non-motorized traffic". However, in the ASEAN regional transport plans no reference to lifestyles was found. For illustration purposes another regional transport policy example can be looked at. In the European Commission White Paper on Transport (2011) lifestyles is not touched upon either, rather it is explicitly stated that 'curbing mobility is not an option' (p. 5) and modal shift for passenger transport is neither discussed nor included as an objective. 
Private vehicles, particularly cars, are an important status symbol, and car ownership has been rising in all ASEAN countries except Singapore. Multiple countries include the need to limit motorisation as a policy objective qualitatively (Indonesia and Vietnam ${ }^{61}$ ) and quantitatively (Singapore, which limits vehicle fleet growth to $0.25 \%$ per year since 2012, aiming for $0 \%$ growth in the future). Public transport modal share objectives are common in ASEAN countries and cities.

Lifestyles, and their associated preferences and attitudes, have been found to be a key factor in mode choice, for example for non-working trips in Iran (EtminaniGhasrodashti \& Ardeshiri, 2015). In Chapter 5, we find that cycling fits in healthy, active lifestyle and concerns for the environment. Articles covering cycling in various media are sometimes about the bicycle as a lifestyle choice, rather than a means of mobility chosen for practical reasons. University students appear to be a group with relatively positive attitudes to cycling, both in Bangkok and Manila. We did not analyse the reasons for this, but potentially this could be due to a less strong preference for motorised vehicles compared to the older generations, however this may change when they start working and having families. For policymakers this could be an interesting target group for behaviour change policies, as it has been shown that attitudes are less fixed when 'life events' take place; in this case, the positive experience during student life should be nurtured. Beyond the bicycle, such policies may focus on e-bikes and electric motorcycles, which fit will in the current mobility system in most ASEAN countries where two-wheelers play a key role, and where are pollution is increasingly high on the agenda.

\subsection{Contribution and link to theory}

This thesis contributes to the academic literature by conceptual development on transport policy, application of multiple theoretical frameworks on policy studies and governance, and by the focus on Southeast Asia, a region underrepresented in peer-reviewed research on (transport) policy (see the research gaps identified in Section 1.4).

Chapter 2 connects thinking on sustainable transport policy with low-carbon development, the Avoid-Shift-Improve framework, the concept of 'access', as well as transition studies and sustainable lifestyles. Thereby it provides a comprehensive policy approach that emphasises the development aspect of transport, as well as the need for long-term changes required to meet climate change objectives. In addition,

${ }^{61}$ In addition, reference to 'greening lifestyles' was found in the Green Growth Strategy of Vietnam. 
it is still the only academic paper that elaborately discusses the ASI approach and traces back its origins to German literature of the 1990s.

In the following chapters and in this synthesis chapter, the A-ASI, lifestyle and transition concepts are applied to policy practice at the regional, national and local levels. For example, the ASI approach is being used at the regional level and in national strategies in some ASEAN countries. At the local level, cycling can be seen as an example of enhancing access while contributing to a shift strategy, while it entails a transition from current practice, which assumes a significant change in lifestyles.

Chapter 5 uses policy science to carry out a comparative analysis of transport policy in four ASEAN countries. It applies a policy component taxonomy developed by Howlett \& Cashore (2007), who build on Hall (1993). It has been applied to transport analysis before in the UK, however never in Asia. Using six different components, this taxonomy helps in understanding the relation between policy ends and means, and in highlighting differences and similarities in emphasis across the four countries analysed. Repeating this analysis, say after 5 and 10 years, could yield insights in policy innovation.

This thesis also contributes to the domain of transition studies by applying an established concept (Technological Innovation Systems, Bergek et al., 2008) to a novel 'case': cycling. Chapter 6 shows that doing so results in helpful insights for policymakers who seek to increase the modal share of cycling. Elements such as advocacy coalitions and industry development may have gone unnoticed in an analysis with a narrower focus. On the other hand, applying the TIS functions of knowledge development and entrepreneurial experimentation is perhaps less straightforward. In addition, relatively little literature exists on transition studies in Southeast Asia.

Finally, a contribution is in the realm of regional and multi-level governance. A common distinction in regional governance is that between hard law and soft law. However, a more elaborate typology was required to analyse transport cooperation in ASEAN, which did not exist, and therefore developed in Chapter 4. Its application fills a gap in literature, as land transport cooperation in ASEAN has not been dealt with in peer-reviewed literature before. Related to this, Section 7.3 integrates insights at the global, regional, national and local level in the context of multi-level governance. I show how global and regional policies have a supplementary role to national and local governments, mainly by agenda setting and cooperation instruments. 


\subsection{Linking academics and practice}

In this section, we discuss how this thesis contributes to policy practice. It does so in three ways: by conducting policy analysis, by including global discussions on the interaction of transport and climate change policy in academics, and by reflecting academic thinking in policy-relevant research and vice versa. With reference to Table 1.1 on how research can help addressing barriers to sustainable transport policy, this research contributes to ex-post analysis, comparative policy analysis, policy transfer, impact of policy paradigms, and regional cooperation options.

This thesis is relatively practice-oriented and in fact most results are based on concrete questions by policymakers and development banks. The research in Chapter 3 originated from the lack of transport-CDM projects and more generally underrepresentation of the transport sector in climate change discussions, which was signalled in 2007. Chapter 4 follows from an action item in the ASEAN Transport Plan 2016-2025, which calls for a regional strategy on sustainable transport, including the need to make a better link between ASEAN transport cooperation and the global agendas on climate change and sustainable development. The work from Chapter 5 is an input to the same strategy, however also aims at cross-country learning, best practice sharing and policy transfer. Both the large potential as well as the difficulty in accomplishing policy transfer is acknowledged (Pojani \& Stead, 2015). Policy analysis, especially multi-country/city studies such as in Chapter 5 and 6 , can help achieving this. In our policy support practice, the comparative analysis and best practice examples are used in national and regional workshops with policymakers and stakeholders in ASEAN, as well as in social media to inform the general public. In addition, more elaborate consultancy reports are also published online, and are easily accessible for interested stakeholders.

In the past ten years, a number of international organisations such as the SLoCaT Partnership, development banks, GIZ, UNESCAP and UNCRD have been doing a lot of work - e.g. through workshops and knowledge development - to link climate change and sustainable development to transport in developing countries ${ }^{62}$, and to bring transport into the global agendas of climate change and sustainable development. Examples include the Paris Process on Mobility and Climate (2014present) and the Bridging the Gap initiative (2008-2015). Key outputs include the Results Framework on Sustainable, low-carbon transport ${ }^{63}$ and annual reporting by the MDB Working Group on Sustainable Transport, formed by eight multilateral development banks (AfDB et al., 2017). This thesis brings some of this work to the

${ }^{62}$ For example the UNCRD Asia Regional Environmentally Sustainable Transport Forum

63 http://www.slocat.net/resultsframework 
academic domain, in particular, Chapter 2 on transport, climate and development, Chapter 3 on climate policy and transport, Chapter 4 on regional cooperation. For these organisations the time and incentives to produce peer-reviewed publications are not always there. However, recognition in the scientific realm may benefit practice and vice versa.

Low-carbon transport is a rapidly evolving field of scientific inquiry, both in peerreviewed and 'grey' literature. It is therefore of importance to translate developments in the realm of theory and science into policy practice. For example, the (draft) ASEAN regional strategy on sustainable transport, expected to be finalised in 2018, aims to reflect recent thinking on sustainable transport and the global agendas on climate change and sustainable development. Similarly, the evolving practice of policymaking needs to be properly documented and analysed in science (for example, Section 3.5), so that the academic world can take these into account and further develop concepts that can be applied to improve policymaking.

In addition, below a few remarks on the research and policy practice. First, a useful element of policy science is the public policy cycle (Howlett et al., 2009). The TCC project is playing a role in four of the five stages of the policy cycle, both at regional and national level: agenda setting, policy formulation, policy implementation and monitoring and evaluation. In presentations for project partners such as Ministries of Transport I've used this to explain the scope and approach of the project.

Regarding roles that researchers may play in the policy process, Pielke's (2007) distinction between the Pure Scientist, the Science Arbiter, the Issue Advocate and the Honest Broker is helpful. In my case, the Issue Advocate role is to some extent applicable, as I and the Transport and Climate Change in ASEAN project team were working in ASEAN based on the agreed objective to support policies and strategies that help reducing GHG emissions from transport. In addition, however, the Honest Broker role is also applicable, since we provide independent knowledge on policy options, including options that were not or less considered before, for example electric two-wheelers.

\subsection{Research recommendations}

What do the findings in this thesis mean for future work in academics and policy on transport and climate change? Topics and questions may include the following:

- There is a significant lack of ex-post analysis of policy processes in the ASEAN region. Theories of policy process such as the Advocacy Coalition Framework and the Multiple Streams Framework (Sabatier, 2007) could be applied and tested in a Southeast Asian context, and more specifically in the domain of 
transport policy. For example: What are effective ways of using climate change as a driver for sustainable transport, or sustainable development as a driver in transport policy?

- Assessment of policy change in sustainable transport, including choice for an appropriate methodology. This could be based on the policy component taxonomy and 'baseline' results in Chapter 5. This could result in better insights in what key factors can bring about necessary policy changes for a low-carbon transport system

- Research into effective policy transfer mechanisms or diffusion models (Berry \& Berry, 2007) could help making further use of these insights, i.e. policy learning

- Better linkage of sustainable transport policy paradigms and policy practice: how can the principles and concepts be applied to policy-making and implementation? What has been the impact to date of policy paradigms on policy development?

- What are effective and feasible technology and policy transition pathways to sustainable, low-carbon transport at the global, regional, national and local level?

- What does the application of transition thinking, consideration of 'lifestyles' and the Access + Avoid-Shift-Improve mean for transport and climate policy? Would this involve 'radical policy change' and if so, how could this take place?

- How can the implementation of the Paris Agreement, and more particular, transformational change, be monitored and evaluated for transport at various geographical levels?

- How can climate change instruments and - more broadly - international support be optimised so as to promote a transition to sustainable, low-carbon transport?

- How the multi-level governance and cooperation framework for sustainable transport be improved?

- How can the Technological Innovation System be analysed for key sustainable mobility solutions in Southeast Asia, such as electric two and three-wheelers? 


\section{References}

AASHTO (American Association of State Highways and Transportation Officials) (2007). A new vision for the $21^{\text {st }}$ century.

Abbott, K., D. Snidal (2000). Hard and Soft Law in International Governance. International Organization 54, 3, Summer 2000, pp. 421-456

ADB (2010). Sustainable Transport Initiative Operational Plan. Asian Development Bank, Manila, ISBN 978-92-9092-101-1

African Development Bank (AfDB), Asian Development Bank, CAF - Development Bank of Latin America, European Bank for Reconstruction and Development, European Investment Bank, Inter-American Development Bank, Islamic Development Bank and the World Bank (2017). Progress Report (2015-2016) of the MDB Working Group on Sustainable Transport. https://www.adb.org/sites/default/files/institutionaldocument/211966/mdb-progress-report-2015-2016.pdf

Aggarwal, V., J. Chow (2010). The perils of consensus: how ASEAN's meta-regime undermines economic and environmental cooperation. Review of international political economy, vol, pp

Agrawala S., S. Klasen, R. Acosta Moreno, L. Barreto, T. Cottier, D. Guan, E. E. GutierrezEspeleta, A. E. Gámez Vázquez, L. Jiang, Y. G. Kim, J. Lewis, M. Messouli, M. Rauscher, N. Uddin, and A. Venables (2014) Regional Development and Cooperation. In: Climate Change 2014: Mitigation of Climate Change. IPCC working Group III. Cambridge University Press, Cambridge, United Kingdom and New York, NY, USA.

Akimura, S. (2015). Transportation statistics that can contribute to policies and social infrastructure development aimed at ensuring the healthy growth of cities and providing support for smooth economic activity. LATSS Res. 2015, 39, 9-18.

Akinyemi, E.O. and Zuidgeest, M.H.P. (2000). Sustainable development \& transportation: past experiences and future challenges. In: World transport policy \& practice, 6 (2000)1, 31 39.

Akinyemi, E.O. and Zuidgeest, M.H.P. (2002). Managing transportation infrastructure for sustainable development. In: Computer aided civil and infrastructure engineering, 17(2002) 3, 148-161.

Aldred, R, Jungnickel, K. (2014). Why culture matters for transport policy: the case of cycling in the UK. Journal of Transport Geography 34 (2014) 78-87

Alphen, K. van, Ruijven, J. van, Kasa, S., Hekkert, M., Turkenburg, W. (2009). The performance of the Norwegian carbon dioxide, capture and storage innovation system. Energy Policy 37 (1): 43-55

Anable, J., C. Brand, M. Tran, N. Eyre (2012) Modelling transport energy demand: A sociotechnical approach. Energy Policy 41 (2012), 125-138

Anenberg, S., J.Miller, R. Minjares, L. Du, D. Henze, F. Lacey, C. Malley, L. Emberson, V. Franco, Z. Klimont, C. Heyes (2017). Impacts and mitigation of excess diesel-related $\mathrm{NO}_{x}$ emissions in 11 major vehicle markets. Nature 545, 467-471

ASEAN (2007). The ASEAN Charter. ISBN 978-979-3497-62-7. ASEAN Secretariat, Jakarta.

ASEAN (2012). Regional Action Plan on Healthy ASEAN Lifestyles. http://asean.org/?static_post=regional-action-plan-on-healthy-asean-lifestyles (Last access 5 April 2016)

ASEAN (2014). ASEAN peatland management strategy 2006-2020. ISBN 978-602-7643-86-4 http://environment.asean.org/wp-content/uploads/2015/06/ASEAN-PeatlandManagement-Strategy-2006-20201.pdf 


$$
\begin{aligned}
& \text { ASEAN (2015). ASEAN Economic Community at a glance. } \\
& \text { http://asean.org/storage/2012/05/Binder-AEC-at-a-Glance.pdf }
\end{aligned}
$$

ASEAN (2015a). ASEAN Community Vision 2025.
http://www.asean.org/storage/images/2015/November/aec-page/ASEANCommunity-Vision-2025.pdf

ASEAN (2015b). ASEAN Economic Community. Blueprint 2025. ISBN 978-602-0980-59-1. ASEAN Secretariat, Jakarta.

ASEAN (2015c). ASEAN ITS Policy Framework v 2.0

ASEAN (2016a). Kuala Lumpur Transport Strategic Plan (ASEAN Transport Strategic Plan) 20162025. Jakarta, the ASEAN Secretariat ISBN 978-602-0980-70-6

ASEAN (2016b). ASEAN Socio-Cultural Community blueprint. http://www.asean.org/storage/2016/01/ASCC-Blueprint-2025.pdf

ASEAN (2016c). Masterplan on ASEAN connectivity 2025. ISBN 978-602-6392-02-2. ASEAN Secretariat, Jakarta http://asean.org/storage/2016/09/Master-Plan-on-ASEANConnectivity-20251.pdf

ASEAN (2016d). Regional road safety strategy. ISBN 978-602-6392-14-5 Jakarta, ASEAN Secretariat. http://asean.org/storage/2016/10/ASEAN-Road-SafetyStrategy_full_24Oct16_rev_clean.pdf

ASEAN (2017). ASEAN Community in Figures 2016. ASEAN Secretariat, Jakarta. bttp:/ / wnw.aseanstats.org/publication/ asean-community-in-figures-acif-2016/

ASEAN Automotive Federation (2016). AAF Statistics 2015. Available online: http://www.asean-autofed. com/files/AAF_Statistics_2015.pdf (accessed on 23 May 2017).

ASEAN Centre for Energy (2015). The 4th ASEAN Energy Outlook 2013-2035. http:/ /www.aseanenergy.org/resources/publications/the-4th-asean-energy-outlook/

ASEAN-Japan Transport Partnership (2013). Compilation of statistical database of Road, Rail, Water and Air transport sector in ASEAN and Japan. In ASEAN-Japan Transport Statistics Book; ASEAN-Japan Transport Partnership: Chiyoda-ku, Tokyo

Asian Development Bank (ADB) (2017). Urban Transport. https://www.adb.org/sectors/transport/key-priorities/urban-transport

Bache, I., Reardon, L., Bartle, I., Flinders, M. (2014). Symbolic Meta-Policy: (Not) Tackling Climate Change in the Transport Sector. Political Studies 63, 4, 830-851

Bakker, S., C. Huizenga (2010) Making climate instruments work for sustainable transport in developing countries. Natural Resource Forum 34 (4), pp 314-326.

Bakker, S., Haug, C., van Asselt, H., Saïdi, R., Gupta, J. (2010a). Future of CDM: same same but differentiated? Climate Policy, 10, forthcoming.

Bakker, S., De Vita, A., Olivier, J., (2010b). Measuring and reporting emissions and reductions in the post-2012 regime. Netherlands Environmental Assessment Agency WAB report 5000102034.

Bakker, S., Zuidgeest, M., de Coninck, H., Huizenga, C. (2014). Transport, development and climate change mitigation: Towards and integrated approach. Transport Reviews: $A$ Transnational Transdisciplinary Journal 34 (3), pp 335 - 355

Bakker, S., Guillen, M.D., Nanthachatchavankul, P. (2016). Cycling as a mobility option for ASEAN megacities. Developments in Bangkok and Metro Manila and regional policy options. Published by GIZ Thailand, www.transportandclimatechange.org

Bakker, S., K. Dematera, M. Kappiantari, A. T. Nguyen, M. D. Guillen, G. Gunthawong, M. Zuidgeest, D. Liefferink, M. van Maarseveen (2017a). Low-Carbon Transport Policy in Four ASEAN Countries: Developments in Indonesia, the Philippines, Thailand and Vietnam. Sustainability 9 (7), 1217-1233 
Bakker, S., Guillen, M.D., Nanthachatchavankul, P., Zuidgeest, M., Pardo, C., van Maarseveen, M. (2017b) Hot or not? The role of cycling in ASEAN megacities: A case study on Bangkok and Manila. Int. J. Sustain. Transp., published online October 2017

Bakker, S., forthcoming. National strategies on sustainable, low-carbon transport in ASEAN. Synthesis report. To be published by GIZ.

Banister, D. (2008). The sustainable mobility paradigm. Transport Policy 15, 73-80

Banister, D. (2011) Cities, mobility and climate change, J. Transp. Geogr. 19, 1538-1546.

Banister, D., K. Anderton, D. Bonilla, M. Givoni, T. Schwanen (2011) Transportation and the Environment. Annu. Rev. Environ. Resour 36, 247-70

Barías, J., Browne, J., Sanhueza, E., Silsbe, E., Winkelman, S., Zegras, C. (2005). Getting on track: Finding a path for transportation in the CDM, International Institute for Sustainable Development, Winnipeg, Canada.

Barter, P (1999). An international Comparative Perspective on Urban Transport and Urban form in Pacific Asia: The Challenge of Rapid Motorisation in Dense Cities. Ph.D. Thesis, Murdoch University, Murdoch, Australia.

Barter, P. (2012). Off-street parking policy surprises in Asian cities. Cities 2012, 29, 23-31.

Baumann, C., S. White (2012). Making better choices: a systematic comparison of adversarial and collaborative approaches to the transport policy process. Transport Policy 24 (2012) 83-90

Bellagio Declaration on Transportation and Climate Change (2009) Available at: http://www.slocat.net/sites/default/files/bellagio_declaration_on_transportation_and _climate_change_-_final.pdf

Bergek, A., S. Jacobsson, B. Carlsson, S. Lindmark, A. Rickne (2008). Analyzing the functional dynamics of technological innovation systems: A scheme of analysis. Research Policy 37, 407-429

Berkhout, F., A. Wieczorek, R. Raven (2011). Avoiding Environmental Convergence: A Possible Role for Sustainability Experiments in Latecomer countries? International Journal of Institutions and Economies 3 (2) 367-385

Berkhout, F., Angel, D., Wieczorek, A. (2009). Asian development and sustainable sociotechnical regimes. Technological Forecasting and Social Change 76 (2), 218-228.

Berry, F.S., Berry, W.D. (2007) Innovation and diffusion models in policy research. In Theories of the Policy Process; Sabatier, P., Ed.; Westview Press: Boulder, CO, USA, 1999; pp. 169-200.

Bhandary, R. (2017). Markets and Non-Market Approaches for International Cooperation in the Paris Agreement: Open Questions in the International Negotiations. https://www.climatepolicylab.org/news/2017/8/25/markets-and-non-marketapproaches-for-international-cooperation-in-the-paris-agreement-open-questions-inthe-international-negotiations

Böcker, L., Dijst, M., Prillwitz, J. (2013). Impact of Everyday Weather on Individual Daily Travel Behaviours in Perspective: A Literature Review, Transport Reviews, 33 (1), 71-91, DOI: $10.1080 / 01441647.2012 .747114$

Bodansky, D. (2007). International sectoral agreements in a post-2012 climate framework, Working Paper Prepared for the Pew Center on Global Climate Change, Pew Center, Washington DC, USA.

Bongardt D., F. Creutzig, H. Hüging, K. Sakamoto, S. Bakker, S. Gota, S. Böhler-Baedeker (2013). Low-Carbon Land Transport: Policy Handbook. Routledge, New York, USA, 264 pp. ISBN: 9781849713771 
Bongardt, D., Sterk, W., Rudolph, F. (2009). Achieving sustainable mobility in developing countries: Suggestions for a post-2012 agreement. Gaia, 18/4: 307-314; available at www.slocat.net.

Boschmann, E., \& Kwan, M. (2008). Towards socially sustainable urban transportation: Progress and potentials. International journal of sustainable transportation, 2(3), 138-157.

Brons, M., Givoni, M., Rietveld, P. (2009). Access to railway stations and its potential in increasing rail use. Transportation Research Part A 43, 136-149

Brown, D., J. Dillard and R. Marshall (2006). Triple bottom line: a business metaphor for a social construct. Document de Treball núm. 06/2. Access on: http://www.recercat.net/bitstream/2072/2223/1/UABDT06-2.pdf.

Bruun, E., M. Givoni (2015). Six research routes to steer transport policy. Nature 523, 28-31 Bryman, A. (2016). Social Research Methods, 5th ed.; Oxford University Press: Oxford, UK

Buchanan, C. (1963). Traffic in Towns: A Study of Long-Term Problems of Traffic in Urban Areas; Ministry of Transport: London, UK, 1963. Available Online: http:/ / temis.documentation.developpement-durable. gouv.fr/pj/1486/1486_9.pdf (accessed on 23 May 2017).

Bundestag (1994). Zweiter Bericht der Enquete-Kommission "Schutz der Erdatmosphaere" zum Thema Mobilitaet und Klima - Wege zu einer klimavertraeglicher Verkehrspolitik. Deutscher Bundestag Drucksache 12/8300

Carse, A. (2011). Assessment of transport quality of life as an alternative transport appraisal technique. Journal of Transport Geography 19 (2011) 1037-1045

CEC (2009). Stepping up international climate finance: A European blueprint for the Copenhagen deal. Commission of the European Communities, COM(2009) 475/3, CEC, Brussels.

Center for Clean Air Policy (2010). Transportation NAMAs: a proposed framework. CCAP, Washington.

Centre for Sustainable Transport (CST) (2005). Update of Defining sustainable transportation: Draft 2. http://cst.uwinnipeg.ca/documents/Defining_Sustainable_2005.pdf

Chapman, L. (2007). Transport and climate change: a review. Journal of Transport Geography 15 , $354-367$

Charoentrakulpeeti, C., Sajor, E., Zimmermann, W. (2006). Middle-class Travel Patterns, Predispositions and Attitudes, and Present-day Transport Policy in Bangkok, Thailand. Transport Reviews, 26 (6), 693-712.

City of Copenhagen (2015). Copenhagen City of Cyclist. The Bicycle Account 2014. http://www.cycling-embassy.dk/wp-content/uploads/2015/05/Copenhagens-BiycleAccount-2014.pdf (last access 21 March 2016)

Clean Air Asia (2012). Accessing Asia. Air Pollution and Greenhouse Gas Emissions, Indicators for Road Transport and Electricity; Clean Air Asia: Pasig City, Philippines, 2012. Available online: http://www.cleanairasia.org (accessed on 23 May 2017).

Coninck, H. de (2007). Technology rules! Can technology-oriented agreement help address climate change. $\mathrm{PhD}$ thesis, Amsterdam Free University, ISBN 978-90-8659-354-5

Council of the European Union (2006). Renewed EU Sustainable Development Strategy. Note from the General Secretariat 10917/06.

CTC (2015). Cycling and the economy. CTC Campaigns briefing 1F. www.ctc.org.uk/campaigns

CTF (2009a). Clean technology fund investment criteria for public sector operations. Available at: http://www.climateinvestmentfunds.org/cif/

sites/climateinvestmentfunds.org/files/CTF_Investment_Criteria_

Public_Sector_revisedFeb9.pdf. 
CTF (2009b). Clean technology fund result measurement system. CTF/ TFC.3/8. Available at: http://www.climateinvestmentfunds.org/cif/

sites/climateinvestmentfunds.org/files/CTFresultsmeasurement.pdf

CTF (2010). Country and regional investment plans. Available at: http://www.climateinvestmentfunds.org/cif/Country\%20Investment $\% 20$ Plans

Dalkmann, H., Binsted, A. (2010). Copenhagen Accord NAMA submissions implications for the transport sector. Available at: http://ledsgp.org/resource/copenhagen-accord-namasubmissions-implications-for-the-transport-sector/

Dalkmann, H., C. Brannigan (2007). Transport and Climate Change. Sustainable Transport: A Sourcebook for Policy-makers in Developing Cities, Module 5e. GTZ, www.sutp.org

Daly, H. (1996). Beyond Growth: The Economics of Sustainable Development. ISBN 978-0-80704709-5. Beacon Press, Boston.

Dargay, J., Gately, D., Sommer, M. (2007). Vehicle Ownership and Income Growth, Worldwide: 1960-2030. Energy J. 28, 143-170.

de Groot, J., L. Steg (2006). Impact of transport pricing on quality of life, acceptability, and intentions to reduce car use: An exploratory study in five European countries. Journal of Transport Geography 14 (2006) 463-470

Deffner, J., Hefter, T., Rudolph, C., Ziel, T. (2012). Handbook on cycling inclusive planning and promotion. Capacity development material for the multiplier training within the mobile2020 project. Frankfurt/Hamburg, www.mobile2020.eu

Delbosc, A. (2012). The role of well-being in transport policy. Transport Policy 23 (2012) 2533

Delbosc, A., Currie, G. (2011). Using Lorenz curves to assess public transport equity. Journal of Transport Geography, 19(6): 1252-1259.

Dematera, K., Mejia, A., Phan, N., Tacderas, M., Patdu, K., Daude, L., Nguyen, A.T., Bakker, S. (2015). Tracking Sustainable Transport in Vietnam: Data and Policy Review for Energy Efficiency and Climate Change 2015; GIZ Vietnam: Hanoi, Vietnam, 2015. Available Online: http://transportandclimatechange.org/

den Elzen, M., Höhne, N. (2008). Reductions of greenhouse gas emissions in Annex I and non-Annex I countries for meeting concentration stabilisation targets, Climatic Change, 91(3): 249-274.

Department of Transportation and Communications (DOTC) (2016). Philippines National Implementation Plan on Environment Improvement in the Transport Sector, FY 2016-2020; Department of Transportation and Communications (DOTC): Mandaluyong, Philippines

Dupuis, J.; Biesbroek, R. (2013). Comparing apples and oranges: The dependent variable problem in comparing and evaluating climate change adaptation policies. Glob. Environ. Chang. 2013, 23, 1476-1487.

ECF (2016). Cycling delivers on the global goals. Shifting towards a better economy, society, and planet for all. Brussels.

Eckermann, A., I. Eekhoff, S. Bakker, F. Krämer, M. Arnd, T. Hohenberger, L. Vlasak, A. (2015). Transport NAMA Monitor 2015. GIZ, Eschborn. http://transferproject.org/wpcontent/uploads/2015/12/giz_TRANSfer_TNAMA_Monitor_2015-online.pdf

ECMT (2007). Cutting transport $\mathrm{CO}_{2}$ emissions: what progress? ISBN 92-821-0382-X. OECD publishing, Paris.

ECMT (European Conference of Ministers of transport) (2004) Assessment \& decision making for sustainable transport. DOI :10.1787/9789282113134-en. Organization for Economic Co-operation and Development: Paris. 
Ecola, L., \& Wachs, M. (2012). Exploring the Relationship between Travel Demand and Economic Growth, (Report of The RAND Corporation), USA.

EEA (2012). The contribution of transport to air quality: TERM 2012: transport indicators tracking progress towards environmental targets in Europe. EEA Report No 10/2012, ISSN 1725-9177

EEA (2016). Transitions towards a more sustainable mobility system. TERM 2016: Transport indicators tracking progress towards environmental targets in Europe. EEA Report 34/2016, ISSN 1977 8449. European Environment Agency, Copenhagen, Denmark.

Eichhorst, U., D. Bongardt, V. Novikova (eds.) (2017). Compendium on GHG Baselines and Monitoring. Passenger and freight transport. UNFCCC/GIZ, https://www.internationalclimate-

initiative.com/fileadmin/Dokumente/2017/170602_Compendium_GHG_Monitoring _Transport.pdf

Elliott, L. (2012). ASEAN and Environmental Governance: Strategies of Regionalism in Southeast Asia. Global Environmental Politics 12 (3), pp 38-57

EMBARQ \& SLoCaT (2013) The role of sustainable transport in road safety. http://www.slocat.net/sites/default/files/u10/2pager_the_role_of_sustainable_transp ort_in_traffic_safety.pdf Last accessed 8 January 2014

ERIA (2010). ASEAN Strategic Transport Plan. Final Report. October 2010. http://www.eria.org/ASEAN\%20Strategic\%20Transport\%20Plan.pdf

EST (2011). Bangkok 2020 Declaration. http://www.uncrd.or.jp/env/5th-regional-estforum/doc/bangkok_declaration.pdf. Last accessed 8 January 2014

Etminani-Ghasrodashti, R., M. Ardeshiri (2015) Modeling travel behavior by the structural relationships between lifestyle, built environment and non-working trips. Transportation Research Part A 78 (2015) 506-518

European Commission (2011). White Paper. Roadmap to a Single European Transport Area Towards a competitive and resource efficient transport system. COM(2011) 144 final, Brussels. Available from http://eur-lex.europa.eu/legalcontent/EN/ALL/?uri=CELEX\%3A52011DC0144

European Commission (2016). A European Strategy for Low-Emission Mobility. EC Communication, https://ec.europa.eu/transport/themes/strategies/news/2016-07-20decarbonisation_en

European Parliament (2016) Research for the TRAN Committee - the Paris Agreement and the EU transport policy. Briefing.

http://www.europarl.europa.eu/RegData/etudes/BRIE/2016/573433/IPOL_BRI(20 16)573433_EN.pdf

European Union (no date). EU transport policy. https://europa.eu/europeanunion/topics/transport_en

Ewing-Choi, M., T. Hsien-Li (2013). The Role of the Rule of Law in ASEAN Integration. EUI Working Paper RSCAS 2013/16, Robert Schuman Centre for Advanced Studies, San Domenico di Fiesole, Italy

Facanha, C., K. Blumberg, J. Miller (2012). Global Transportation Energy and Climate Roadmap. The impact of transportation policies and their potential to reduce oil consumption and greenhouse gas emission. International Council for Clean Transportation, Washington.

Figueroa, M., L. Fulton, G. Tiwari (2014). Avoiding, transforming, transitioning: Pathways to sustainable low carbon passenger transport in developing countries. Current Opinion in Environmental Sustainability 2013 5, 184-190

Fishman, E. (2016). Bikeshare: a review of recent literature. Transport Reviews 36 (1), 92-113 
Fishman, E., Washington, S., Haworth, N. (2014). Bike share's impact on car use: Evidence from the United States, Great Britain, and Australia. Transportation Research Part D 31, 13 20

Foth, N., Manaugh, K., El-Geneidy, A.M. (2013). Towards equitable transit: examining transit accessibility and social need in Toronto, Canada, 1996-2006. Journal of Transport Geography 29(0): 1-10.

Fulton, L., J. Mason, D. Meroux (2017) Three revolutions in urban transportation. UC Davis and ITDP

Funder, M., J. Fjalland, H. Ravnborg, H. Egelyng (2009). Low carbon development and poverty alleviation. Options for development cooperation in energy, agriculture and forestry. DIIS report 2009:20. Danish Institute for International Studies: Copenhagen, www.diis.dk.

Gatersleben, B., Appleton, A. (2007). Contemplating cycling to work: Attitudes and perceptions in different stages of change. Transportation Research Part A 41, 302-312

Gausemeier, P., Seidel, J., Riedelsheimer, T., Seliger, G. (2015). Pathways for sustainable technology development - The case of bicycle mobility in Berlin. Procedia CIRP 26, 202 207

GCF (2014). Investment Framework. GCF/B.07/06, 9 May 2014. https://www.greenclimate.fund/documents/20182/24943/GCF_B.07_06__Investment_Framework.pdf/

GCF (2016). Further development of some indicators in the performance measurement frameworks. GCF/B.13/26, 10 June 2016. https://www.greenclimate.fund/documents/20182/226888/GCF_B.13_26__Further_development_of_some_indicators_in_the_performance_measurement_frame works.pdf

GCF (2017). Status of the GCF portfolio: pipeline and approved projects. GCF/B.18/Inf.03, 30 September 2017.

https://www.greenclimate.fund/documents/20182/820027/GCF_B.18_Inf.03__Status_of_the_GCF_portfolio_pipeline_and_approved_projects.pdf/

Geels, F. (2002). Technological transitions as evolutionary reconfiguration processes: a multilevel perspective and a case-study. Research Policy 31 (8-9), 1257-1274

Geels, F., R. Kemp, G. Dudley, G. Lyons (2012). Automobility in Transition? A Socio-Technical Analysis of Sustainable Transport. New York: Routledge, ISBN13: 978-0-415-88505-8

Geels, F.W. (2012). A socio-technical analysis of low-carbon transitions: introducing the multi-level perspective into transport studies. J. Transp. Geogr. 24 (2012), 471-482. doi:10.1016/j.jtrangeo.2012.01.021

Geerlings, H., Y. Shiftan, D. Stead (2012). The Complex Challenge of Transitions Towards Sustainable Mobility - An Introduction. In Geerlins et al. (eds): Transition towards Sustainable Mobility: The Role of Instruments, Individuals and Institutions. Routledge, Taylor and Francis, Oxford, UK

GEF (2008). Manual for calculating GHG benefits of GEF projects: Energy efficiency and renewable energy projects, GEF, Washington, DC.

http:/ / www.thegef.org/gef/sites/thegef.org/files/publication/STAPSustainable $\% 20$ transport.pdf

GEF (2009a). Investing in sustainable urban transport. The GEF experience, GEF, Washington, DC. GEF (2009b). GEF-5 focal area strategies. GEF/R.5/Inf.21, GEF, Washington, DC. Available at: http://www.thegef.org/gef/node/1974.

GEF-STAP (2010). Advancing Sustainable Low-Carbon Transport Through the GEF, A STAP advisory document by Holger Dalkmann and Cornie Huizenga. Global Environment Facility. Washington, D.C. 
Gilbert, G., J. Dajani (1974). Energy, urban form and transportation policy. Transportation Research. 8, 267-276

GIZ (2012) Sustainable Urban Transport: Avoid-Shift-Improve (A-S-I) Available online http://www.sutp.org/files/contents/documents/resources/E_Fact-Sheets-

and-Policy-Briefs/SUTP_GIZ_FS_Avoid-Shift-Improve_EN.pdf (accessed on 23 May 2017).

GIZ (2015) International Fuel Prices 2014, Data Preview. Available online: https://www.giz.de/expertise/downloads/giz-2015-en-ifp2014.pdf (accessed on 23 May 2017).

GIZ (2016). ASEAN's transport sector contributions to combating climate change: INDC analysis. Available from http://transportandclimatechange.org/news-events/aseans-transportsector-contributions-to-combating-climate-change-indc-analysis/

Global Carbon Project (2017). Carbon budget and trends 2017. Earth Science System Data, 13 November 2017, DOI: 10.5194/essdd-2017-123 (in review), https://www.earth-syst-scidata-discuss.net/essd-2017-123/

Gössling, S. (2013). Urban transport transitions: Copenhagen, City of Cyclists. Journal of Transport Geography 33, 196-206

Gössling, S., S. Cohen, A. Hares (2017). Inside the black box: EU policy officers' perspectives on transport and climate change mitigation. Journal of Transport Geography 57 (2016), 8393

Gota, S., C. Huizenga, K. Peet, G. Kaar (2016). Nationally-Determined Contributions (NDCs) Offer Opportunities for Ambitious Action on Transport and Climate Change. http:/ /www.ppmctransport.org/wp-content/uploads/2015/06/NDCs-Offer-Opportunities-forAmbitious-Action-Updated-October-2016.pdf

Gota, S., C. Huizenga, K. Peet, N. Medimorec, S. Bakker (forthcoming). Decarbonising Transport to Achieve Paris Agreement Targets. Energy Efficiency, accepted

Gozun, B. (2001). Attitudinal Factors Toward Cycling As A Transport Mode for School Trips. Research paper published by the University of the Philippines. http://serpp.pids.gov.ph/details.php?pid=3041\&param $=$ (Last access 25 March 2016)

Gozun, B., Guillen, M.D. (2008). Towards a Sustainable Transportation Environment: The Case of "Pedicabs" and Cycling in the Philippines. CODATU XIII conference paper

Gray, D., R. Laing, I. Docherty (2017). Delivering lower carbon urban transport choices: European ambition meets the reality of institutional (mis)alignment. Environment and Planning A 2017, Vol. 49(1) 226-242, DOI: 10.1177/0308518X16662272

Grazi, F., and J. van den Bergh (2008). Spatial organization, transport, and climate change: Comparing instruments of spatial planning and policy. Ecological Economics 67 (2008) 630_ 639

Grengs, J. (2001). Does Public Transit Counteract the Segregation of Carless Households? Measuring Spatial Patterns of Accessibility with GIS. Transportation Research Record: Journal of the transportation research board, 1753, 3-10.

Gudmundsson, H., M. Höjer (1996). Sustainable development principles and their implications for transport. Ecological Economics 19 (1996), pp 269-282.

Gudynas, Eduardo (2011). Buen Vivir: Today's tomorrow. Development 54(4) 441-447.

Guillen, M.D. (2000). A policy study of non-motorised public transport in urban and urbanizing areas: the case of pedicab operations in the city of Manila and in the municipality of Los Baños, Laguna. University of the Philippines.

Hajer, M., H. Wagenaar (2003). Deliberative policy analysis: Understanding governance in the network society. Cambridge: Cambridge University Press. 
Hall, P. (1993) Policy Paradigms, Social Learning and the State: The Case of Economic Policymaking in Britain, Comparative Politics 25, 275-96.

Han, S. (2010). Managing motorization in sustainable transport planning: The Singapore experience. J. Transp. Geogr. 18, 314-321.

Handy, S., van Wee, B., Kroesen, M. (2014). Promoting Cycling for Transport: Research Needs and Challenges, Transport Reviews: A Transnational Transdisciplinary Journal, 34:1, 424, DOI: $10.1080 / 01441647.2013 .860204$

Heilmann, D. (2015). After Indonesia's Ratification: The ASEAN Agreement on Transboundary Haze Pollution and Its Effectiveness As a Regional Environmental Governance Tool. Journal of Current Southeast Asian Affairs, 34, 3, 95-121

Heinen, E., van Wee, B., Maat, K. (2010). Commuting by Bicycle: An Overview of the Literature, Transport Reviewss, 30 (1), 59-96

Hidalgo, D., C. Huizenga (2013). Implementation of sustainable urban transport in Latin America. Research in Transportation Economics 39, 66 - 77.

Ho, C. Y. Matsuoka, J. Simson, K. Gomi (2013). Low carbon urban development strategy in Malaysia The case of Iskandar Malaysia development corridor. Habitat International 37 (2013) 43-51

Hoffmann, S., J. Weyer, J. Longen (2017). Discontinuation of the automobility regime? An integrated approach to multi-level governance. Transportation Research Part A 103 (2017) 391-408

Hood, C. (1983). The tools of government (Public Policy and Politics). Palgrave Macmillan, London

Hooghe, L. \& G. Marks (2003). Unraveling the Central State, but How? Types of Multi-level Governance. American Political Science Review 97 (2), 233-243

Howlett, M., Cashore, B. (2009). The Dependent Variable Problem in the Study of Policy Change: Understanding Policy Change as a Methodological Problem. J. Comp. Policy Anal. Res. Pract. 11, 33-46.

Howlett, M.; Ramesh, M.; Perl, A. (2009) Studying public policy. Policy cycles and policy subsystems. Third edition. ISBN 978-0-19-542802-5 Oxford University Press, Canada

Huizenga, C. (2013). Post 2015 Development Framework and Transport: a unique opportunity for transformational change. Global Consultation on Sustainable Transport in the post-2015 Development Agenda, 25 April 2013, Bali, Indonesia.

Huizenga, C. and J. Leather (2012). Transport and Climate Policy in the Developing World - The Region that Matters Most. In: Cars and Carbon - Automobiles and European Climate Policy in a Global Context, Zachariadis T. (ed.), Springer Science+Business Media, 2012. ISBN 978-94-007-2122-7

Huizenga, C., 2010. Financing of sustainable, low carbon transport in developing countries: Improving existing instruments and creating new instruments, Presentation made at Next Steps after Copenhagen: Opportunities and Challenges in the Transport Sector, Transforming Transportation 2010.Washington, DC, January.

Huizenga, C., Castillo, C.K., Ajero, M., Sanqui, D.C. (2008). The co-benefits approach: an integrated policy response to climate change and development in Asia, in Loh, C. Stevenson, A. and Tay, S. (eds), Climate change negotiations, can Asia change the game, Civic Exchange, Hong Kong.

Huizenga, C., H. Dalkmann, S. Sanchez (2010). The future climate regime and the transport sector in developing Asia: the importance of local action, Earthscan, London.

Hygge, K.; Mahalana, A. (2026) $1^{\text {st }}$ Forum of the ASEAN fuel Economy platform; Summary Report; Kuala Lumpur, Malaysia, 9 November 2016. Available online: www.transportandclimatechange.org (accessed on 23 May 2017).

IEA (2012a). CO Emissions from Fuel Combustion (2012 Edition), IEA: Paris, France. 
IEA (2012b) Energy Technology Perspectives 2012 -- Pathways to a Clean Energy System, 690 pages, ISBN 978-92-64-17488-7

IEA (2014) Energy Technology Perspectives 2014. IEA, Paris

IEA (2017) Key world energy statistics. IEA, Paris https://www.iea.org/publications/freepublications/publication/KeyWorld2017.pdf

IEA/OECD (2009) Moving Toward Sustainability. Transport, Energy and CO2. ISBN 978-92-6407316-6, IEA/OECD, Paris

IEA/OECD, 2012. World Energy Outlook 2012. IEA/OECD: Paris, France.

Imboden, A. (2017). $2^{\text {nd }}$ Forum of the ASEAN Fuel Economy Platform. Workshop report, 28 March 2017. Published by GIZ

IPCC, 2007: Climate Change 2007: Mitigation. Contribution of Working Group III to the Fourth Assessment Report of the Intergovernmental Panel on Climate Change [B. Metz, O.R. Davidson, P.R. Bosch, R. Dave, L.A. Meyer (eds)], Cambridge University Press, Cambridge, United Kingdom and New York, NY, USA., 852 pp.

ITPS (Institute for Transport Policy Studies) \& Clean Air Asia (2014) A Study on a Long-term Transport Action Plan for ASEAN. http://cleanairasia.org/study-of-long-term-transportaction-plan-for-asean-region-lpa-project/ (accessed on 23 May 2017)

Jackson, Tim (2008). The challenge of sustainable lifestyles. In: State of the World 2008: Innovations for a sustainable economy. World Watch Institute: Washington DC, United States.

Jaeger, A., S. Nugroho, E. Zusman, R. Nakano, R. Daggy (2015). Governing sustainable lowcarbon transport in Indonesia: An assessment of provincial transport plans. Natural Resources Forum 39 (2015) 27-40, DOI: 10.1111/1477-8947.12066

Jaensirisak, S., Paksarsawan, S., Luathep, P.; Fukuda, T. (2016). Development of national transport master plan in Thailand. In Proceedings of the World Conference on Transport ResearchWCTR, Shanghai, China, 10-15 July 2016.

Jann, W., Wegrich, K. (2004). Theories of the policy cycle. In: Fischer, F., Miller, Gerlad J., Sidney, Mara S. (Eds.), Handbook of Public Policy Analysis. CRC Press, London, pp. 43-62.

Jayasuriya, K. (2009). Regulatory regionalism in the Asia-Pacific: drivers, instruments and actors, Australian Journal of International Affairs, 63:3, 335-347, DOI: 10.1080/10357710903104810

Jenkins, W. (1978). Policy analysis: A political and organisational perspective. St. Martin's Press, New York

Jeon, C.M., Amekudzi, A. (2005). Addressing sustainability in transportation systems: definitions, indicators, and metrics. ASCE Journal of Infrastructure Systems 11 (1), 31-50.

Jetschke, A., J. Rüland (2009). Decoupling rhetoric and practice: the cultural limits of ASEAN cooperation, The Pacific Review, 22:2, 179-203, DOI: 10.1080/09512740902815326

Jittrapirom, P., S. Jaensirisak (2017). Planning our way ahead: A review of Thailand's transport master plan for urban areas. Transportation Research Procedia 25, 3985 - 4002

Johansson, B. (2009). Will restrictions on $\mathrm{CO}_{2}$ emissions require reduction in transport demand? Energy Policy, 37: 3212-3322.

Johnson, T., Alatorre, C., Romo, Z., Liu, F. (2009). Low-carbon development for Mexico. The World Bank, Washington, DC.

Jones, T., Novo de Azevedo, L. (2013). Economic, social and cultural transformation and the role of the bicycle in Brazil. Journal of Transport Geograpby 30, 208-219

Jonsson, R. (2008). Analysing sustainable urban transport and land-use. Modelling tools and appraisal frameworks. PhD thesis ISSN 1653-4468, Royal Institute of Technology: Stockholm. 
Journard, R., J-P. Nicolas (2010). Transport project assessment methodology within the framework of sustainable development. Ecological Indicators 10 (2010) 136-142

Jung, M., Vieweg, M., Eisbrenner, K., Höhne, N., Ellermann, C., Schimschar, S., Beyer, C. (2010). Nationally appropriate mitigation actions. Insights from example development. Ecofys report. Available https://www.ecofys.com/files/files/report_ecofys_nama_overview_eng_04_2010.pdf

Kagermeier, A. (1998). Nachhaltigkeitsdiskussion: Herausforderung für Verkehrsgeographie. Geographische Rundschau 50, pp 548-549

Karousakis, K., Guay, B., Philibert, C. (2008). Differentiating countries in terms of mitigation commitments, actions and support, OECD/IEA, Paris, France.

Kemp, R., Schot, J. \& Hoogma, R. (1998). Regime shifts to sustainability through processes of niche formation: The approach of strategic niche management. Technology Analysis \& Strategic Management, 10(2), 175-195.

Kheng-Lian, K., N. Robinson, L. Lin-Heng (2016). ASEAN environmental legal integration. Sustainable goals? ISBN 978-1-316-60431-1. Cambridge, UK, Cambridge University Press

Khuat H. (2006). Traffic Management in Motorycle Dependent Cities. PhD thesis, Technische Universitaet Darmstadt, Germany, 5/12/2006. Available online http://tuprints.ulb.tudarmstadt.de/767/1/Dissertation_main_report.pdf

Kijmanawat, K., N. Wongchavalidkul, P. Sungsomboon, S. Bakker (2016). Monitoring transport GHG emissions in Thailand. Towards a measurement, reporting and verification system for the land transport sector. Published by GIZ, www.transportandclimatechange.org

Kivimaa, P.; Virkamäki, V. (2014). Policy Mixes, Policy Interplay and Low Carbon Transitions: The Case of Passenger Transport in Finland. Environ. Policy Gov. 2014, 24, 28-41.

Koh, P.P., Wong, Y.D. (2012). The evolution of cycling in Singapore. Journeys, November 2012.

Korzhenevych, A. N. Dehnen, J. Bröcker, M. Holtkamp, H. Meier, G. Gibson, A. Varma, V. Cox (2014). Update of the Handbook on External Costs of Transport. Final Report, RicardoAEA/R/ ED57769 - Issue Number 1.

https:/ / ec.europa.eu/transport/sites/transport/files/handbook_on_external_costs_of _transport_2014_0.pdf

Kuhnimhof, T., D. Zumkeller, B. Chlond (2013). Who Made Peak Car, and How? A Breakdown of Trends over Four Decades in Four Countries. Transport Reviews, Vol. 33, No. 3, 325-342, http://dx.doi.org/10.1080/01441647.2013.801928

Kumar, A., Nguyen, V.A., Teo, K. (2014). Commuter cycling policy in Singapore: a farecard data analytics based approach. Annals of Operations Research, pp 1-17 DOI 10.1007/s10479014-1585-7

Kuroda, H., M. Kawai, R. Nangia (2007). Infrastructure and Regional Cooperation. ADB Institute Discussion Paper No. 76. http://hdl.handle.net/10419/53537

Lambrecht, et al. (2009) Strategie für einen nachbaltigen Güterverkehr. Umwelt Bundes Amt report 18/2009, Dessau-Rosslau (in German)

Lanzendorf, M., Busch-Geertsema, A. (2014). The cycling boom in large German citiesEmpirical evidence for successful cycling campaigns. Transport Policy 36, 26-33

Larsen, J., J. Urry, K. Axhausen (2012). Mobilities, Networks, Geographies. Ashgate Publishing, Ltd., 28 nov. 2012 - 174 pp

Lasswell, H. (1956). The decision process: seven categories of functional analysis. Bureau of Governmental Research, College of Business and Public Administration, University of Maryland 
Leather, J., CAI-Asia Team (2009). Rethinking Transport and Climate Change. ADB Sustainable Development Working Paper Series, No. 10 (December 2009), Manila, The Philippines.

Leather, J., Fabian, B., Gota, S., Mejia, A. (2011). Walkability and Pedestrian Facilities in Asian Cities. State and Issues. ADB Sustainable Development Working Paper Series, No. 17. Asian Development Bank, Manila.

Lefevre, B., A. Iqbal, D. Yavrom, A. Srivastava (2016). The Trillion Dollar Question II: Tracking Investment Needs in Transport. World Resources Institute, Working Paper, Washington DC. http://www.wri.org/sites/default/files/The_Trillion_Dollar_Question_II_Tracking_I nvestment_Needs_in_Transport_0.pdf

Litman, T. (2003). Reinventing Transportation. Exploring the Paradigm Shift Needed to Reconcile Transportation and Sustainability Objectives. Victoria Transport Policy Institute.

Litman, T. (2008). Evaluating accessibility for transportation planning. Victoria Transport Policy Institute, Victoria, Canada. http://www.vtpi.org/access.pdf

Litman, T. (2010). Evaluating Transportation Economic Development Impacts. Victoria Transport Policy Institute, http:/ / www.vtpi.org/econ_dev.pdf

Litman, T. (2013). The new transportation planning paradigm. Institute of Transport Engineers Journal, vol. 83 (2013), pp 20-28.

Litman, T., D. Burwell (2006) Issues in sustainable transportation. Int. J. Global Environmental Issues, Vol. 6, No. 4, 2006

Löhr, E., N. Perera, N. Hill, D. Bongardt, U. Eichhorst (2017). Transport in Nationally Determined Contributions (NDCs). Lessons learnt from case studies of rapidly motorising countries Synthesis Report. Published by GIZ, Eschborn, Germany.

Loorbach, D. (2007). Transition Management. New Mode of Governance for Sustainable Development, Utrecht, International Books.

Lundvall, B.A. (Ed.) (1992). National Systems of Innovation - Toward a Theory of Innovation and Interactive Learning. Pinter Publishers, London.

Manheim, M. (1979). Fundamentals of Transport System Analysis. The MIT Press, Cambridge, Massachusettes and London, England.

Markard, J., R. Raven, B. Truffer (2012). Sustainability transitions: An emerging field of research and its prospects. Research Policy 41 (2012) 955-967

Marsden, G., Kimble, M., Nellthorp, J., and Kelly, C (2009). Sustainability Appraisal: The definition deficit. International Journal of Sustainable Transportation, 4 (4), 189 - 211

Marsden, G., Bache, I., Kelly, C. (2012). A policy perspective in transport and climate change issues. In Transport and Climate Change; Chapman, L., Ryley, T., Eds.; Emerald Group Publishing: Bradford, UK; Volume 2, pp. 197-224. Available Online: 10.1108/S2044 9941(2012)0000002011

Marsden, G., Reardon, L. (2017). Questions of Governance: Rethinking the Study of Transportation Policy. Transp. Res. A Policy Pract. 2017, 101, 238-251.

Martens, K. (2017). Transport Justice. Designing Fair Transportation Systems. ISBN 9780415638319, Routledge, New York, 2017.

Massen, I, O. Svidén, M. Wegener (1992). From growth to equity and sustainability: Paradigm shift in transport planning? Futures 24 (6) 539-558.

Massink, R., Zuidgeest, M., Rijnsburger, J., Samiento, O., van Maarseveen, M. (2011). The climate value of cycling. Natural Resources Forum 35, 100-111

May, A., M. Page, A. Hull (2009). Developing a set of decision support tools for sustainable urban transport in the UK. Transport Policy 15 (2008) 328-340

McCollum, D. and C. Yang (2009). Achieving deep reductions in US transport greenhouse gas emissions: Scenario analysis and policy implications. Energy Policy 37 (2009) 55805596 
McKinnon (2007). Decoupling of Road Freight Transport and Economic Growth Trends in the UK: An Exploratory Analysis, Transport Reviews: A Transnational Transdisciplinary Journal, 27:1, 37-64, DOI: 10.1080/01441640600825952

Meckling, J O., Chung, G.Y. (2009). Sectoral approaches to international climate policy: a typology and political analysis, Discussion Paper 2009-02, Belfer Center for Science and International Affairs, Cambridge, MA.

Mejia, A., Dematera, K., Guillen, M.D.; Villaraza, C.; Bakker, S. (2016). Tracking Sustainable Transport in the Philippines: Data and Policy Review for Energy Efficiency and Climate Change 2015. GIZ Philippines. Available online http://transportandclimatechange.org/

Meng, M., Zhang, J., Wong, Y., Au, P. (2016). Effect of Weather Conditions and Weather Forecast on Cycling Travel Behavior in Singapore. International Journal of Sustainable Transportation 10 (9), 773-780, DOI: 10.1080/15568318.2016.1149646

Mersmann, F., K. Holm Olsen, T. Wehnert, and Z. Boodoo (2014). From theory to practice: understanding transformational change in NAMAs. Wuppertal Institute, ISBN978-87-9313023-4, https://wupperinst.org/en/p/wi/p/s/pd/523/

Meschik, M. (2012). Reshaping city traffic towards sustainability. Why transport policy should favor the bicycle instead of car traffic. Procedia - Social and Behavioral Sciences 48, 495 $-504$

Metrolinx (2008). Towards sustainable transportation. Visions, goals and objectives. Development of a regional transportation plan for the Greater Toronto and Hamilton area. White paper \#1.

Metz, B., Davidson, O.R., Bosch, P.R., Dave, R., Meyer, L.A. (eds), 2007. Climate Change 2007: Mitigation. Contribution of Working Group III to the Fourth Assessment Report of the Intergovernmental Panel on Climate Change, Cambridge University Press, Cambridge, United Kingdom and New York, NY, USA.

Michaelowa, A., S. Hoch (2017). Guardrails for the Paris mechanisms. Operationalizing Article 6 and generating carbon market credibility. Carbon Mechanisms Review 03/2017, 49

Millard-Ball, A., L. Schipper (2011). Are We Reaching Peak Travel? Trends in Passenger Transport in Eight Industrialized Countries. Transport Reviews: A Transnational Transdisciplinary Journal, 31:3, 357-378, DOI: 10.1080/01441647.2010.518291

Millard-Ball, A., Ortolano, L. (2010). Constructing carbon offsets: the obstacles to quantifying emission reductions. Energy Policy, 38: 533- 546.

Mitchell, M., S. Maxwell (2010). Defining climate compatible development. Climate Development Knowledge Network, CDKN ODI Policy Brief November 2010/A, www.cdkn.org

MMDA (2015). Metro Manila bike lanes and bikesharing. http://www.gov.ph/2015/08/29/metro-manila-bike lanes-and-bikesharing/ (Accessed 22 February 2016)

Mofijur, M., Masjuki, H., Kalam, M., Ashrafur Rahman, S., Mahmudul, H. (2015). Energy scenario and biofuel policies and targets in ASEAN countries. Renew. Sustain. Energy Rev. 46, 51-61.

Morichi, S. S. Acharya (eds., 2013). Transport Development in Asian Megacities. A new perspective. ISBN 978-3-642-29742-7. Springer-Verlag Berlin Heidelberg, Germany

Moving on Sustainable Transportation (MOST) (1999). Transport Canada, cited in Litman, T. and D. Burwell (2006) Issues in sustainable transportation. Int. J. Global Environmental Issues 6 (4) 331-346

Mulugetta, Y., F. Urban (2010). Deliberating on low carbon development. Energy Policy 38 (2010) 7546-7549

Muncrief, R., B. Sharpe (2015). overview of the heavy-duty vehicle market and CO2 emissions in the european Union. International Council on Clean Transportation, 
http:/ / theicct.org/sites/default/files/publications/ICCT_EU-HDV_mktanalysis_201512.pdf

Narupiti, S., Tippichai, A., Nanthachatchavankul, P., Sutjaritthanarak, M., Bakker, S. (2014). Thailand Stocktaking report on Sustainable Transport and Climate Change. Data, policy, monitoring. GIZ Thailand, www.transportandclimatechange.org

National Health Commission Office of Thailand (2012). Health Assembly 5/Resolution 1 'Supportive Systems and Structures for Walking and Cycling in Daily Living.' Bangkok: National Health Commission Office of Thailand.

Nemet, G., Holloway, T., Meier, P. (2010). Implications of incorporating air-quality cobenefits into climate change policymaking. Environmental Research Letters, 5(1).

Nesadurai, H. (2008). Association of Southeast Asian Nations (ASEAN). Global Monitor. New Political Economy 13 (2), 225-239

Neuhoff, K. (ed) (2009). International support for domestic climate policies in developing countries. Climate Policy, 9(5), special issue October.

New Zealand Ministry of Transport (2008). The New Zealand Transport Strategy 2008. http:/ /www.transport.govt.nz/ourwork/Documents/NZTS2008.pdf

Nguyen, N.Q., Zuidgeest, M., van den Bosch, F., Sliuzas, R., van Maarseveen, M. (2013). Using Accessibility Indicators to Investigate Urban Growth and Motorcycles Use in $\mathrm{Ha}$ Noi City, Vietnam. In Proceedings of the 10th International Conference of Eastern Asia Society for Transportation Studies, Tokyo, Japan, 9-12 September 2013. Available Online: http://doc.utwente.nl/90352/

Nicolas, F. (2009). ASE AN Energy Cooperation An Increasingly Daunting Challenge. Note de l'Ifri. ISBN : 978-2-86592-603-9, Institut Français des Relations Internationales, Paris, Bruxelles.

Nieuwenhuijsen, M., H. Khreis (2016). Car free cities: Pathway to healthy urban living. Environment International 94, 251-262, https://doi.org/10.1016/j.envint.2016.05.032

Nikkei Asian Review (2017) Booming Southeast Asian vehicle sales drive urban congestion, https://asia.nikkei.com/Business/Trends/Booming-Southeast-Asian-vehicle-salesdrive-urban-congestion

Nishitateno, S., Burke, P. (2014). The motorcycle Kuznets curve. Journal of Transport Geography 36, 116-123.

Nkurunziza, A., Zuidgeest, M., Brussel, M., van Maarseveen, M. (2012). Examining the potential for modal change: Motivators and barriers for bicycle commuting in Dar-esSalaam. Transport Policy 24, 249-259

Nongnuch Y. (2015). Public Image of Bicycle in Daily routine. Proceedings from the 3rd Thailand Bike \& Walk Conference, April 2015

Ockwell, D., A. Ely, A. Mallett, O. Johnson, J. Watson (2009). Low Carbon Development: The Role of Local Innovative Capabilities. STEPS Working Paper 31, Brighton: STEPS Centre and Sussex Energy Group, SPRU, University of Sussex.

OECD (1997). Towards sustainable transportation. The Vancouver Conference 24-27 March 1996, conference highlights and overview of issues.

OECD/ IEA (2017a). Southeast Asia Energy Outlook. World Energy Outlook Special Report. Paris, http://www.iea.org/publications/freepublications/publication/weo-2017-specialreport-southeast-asia-energy-outlook-.html

OECD/IEA (2017b). Tracking Clean Energy Progress 2017. Energy Technology Perspectives 2017 Excerpt, Informing Energy Sector Transformations. OECD, Paris http://www.iea.org/publications/freepublications/publication/TrackingCleanEnergyP rogress2017.pdf 
OECD/IEA (2015). South-East Asia Energy Outlook 2015. In World Energy Outlook Special Report, OECD/IEA: Paris, France

OECD/ITF (2017). ITF Transport Outlook 2017. Transport demand and $\mathrm{CO}_{2}$ emissions to 2050. http://www.oecd.org/about/publishing/itf-transport-outlook-2017-9789282108000en.htm and https://www.ttm.nl/wp-content/uploads/2017/01/itf_study.pdf

Oke, O., Bhalla, K., Love, D., Siddiqui, S. (2015). Tracking global bicycle ownership patterns. Journal of Transport \& Health 2, 490-501. http:/ / dx.doi.org/10.1016/j.jth.2015.08.006

Okma, K, Cheng, T., Chinitz, D., Crivelli, L., Lim, M., Maarse, H., Eliana Labra, M. (2010). Six Countries, Six Health Reform Models? Health Care Reform in Chile, Israel, Singapore, Switzerland, Taiwan and The Netherlands. J. Comp. Policy Anal. Res. Pract. 12, 75-113.

Oldenziel, R., de la Bruhèze, A. (2012). Cycling in a global world: introduction into the special issue. Transfers 2 (2), Summer 2012: 22-30. doi: 10.3167/tranS.2012.020203

Olsen, K, C. Arens, F. Mersmann (2018). Learning from CDM SD tool experience for Article 6.4 of the Paris Agreement. Climate Policy 18 (4), 383-395, http://dx.doi.org/10.1080/14693062.2016.1277686

Olsen, K.H., Fenhann, J. (2008). Sustainable development benefits of clean development mechanism projects. A new methodology for sustainability assessment based on text analysis of the project design documents submitted for validation. Energy Policy, 36: 28192830.

Olsen, S., S. Teoh, I. Miyazawa (2015). ASEAN Community and the Sustainable Development Goals: Positioning Sustainability at the Heart of Regional Integration. In: Greening Integration in Asia. how regional integration can benefit people and the environment, Institute for Global Environmental Strategies, Japan.

Organisation for Economic Co-operation and Development (OECD) (2013). Economic Outlook for Southeast Asia, China and India 2014: Beyond the Middle-Income Trap; Organisation for Economic Co-operation and Development (OECD) Publishing: Paris, France

OTP (2014). A project study on promotion of non-motorized transport (NMT) and improvement of public transport connectivity for sustainable and environmentally friendly transportation. Executive Summary. Bangkok: OTP, Ministry of Transport

OTP (Office of Transport and Traffic Policy and Planning, 2012). Sustainable Transport Systems Development Master Plan for Mitigating Climate Change, Summary. Bangkok: Office of Transport and Traffic Policy and Planning (OTP), Ministry of Transport.

Pardo, C. (2013a). 'How to Start'. In: Dextre, J. C., Hughes, M., \& Bech, L. (Eds.). Cyclists \& Cycling Around the World: Creating Livable \& Bikeable Cities. Lima: Fondo Editorial Pontificia Universidad Católica del Perú.

Pardo, C. (2013b). Bogota's non-motorised transport policy 1998-2012: the challenge of being an example. In W. Gronau, W. Fischer, \& R. Pressl (Eds.), Aspects of Active Travel How to encourage people to walk or cycle in urban areas (pp. 49-65). Mannheim: Verlag MetaGISInfosysteme.

Park, H., Lee, Y., Shin, H., Sohn, K (2011). Analyzing the time frame for the transition from leisure-cyclist to commuter-cyclist. Transportation 38, 305-319, doi 10.1007/s11116-0109299-4

Peet, K., H. Dalkmann, H. Gudmundsson, Y. Huisman, G. Jennings, M. Major, T. Raczek (2017). COP23: Transport Building Momentum to Raise Ambition and Define Implementation Pathways. Final Report, published by SLoCaT, http://www.ppmc-transport.org/wpcontent/uploads/2017/09/Transport-COP23-Final-Report-01-12-2017-1.pdf

Pendakur, S. (2005). Non motorized transport in African cities. Lessons from experience in Kenya and Tanzania. (S.-S. A. T. P. Program, Ed.). World Bank. 
Perschon, J. (2012). Sustainable Mobility. Recommendations for Future-Proof Transport Strategies. Development and Peace Foundation, Policy Paper 36 ISSN 1437-2819, www.sefbonn.org

Pettinga, A., Rouwette, A., Braakman, B., Pardo, C., Kuijper, D., de Jong, H., Spapé, I., Zuidgeest, M., Wittink, R., Kager, R., Schepel, S., Godefrooij, T. (2009). Cycling-Inclusive Policy Development: A Handbook. Utrecht, the Netherlands: Interface for Cycling Expertise.

Pielke, R. (2007). The Honest Broker: Making Sense of Science in Policy and Politics. Cambridge University Press, UK

Pojani, D., D. Stead (2015). Going Dutch? The export of sustainable land-use and transport planning concepts from the Netherlands. Urban Studies 52(9) 1558-1576, DOI: 10.1177/0042098014562326

PPMC (Paris Process on Mobility and Climate) (2017). An Actionable Vision of Transport Decarbonization. Implementing the Paris Agreement in a Global Macro-Roadmap aiming at net zero emissions tranpsort. Draft March 2017. http://www.ppmc-transport.org/wpcontent/uploads/2016/04/Global-Macro-Roadmap-Consultation-Draft-March2017.pdf

Preece, R. (2016). Reforming automobile excise taxes in the ASEAN region for pro-growth and pro-environment outcomes. World Customs Journal 10 (1), 45-72

Pucher, J., \& Buehler, R. (2008). Making cycling irresistible: lessons from the Netherlands, Denmark and Germany. Transport Reviews, 28 (4), 495-528.

Pucher, J., de Lanversin, E., Suzuki T., Whitelegg, J. (2012). Cycling in Megacities: London, Paris, New York, and Tokyo. In: Pucher, J. \& R. Buehler (Eds.) City Cycling. MIT Press, Cambridge, US, and London, UK.

Purwanto, J., Karmini, Kappiantari, M., Sehlleier, F. (forthcoming) Indonesia Stocktaking Report on Sustainable Transport and Climate Change. Data, Policy, and Monitoring; GIZ Indonesia: Jakarta, Indonesia, forthcoming

Raha, U. (2015). Analysis of the Characteristics of Bike-Sharing Program in Bangkok. http://hrm.ru.ac.th/index.php/2015-06-30-04-22-33/144-0023

Raha, U., K. Taweesin (2013). Encouraging the use of non-motorized in Bangkok. The 3rd International Conference on Sustainable Future for Human Security SUSTAIN 2012. Procedia Environmental Sciences 17 (2013) 444 - 45

Rahul, T., Verma, A. (2014). A study of acceptable trip distances using walking and cycling in Bangalore. Journal of Transport Geography 38, 106-113. http://dx.doi.org/10.1016/j.jtrangeo.2014.05.011

Raven, R. et al. (2017). Unpacking sustainabilities in diverse transition contexts: solar photovoltaic and urban mobility experiments in India and Thailand. Sustainability Science $12(4), 579-596$

Regidor, R. (2015). Canght (up) in traffic. Just another wordpress.com weblog. https://d0ctrine.com/category/cycling/ (accessed 23 February 2016)

Replogle, M., Hook, W. (2010). Proposed methodology for calculating GHG benefits of GEF transportation projects. Presentation at workshop: towards measuring GHG mitigation potential of land transportation projects in the GEF, Manila 17-18 February 2011.

Rimano, A. Piccini, M., Passafaro, P., Metastasio, R., Chiarolanza, C., Boison, A., Costa, F. (2015). The bicycle and the dream of a sustainable city: An explorative comparison of the image of bicycles in the mass-media and the general public. Transportation Research Part F 30, 30-44

Rios, R. A., Taddia, A., Pardo, C., \& Lleras, N. (2015). Ciclo-inclusión en América Latina y el Caribe: guía para impulsar el uso de la bicicleta. Washington D.C.: Banco Interamericano de Desarrollo, retrieved from www.bit.ly/cicloinclusion 
Rittel, H., M. Webber (1973). Dilemmas in a General Theory of Planning. Policy Sciences 4, 155-169.

Rodriguez, J. (2013). The geography of transport systems. Third edition, New York: Routledge, 416 pages. ISBN 978-0-415-82254-1

Rogelj, J., M. Schaeffer, P. Friedlingstein, N. P. Gillett, D. P. van Vuuren, K. Riahi, M. Allen, and R. Knutti (2016). Differences between carbon budget estimates unravelled. Nature Climate Change, 6, 245-252 http://www.nature.com/doifinder/10.1038/nclimate2868

Romero-Lankao, P., Burch, S., Hughes, S., Auty, K., Aylett, A., Krellenberg, K., et al. (2018). Governance and policy. In: Climate Change and Cities: Second Assessment Report of the Urban Climate Change Research Network, C. Rosenzweig, W. Solecki, P. Romero-Lankao, S. Mehrotra, S. Dhakal, and S. Ali Ibrahim (Eds.). Cambridge University Press, ISBN: 9781316603338

Romero, S., Guillen, M.D., Cordova, L., Gatarin, G. (2014). Land-Based Transport Governance in the Philippines: Focus on Metro Manila. Inclusive Mobility Project, Ateneo School of Government, Ateneo de Manila University 2014

Rose, G., Marfurt, H. (2007). Travel behaviour change impacts of a major ride to work day event. Transportation Research Part A 41 (2007) 351-364

Roy, P., A.J. Martínez, G. Miscione, M.H.P. Zuidgeest, M.F.A.M. van Maarseveen (2012). Using Social Network Analysis to profile people based on their e-communication and travel balance. Journal of Transport Geography, volume 24, pp. 111-122

Sabatier, P. (ed, 2007). Theories of the policy process. Westview Press, Boulder, Colorado, US

Sagaris, L, \& Ortuzar, J. (2015). Reflections on citizen-technical dialogue as part of cyclinginclusive planning in Santiago, Chile. Research in Transportation Economics 53, 20-30

Sayeg, P., P. Starkey, C. Huizenga (2014). Sustainable Development Goal for Sustainable Transport and Associated Results Framework, draft January 2014. http://www.slocat.net/sites/default/files/u10/draft_sustainable_transport_results_fra mework_owg_7_input-jan_3_0.pdf

Schipper, L., E. Deakin, D. Sperling (1994). Sustainable Transportation: the future of the automobile in an environmentally constrained world. Berkeley: University of California Transportation Center, paper No. 697.

Schipper, L., Marie-Lilliu, M., Gorham, R. (2000). Flexing the Link between Transport Greenhouse Gas Emissions: A Path for the World Bank. International Energy Agency, Paris June. http://www.iea.org/textbase/nppdf/free/2000/flex2000.pdf

Schmidt, J. Helme, N. Lee, J. Houdashelt, M. (2008). Sector-based approach to the post2012 climate change policy architecture, Climate Policy, 8(5): 494-515.

Schroten, A., I. Skinner, L. Brinke et al. (2012) Potential for less transport-intensive paths to societal goals. Task 4 paper produced as part of a contract between European Commission Directorate-General Climate Action and AEA Technology plc; see website www.eutransportghg2050.eu

Schwanen, T., Dijst, M., Kwam, M.P. (2006). Introduction - the internet, changing mobilities, and urban dynamics. Urban Geography 27, 585-589.

Schwanen, T., D. Banister, J. Anable (2011). Scientific research about climate change mitigation in transport: A critical review. Transportation Research Part A: Policy and Practice, 45 (10), 993-1006

Selvakkuraman, S., Limmeechokchai, B. (2015). Low carbon society scenario analysis of transport of an emerging economy - The AIM/Enduse modelling approach. Energy Policy 81 (2015) 199-214 
Sengers, F. (2016). Transforming Transport in Thailand. Experimenting for Transitions to Sustainable Urban Mobility. PhD thesis Eindhoven University of Technology, ISBN 978-90-3864022-8, 's Hertogenbosch, the Netherlands.

Sengers, F., Raven, R. (2014). Metering motorbike mobility: informal transport in transition? Technology Analysis \& Strategic Management, DOI: 10.1080/09537325.2013.870991

Severino, R. (2007). ASEAN Beyond Forty: Towards Political and Economic Integration. Contemporary Southeast Asia: A Journal of International \& Strategic Affairs, 29 (3), 406-423

Shaheen, S., Guzman, S., Zhang, H. (2010). Bikesharing in Europe, the Americas, and Asia. Past, Present, and Future. Transportation Research Record: Journal of the Transportation Research Board, No. 2143, Transportation Research Board of the National Academies, Washington, D.C., 2010, pp. 159-167. DOI: 10.3141/2143-20

Sheller, M., J. Urry (2006). The new mobilities paradigm. Environment and Planning A 2006, volume 38, pp 207-226

Shove, E. (2012). The shadowy side of innovation: unmaking and sustainability: unmaking and sustainability. Technology Analysis \& Strategic Management, 24 (4), 363-375, DOI: 10.1080/09537325.2012.663961

Silitonga, A., Atabania, E., Mahlia, T. (2012). Review on fuel economy standard and label for vehicle in selected ASEAN countries. Renew. Sustain. Energy Rev. 16, 1683-1695.

Sims R.; Schaeffer, R.; Creutzig, F.; Cruz-Núñez, X.; D’Agosto, M.; Dimitriu, D.; Figueroa Meza, M.J.; Fulton, L.; Kobayashi, S.; Lah, O.; et al. (2014). Transport. In Climate Change 2014: Mitigation of Climate Change. Contribution of Working Group III to the Fifth Assessment Report of the Intergovern-Mental Panel on Climate Change; Edenhofer, O., Pichs-Madruga, R., Sokona, Y., Farahani, E., Kadner, S., Seyboth, K., Adler, A., Baum, I., Brunner, S., Eickemeier, P., et al., Eds.; Cambridge University Press: Cambridge, UK; New York, NY, USA

Sintusingha, S. (2010). Bangkok's urban evolution: Challenges and opportunities for 1039 urban sustainability. In A. Sorensen \& J. Okata (Eds.), Megacities: Urban form, governance, and sustainability (pp. 133-162). Tokyo: Springer.

Site, P., M. Salucci (2010). Economic aspects of sustainable mobility. Thematic research summary. European Commission DG Energy and Transport, www.transport-research.info

Skeie, R., Fuglestvedt, J., Berntsen, T., Lund, M., Myhre, G., Rypdal, K. (2009). Global temperature change from the transport sectors: Historical development and future scenarios, Atmospheric Environment, 43(39): 6260-6270.

SLoCaT Partnership (2012). Rio+20: a Breakthrough for Sustainable Transport. http://www.slocat.net/sites/default/files/slocatfiles/slocat_letter_uncsd_focal_points _sustainable_transport_13_june.pdf

SLoCaT Partnership (2016). Climate finance transport projects database, version November 2016, http://www.slocat.net/news/1447

Spinney, J., D. Scott, K. Newbold (2009). Transport mobility benefits and quality of life: A time-use perspective of elderly Canadians. Transport Policy 16 (2009) 1-11

SPREAD (2012). European Lifestyles: the future issue. By Cheryl Hicks, Rosa Groezinger, Sarah Thorne and others: https://cordis.europa.eu/result/rcn/59298_en.html

Statistics Indonesia (2014). Land Transport Statistics 2014. Available online: http://bps.go.id/website/pdf_publikasi/Statistik-Transportasi--Darat--2014.pdf

Stavins R., J. Zou, T. Brewer, M. Conte Grand, M. den Elzen, M. Finus, J. Gupta, N. Höhne, M.-K. Lee, A. Michaelowa, M. Paterson, K. Ramakrishna, G. Wen, J. Wiener, and H. Winkler (2014). International Cooperation: Agreements and Instruments. In: Climate Change 2014: Mitigation of Climate Change. IPCC Working Group III. Cambridge University Press, Cambridge, United Kingdom and New York, NY, USA. 
Stead, D. (2016). Key research themes on governance and sustainable urban mobility. International Journal of Sustainable Transportation 10 (1), 40-48

Straatemeier, T. (2008). How to plan for regional accessibility? Transport policy, 15(2008), $127-$ 137.

Strange, L. (2002). The Bicycle, Women s Rights, and Elizabeth Cady Stanton. Women's Studies, an inter-disciplinary journal. Volume 31, 2002 - Issue 5, 609-626

Thailand Cycling Club (2016). Standards for Bikeway Design and Construction in Thailand. http:/ /www.thaicyclingclub.org/sites/default/files/05standards_for_bikeway_design_and_construction_in_thailand.pdf

Tigabu, A., Berkhout, F., van Beukering, P. (2015). The diffusion of a renewable energy technology and innovation system functioning: Comparing bio-digestion in Kenya and Rwanda. Techn. Forecast. Soc. Change 90(A); 331-345.

Tilburg, X. van, L. Würtenberger, H. de Coninck, S. Bakker (2011). Paving the way for low-carbon development strategies. ECN report E-011-059, Petten, The Netherlands.

Tongsopit, S., N. Kittner, Y. Chang, A. Aksornkij, W. Wangjiraniran (2016). Energy security in ASEAN: A quantitative approach for sustainable energy policy. Energy Policy 90 (2016) 60-72

Tongzon, J. and S-Y. Lee (2015). Achieving an ASEAN single shipping market: shipping and logistics firms' perspective. Maritime Policy \& Management 43 (4), 407-419

Tran, A. D. (2013). Emission Mitigation and Sustainable Transport Policies in Viet Nam. Presentation as UNESCAP, http://www.unescap.org/ttdw/common/TPT/WS-CO2Emissions-2013/3.11.VietNam.pdf

Transport Association of Canada (1999). Urban transportation indicators. Cited in Jeon and Amedkudzi (2005)

Transport-NAMA Database. Available online: www.transport-namadatabase.org (accessed on 23 May 2017).

Treaty of Paris (1951). Treaty establishing the European Coal and Steel Community, ECSC Treaty. Available from http://eur-lex.europa.eu/legalcontent/EN/TXT/?uri=uriserv $\% 3$ Axy0022

TRL (2010). Submission on modalities and procedures for the development of standardized baselines. Available from www.transport2012.org.

Tyfield, D. (2014). Putting the Power in 'Socio-Technical Regimes' - E-Mobility Transition in China as Political Process, Mobilities, 9:4, 585-603, DOI: 10.1080/17450101.2014.961262

Uabharadorn, M. (2013). Strategic Master Plan for Establishing Sustainable Transport System and Mitigating Climate Change Impacts in Thailand. Proceedings of the 10th International Conference of Eastern Asia Society for Transportation Studies, Tokyo, Japan, 9-12 September 2013.

UNCRD (2011). Bogota Declaration on sustainable transport objectives. http://sustainabledevelopment.un.org/content/documents/Bogota\%20Declaration_di scussed\%20_ENG.pdf

UNEP (2011). Transport. Investing in energy and resource efficiency. In: Towards a Green Economy: Pathways to Sustainable Development and Poverty Eradication. www.unep.org/greeneconomy

UNEP/Risø (2010). CDM pipeline July 1, 2010. www.cdmpipeline.org. UNFCCC, 2005. Modalities and procedures for clean development project activities. FCCC/KP/CMP/2005/8/Add.1, Decision 3/CMP.1.

UNESCAP (2011). Transport and the Millennium Development Goals. Note by the Secretariat, E/ESCAP/MCT.2/9. 
UNFCCC (1992). United Nations Convention on Climate Change. FCC/INFORMAL/84/Rev.1 http://unfccc.int/files/essential_background/convention/background/application/pd $\mathrm{f} /$ convention_text_with_annexes_english_for_posting.pdf

UNFCCC (2007). Bali Action Plan. FCCC/CP/2007/6/Add.1.

UNFCCC (2008). Analysis of possible means to reach emission reduction targets and of relevant methodological issues. Technical Paper, FCCC/ TP/2008/2.

UNFCCC (2009a). Nationally appropriate mitigation actions by developing country parties. Non-paper by the facilitator. Non-paper No. 51. 6 November 2009.

UNFCCC (2009b). Copenhagen Accord. Decision -/CP.15. Advance unedited version, 18 December 2009.

UNFCCC (2009c). Item 3 of the provisional agenda: Consideration of further commitments for Annex I Parties under the Kyoto Protocol. AWG-KP, 10th Session, Copenhagen, December 2009. FCCC/KP/AWG/2009/10/Add.3/Rev.3.

UNFCCC (2009d). Further guidance to the clean development mechanism. Draft decision -/CMP.5, advanced unedited version, www.unfccc.int (accessed 25 January 2010).

UNFCCC (2010a). Report of the ad hoc working group on long-term cooperative action under the Convention on its eighth session, held in Copenhagen from 7 to 15 December 2009. Advance version. FCCC/ AWGLCA/2009/17, 5 February 2010.

UNFCCC (2010b). Appendix II - Nationally appropriate mitigation actions of developing country parties. Available at: unfccc.int/home/ items/5265.php.

UNFCCC (2014). Technical paper on Non market based approaches, UN Doc. FCCC/TP/2014/10, 24 November, 2014. Online available at: http://unfccc.int/resource/docs/2014/tp/10.pdf

UNFCCC (2017a). INDCs as Communicated by Parties. Available online: http://www4.unfccc.int/submissions/indc/Submission\%20Pages/submissions.aspx (accessed on 23 May 2017).

UNFCCC (2017b). Submitted Biennial Update Reports (BURs) from Non-Annex I Parties. Available online: http://unfccc.int/national_reports/nonannex_i_natcom/reporting_on_climate_change/items/8722.php (accessed on 23 May 2017).

Unger, N., Bond, T., Wang, J., Koch, D., Menon, S., Shindell, D., Bauer, S. (2010). Attribution of climate forcing to economic sectors. Proceedings of the National Academy of Sciences, 23(107): 3382-3387.

United Nations (2015). Paris Agreement. https://unfccc.int/files/essential_background/convention/application/pdf/english_pa ris_agreement.pdf

United Nations (2016). Mobilizing transport for development. Analysis and Policy Recommendations from the United Nations Secretary-General's High-Level Advisory Group on Sustainable Transport. https:// sustainabledevelopment.un.org/content/documents/2375Mobilizing\%20Sustai nable\%20Transport.pdf

UP-NCTS (2011). Formulation of a National Sustainable Environmentally Sustainable Transport Strategy for the Philippines - Final Report. Published by UNCRD, supported by DOTC, DENR, CAI-ASI and IGES. http://www.uncrd.or.jp/content/documents/Philippine_NESTS.pdf

Urry, J. (2004) The 'System' of Automobility. Theory, Culture \& Society 21 (4-5), 25-39

US Department of Transport (2010). Transportation's role in reducing US greenhouse gas emissions. Report to Congress. 
Van, H.T., Choochkarukul, K., Fuji, S. (2014). The effect of attitudes toward cars and public transportation on behavioral intention in commuting mode choice-A comparison across six Asian countries. Transp. Res. Part A 2014, 69, 36-44.

Vergel, K., Tiglao, N. (2013). Estimation of emissions and fuel consumption of sustainable transport measures in Metro Manila. Philippine Engineering Journal Vol. 34 (1), 31-46

Voss, J., A. Smith, J. Grin (2009) Designing Long-Term Policy: Rethinking Transition Management. Policy Science (2009) 42:275-302. DOI 10.1007/s11077-009-9103-5

Wang, R. (2011). Autos, transit and bicycles: Comparing the costs in large Chinese cities. Transport Policy 18, 139-146

Watson, M. (2012). How theories of practice can inform transition to a decarbonised transport system. Journal of Transport Geography 24, 488-496

Wee, B. van \& K.T. Geurs (2011). Discussing equity and social exclusion in accessibility evaluations. European journal of transport and infrastructure research, 11(4), 350-367.

WHO (2015). Global status report on road safety. WHO Press, Geneva, Switzerland http://www.who.int/violence_injury_prevention/road_safety_status/2015/en

Wijaya, S. E. (2017) Multi-level tensions in transport policy and planning: bus-rapid transit (BRT) in Indonesia. PhD dissertation, Massey University, Palmerston North, New Zealand

Wittneben, B., Bongardt, D., Dalkmann, H., Sterk, W., Baatz, C. (2009). Integrating sustainable transport measures into the clean development mechanism, Transport Reviews, 29(1): 91-113.

World Bank (2008a). Safe, Clean, and Affordable... Transport for Development. The World Bank Group's Transport Business Strategy for 2008-2012. Washington D.C.

World Bank (2008b). Clean Technology Fund. The World Bank, Washington, DC. Available at: http://www.climateinvestmentfunds.org/cif/sites/ climateinvestmentfunds.org/files/Clean_Technology_Fund_paper_June_9_final.pdf.

World Bank (2017a). World Development Indicators. Available Online: http://databank.worldbank.org/ data/reports.aspx?source $=$ world-development-indicators (accessed on 23 May 2017).

World Bank (2017b). Worldwide Governance Indicators. Online database: http://databank.worldbank.org/data/reports.aspx?source=worldwide-governanceindicators

World Bank Group (2017) Global Mobility Report 2017. Tracking Sector Performance. Sustainable Mobility for All, ISBN: 978-0-692-95670-0

Wright, L, Fulton, L. (2005). Climate change mitigation and transport in developing countries. Transport Reviews, 25(6): 691-717.

Wright, L. (2001). Latin American Busways: Moving People Rather than Cars. Nat. Resour. Forum 2001, 25, 121-134.

Yan, X, R. Crookes (2009). Reduction potentials of energy demand and GHG emissions in China's road transport sector. Energy Policy 37 (2), pp. 658-668

Zhang, J., V. van Acker (2017) Life-oriented travel behavior research: An overview. Transportation Research Part A 104 (2017) 167-178

Zhao P., B. Lü, G. de Roo (2010). Urban expansion and transportation: the impact of urban form on commuting patterns on the city fringe of Beijing. Environment and Planning A $42(10) 2467-2486$

Zuidgeest, M. (2005). Sustainable urban transport development. A dynamic optimisation approach. PhD thesis University of Twente, Trail thesis T2005/3, Enschede, the Netherlands.

Zuidgeest, M.H.P., Gupta, N, Brussel, M.J.G., Salzberg, A., van den Bosch, F.H.M., Munshi, T., van Maarseveen, M.F.A.M. (2013). Measuring accessibility to jobs for the urban poor 
in Ahmedabad. In: Proceedings of the 13th World Conference on Transport Research WCTR 2013, 15-18 July 2013, Rio de Janeiro, Brazil. 20 p.

Zusman, E., A. Srinivasan, S. Dhakal (2012). Low Carbon Transport in Asia: Strategies for Optimizing Co-benefits. Routledge, ISBN 9781136576386 


\section{Summary}

The need for sustainable transport in a rapidly motorising region

Whereas mobility plays a key role in social and economic development by providing access to opportunities and enabling trade, the transport sector also has direct negative impacts. For example, the economic cost of health impacts from air pollution from road transport in OECD countries is estimated at close to USD 1 trillion per year. Other impacts and concerns include energy security, congestion, transport equity, fatalities and injuries from traffic crashes, noise, urban liveability and habitat fragmentation. In addition, the transport sector needs to respond to the challenge of climate change, as it produces $23 \%$ of energy-related $\mathrm{CO}_{2}$ emissions globally, and rising by $2.5 \%$ annually. The strongest growth is taking place in rapidly motorising regions, such as Southeast Asia, yet per capita emissions are far higher in the developed world. Evidently, a transformation to sustainable, low-carbon transport is required in both developed and developing countries.

\section{Research problem and contribution}

Policies to achieve such a transition face a range of barriers in the realms of economy, policy development, institutions, analysis techniques and society. We see the following gaps in research and policy that are required to be filled to deal with these. First, as climate change mitigation is an international policy objective and (sustainable) development issues are priorities for transport policymakers, there is a conceptual challenge on how to reconcile these two for the transport sector. Second, a research gap is the lack of knowledge on the current status of and the applicability of concepts of policy analysis and transition thinking to sustainable transport policy in the ASEAN region. The third gap is of a more practical nature, i.e. the lack of knowledge on how low-carbon transport policy can be developed further, given the various barriers policymakers are facing. Finally, a knowledge gap exists on how various governance levels can contribute to each other's' goals in transport and climate change policy.

This thesis analyses low-carbon transport policy development at the global, regional, national and local level, particularly in Southeast Asia. It thereby aims to contribute to filling the above-mentioned four gaps, with the following central research question:

What are current policy responses to sustainability challenges in the transport sector and how can these be strengthened, particularly for climate change mitigation in rapidly motorising ASEAN countries? 
This thesis contributes to academic literature by conceptual development on transport policy, application of theoretical frameworks on policy studies, transitions and governance, and by the focus on Southeast Asia, a region underrepresented in peer-reviewed research on (transport) policy. In particular, it uses a policy component analysis framework developed by Howlett \& Cashore for low-carbon transport policy analysis and applies Technological Innovations Systems framework to cycling, which has not been done before. In addition, it contributes to reflecting policy-relevant research and discussions on the interaction of transport and climate change policy in literature.

Policy development in the transport sector in the ASEAN region is not yet in line with global climate change objectives, however policies undertaken in the context of sustainable development support low-carbon mobility.

An overall conclusion of this thesis is that initial low-carbon transport policies are being taken at different levels of governance in the rapidly motorising region of Southeast Asia, however these do not yet lead to the transition needed to meet the Paris Agreement objective of staying well below 2 degrees warming.

The global climate change agenda is reflected at the national level, and to a limited extent at the ASEAN regional and local level, in policy and institutional development. Global climate policy and regional cooperation complement and support national and local low-carbon transport policy development. Nevertheless, there is scope to further strengthen the multi-level governance system on transport and climate change by improving the institutional and policy linkages between the various levels.

The Avoid - Shift - Improve approach needs to be expanded with Access, Lifestyle and Transition considerations in order to be an effective framework that does justice to the distributional, systemic and behavioural aspects of (low-carbon) transport policy.

A coherent policy framework to integrate transport, development and climate change mitigation is lacking, however there are concepts looking at the various aspects. First, there are frameworks and approaches for transport policy and planning that emphasise the need to move from a narrow focus on mobility and vehicular travel, to a broader view on accessibility, i.e. the proximity of people to opportunities and the relative ease at which these can be reached. Second, thinking on development and climate change emphasise that for developing and emerging countries, reducing greenhouse gas emissions needs to be compatible with national and local development objectives. Third, to address environmental challenges in the transport sector, the Avoid - Shift - Improve (ASI) approach was developed, yet 
not well-reflected in academic literature. ASI suggests that for low-carbon transport, policy and planning should look at 1) reducing the need to travel, 2) shifting to more environmentally-friendly transport modes, and 3) improve the carbon-efficiency of vehicles and fuels. This also implies that both technological and behavioural change is required to enable a long-term transition to low-carbon, sustainable transport.

Therefore, if ASI is combined with a development focus based on accessibility and thinking on sustainable lifestyles and transitions, it could lead to a comprehensive policy framework for sustainable transport. This framework is used in the remainder of this thesis for analysing sustainable transport development at various governance levels. We conclude that transport policies objectives are focusing mostly on improving connectivity and infrastructure, yet in some countries and cities accessibility is considered in land-use - transport integration. The ASI approach is used by multiple ASEAN countries, as well as at the regional level, whereas a longterm transition perspective is not apparent. However, there are developments in electric vehicles, and consideration of policies to limit the growth of private vehicles, and international climate instruments aim at catalysing systemic change. Finally, behaviour change and sustainable lifestyles are touched upon in some policy documents, and in the framing and promotion of cycling as a mobility option.

The newer international climate instruments, such as NAMAs, NDCs and the GCF, show more potential than the Kyoto Protocol instruments to promote sustainable, low-carbon transport, as they are better aligned to national circumstances and better suited to address the barriers that developing country policymakers face.

In carbon trading instruments such as the Clean Development Mechanism, the transport sector does not play a significant role with approximately $1 \%$ of the projects. Nationally Appropriate Mitigation Actions are a better fit with the transport sector, as it includes technical as well as financial assistance, and programmes can be tailored to the needs of the countries. Thereby they can support policy development at the national and local level. As NAMAs do not involve carbon trading, monitoring requirements are flexible and lack of data is less of a barrier. There is a key role for sustainable development co-benefits, and the potential for transformational change, when assessing NAMAs.

Since 2011, significant effort has been put in developing transport-NAMAs, and as of mid-2017, 11\% of the 229 existing NAMAs are in the transport sector, which is not too far from the sector's contribution to global greenhouse gas emissions (14\%). However, few NAMAs are in the implementation stage yet and securing funding is a challenge due to limited available funding compared the proposals developed. If 
climate finance can be used more effectively to leverage finance from development banks, domestic public and private sources, the impact of NAMAs could be larger.

In the Nationally Determined Contributions of ASEAN countries, transport plays a key role as a sector for mitigation actions. In addition, the development of the NDCs has contributed to more attention for low-carbon transport and led to more multisectoral and inter-ministerial cooperation. In Article 6 of the Paris Agreement, a new market mechanism and a non-market mechanism are introduced. In the relatively new Green Climate Fund, low-carbon transport is acknowledged as a key sector, although no transport project has been approved yet. The experience with transportNAMAs can provide valuable lessons in the development of those new mechanisms.

ASEAN instruments around transport focus on policy cooperation and reflect 'networked regionalism'. Sustainable transport has played a relatively small role in ASEAN cooperation but this role is growing, and a range of 'soft' measures can be used to promote low-carbon transport.

Since the 1990s, transport cooperation in ASEAN has focused on promoting connectivity by cross-border infrastructure and reducing regulatory barriers. Sustainable transport was included in the ASEAN Kuala Lumpur Transport Strategic Plan 2016-2025 (KLTSP) for the first time as a dedicated chapter. Actions in this KLTSP chapter focus on topic such as fuel economy, green freight, nonmotorised transport, data and indicators, capacity building, and strategy development based on the avoid-shift-improve approach. Instruments include knowledge sharing, information platforms, development of a regional strategy, roadmap and action plan, training, workshops, expert groups and development of guidelines. Such 'soft law' measures are common in ASEAN cooperation settings, with its preference for consultation and networking, dialogue, non-interference, and soft diplomacy.

Although sustainable transport supports a range of objective in ASEAN strategies outside the transport sector, these are not acknowledged explicitly. There are no references to the global agendas on sustainable development and climate change in the KLTSP, and collaboration with other relevant sectors, such as energy and environment, is still limited. To strengthen policy and technology cooperation on sustainable transport, instruments such as harmonisation of standards, coordination of research, infrastructure action plans, high-level policy dialogues and a joint vision can be used, supported by development of a monitoring system and improved institutional structure. 
Countries' policy objectives are in line with international SD and climate goals, however the instruments, mechanisms and calibrations need to be strengthened to reach those objectives. Climate change has, in a few cases, led to policy windows for modifying transport policy.

The current status of policies on sustainable transport and climate change in Indonesia, the Philippines, Thailand and Vietnam is analysed using a taxonomy of Howlett and Cashore, who distinguish six policy components. We found several common elements across the four countries. First, at the level of policy ends, each country has a set of goals, objectives and specific targets or settings in policy plans and strategies that support sustainable transport, and, directly or indirectly, climate change mitigation. Second, looking at the component of policy mechanisms, all four countries are active in development of nationally appropriate mitigation actions in the transport sector. In the realm of transport demand management and "Avoid" strategies, policies and measures are in an early stage of development or absent. Shift and Improve measures are generally more developed. Third, the policy ends are not always consistently matched with the policy tools.

There are notable differences as well: (i) a policy objective to limit motorisation was only found in two countries, while the others do not address this explicitly; (ii) as part of the instrument logic, the Avoid Shift Improve approach is used in transport policy documents in two countries, however as yet it does not appear to have major importance as a framework to structure and develop policies; and (iii) with regard to policies to improve vehicle fuel efficiency, the use of different policy mechanisms and their calibrations vary strongly from one country to the other.

Although climate change mitigation is generally of lower concern for transport policymakers compared to improving efficiency of the transport system and reducing local impacts, we found significant attention to the climate change agenda. Climate change is addressed in key transport policy documents and is becoming relevant as a policy driver; and, vice versa, transport plays a role in climate change policies. In addition, institutions are being set up to specifically deal with transport and climate change.

A range of ASI policies are being discussed, developed or implemented, which could result in significant emission savings compared to business as usual. However, stabilisation or an absolute reduction in GHG emissions from transport, which would be required to stay below the temperature limits in the Paris Agreement, is not likely in the near future, nor are long-term plans in place that enable a transition to climate-compatible transport development. 
ASEAN cities increasingly recognise the potential and benefits of cycling, yet much remains to be done in policy and planning to move cycling beyond a niche activity.

In analysing the how urban mobility policy is contributing to the transition to sustainable transport, we use cycling as an example. Policymakers and media in Bangkok and Metropolitan Manila acknowledge cycling as an option to achieve sustainable, low-carbon urban transport and public health. The bicycle is often used by the poor for short trips and by the more affluent for sports, recreation and fun activities. As a fashion symbol, group activities, social media and events, cycling or the bicycle is popular. As a mobility option, cycling is still a niche and not (yet) an established culture.

Using a Technological Innovation Systems framework, we show that common elements not sufficiently developed include limited knowledge development, actor networks, advocacy coalition, e-bike adoption, infrastructure, resource mobilisation and legitimation; the latter due to issues such as car-oriented planning, competition from motorcycles and paratransit, and potentially limited public acceptance - with weather being one among several factors. Although initial investments in infrastructure dedicated to cycling are being made, these are fragmented and there are no integrated plans or visions. On the other hand, flat terrain, attention for cycling for health and environment, heavy congestion, expansion of public transport, growing bike industry, active university communities, emergence of advocacy coalitions and a potential to fit with cultural values, could open up opportunities.

To move cycling beyond a niche transport practice and achieve a transition to significant modal shares, incremental but consistent improvements in infrastructure focusing on a comprehensive network based on cycling-inclusive planning are required. Other policy issues include 1) improving regulations to protect cyclists, 2) education towards bicycle use and respect of cyclists and communication, 3) progressive transport demand management policies, 4) ensuring sufficient dedicated staff in relevant government institutions, 5) promotion of e-bikes as a convenient option in a tropical climate and alternative for motorcycles, 6) data and monitoring, 7) working with the private sector and 8) enhancing the advocacy coalition.

These findings are specifically for the case of cycling, however a similar approach can be used for other urban mobility options, such as electric vehicles (two and three-wheelers, cars and buses), intelligent transport systems, water transport, mass rapid transit systems as well as green logistics systems. 


\section{Samenvatting}

\section{De behoefte aan duurzaam verkeer in een snel-motoriserende regio}

Mobiliteit speelt een belangrijke rol in sociale en economische ontwikkeling, maar de verkeerssector heeft ook directe negatieve effecten. De economische kosten van gezondheidseffecten door luchtvervuiling van wegverkeer in rijke landen, bijvoorbeeld, worden geschat op bijna 1 biljoen dollar jaarlijks. Andere effecten zijn energie-voorzieningszekerheid, files, verkeersveiligheid, geluidsoverlast, stedelijke leefbaarheid en habitatfragmentatie. Daarbij komt het klimaatprobleem, waar de verkeerssector aan bijdraagt met $23 \%$ van de energie-gerelateerde $\mathrm{CO}_{2}$-emissies wereldwijd, welke met $2.5 \%$ per jaar groeien. De sterkste groei vindt plaats in regio's waar het autogebruik snel toeneemt, zoals Zuidoost-Azië, hoewel per inwoner de emissies veel hoger zijn in geïndustrialiseerde landen. Duidelijk is dat een transformatie naar een duurzame, koolstofarme mobiliteit nodig is over de hele wereld.

\section{Onderzoeksvraag en wetenschappelijke bijdrage}

Beleid dat probeert zo'n transitie te bewerkstelligen heeft met barrières te maken op het gebied van economie, beleidsontwikkeling, instituties, analysemethoden en maatschappij. Ik zie de volgende missende elementen in onderzoek en beleid welke moeten worden opgevuld om die barrières weg kunnen te nemen. Ten eerste, omdat klimaatverandering een internationaal beleidsdoel is en (duurzame) ontwikkelingsdoelen prioriteiten zijn voor verkeersbeleidsmakers, is er een conceptuele uitdaging om die twee te verenigen voor de verkeerssector. Een tweede lacune in onderzoek is het gebrek aan kennis over de huidige stand van zaken van duurzaam mobiliteitsbeleid in de ASEAN ${ }^{64-r e g i o, ~ e n ~ d e ~ t o e p a s s i n g ~ v a n ~}$ beleidsanalyse en transitietheorie daarop. Ten derde is er behoefte aan meer kennis over hoe klimaat-vriendelijk mobiliteitsbeleid verder kan worden ontwikkeld, gegeven de barrières waar beleidsmakers mee te maken hebben.

Dit proefschrift analyseert beleid voor koolstofarme mobiliteit op mondiaal, regionaal ${ }^{65}$, nationaal en lokaal niveau, in het bijzonder in Zuidoost-Azië. Hiermee draagt het bij aan het dichten van bovengenoemde lacunes, met als centrale onderzoeksvraag:

\footnotetext{
${ }^{64}$ Verbond van Zuidoost-Aziatische Naties, met als deelstaten Brunei, Cambodja, Filippijnen, Indonesië, Laos, Maleisië, Myanmar, Singapore, Thailand en Vietnam

65 'regionaal' staat in dit proefschrift voor (samenwerking) 'tussen landen'
} 
Wat is het antwoord van het beleid op duurzaambeidsuitdagingen in de verkeerssector en hoe kan het beleid worden versterkt, in het bijzonder als het gaat om mitigatie van klimaatverandering in snel-motoriserende ASEAN-landen?

De wetenschappelijke bijdrage van dit proefschrift ligt in conceptuele ontwikkeling van duurzaam mobiliteitsbeleid, toepassing van theoretische raamwerken van beleidsstudies, transities en 'governance', en door de focus op Zuidoost-Azië, een regio die relatief weinig is gepresenteerd in academisch onderzoek naar (mobiliteits)beleid. Meer specifiek gebruik ik een analysemethode voor beleidscomponenten van Howlett \& Cashore voor koolstofarm mobiliteitsbeleid en pas het Technologische Innovatie-Systemen raamwerk toe op fietsen, iets wat nog niet eerder is gedaan. Een andere bijdrage is dat het beleidsrelevant onderzoek en discussies over de interactie van mobiliteit- en klimaatbeleid naar de wetenschappelijke literatuur brengt.

Beleid in de verkeerssector in de ASEAN-regio is nog niet in lijn met mondiale klimaatdoelen, maar beleid ontwikkeld voor duurzame ontwikkeling draagt wel bij aan koolstofarme mobiliteit.

Een overkoepelende conclusie van dit proefschrift is dat er soms wel beleid voor koolstofarm verkeer wordt gemaakt, op verschillende beleidsniveaus in snelmotoriserend Zuidoost-Azië, maar dat dit nog niet leidt tot de transitie die nodig is om het doel van het Akkoord van Parijs - beneden 2 graden temperatuurstijging blijven - te halen. In nationaal beleid, en tot op zekere hoogte ASEAN-regionaal en lokaal, wordt de mondiale klimaatagenda meegenomen in ontwikkeling van beleid en instituties. Mondiaal klimaatbeleid en regionale samenwerking complementeren en ondersteunen nationaal- en lokaal duurzaam verkeersbeleid, echter er zijn nog genoeg mogelijkheden het meerlagig bestuurssysteem ${ }^{66}$ in verkeer en klimaat te verbeteren.

De Vermijden - Verschuiven - Verbeteren aanpak moet worden uitgebreid met noties van Bereikbaarheid, Levensstijl, en Transities om het een effectief beleidsraamwerk te laten zijn dat recht doet aan de gelijkheids, systemische en gedragsaspecten van (koolstofarm) mobiliteitsbeleid.

Een coherent beleidsraamwerk om verkeer, ontwikkeling en (mitigatie van) klimaatverandering met elkaar te verbinden mist nog, maar er zijn wel concepten die naar de verschillende aspecten kijken. Waar vroeger een eenzijdige nadruk op voertuigdoorstroming gebruikelijk was, richt mobiliteitsbeleid en -planning richt zich steeds meer op 'bereikbaarheid' en toegankelijkeheid, oftewel de nabijheid van

${ }^{66}$ Vertaald van 'multi-level governance' 
mensen tot wat ze willen bereiken, en het relatieve gemak waarmee ze dat kunnen bereiken. Ten tweede, het denken over klimaat en ontwikkeling erkent dat voor ontwikkelingslanden en opkomende economieën het terugbrengen van broeikasgasemissies in lijn moet zijn met nationale en lokale ontwikkelingsdoelen. Ten derde, om milieuaspecten van mobiliteit te verminderen is de Vermijden Verschuiven - Verbeteren (VVV) aanpak ontwikkeld, hoewel die tot nu toe niet goed is opgenomen in de wetenschappelijke literatuur. Volgens VVV zou het beleid en planning voor koolstofarme mobiliteit zich moeten richten op 1) het verminderen van de vraag naar mobiliteit, 2) verschuiven van de mobiliteitsvraag naar milieuvriendelijkere verkeermodaliteiten, en 3) verbeteren van de energie- en koolstofefficiëntie van voertuigen en brandstoffen. Dit houdt ook in dat zowel technologische als gedragsverandering nodig is om een transitie naar duurzame, koolstofarme mobiliteit te bewerkstelligen.

Als VVV wordt gecombineerd met een visie op ontwikkeling waarin 'bereikbaarheid' een centrale rol speelt en noties van transities en duurzame levensstijl, leidt dit naar een omvattend raamwerk voor duurzame mobiliteit. In de rest van dit proefschrift gebruik ik dit beleidsraamwerk om koolstofarm verkeersbeleid op verschillende governance niveaus te analyseren. In de meeste gevallen richt verkeersbeleid zich op verbetering van 'connectivity' en infrastructuur, hoewel in sommige landen en steden ook bereikbaarheid ook terugkomt in de integratie van ruimtelijke ordening en mobiliteit. De VVV-aanpak wordt gebruikt in verscheidene ASEAN-landen, en ook op het regionale niveau, maar een lange-termijn transitie perspectief laat zich nog niet zien. Aan de andere kant zijn er ontwikkelingen in beleid voor elektrische auto's en beperking van de groei van persoonlijke voertuigen, en sommige internationale klimaatmechanismen richten zich op het bevorderen van systemische verandering. Gedragsverandering en duurzame levensstijl komen terug in verscheidene beleidsdocumenten, alsmede in beleid en 'framing' van fietsen als mobiliteitsoptie.

Nieuwere internationale klimaatinstrumenten, zoals NAMA's, NDC's en het GCF, hebben een groter potentieel dan de Kyoto Protocol mechanismen voor het bevorderen van koolstofarme mobiliteit, omdat deze beter passen bij nationale omstandigheden en beter de barrières die beleidsmaker in ontwikkelingslanden tegen komen, aan kunnen pakken.

In $\mathrm{CO}_{2}$-handelinstrumenten zoals het Clean Development Mechanism speelt de verkeerssector geen significante rol met minder dan $1 \%$ van de projecten. Nationally Appropriate Mitigation Actions (NAMA's) passen beter bij de sector doordat deze zowel financiële als technische ondersteuning bieden, en de projecten op maat kunnen worden vormgegeven op een manier die bij het land past. Hierdoor kunnen 
deze beleid op nationaal en lokaal niveau ondersteunen. Doordat bij NAMA's geen $\mathrm{CO}_{2}$-handel komt kijken zijn de voorwaarden voor monitoren van emissiereducties niet zo stringent en gebrek aan gegevens geen grote barrière. Daarnaast spelen de bijdrage aan duurzame ontwikkeling, en potentieel voor systemische verandering, een rol bij de beoordeling van NAMA's.

Sinds 2011 is er flink wat moeite gestoken in het ontwikkelen van verkeers-NAMA's, zodat nu $11 \%$ van de 229 NAMAs in de verkeerssector zijn - wat dichtbij het aandeel van de sector in mondiale broeikasgasemissies is (14\%). Echter er zijn slechts enkele NAMA's in de fase van implementatie, en het verkriigen van financiering moeilijk vanwege de beperkte fondsen in vergelijking tot het aantal ontwikkelde NAMA-voorstellen. De positieve effecten van NAMA zouden groter kunnen wanneer klimaatfinanciering beter in staat zijn geld voor ontwikkelingssamenwerking en private middelen te combineren.

In de klimaatplannen (NDC's) van Zuidoost-Aziatische landen speelt de verkeerssector een belangrijke rol. Daarnaast heeft het ontwikkelen van die plannen geleid tot meer aandacht voor koolstofarme mobiliteit en meer samenwerking tussen ministeries. In Artikel 6 van het Akkoord van Parijs zijn een nieuw emissiemarktmechanisme en een niet-markt mechanisme in het leven geroepen. In het eveneens relatief nieuwe Green Climate Fund (GCF) wordt verkeer als een belangrijke sector gezien, maar er is nog geen project voor koolstofarme mobiliteit goedgekeurd. De ervaring die is opgedaan met NAMA's levert bruikbare lessen op bij het verder ontwikkelen van deze nieuwe instrumenten.

De instrumenten die ASEAN gebruikt bij mobiliteit richten zich op beleidssamenwerking en kunnen worden gezien als 'networked regionalism' in plaats van krachtigere vormen van samenwerking. Duurzaam verkeer heeft tot nu toe een relatief kleine rol gespeeld in ASEAN-samenwerking, maar deze is groeiende. Er is een aantal 'soft' instrumenten die kunnen worden gebruikt om koolstofarme mobiliteit te bevorderen.

Sinds de 90-er jaren heeft ASEAN-samenwerking op het gebied van verkeer zich gericht op verbetering van de onderlinge bereikbaarheid ('connectivity') door middel van grensoverschrijdende infrastructuur en vermindering van barrières in regelgeving. Duurzame mobiliteit zat voor het eerst als een apart hoofdstuk in het ASEAN Kuala Lumpur Transport Strategic Plan (KLSTP). Belangrijke onderwerpen daarin zijn brandstofefficiëntie, groen goederenvervoer, capaciteitsopbouw en strategieontwikkeling op basis van de VVV-aanpak. Instrumenten die in het KLTSP worden gebruiken zijn bijvoorbeeld kennis delen, informatieplatforms, ontwikkeling van een regionale strategie, routekaart en 
actieplan, training, workshops expertgroepen en ontwikkeling van richtlijnen. Zulke 'soft' maatregelen zijn gebruikelijk bij ASEAN-samenwerking, waarbij er een voorkeur is voor consultatie, netwerken, dialoog en zachte diplomatie.

Hoewel duurzame mobiliteit allerlei beleidsdoelen ondersteunt in ASEANstrategieën in andere sectoren, wordt dit niet als zodanig erkent in verkeersstrategieën. Er zijn geen verwijzingen naar de mondiale agenda's voor duurzame ontwikkeling en klimaatverandering (hoewel dit binnenkort gaat veranderen), en samenwerking of coördinatie met andere relevante sectoren zoals milieu en energy is nog beperkt. Om samenwerking voor beleid en technologie voor duurzame mobiliteit te versterken kunnen instrumenten worden ingezet, bijvoorbeeld harmonisatie van standaarden, onderzoekscoördinatie, actieplannen voor infrastructuur, beleidsdialoog op hoog niveau en ontwikkeling van een gemeenschappelijke visie; ondersteund door een verbeterd monitoringssysteem en institutionele structuur.

De beleidsdoelen van landen zijn in lijn met internationale duurzaamheidsen klimaatdoelen, echter de instrumenten en maatregelen zijn niet genoeg om de doelen te bereiken. Klimaatverandering heeft in enkele gevallen geleid tot "policy windows" voor het aanpassen van verkeersbeleid.

De huidige stand van zaken in beleid voor verkeer en klimaat in Indonesië, de Filippijnen, Thailand en Vietnam analyseren we met een taxonomie van Howlett \& Cashore, die zes componenten van beleid onderscheiden. Gemeenschappelijke resultaten voor de vier landen zijn als volgt. Ze hebben allen beleidsdoelen en specifieke 'targets' in plannen en strategieën die duurzaam verkeer, en, direct of indirect, broeikasgasreductie, ondersteunen. Als het gaat om beleidsmechanismen, valt op dat alle vier landen actief zijn in het ontwikkelen van NAMA's in de verkeerssector. Daarnaast zien we bij de ontwikkeling van mobiliteitsvraagreductie en management ("Vermindering") dat beleidsmaatregelen nog in de kinderschoenen staan of afwezig zijn. Maatregelen voor "Verschuiving" en "Vermindering" zijn veelal beter ontwikkeld. Daarnaast valt op dat de beleidsdoelen vaak niet haalbaar zijn met de voorgenomen maatregelen, waarbij er dus sprake is van een 'mismatch'.

Er zijn ook allerhande verschillen: (i) het beleidsdoel beperking van motorisatie is in twee landen gevonden, en de anderen behandelen dit niet expliciet; (ii) als onderdeel van het instrumentenpalet, de VVV-aanpak is in beleidsdocumenten van twee landen gevonden, waarbij tegelijkertijd het lijkt alsof deze nog geen substantiële rol speelt in het structureren van beleid; en (iii) bij beleid voor brandstofefficiëntie voor voertuigen is er duidelijk verschil tussen landen in het type maatregelen en de uiteindelijke invulling hiervan (bijvoorbeeld de hoogte van de normen). 
Hoewel in het algemeen broeikasgasreductie van een minder belang is voor verkeersbeleidsmaker dan efficiëntie van het mobiliteitssysteem en reduceren van lokale impacts, vonden wij dat er toch aandacht is voor de klimaatagenda. Klimaatverandering speelt een rol in belangrijke mobiliteitsbeleidsdocumenten en wordt relevant als beleidsdoel; omgekeerd speelt ook verkeer mee in klimaatbeleid. Ook worden en instituties opgezet speciaal met als doel verkeer en klimaat aan te pakken.

Allerlei VVV-beleidsmaatregelen worden bediscussieerd, ontwikkeld of geïmplementeerd, die met elkaar kunnen leiden tot significante emissiebesparingen vergeleken met als er geen actie zou worden ondernomen. Maar een stabilisatie of neergaande trend in emissies door verkeer, welke nodig is om de temperatuur doelstelling uit het Akkoord van Parijs te halen, is niet waarschijnlijk in de nabije toekomst. Ook zijn er nog geen lange-termijnplannen die een transitie naar klimaatvriendelijke mobiliteit mogelijk maken.

Steden in ASEAN zien mogelijkheden en voordelen van fietsen, maar hebben nog een lange weg te gaan voordat de fiets een significante rol speelt in het mobiliteitssysteem.

Bij het analyseren hoe stedelijk mobiliteitsbeleid bijdraagt aan duurzaam verkeer gebruiken we fietsen als voorbeeld. In Bangkok en de metropoolregio Manila zien beleidsmakers en de media dat fietsen bijdraagt aan duurzame mobiliteit en volksgezondheid. De fiets wordt veel gebruikt door het armere deel van de bevolking voor korte ritten, en door het rijkere gedeelte voor sportieve en recreatieve activiteiten. Als mode-symbool en voor groepsactiviteiten en evenementen is de fiets populair. Als vervoermiddel echter, is de fiets nog een 'niche' en nog geen onderdeel van de mobiliteitscultuur.

Gebruikmakende van het Technologische Innovatie-Systemen raamwerk laten we zien dat verschillende elementen in het fietssysteem nog niet genoeg zijn ontwikkeld: kennisontwikkeling, netwerken van actoren, e-bikes, infrastructuur, mobilisatie van financiële middelen, en de legitimatie; de laatste vooral door auto-gerichte planning, competitie met bromfietsen en driewielers, en mogelijk beperkte publieke acceptatie - waarbij het tropische weer een van verschillende factoren is. Hoewel er sinds kort investeringen worden gedaan in infrastructuur zoals fietspaden, zijn die gefragmenteerd en zijn er geen overkoepelende plannen of visies. Aan de andere kant zijn er allerhande factoren die mogelijkheden bieden voor de fiets: overwegende vlak terrein, aandacht voor gezondheid en milieu, actieve universiteitsgroepen, opkomende coalities van pro-fietsactoren en dat het aansluit bij sommige culturele waarden. 
Om een transitie te bewerkstelligen waarbij fietsen een substantiële rol speelt als modaliteit zijn incrementele maar consequente verbeteringen nodig in de infrastructuur, gebruikmakend van fiets-inclusieve planning, met als uiteindelijke doel een geïntegreerd netwerk. Andere relevante beleidsaspecten zijn bijvoorbeeld 1) regulering die bescherming aan fietsers voorop zet, 2) bewustwording bij alle verkeersdeelnemers, 3) vraag-gestuurd mobiliteitsbeleid waaronder parkeerbeleid en snelheidsreductie, 4) voldoende werknemers in de overheid die zich met fietsen bezighouden, 5) stimuleren van e-bikes als comfortabel vervoermiddel in tropisch klimaat en alternatief voor brommers, 6) verzamelen van gegevens en monitoring, 7) samenwerking met de private sector, en 8) verbeteren van de actornetwerken.

Deze bevindingen richten zich op fietsen, maar een soortgelijke analyse-aanpak kan worden gebruikt voor andere mobiliteitsopties, zoals elektrisch vervoer (waaronder twee- en driewielers en bussen), intelligente verkeerssystemen, mobiliteit over water, openbaar vervoer en groene logistiek. 


\section{Acknowledgements}

This journey began in a bus in Brazil, where I took the decision to pursue a $\mathrm{PhD}-$ though the topic of low-carbon transport emerged some months later. I officially started in November 2010 with ITC/University of Twente. I got approval from my employer then, ECN, to work part-time on my thesis - for which I am grateful -, and could already use some of my ongoing project work for academic papers. Shifting jobs to GIZ in Thailand two years later changed the working mode quite a bit. Allocating sufficient time to research and writing became more challenging due to a demanding, though very satisfying, job as a team leader. On the other hand, working full-time on low-carbon transport policy in Southeast Asia was a good opportunity to focus my thesis more on this region.

Since moving back to the Netherlands in 2015 I have been able to dedicate more time to research, while still being able to use the outputs, experience and contacts from the Transport and Climate Change project that I continued to work for, although home-based. Combining research and practice in this way has been most rewarding, and I am very grateful for the opportunities I got in my professional life as a climate policy researcher, international development project manager, and independent consultant.

Throughout these years, I received support from so many people, without which this thesis would not have come about. First of all, I wish to express my gratitude to Martin, for accepting me as a PhD candidate in the PGM department, being my promoter, and providing guidance and support. With you and my two supervisors I have been supported by an excellent team. Mark, thank you for all our conversations and joint work, and your encouragements, that continued over skype after you moved to Cape Town. Heleen, in the past fifteen years you have been my colleague, friend, manager and mentor. I deeply appreciate your constructive feedback, scientific suggestions, engaging discussions with you, your personality and humour, all of which have shaped my research and work with ECN and beyond.

In Southeast Asia I have been, and still am, working with many amazing people. First of all, I want to thank Roland for the opportunity to work with GIZ in Thailand. Friedel, Papondhanai, Mattawan, Indira, Ellie, Vanisara, Danielle, Tina, Tuan, Jeya, Julia, Aditya, Rungtip, Monica, Tali, Gessarin, Janthorn, Hannah and interns: thank you for being such a professional and fun team! You're great to work with and I've learnt a lot. Keep up the good work! Daniel, André, Andrea and others in the GIZ Transport team in Eschborn/Bonn, thank you for the great collaboration as well. 
Alvin, Kathleen and lots of other Clean Air Asia colleagues, working with you on reports, papers and regional events is a big pleasure. Sorawit, Chutinthorn, Frans, Duong, Hien, Puput, Ko, Natachai, Pat, Anna, Jürg, thank you for our fruitful and nice meetings in offices, conference venues, coffee shops and various kinds of vehicles throughout ASEAN: these have contributed a lot to my research.

I want to thank Sudhir, Karl and Mark of the SLoCaT Partnership as well, and my special appreciation is for Cornie: you have helped my work in so many ways, and your tireless efforts have been key in putting transport and climate change on the international agenda.

I also much appreciate the collaboration with the ASEAN Secretariat and the Ministries of Transport and Environment in Thailand, Indonesia, Vietnam, the Philippines and Malaysia.

Martina, Nikola, Franca, Marco, Hanh, and other (temporary) Bangkokians, thank you for making my time there even more enjoyable and I'm happy we're still friends.

Even though I went to the university in Enschede only a few times a year, I always liked being there, and ITC is a very pleasant place to work. Rehana, Johannes, Petra, Mark, Adish, Loes and other ITC colleagues, thank you for making me feel welcome and I appreciate our nice conversations.

ECN colleagues, it's a little while ago, but I look back on a great time working together with you, and appreciate the many ways I've benefited from that.

Friends in Amsterdam and nearby places, Kim, Arjuna, Orlanda, Bas, Johan, Lex, Simone, Krista, Xander, Binayak, and many others, thank you for your friendship and love.

Finally, I am grateful for having such a wonderful family. My siblings, and especially mum and dad, thank you for being there for me, and for your support and love. 


\section{Biography}

Stefan Bakker ${ }^{67}$ was born in Texel, The Netherlands, on February $4^{\text {th }}, 1976$. After a BSc in chemical engineering he pursued his MSc in environmental science with the Radboud University Nijmegen. He worked for nine years as an energy, transport and climate policy

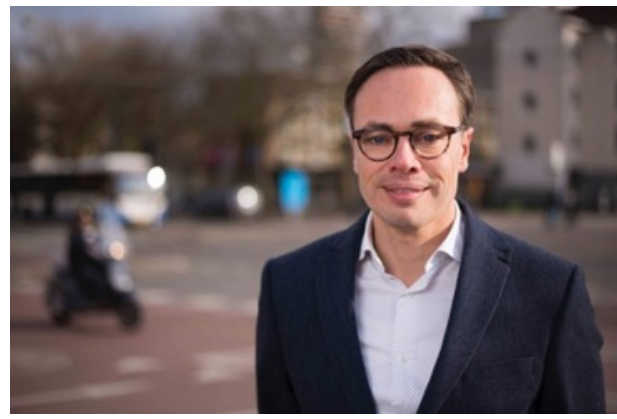
expert with the Energy research Centre of the Netherlands, after which he switched to the Deutsche Gesellschaft für Internationale Zusammenarbeit (GIZ). He was the team leader of the ASEAN-German technical cooperation project on "Energy Efficiency and Climate Change Mitigation for the Land Transport Sector in the ASEAN Region", based in Bangkok, Thailand, and senior adviser in other GIZ transport projects. Currently he is an independent consultant, assisting international organisations in low-carbon transport projects.

\section{Selected peer-reviewed articles and books}

Bakker, S., M.D. Guillen, P. Nanthachatchavankul, M. Zuidgeest, C. Pardo, M. van Maarseveen (2017) Hot or not? The role of cycling in ASEAN megacities: case studies of Bangkok and Manila. International Journal of Sustainable Transportation, online October 2017

Bakker, S. M. Major, A. Mejia, R. Banomyong (2017) ASEAN cooperation on sustainable transport: progress and options. Transport and Communications Bulletin for Asia and the Pacific, No 87, 1-15

Bakker, S., K. Dematera, M. Kappiantari, A. T. Nguyen, M. D. Guillen, G. Gunthawong, M. Zuidgeest, D. Liefferink, M. van Maarseveen (2017) LowCarbon Transport Policy in Four ASEAN Countries: Developments in Indonesia, the Philippines, Thailand and Vietnam. Sustainability 9 (7), 1217

Bakker, S., Zuidgeest, M.H.P., de Coninck, H. and Huizenga, C. (2014) Transport, development and climate change mitigation: towards an integrated approach. Transport reviewss, 34 (3) pp. 335-355.

Bongardt, D., F. Creutzig H. Hüging, K. Sakamoto, S. Bakker, S. Gota, S. BöhlerBaedeker (2013). Low-Carbon Land Transport: Policy Handbook. Routledge 978-184971-377-1, 264 pp.

Bakker, S., H. van Asselt, C. Haug, J. Gupta, R. Saidi (2011) Future of the CDM: same same but differentiated? Climate Policy 11 (1), pp 752-767.

Bakker, S., C. Huizenga (2010) Making climate instruments work for sustainable transport in developing countries. Natural Resources Forum 34 (3), $316-32$

${ }^{67}$ Contact: sjabakker@gmail.com; twitter.com/sjabakker; www.researchgate.net/profile/Stefan_Bakker 


\section{ITC Dissertation List}

https://www.itc.nl/research/phd-projects/ 